\title{
Metal Oxide Nanostructures for Sensor Applications
}

\author{
D. Nunes*, A. Pimentel, A. Gonçalves, S. Pereira, R. Branquinho, P. Barquinha, E. \\ Fortunato, and R. Martins* \\ i3N/CENIMAT, Department of Materials Science, Faculty of Sciences and Technology, \\ Universidade NOVA de Lisboa, Campus de Caparica, 2829-516 Caparica
}

\section{Abstract}

Human health, environmental protection and safety are just a few examples of current humankind main concerns, that drive the scientific community to develop sensors able to precisely monitor and alert to possible harms in real time. Over the years, semiconductor metal oxide-based materials have been largely employed as sensors dedicated to several applications, being particularly interesting at the nanometer scale, since it is largely known that smaller crystallite size enhances sensor's performance. Moreover, these materials are highly appealing as they can be produced by low-cost wet-chemical synthesis routes and are in general nontoxic, earth abundant and low-cost. This manuscript extensively reviews the recent developments of nanostructured semiconductor metal oxide sensors ranging from gas to humidity sensors, including ultraviolet (UV) sensors and biosensors. Zinc oxide ( $\mathrm{ZnO})$, titanium dioxide $\left(\mathrm{TiO}_{2}\right)$, tungsten trioxide $\left(\mathrm{WO}_{3}\right)$, copper oxide $\left(\mathrm{CuO}\right.$ and $\left.\mathrm{Cu}_{2} \mathrm{O}\right)$, tin oxide $\left(\mathrm{SnO}\right.$ and $\left.\mathrm{SnO}_{2}\right)$, and vanadium oxide $\left(\mathrm{VO}_{2}, \mathrm{~V}_{2} \mathrm{O}_{5}\right)$-based sensors either as nanoparticles or as continuous films/layers are described. Their sensing properties are correlated to size, shape, presence of defects, doping elements, amongst other relevant parameters. Different techniques and methods of fabricating these materials are addressed. The review is concluded with novel approaches for functionalization and future perspectives for sensor developments.

Keywords: semiconductor metal oxides; low-cost materials; nanostructures; sensors; sensing properties.

*Corresponding Authors: Rodrigo Martins and Daniela Nunes, i3N/CENIMAT, Department of Materials Science, Faculty of Science and Technology, Universidade NOVA de Lisboa, Campus de Caparica, 2829-516 Caparica, Portugal, Tel: (+351) 212948562, Fax: (+351) 21294 8558, e-mails: rm@uninova.pt (R. Martins); daniela.gomes@fct.unl.pt (D. Nunes). 


\section{Outline}

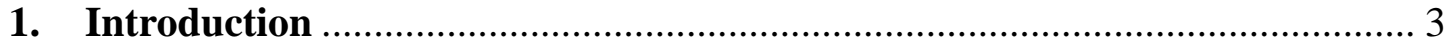

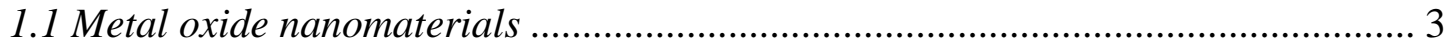

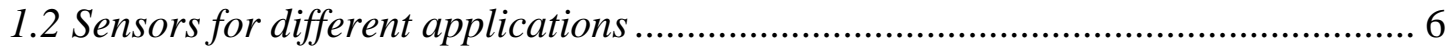

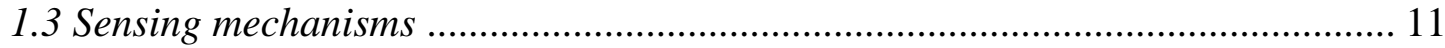

2. Semiconductor metal oxide nanostructures ............................................. 18

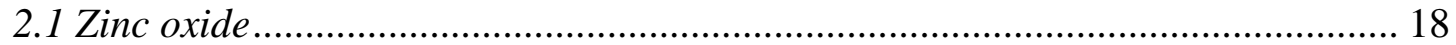

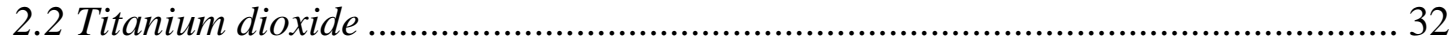

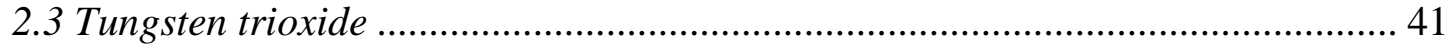

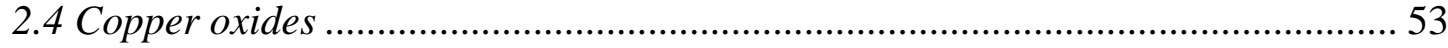

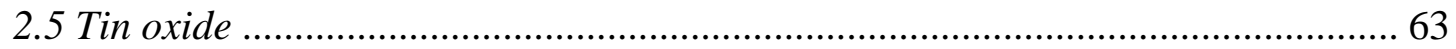

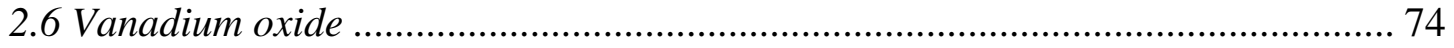

3. Overview of the metal oxide sensors performance ................................... 83

4. Field-effect transistor structures for sensing applications........................... 92

4.1. Advantages and challenges of sensing with (oxide nanostructure) field-effect

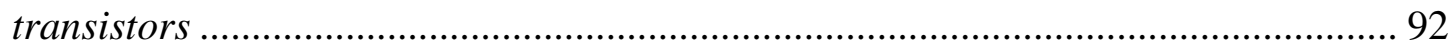

4.2. Gas sensing with oxide nanowire field-effect transistors .................................. 95

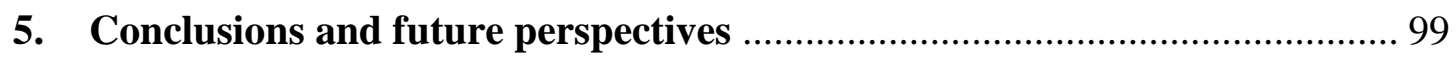

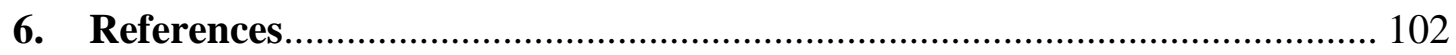




\section{Introduction}

\subsection{Metal oxide nanomaterials}

Nanotechnology is compromised as a group of novel technologies capable of designing, producing, characterizing and controlling structures, materials, devices and systems at the nanometer scale, i.e. less than 100 nanometres. This term is very transversal, being used across many fields, such as chemistry, medicine, biology, physics, materials science, environment, engineering, amongst others. The structures or materials at the nanometer scale can be classified as: OD (zero dimension) if all three spatial dimensions are in the nanometric range, i.e. nanoparticles or clusters; 1D (one dimension) if two dimensions are in the nanometric range, like nanotubes, nanorods and nanowires; or 2D (two dimensions) if only one spatial dimension is nanometric, such as in thin films or nanosheets. 3D (three dimensional) materials implies that the 0D, 1D and 2D elements are in close contact forming interfaces, for example compact polycrystals with nanosized grains or 3D porous nanostructures (Figure 1) [1].

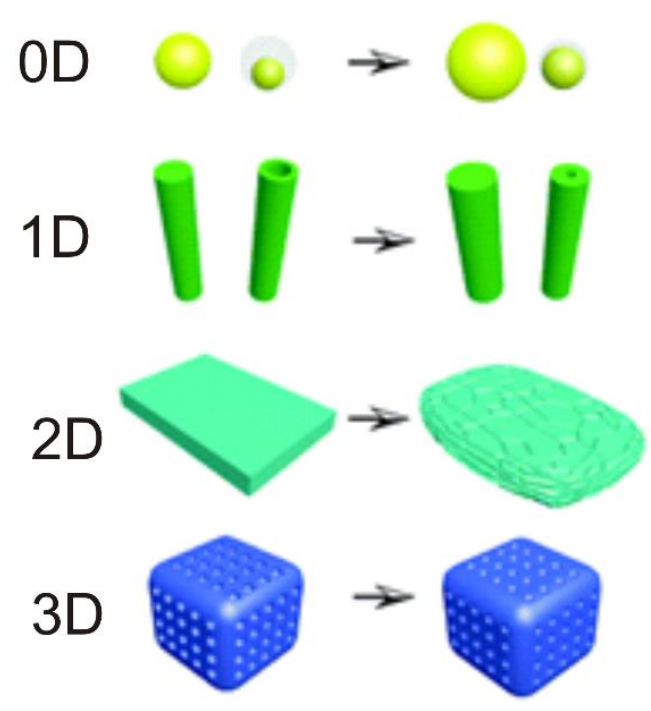

Figure 1. Scheme of the types of nanostructured materials based on their dimensions: 0D, 1D, 2D and 3D [1]. Reproduced with permission of Royal Society of Chemistry (2018). 
Nanosized materials possess unique and enhanced chemical, physical and mechanical properties when compared to their bulk counterparts due to their high specific surface area and surface-to-volume ratio [2-4]. Generally, the high surface-to-volume ratio of nanomaterials increases as nanoparticle size decreases [5]. Moreover, the size reduction of materials gives rise to quantum confinement phenomena, which modify their intrinsic properties with respect to their corresponding bulk materials [6]. Nanomaterials can occur in several morphologies ranging from nanorods, nanowires, nanowhiskers, nanoflakes, nanocubes, nanopillars, nanospheres, and others [3, 7, 8]. Carbon-based, metal, ceramic, polymeric and metal oxide nanoparticles are well-known classes of nanoparticles [3]. The latter are largely investigated since these are earth abundant, environmentally benign, low cost and, in some cases, chemically stable with suitable electrical and optical characteristics [9-16]. Moreover, these materials display exceptional properties that include mechanical stress tolerance, high optical transparency, high carrier mobilities, wide band gap, high dielectric constant, superconductivity, amongst others $[16,17]$. Metal oxides are ionic compounds composed by positive metallic and negative oxygen ions [16], and can exhibit metallic, semiconductor or insulator characteristics [18]. In metal oxides, although the s-shells of positive metallic ions are always fully filled by electrons, their d-shells may not be completely filled [19]. Semiconductor metal oxides can either be classified as $n$-type, in which electrons are the majority charge carriers, or p-type, in which the majority charge carriers are holes.

Metal oxide electronic, physical and chemical properties can be engineered by modifying their size, structure, composition, stoichiometry and by doping $[4,20]$. Nevertheless, the electronic structure range of these materials is extensive, being divided into two main categories, i.e. transition and non-transition metal oxides, where the latter englobes the pre- and post-transition metal oxides. Transition metal oxides are known to 
have small energy difference between a cation $\mathrm{d}^{\mathrm{n}}$ and either a $\mathrm{d}^{\mathrm{n}+1}$ or $\mathrm{d}^{\mathrm{n}-1}$ configuration, which allows a fast transformation between the different forms, however with unstable structures. Metal oxides with $\mathrm{d}^{0}$ and $\mathrm{d}^{10}$ electronic configurations are characterized as materials with stable properties. The $\mathrm{d}^{0}$ configuration is found in transition-metal oxides such as, $\mathrm{TiO}_{2}, \mathrm{~V}_{2} \mathrm{O}_{5}$ and $\mathrm{WO}_{3}$, whereas $\mathrm{d}^{10}$ configuration is found in post-transition-metal oxides, as $\mathrm{ZnO}$ or $\mathrm{SnO}_{2}$. Regarding the pre-transition-metal oxides, these are expected to be inert in several applications, since these have large band gaps, electrons and holes are hardly formed [21]. In general, nanoparticles of metal oxides have high density of corner or edge surface sites [22].

Over the years, semiconductor metal oxides have been extensively studied for applications ranging from solar cells [23-26], passing through their integration in electrochromic devices [27-30], lithium-ion batteries [31-33], photocatalyst agents [9, 10, 14, 34-38] and as sensors [39-42]. The interest on the latter application with semiconductor metal oxides has been reported half a century ago and has been increasing along the years due to their practical applications in everyday life, as well as in environmental protection, bio detection, to name just a few. Nowadays, semiconductor metal oxide nanostructures are widely chosen to be integrated in sensors due to their exceptional intrinsic properties associated to their high surface-to-volume ratios, high surface reaction activity, high catalytic efficiency, strong adsorption ability, and electron and phonon confinements [43]. Gas sensors are amongst the most common sensing devices, in which semiconducting metal oxides are frequently used as gas-sensing materials [44]. Another type of sensor where metal oxides are largely present are humidity sensors, which normally determine the amount of water vapor present in a gas that can be a mixture, such as air, or a pure gas, such as nitrogen or argon [45]. UV photosensors/photodetectors are also frequently used in terms of sun/UV exposure, as 
well in environmental safety, flame detection, among others [46]. And finally, biosensors that are designed to have a fast response, be low-cost and portable in both clinical and non-clinical applications [47].

\subsection{Sensors for different applications}

Detection systems for monitoring air and water quality using semiconductor metal oxides are of great interest to improve the selectivity and sensitivity of current sensing devices, and at the same time allowing simultaneous measurements of numerous parameters with real-time response [48]. In the literature, application of metal oxides in gas sensors is vast, with several studies reporting the advantages of integrating these materials in such devices, as well as their gas sensing performance in respect to the size properties [21, 44, 49-52].

The gas sensing technology is largely spread in different industrial fields, but also in domestic environments, some examples are the automotive industry, for indoor air quality control, greenhouse gas monitoring, among others [52]. The most important parameters of gas sensor devices are their sensitivity, operating temperature, selectivity, long-term stability, energy consumption, reversibility, low humidity dependence and finally production cost $[44,52]$. Thus, for these devices to be commercially viable, they must be stable during operation, with a uniform and reproducible signal for a prolonged period of time, despite being able to precisely detect a specific gas even in mixtures of different gases. Moreover, the precise control of metal oxide electronic and structural properties, including grain size distribution, local doping, grain boundaries and surface states is mandatory to obtain optimized performance of such devices [53].

Liu et al. [52] has classified gas sensors based on their sensing methods in two groups: (a) methods based on variation of electrical properties and (b) methods based on variation of other properties. Semiconductor metal oxide gas sensing relies on the 
variation of electrical properties [49]. Gas sensors based on $\mathrm{ZnO}, \mathrm{TiO}_{2}, \mathrm{SnO} / \mathrm{SnO}_{2}, \mathrm{WO}_{3}$, $\mathrm{CuO} / \mathrm{Cu}_{2} \mathrm{O}$, and $\mathrm{V}_{2} \mathrm{O}_{5}$ are commonly used to detect combustible, reducing, and oxidizing gases [41, 52, 54-59], and sensing is mainly based on the resistance change responses to the target gases [52]. $\mathrm{SnO}_{2}$ followed by $\mathrm{WO}_{3}$ (Figure 2 (a)) are the most commonly used semiconducting metal oxides in commercial gas sensors [60]. In general, reducing gases, such as $\mathrm{H}_{2} \mathrm{~S}, \mathrm{NH}_{3}, \mathrm{CO}, \mathrm{H}_{2}, \mathrm{SO}_{2}, \mathrm{CH}_{4}$, and $\mathrm{HCHO}$ cause an increase of conductivity in $n$ type semiconductors and a decrease in $p$-type semiconductors, while the opposite effect is observed for oxidizing gases $\left(\mathrm{NO}, \mathrm{N}_{2} \mathrm{O}, \mathrm{NO}_{2}, \mathrm{CO}_{2}, \mathrm{O}_{3}\right.$ and $\left.\mathrm{Cl}_{2}\right)[61,62]$.

Humidity sensors have been receiving a lot of attention in industrial, medical and even in domestic environments for human comfort. For example, these devices are employed in microelectronic and automobile industries, but also in the pharmaceutical field, food processing, humidity control in hospitals and houses, among other applications [45]. The humidity sensor performance is directly related to the properties of the sensing material including porosity, surface area, pore size distribution and morphology [63]. In similarity to the gas sensors, these devices are expected to have constant response, high sensitivity, fast response time, negligible hysteresis, chemical and physical stability, wide operating humidity range and low cost [64].

There are several humidity evaluation terms, nevertheless the most accepted are absolute and relative humidity (RH), where the latter is normally described. Per million by weight $\left(\mathrm{PPM}_{\mathrm{w}}\right)$ or volume $\left(\mathrm{PPM}_{\mathrm{v}}\right)$ and dew/frost point $(\mathrm{D} / \mathrm{F}$ PT) are subclasses of absolute humidity $[45,65]$. Generally, RH is temperature dependent, and can be described by Equation 1 [65]:

$$
R H=\frac{P_{V}}{P_{S}} \times 100
$$

where $P_{V}$ is the actual partial pressure of water vapor present in a gas and $P_{S}$ is the saturated vapor pressure of the gasat a given temperature. Nowadays, RH sensors are 
largely commercialized and can be categorized into three classes, i.e. ceramic-based sensors, organic polymer-based sensors, and organic/inorganic hybrid sensors (polymer/ceramic). Ceramic-based sensors can be designed using either semiconducting or dielectric metal oxide materials. Moreover, these sensors are divided into two groups in accordance to their sensing mechanisms, i.e. impedance (resistive) or capacitive categories, in which the former uses the conductance, and the latter, the capacitance properties of the sensing layer. Impedance-based sensors are subdivided into ionicconduction and electronic-conduction. The $p-n$ heterojunction humidity sensors are also included in ceramic-based sensors [65]. Different approaches have also been suggested, in which an integrated solution having a humidity sensor chip that contains humidity sensors of capacitive type is shown on Figure 2 (b) [66].

Another kind of devices that have recently drawn growing attention are UV sensors/photodetectors, which are interesting for everyday life in terms of sun/UV irradiation exposure, but also for environmental safety, medicine, military defence, flame detection, environmental sensors, space exploration, among others [67, 68]. UV photodetectors detect light in the ultraviolet wavelength ranging from $100 \mathrm{~nm}$ to $400 \mathrm{~nm}$.

A high-performance photodetector must have high sensitivity and spectral selectivity, as well as a fast and linear response speed, together with high light transmission and improved chemical and physical stability $[69,70]$. The most important parameters of photodetectors are sensitivity, responsivity and external quantum efficiency (EQE) [69]. These parameters are normally used to categorize the UV sensor performance. UV photodetector sensitivity is given by Equation (2) [69], while the responsivity is estimated according to the Equation (3) $[13,71]$. The external quantum efficiency, which is defined as the number of electrons detected per light photon, $[69,72]$ can be obtained by Equation (4). 


$$
\begin{aligned}
& S=\frac{\Delta I}{I_{\text {dark }}} \times 100 \\
& R=\frac{\Delta I}{P_{U V}} \\
& E Q E=\frac{h c}{e \lambda} \cdot \frac{I_{\text {ph }}-I_{\text {dark }}}{P_{U V}}
\end{aligned}
$$

where $\Delta I$ is the difference between the photocurrent and the dark current, $I_{d a r k}$ is the dark current, and $P_{U V}$ is the UV light power, $h$ is Planck's constant, $c$ is the speed of light in vacuum, $e$ is the electron charge, and $\lambda$ is the exciting wavelength. Several photodetectors types have been reported, including photoconductors, metal-semiconductor-metal (MSM) photodetectors, Schottky photodiodes and $p-n$ junction photodiodes. A photoconductor is composed by a semiconductor material with two ohmic contacts, forming a radiation-sensitive resistor. MSM photodiodes are based on two back-to-back Schottky diodes and using an interdigitated electrode configuration on top of the active layer. Schottky diodes consist of a metal layer that contacts a semiconductor material, and the metal/semiconductor junctions exhibit rectifying behaviour. $p$ - $n$ junction photodiodes are based on a heterojunction of a $p$ - and $n$-type materials, without the requirement of a reverse bias and displaying improved noise performance [73]. The $p-i-n$ has an intrinsic layer and provides additional sensitivity and performance over that of the basic $p-n$ junction photodiode due to the reveres bias operation. Nevertheless, innovative approaches to extract the best photodetector performance, more recently with nanostructured metal oxides, are under constant development (Figure 2 (c)).

Metal oxide nanostructures are also widely present in biosensors. A biosensor is described as a sensing device that combines a transducer for signal detection with a biologically sensitive and selective component, i.e. bioreceptor (antibody, enzyme, receptor protein, nucleic acid, whole cell or tissue section). Typically enzymes are used as bio component, and they are large protein molecules that act as a catalyst in chemical 
reactions, remaining unchanged during the process [74]. Upon interaction of a target molecule with the bio component, a signal is generated and detected by the transducer (Figure 2 (d) [75]). It is possible to occur optical or electrical signals [76]. This signal is proportional to the concentration of the component. The target molecules/analytes can be proteins, DNA, glucose, cholesterol, toxins, hormones, bacteria, among others [77]. These devices are considered a powerful analytical tool in medical diagnostics with the fast and precise detection of diseases, virus , food quality and safety, fermentation industry, in metabolic engineering and other areas $[47,78]$. The device is expected to be highly accurate, homogeneous and reproducible, despite having optimized response time, high stability, sensitivity, specificity, selectivity (low interference) and bioactivity [76, 79].

There are many types of biosensors, in which these are mainly classified according to bioreceptors and transducers. The most common are immunosensors, calorimetric, DNA, enzyme-based, tissue-based, optical, thermal, optical, piezoelectric and electrochemical biosensors, in which the latter is subdivided in conductimetric, amperometric and potentiometric sensors $[74,78]$. The most successful commercial biosensor is the amperometric glucose biosensor, with which diabetic patients are able to periodically monitor blood glucose levels [74]. Nevertheless, the full integration of metal oxides nanostructures in biosensors still raises questions regarding the maintenance of their bioactivity for extended periods of time and their toxicity. 
Gas sensor

(a)

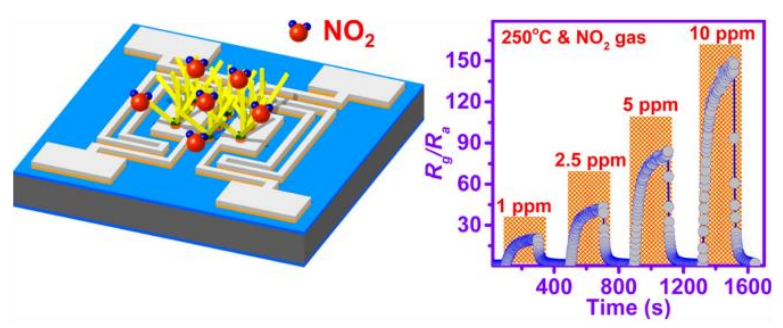

(c)

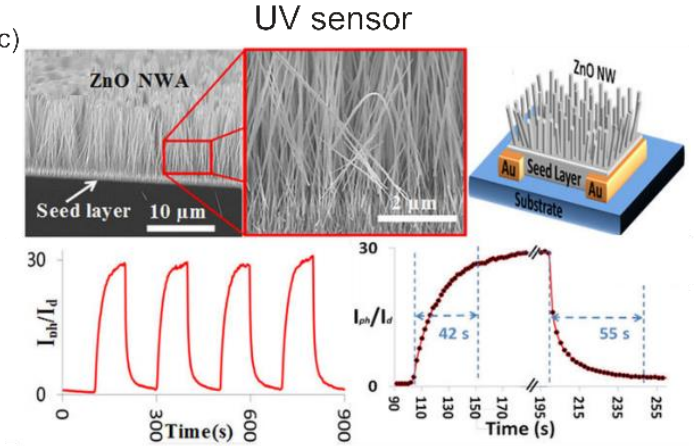

Humidity sensor

(b)

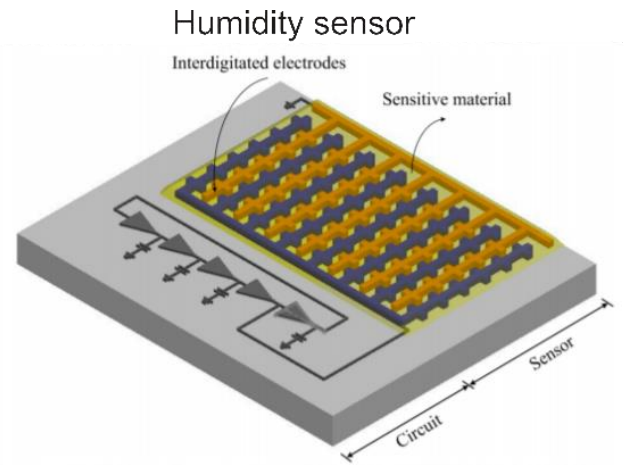

(d)

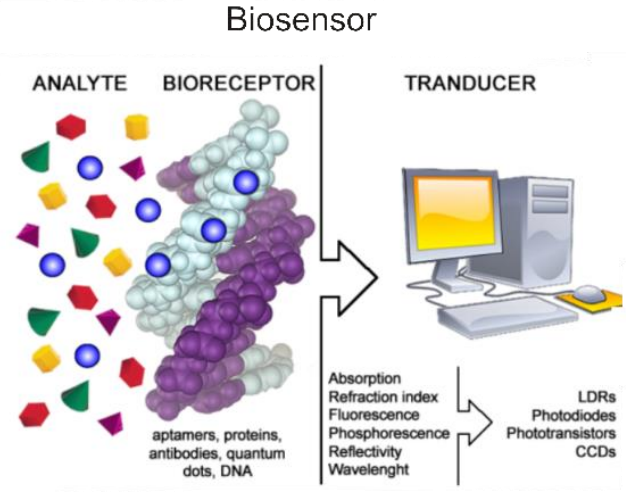

Figure 2. (a) Gas sensor and its respectively gas sensing characteristics for $\mathrm{NO}_{2}$ [80], (b) integrated humidity sensor [66], (c) photoresponse characteristics of a UV photodetector [81] and (d) biosensor detection process [75]. Reproduced with permission of Elsevier [80], MDPI [66], Springer Nature [81], and Intech (2018) [75].

\subsection{Sensing mechanisms}

The mechanisms responsible for gas, humidity and UV responses have similar concepts. Despite being a controversial topic, the mostly accepted mechanism for these sensors is resultant of a change in electrical conductivity or resistivity of the semiconductor metal oxide materials $[82,83]$. In the case of gas sensors, the gas sensing is resultant of a shift on equilibrium of the surface chemisorbed oxygen reaction due to the presence of a target gas, creating extrinsic surface acceptor states that immobilize conduction band electrons from the near-surface region of an $n$-type semiconductor material. For $p$-type semiconductor materials, the chemisorption of oxygen leads to an accumulation surface layer which alters their conductance $[44,61]$. Under ambient conditions, the oxygen molecules are adsorbed on surface of the $n$-type 
semiconductor materials and can capture inner free electrons from of these materials. The negative charge trapped in these oxygen species causes a depletion layer near the surface, which results in the reduction of the conduction layer $\left[O_{2(\mathrm{~g})}+e^{-} \rightarrow{O_{2}^{-}(\mathrm{ads})}^{-}[71,82]\right.$. When the sensor is exposed to reducing or oxidizing gases, this will affect the density of charge carriers ( $n$-type electrons or $p$-type holes) in the near-surface region of each grain. Reducing gas molecules will remove surface-bound oxygen atoms, releasing immobilised electrons, whereas oxidising gases immobilise conduction-band electrons from the nearsurface region by creating additional surface-acceptor states. Thus, the gas molecules will result in the decrease or increase of the depletion layer thickness by changing the surfacestate density, which in consequence leads to a change in the materials' conductance [44].

In summary, upon interaction with oxidizing gases, the gas species will act as acceptors, which will lead to a resistance increase for $n$-type semiconductor metal oxides. When the oxidizing gases are adsorbed on $n$-type material surface, it will gain electrons from the adsorbed oxygen, which will increase the depletion region, and thus decrease its conductivity [39]. The opposite behaviour is observed for $p$-type metal oxide materials. Figure 3 (a) shows the negative surface charge causing the upward band bending of conduction $\left(\mathrm{E}_{\mathrm{C}}\right)$ and valence $\left(\mathrm{E}_{\mathrm{V}}\right)$ bands, the electron depleted region (space-charge layer), the average thickness, i.e. the depth of band bending region (q.Vs), and the effective surface potential barrier $(\mathrm{eV})$. The depth and height $(\mathrm{eV})$ of the band bending depend on the overall surface charge present (amount and type of adsorbed oxygen). In Figure 3 (b), it is represented the grain boundary structures and corresponding band models showing the electron conduction mechanism. In polycrystalline sensing materials, the electronic conductivity occurs through the percolation paths along grain-to-grain contacts depending on the value of potential barrier $(\mathrm{eV})$ or Schottky barrier of the surrounding grains. Upon gas exposure, the Schottky barrier between two grains is 
lowered facilitating the electronic conduction in sensing layers through different grains via grain to grain percolation path [84].

In fact, the gas adsorption on the surface and the change in the resistance of metal oxide semiconductors are quite complex processes. It has been accepted that the sensor resistance is a function of the gas partial pressure, following a power-law response, in which the power-law exponent is specific to the gas and temperature used [85-87]. Several studies have extensively discussed the processes, including when using metal oxide nanostructures. In the case of metal oxide nanowires, the conductivity for $n$ - and $p$ type materials, Equations 6 and 7, respectively, can be described as [88, 89]:

$$
\begin{aligned}
& G_{n}=\frac{\sigma_{d}}{\ell} \pi\left(\frac{D}{2}-L_{D_{n}}\right)^{2}=N_{d} q \mu_{n} \frac{\pi\left(D-2 L_{D_{n}}\right)^{2}}{4 \ell} \\
& G_{p}=\frac{\sigma_{a}}{\ell} \pi\left(\left(\frac{D}{2}\right)^{2}-\left(\frac{D}{2}-L_{D_{p}}\right)^{2}\right)=N_{a} q \mu_{p} \frac{\pi\left(D L_{D_{p}}-L^{2} D_{p}\right)}{\ell}
\end{aligned}
$$

where $\sigma=q \mu N$ is the conductivity of the nanowire; $D$ is its diameter; $\ell$ is the length; $N$ is the carrier concentration; $\mu$ is the carrier mobility; $q$ is the carrier charge; and $L_{D n}$ and $L_{D p}$ are the thicknesses of the depletion and accumulation layers, respectively.

The gas-sensing response for $n$-type (Equation $8,\left(S_{O X}^{n}\right)$ ) and $p$-type (Equation 9 , $\left.\left(S_{O X}^{p}\right)\right)$ semiconducting metal oxide to an oxidizing gas can be defined as [62]:

$$
\begin{gathered}
S_{O X}^{n}=\frac{R_{o g}}{R_{a}} \\
S_{O X}^{p}=\frac{R_{a}}{R_{o g}}
\end{gathered}
$$

where $R_{\mathrm{og}}$ and $R_{\mathrm{a}}$ are the sensor electrical resistances measured with an oxidizing gas and pure dry air, respectively.

In the case of reducing gases, the gas species act as donors, i.e. electrons will be injected into $n$-type material surface, reducing the depletion region and releasing the band bending, and this will lead to a resistance decrease in the case of $n$-type materials and 
increase for $p$-type materials $[39,61]$. The gas-sensing response for $n$-type (Equation 10, $\left(S_{r d}^{n}\right)$ ) and p-type (Equation 11, $\left.\left(S_{r d}^{p}\right)\right)$ semiconducting metal oxide to a reducing gas is normally represented as [62]:

$$
\begin{gathered}
S_{r d}^{n}=\frac{R_{a}}{R_{r g}} \\
S_{r d}^{p}=\frac{R_{r g}}{R_{a}}
\end{gathered}
$$

where $R_{\mathrm{rg}}$ and $R_{\mathrm{a}}$ are the sensor electrical resistances measured with an reducing gas and pure dry air, respectively.

Mechanisms of water vapor adsorption on metal oxide surfaces have been well studied [45, 90, 91], and it is known that most metal oxides have adsorbed hydroxyl groups on their surface which influences the surface phenomena, including the response of a sensor to the detected gas [92]. In general, water molecules can be adsorbed by an acid-base type dissociative chemisorption followed by hydrogen bonded physisorption, however some oxides can also chemisorb water vapor through redox reactions involving electron transfer to the metal oxide [63, 92]. Moreover, water molecules have been reported to increase the conductivity of $n$-type semiconductor metal oxides and to decrease the conductivity of $p$-type semiconductor metal oxides, in which this effect was related to the donation of electrons from the chemically adsorbed water molecules to the oxide surface $[67,91]$.

The mechanism of all the ceramic humidity sensors, of ionic and electronic conduction (resistive) types and capacitive, depends on the superficial water vapour adsorption, which is based on chemical and physical adsorptions and capillary condensation processes. Resistivity-type humidity sensors measure the electrical resistance in response to humidity. Most of the available humidity sensors utilize the ionic type humidity-sensing mechanism. In ionic sensing devices, when the ceramic surfaces adsorb water, their electrical properties change, and by increasing the humidity, the 
conductivity increases and thus the dielectric constant increases [65, 93]. On the other hand, capacitive-type humidity sensor mechanism relies on electrical permittivity that is sensitive to humidity variation, and the electrical response is linked to water adsorptiondesorption processes on the exposed surface of the sensing material [94].

The UV sensing process occurs when the semiconductor metal oxide with oxygen molecules adsorbed on its surface and without any UV irradiation, can capture free electrons present in the $n$-type semiconductor and form a low conductivity depletion layer in the near-surface region. When exposed to UV irradiation at a photon energy above the materials' band gap, electron-hole pairs are photogenerated $\left[h v \rightarrow e^{-}+h^{+}\right]$, and the holes migrate to the surface along the potential slope. This potential slope is produced by band bending and discharge of negatively charged adsorbed oxygen ions through surface electron-hole recombination, leading to oxygen photo desorption [95] $\left[h^{+}+\mathrm{O}_{2^{-}}^{-}\right.$(ads) $\rightarrow$ $O_{2(\mathrm{~g})}$ (Figures 3 (c) and (d)). This hole-trapping mechanism through oxygen adsorption and desorption enhances the high density of trap states due to the dangling bonds at the surface and thus enhances the photoresponse [96]. The stability and performance of UV sensors are highly influenced by the surrounding environment. Several studies reported that the photodetection of metal oxide nanostructured sensors is strongly dependent on the ambient gas conditions, with significant differences regarding measurements in air, vacuum or inert gases [97-99]. 
(a)

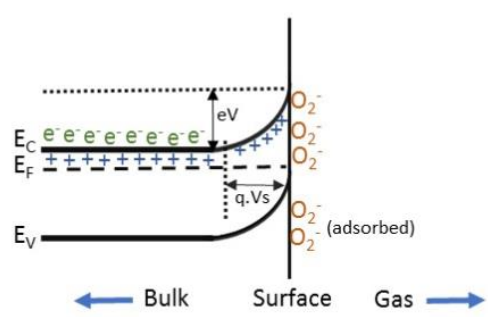

(b)

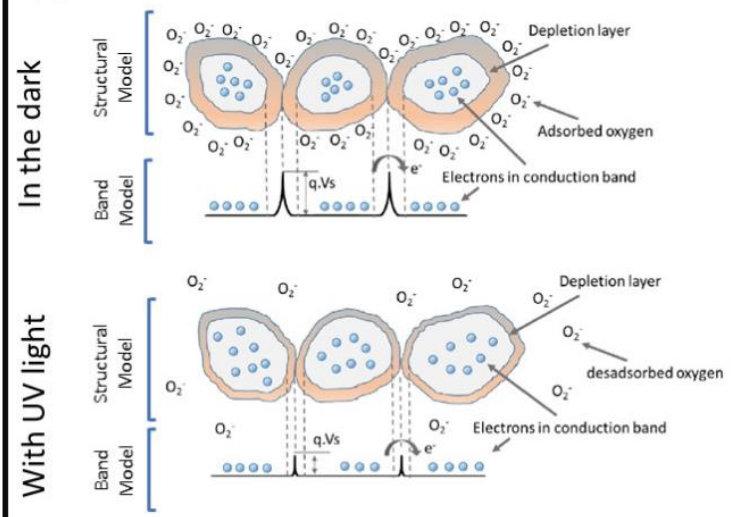

(c)
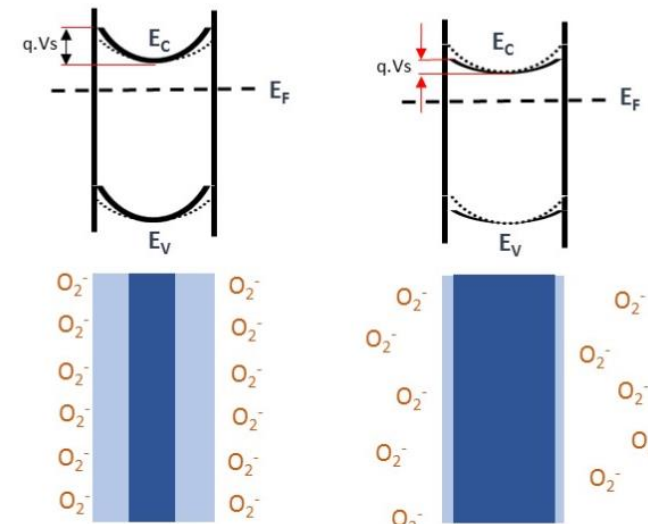

(d)
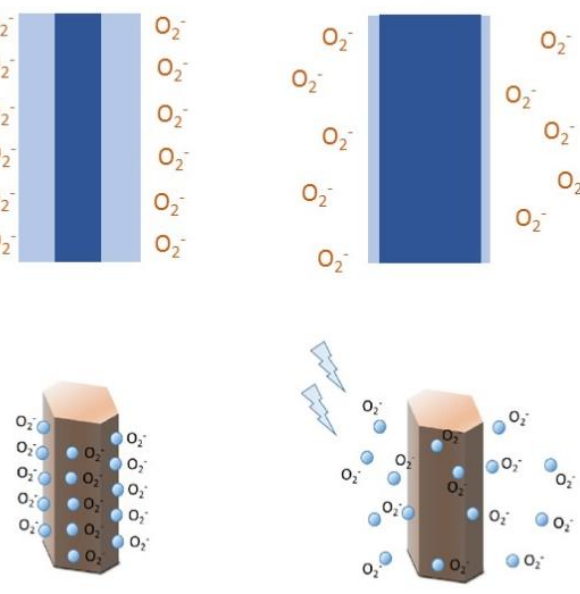

In the dark
With UV light

Figure 3. (a) Scheme of the band bending in a wide band gap semiconductor after chemisorption of charged species on surface sites $\left(E_{C}\right.$ and $E_{V}$ are the conduction and valence band energies in the grain bulk, respectively, $E_{F}$ is the Fermi level, $\mathrm{e}^{-}$is the conducting electrons and ${ }^{+}$the donor positions [49,

85]. (b) Schemes of the structural and band models of a $n$-type semiconductor, and (c) and (b) dark and UV irradiation processes [71, 88]. Reproduced with permission MDPI [71], and Elsevier [49], [85] and [88] (2018).

Regarding biosensors, as previously described, the devices combine a biological element with a transducer to detect specific target analytes and thus produce quantifiable and processable signals $[47,77,100]$. Generally, the measurement of electrical properties in biological systems is from electrochemical nature, in which the bioelectrochemical element will act as the main transduction element. Moreover, for electrochemical detection, enzymes are mostly used, due to their specific binding capabilities and biocatalytic activity. Antibodies, antibody fragments or antigens are usually used in immunosensor to monitor binding events in bioelectrochemical reactions [100]. These electrochemical detection techniques can generate a measurable current (amperometric), 
a measurable potential or charge accumulation (potentiometric), or change in the medium conductive properties between electrodes (conductometric), but also measurements as function of impedance, both resistance and reactance (impedimetric), and using transistor technology (field-effect) to measure current as a result of a potentiometric effect at a gate electrode [100].

Recently, metal oxide materials have been integrated in novel biosensing devices, since they exhibit enhanced electron-transfer kinetics and strong adsorption capability. These properties guarantee appropriate microenvironments for the immobilization of bio molecules and result in enhanced electron transfer and improved biosensing characteristics. The biosensing process involving metal oxide materials relies on the biomolecules binding to these materials via physical adsorption or chemical binding. Physical adsorption of a biomolecule depends on several parameters such as surface morphology, reaction medium and net surface charge, especially when it arises due to weak interactions, such as van der Waals, electrostatic and physisorption. Nevertheless, short-range forces including charge, steric, depletion and solvent interactions can also affect the biointerface. An effective biointerface with metal oxide materials guarantees an enhanced electron transfer rate and assists the biomolecule to maintain a stable biological activity [47]. It has also been reported that adding metal oxides to unlike surfaces can increase the adhesion of negatively-charged bacteria due to their positive charge and hydrophobicity, this is of particular importance for producing high performance biosensing devices [101].

This review will address the two main types of nanostructured semiconducting metal oxide sensors including $n$-type, i.e. zinc oxide, titanium dioxide, tungsten oxide, tin dioxide, and vanadium oxides, but also materials displaying $p$-type characteristics, i.e. copper oxides and tin monoxide. Their sensing properties, production techniques and 
methods will be discussed from an application-oriented perspective. An overview on different sensors such as gas, humidity, UV and biosensors having these nanomaterials integrated will also be presented.

\section{Semiconductor metal oxide nanostructures}

Semiconductor metal oxides have been largely employed in electronics and optoelectronics with their incorporation on transistors, circuits, or panel displays, and more recently on printed and paper electronics [102-104]. Nevertheless, the sensing technology has evolved over the last years and continues to grow to guarantee human well-being, quality and safety from food to air, but also for environmental protection. $\mathrm{ZnO}, \mathrm{TiO}_{2}$, $\mathrm{WO}_{3}, \mathrm{CuO} / \mathrm{Cu}_{2} \mathrm{O}, \mathrm{SnO} / \mathrm{SnO}_{2}$ and $\mathrm{VO}_{2} / \mathrm{V}_{2} \mathrm{O}_{5}$ are examples of such materials and have been integrated in several kinds of sensors, e.g. gas, humidity, UV and biological sensors. These materials can adopt the most distinct structures at the nanoscale, ranging from nanowires to nanospheres or nanosheets, which will directly influence their performance in the final sensing applications.

\subsection{Zinc oxide}

Zinc oxide has been extensively studied since 1935 due to its integration in several applications with special interest in $\mathrm{ZnO}$-based electronic and optoelectronic devices. $\mathrm{ZnO}$ is an $n$-type semiconductor with a wide band gap of 3.2-3.4 eV and a large exciton binding energy of $60 \mathrm{meV}$ at room temperature [105]. At room temperature and pressure, $\mathrm{ZnO}$ crystallizes in the hexagonal wurtzite structure in which each anion is surrounded by four cations at the corner of a tetrahedron [105]. Other structures may appear like "zinc blend" (the term is originated from compounds like $\mathrm{ZnS}$ that can present cubic or hexagonal phases) and "rocksalt" (with a cubic phase) but, under ambient conditions they are not thermodynamically stable phases. Hexagonal $\mathrm{ZnO}$ wurtzite structure has a unit cell with lattice constants $a=0.3296 \mathrm{~nm}$ and $c=0.52065 \mathrm{~nm} \mathrm{[106]} \mathrm{and} \mathrm{ratio} c / a=1.602$, 
corresponding to $\mathrm{P}_{3} m c$ space group $[105,107]$. This $\mathrm{ZnO}$ space group is characterized by presenting two interconnecting sublattices of $\mathrm{Zn}^{2+}$ and $\mathrm{O}^{2-}$ ions in which each zinc ion is surrounded by a tetrahedral of four oxygen ions [105]. The zinc and oxygen ions are arranged alternatively along the $c$-axis and exhibit positive and negative polar plane rich in $\mathrm{Zn}^{2+}$ and $\mathrm{O}^{2-}$, respectively. This $\mathrm{Zn}^{2+}$ and $\mathrm{O}^{2-}$ tetrahedral coordination is the origin of a polar symmetry along the hexagonal axis $[105,108]$. This asymmetry along the $c$-axis is responsible by an anisotropic growth of $1 \mathrm{D} \mathrm{ZnO}$ crystallites. The most common and stable $\mathrm{ZnO}$ crystal exhibit a wurtzite structure with four face terminations - the polar $\mathrm{Zn}$ terminated (0001) and $\mathrm{O}$ terminated $(000 \overline{1})$ facets, and the non-polar (1010) facets, containing equal number of $\mathrm{Zn}$ and $\mathrm{O}$ atoms [14, 105, 108-110]. Figure 4, shows a schematic representation of the $\mathrm{ZnO}$ hexagonal wurtzite structure facets and an atomic model of the polar and non-polar facets.

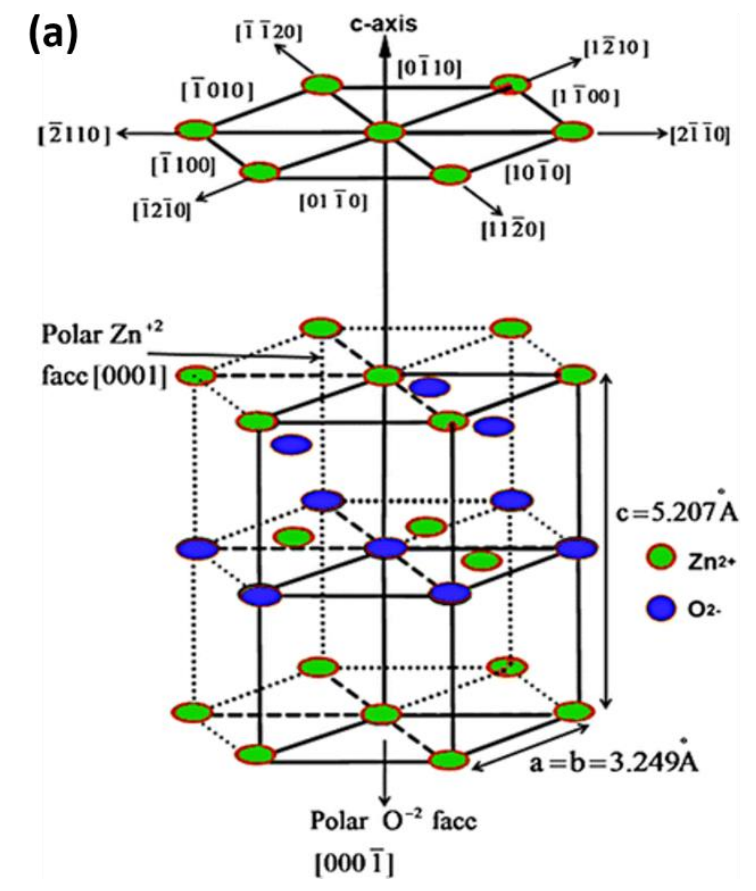

(b)

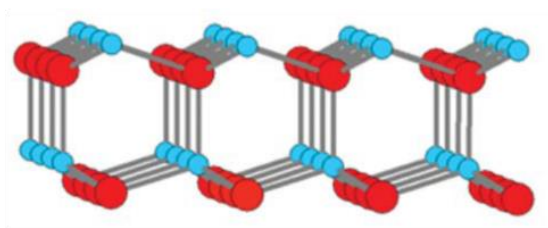

Zn termination

(c)

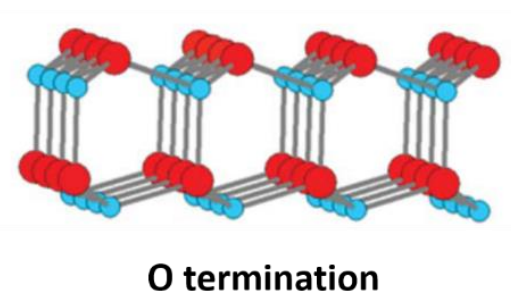

Figure 4. (a) Schematic of the unit cell of the $\mathrm{ZnO}$ hexagonal wurtzite structure and the correspondent ionic

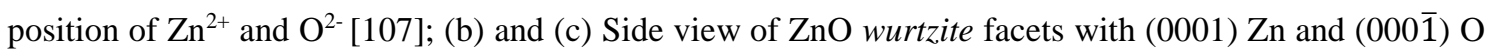
termination, respectively [111]. Reproduced with permission of Springer Nature [107] and the Royal Society of Chemistry (2018) [111]. 
It is well known that polar facets possess different chemical and physical properties from non-polar facets, and that $\mathrm{O}$ terminated polar facets also present a slightly different electronic structure [105]. These characteristics are responsible for the vast properties presented by $\mathrm{ZnO}$ such as piezoelectricity and spontaneous polarization, being a key factor in crystal growth and in defect generation [105].

When used in gas sensing or in other applications, it has been found that the polar $\mathrm{Zn}$ terminated $(0001)$ facets are more active than polar O terminated $(000 \overline{1})$ and the nonpolar (1010) facets due to the abundance of $\mathrm{OH}^{-}$that adheres to low-coordinated $\mathrm{Zn}$ sites, forming highly active $\cdot \mathrm{OH}$ radicals $[111,112]$.

The growth of different $\mathrm{ZnO}$ nanostructures has been reported by several authors in the past few years. Different synthesis methods can be employed to produce $\mathrm{ZnO}$ nanostructures, such as chemical bath deposition, electrospinning, electrodeposition, laser assisted flow deposition (LAFD) and also hydrothermal/solvothermal synthesis, either by conventional or by microwave assisted heating [13, 14, 113-123]. Depending on the synthesis method, precursors used and their concentration, solution $\mathrm{pH}$ or even the solvents selected, zinc oxide may present different nanostructures ranging from nanorods, nanofibers, nanoneedles, nanowires, nanoplates, nanostars, tetrapods to nanoflowers [14, 108, 113, 124-127], as shown in Figure 5. 

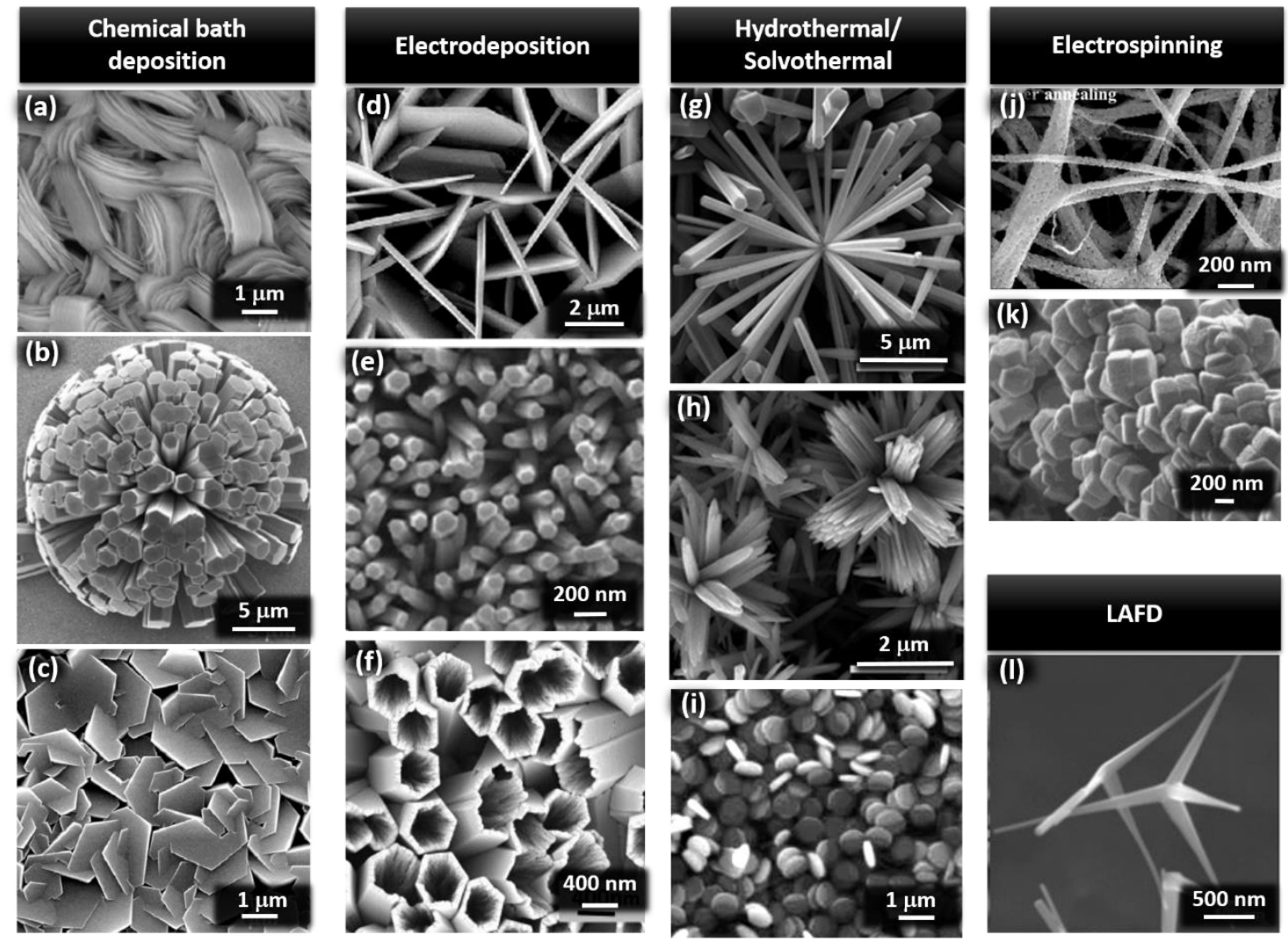

Figure 5. Different $\mathrm{ZnO}$ morphologies produced by different synthesis techniques: (a), (b) and (c) chemical bath deposition [113]; (d), (e) and (f) electrodeposition [123, 128, 129]; (g), (h) and (i) hydrothermal/solvothermal synthesis [112, 130]; (j) and (k) electrospinning [116, 117] and (l) laser assisted flow deposition [121]. Reproduced with permission of Elsevier [112, 113, 116-118, 121, 123, 128, 129] and Royal Society of Chemistry (2018) [130].

Zinc oxide is an inexpensive and earth abundant material, nontoxic and chemically stable, which makes it suitable to be used in several applications, such as field effect transistors [131-134], solar cells [121, 135-137], piezoelectric generators [138140], photocatalysis [14, 141, 142], as a platform for SERS applications [143, 144] and in sensors $[13,71,122,145]$.

Metal oxides semiconductors are commonly used as gas sensors in environmental monitoring and in industrial applications allowing the production of low cost and small devices [146]. $\mathrm{ZnO}$ is capable to detect a great variety of different gases, such as $\mathrm{CO}_{2}$, $\mathrm{H}_{2} \mathrm{~S}, \mathrm{NO}_{2}, \mathrm{NO}, \mathrm{NH}_{3}, \mathrm{C}_{3} \mathrm{H}_{8}$ and $\mathrm{CH}_{4}$ [146-150]. The detection of carbon dioxide is of vital 
importance for human life. The use of inexpensive and highly sensitive miniaturized sensors are of great interest for environmental control of indoor air quality and pollution (considering the impact of $\mathrm{CO}_{2}$ emissions on the global warming) [147].

The most recent studies are focused on devices miniaturization allied to increased sensitivity. So, many authors are studying the influence of $\mathrm{ZnO}$ morphology on gas detection since just by changing its shape it is possible to enhance sensor performance, opening new ways to produce more selective gas sensors [150]. Gupta et al. [146] studied the sensitivity of different $\mathrm{ZnO}$ nanostructures, nanowires, nanobelts and tetrapods in the detection of $\mathrm{H}_{2} \mathrm{~S}$ and NO. Gupta found that sensors based on $\mathrm{ZnO}$ nanobelts were more sensitive to $\mathrm{NO}$ gas, and that $\mathrm{ZnO}$ tetrapods were more sensitive in detecting $\mathrm{H}_{2} \mathrm{~S}$ gas while $\mathrm{ZnO}$ nanowires had no response in detecting $\mathrm{NO}, \mathrm{H}_{2} \mathrm{~S}, \mathrm{NH}_{3}, \mathrm{CO}$ and $\mathrm{CH}_{4}$. The high sensitivity of nanobelts to these gases may be due to their low thickness $(<20 \mathrm{~nm})$ when compared to the nanowire's diameter $(\approx 100 \mathrm{~nm})$, thus presenting a larger surface to volume ratio. It was found that the response mechanism to detect $\mathrm{H}_{2} \mathrm{~S}$ arises from changes in the grain boundary resistance, while for the detection of NO it arises from changes in the grain boundary and intragrain resistances [146].

Jonca et al. [150] studied the use of cloudy-like, isotropic and nanorods $\mathrm{ZnO}$ nanostructures for detection of $\mathrm{CO}, \mathrm{NH}_{3}$ and $\mathrm{C}_{3} \mathrm{H}_{8}$ gases. The $\mathrm{ZnO}$ nanorods nanostructures presented higher sensitivity to the detection of this type of gases.

Nitrogen oxide gases like $\mathrm{NO}$ and $\mathrm{NO}_{2}$ are environmentally harmful gases formed during the combustion in automotive and factories and are frequently associated to greenhouse gas effect [149]. $\mathrm{NO}_{2}$ is a very strong oxidizing gas, so the reaction takes place directly with the $\mathrm{ZnO}$ surface and not with the oxygen chemisorbed at the surface. $\mathrm{NO}_{2}$ molecules will then consume conduction electrons, increasing the depletion region at the surface, thus reducing $\mathrm{ZnO}$ conductivity [151]. Several authors have studied the 
use of different $\mathrm{ZnO}$ nanostructures for detection of $\mathrm{NO}$ and $\mathrm{NO}_{2}$ gases. Sadek et al. [151] used $\mathrm{ZnO}$ nanobelts to detect $\mathrm{NO}_{2}$ gas with concentration as low as $0.51 \mathrm{ppm}$. Cho et al. [152] used $\mathrm{ZnO}$ nanorods and was able to detect $\mathrm{NO}_{2}$ gas concentrations of $1 \mathrm{ppm}$. Figure 6 shows several gas sensors produced with nanostructured $\mathrm{ZnO}$ sensitive layers.

(a)

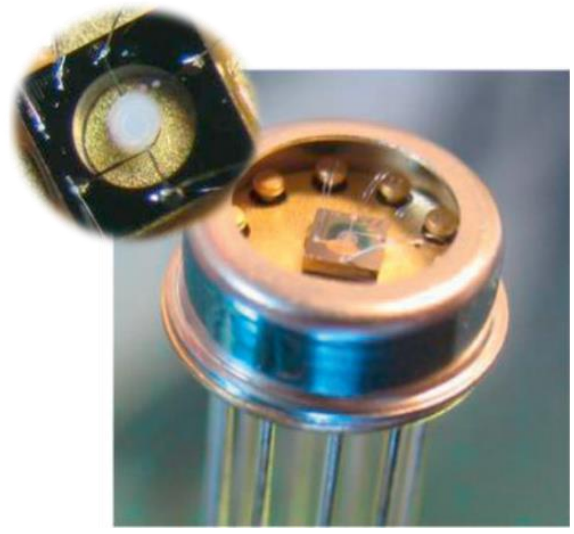

(b)

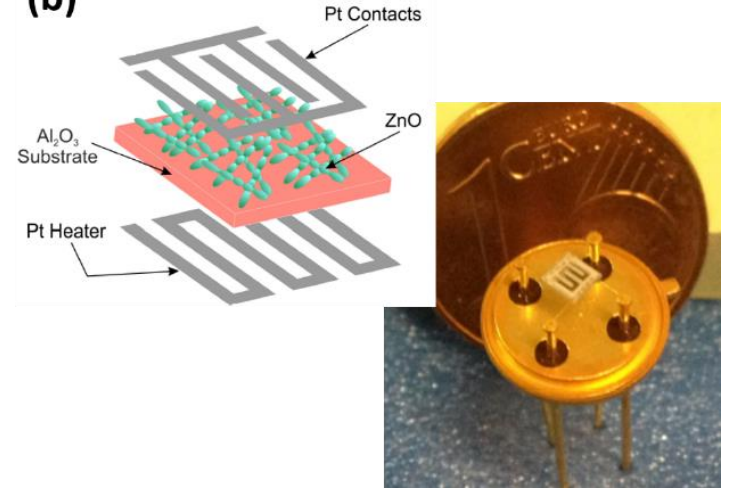

Figure 6. (a) Miniaturized gas sensor with a $\mathrm{ZnO}$ sensitive layer for the detection of $\mathrm{CO}, \mathrm{NH}_{3}$ and $\mathrm{C}_{3} \mathrm{H}_{8}$ gases [150]; (b) Schematic and digital image of a $\mathrm{ZnO}$ based sensor for the detection of $\mathrm{NO}_{2}, \mathrm{H}_{2}$ and $\mathrm{CH}_{4}$ gases [153]. Reproduced with permission of Elsevier (2018) [150] and [153].

Another way to improve $\mathrm{ZnO}$ gas sensor performance is by doping the semiconductor metal oxide with other materials. Dilonardo et al. [154] doped ZnO nanostructures with $\mathrm{Au}$ nanoparticles and was able to detect $\mathrm{NO}_{2}$ gas at $0.2 \mathrm{ppm}$ concentration, presenting a total recovery time of 30 seconds after removing the gas. Moreover, $\mathrm{Li}$ et al. [155] used $\mathrm{ZnO} / \mathrm{NiO}$ nanoheterojunction with porous morphology to detect ethanol. $\mathrm{Li}$ was able to detect $100 \mathrm{ppm}$ of ethanol at $200{ }^{\circ} \mathrm{C}$. By using a heterojunction the sensing mechanism may be a result of two factors. $\mathrm{ZnO}$ is a $n$-type semiconductor and in the presence of ethanol interaction with $\mathrm{O}^{2-}, \mathrm{O}^{-}$at the crystal surface will occur, leading to an increase of conductivity. On the other hand, $\mathrm{NiO}$ is a $p$-type semiconductor as such, the reductive ethanol molecules will react with oxygen ions adsorbed at the $\mathrm{NiO}$ surface and release electrons that will recombine with holes in $p$-type $\mathrm{NiO}$, leading to a decrease in holes concentration and, consequently to a resistance 
increase [155]. Ethanol molecules may also combine with holes in $\mathrm{NiO}$ nanostructures and produce intermediates $\mathrm{CH}_{3} \mathrm{CHO}$ molecules which will react with the absorbed oxygen, resulting in increased sensitivity ethanol for this type of heterojunction [155]. Moreover, it has been reported that in the heterostructure sensor, electrons will be transferred from $n$-type $\mathrm{ZnO}$ to $p$-type $\mathrm{NiO}$, while holes are transferred in the opposite way until the system reaches equilibrium at the Fermi level. This will lead to the formation of the hole depletion layer and increase the amount of chemisorbed oxygen species. The increase of such species allows more surface chemisorbed oxygen species to participate in the oxidation-reduction reactions at the sensing material's surface and thus impose an enhanced change in sensor resistance $[155,156]$.

The control of humidity levels is of great importance in some environments, such as in clean rooms, food management, medical area and chemical substances storage [157]. When using $\mathrm{ZnO}$ nanostructures, it is expected that the impedance of the sensor increases with the increase of adsorbed water at the sensor's surface and that sensors present low hysteresis, high sensitivity with a short recovery time. Some researchers have studied the use of $\mathrm{ZnO}$ nanostructures in humidity sensing applications.

Ghanem et al. [157] produced a humidity $\mathrm{ZnO}$ sensor that presented a resistivity variation in the presence of humidity changing between $15-95 \%$, with hysteresis error of $2 \%$ at $100{ }^{\circ} \mathrm{C}$. Also, Herrán et al.[158] used $\mathrm{ZnO}$ nanoparticles to monitor humidity at room temperature. With a response time of 5 seconds, Herrán was able to measure humidity in the range of 0 to $80 \%$.

Also, in the case of humidity sensors, it is possible to improve sensor properties by synthesizing a composite nanostructured material. Sin et al. [159] produced humidity sensors based on $\mathrm{ZnO} / \mathrm{SnO}_{2}$ cubic structures. The advantages of using a composite sensor are higher thermal stability and increased electron mobility. When using a $\mathrm{ZnO} / \mathrm{SiO}_{2}$ 
cubic structure, Sin was able to obtain sensitivity of 22.5 at $90 \mathrm{RH} \%$, a much higher value when compared to the sensitive values of 7.5 and 2.3, obtained with only $\mathrm{ZnO}$ or $\mathrm{SnO}_{2}$, respectively [159]. The same $\mathrm{ZnO} / \mathrm{SiO}_{2}$ composite was used by Qing et al. [160]. The mesoporous $\mathrm{ZnO} / \mathrm{SiO}_{2}$ produced by Qing presented a high surface area, with uniform structured pores that enhanced water vapour adsorption at the surface, enhancing sensitivity. The produced sensor presented improved humidity sensing in a range of 11 to $95 \mathrm{RH} \%$, with a response time of 50 seconds and maximum humidity hysteresis of $2 \%$ [160].

Leilei et al. [161] have reported the use of a $\mathrm{ZnO} / \mathrm{TiO}_{2}$ composite for humidity detection . The main disadvantage of using $\mathrm{ZnO}$ in humidity sensors is the fact that this semiconductor material can be very hydrophobic, which difficults sensitivity improvement . On the other hand, $\mathrm{TiO}_{2}$ is a hydrophilic material due to the observed dissociative adsorption of water at $\mathrm{Ti}^{3+}$ defects sites. Nevertheless, the use of this material may bring some disadvantages, such as high resistance, pronounced hysteresis and short long-time stability [161-163]. So, the use of a $\mathrm{ZnO} / \mathrm{TiO}_{2}$ composite as complementary materials will favour the enhancement of humidity sensor properties. The $\mathrm{ZnO} / \mathrm{TiO}_{2}$ nanorods composite produced by Leilei et al. [161] presented a considerable sensitivity enhancement when compared with single $\mathrm{ZnO}$ or $\mathrm{TiO}_{2}$ sensors, with an enhancement of 31 and 1380, respectively. The use of a $\mathrm{TiO}_{2}$ coating will enhance the water adsorption at the sensor's surface, due to the rough surface of $\mathrm{TiO}_{2}$ and its remarkable hydrophilicity. Moreover, with the increase of humidity, capillary condensation will occur in the pores with smaller radius than the Kelvin critical radius $\left(\mathrm{TiO}_{2}\right.$ surface and $\mathrm{ZnO} / \mathrm{TiO}_{2}$ interface $)$. The formation of these pores is due to the nanoscale grain boundaries of the $\mathrm{TiO}_{2}$ shell. The introduction of this shell leads to the adsorption of more water molecules by increasing the hydrophilicity of the surface area and by inducing capillary condensation. 
The phenomenon will contribute to the polarization of adsorbed water molecules and induce accelerated capacitance response [161].

Figure 7, shows the adsorption model proposed by Leilei et al. [161].
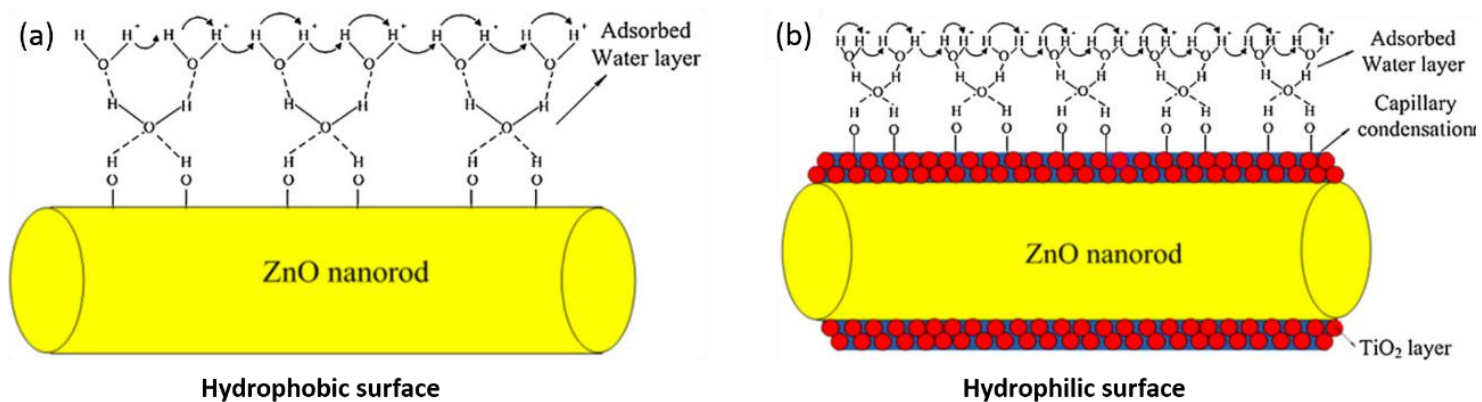

Figure 7. Humidity adsorption models for (a) $\mathrm{ZnO}$ nanorods; (b) $\mathrm{ZnO} / \mathrm{TiO}_{2}$ composite nanorods [161]. Reproduced with permission of Elsevier (2018).

The UV photoresponse of $\mathrm{ZnO}$ material was first observed by Mollow in the 1950s [164]. Since then, zinc oxide has been one of the most studied metal oxide material used in UV sensor applications. Initially, researchers had focused their attention on the development of $\mathrm{ZnO}$ thin films-based sensors however these films presented some intrinsic drawbacks, such as a slow response time and recovery speed. So in the past decade, many authors have reported the use of $\mathrm{ZnO}$ nanostructures (like nanorods, nanostars and tetrapods) with the aim of increasing the photoresponse by increasing the sensor surface area $[114,165-170]$. Due to the fact that $\mathrm{ZnO}$ photoresponse is related to adsorption and desorption of chemisorbed oxygen from (0001) polar facets, the use of 1D nanostructures presents some advantages due to its large surface to volume ratio, allowing increase of the sensor's photoresponse and/or reduction of the active area (very important for devices miniaturization) $[164,166]$.

Many are the factors that can influence the sensitivity of a $\mathrm{ZnO}$ UV sensor including substrate, $\mathrm{ZnO}$ particles morphology or even sensor configuration. Alenezi et al. [81] developed a series of flexible sensors with different configurations that presented distinct values of photocurrent response. With a bridging nanosizing configuration, 
Alenezi et al. [81] were able to improve sensitivity, with an ultrafast response time (90 $\mathrm{ms})$ and also a fast recovery time $(210 \mathrm{~ms})$. Pimentel et. al. reported a set of studies demonstrating the production of $\mathrm{ZnO} \mathrm{UV}$ sensors constructed on rigid or flexibles substrates (glass or PET/PEN) and also on cellulosic based substrates [13, 71, 122]. Figure 8 shows $\mathrm{ZnO}$ UV sensors produced on cellulosic based substrates and glass.

(a)

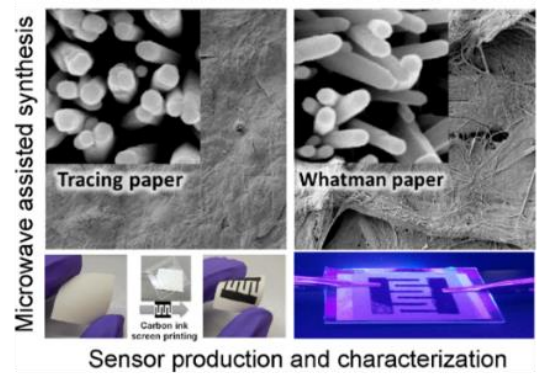

(b)

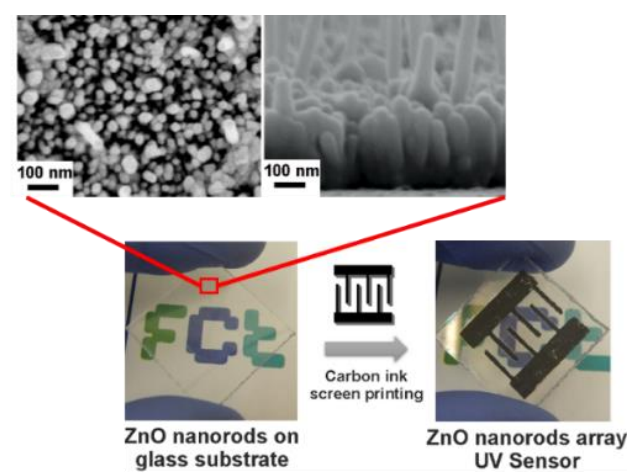

(c)
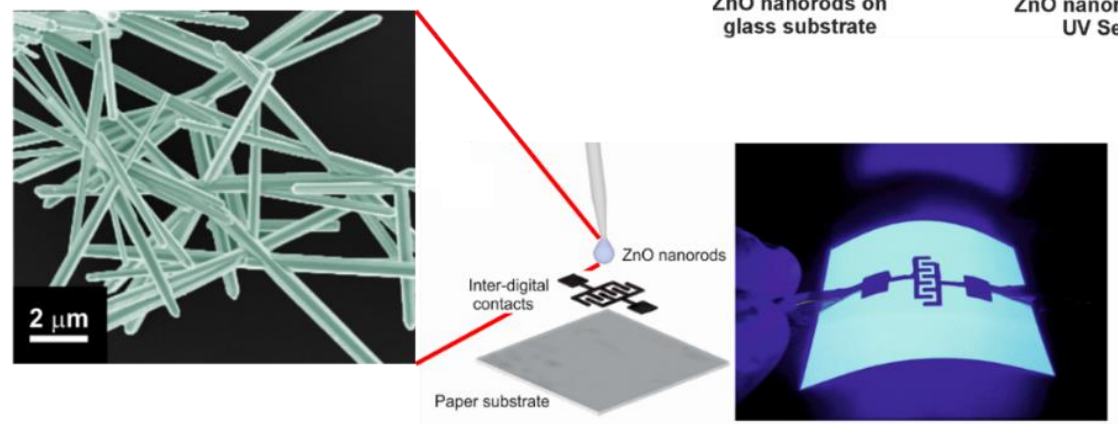

Figure 8. (a) ZnO UV sensor produced on tracing and Whatman paper [13]; (b) Transparent UV sensor produced on glass substrate [71]; (c) UV sensor produced with ZnO nanowires on top of graphite electrodes, screen printed on paper substrate [122]. Reproduced with permission of MDPI [13] and [71], and ACS publications "Copyright (2018) American Chemical Society" [122].

A disadvantage of using $\mathrm{ZnO}$ nanostructures in UV sensing is the low photocurrent value, mainly due the small size of individual nanowires. Some different methodologies are being employed by researches in order to enhance the photoresponse of $\mathrm{ZnO}$ UV sensors. Bai et al. [171] showed the difference in using $\mathrm{ZnO}$ nanowires aligned horizontally along the substrate or using the same nanowires placed vertically against the substrate. By a transfer process, it was possible to transfer the vertically oriented nanowires into a well aligned horizontal orientation and this way increasing the 
photoresponse current from $1.8 \mu \mathrm{A}$ to $12.22 \mathrm{~mA}$, with an on/off current ratios of 82000 [171].

One of the most important characteristics that are being studied by scientific community is sensor miniaturization. Portable and small photodetectors have a wide range of applications, such as the monitoring of UV dosage for skin cancer prevention, optical communications and also in astronomy [172]. Nasiri et al. [172] produced small $\mathrm{ZnO}$ photodetectors with excellent selectivity and milliampere photocurrents. A spray flame synthesis technique was used (see Figure 9 (a)), producing $\mathrm{ZnO}$ nanoparticles with a diameter of $\approx 19 \mathrm{~nm}$. The high sensitivity of this sensor is mainly due to the highly pure crystal surface and the very small particle size that originated ultra-porous $\mathrm{ZnO}$ nanoparticle film, presenting increased photocurrent from $260 \mu \mathrm{A}$ to $1.2 \mathrm{~mA}$ [172].

Another very interesting concept for UV sensor application is presented by Park et al. [164]. Park was able to produce a wireless UV sensor platform based on $\mathrm{ZnO}$ nanorods where real-time collected signals are sent to a smartphone through Bluetooth connection, with responsivity as high as $0.55 \mathrm{~A} \mathrm{~W}^{-1}$, response time of $3.1 \mathrm{~s}$ and recovery time of $1.25 \mathrm{~s}$. Figure 9 (b) shows a photograph of the photocurrent measurement by a smartphone. 

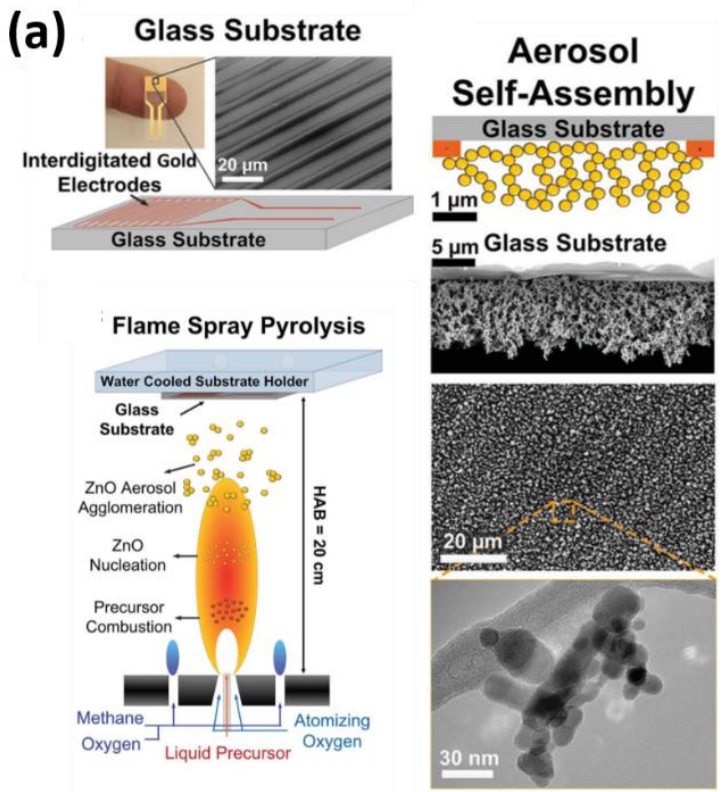

(b)

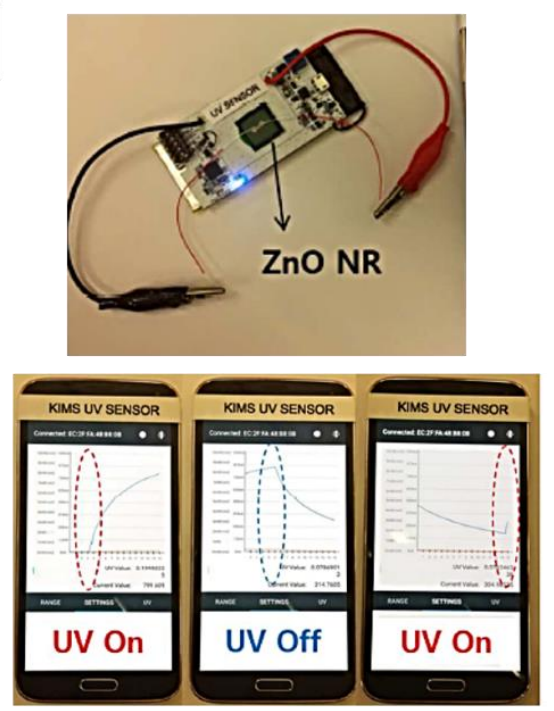

Figure 9. (a) Schematic of a $\mathrm{ZnO}$ photodetector production by flame spray pyrolysis [172]; (b) Photographic image of a ZnO UV sensor Bluetooth-connected to a smartphone [164], where it is visible the photocurrent variation under on/off cycles of UV radiation. Reproduced with permission of John Wiley and Sons [172] and Royal Society of Chemistry (2018) [164].

The most recent approach in $\mathrm{ZnO} \mathrm{UV}$ sensors is the use of graphene as conductive layer to improve their performance [173-175]. The advantage of using graphene relies on its superior conductivity (that prevents recombination of electron-hole pairs in the $\mathrm{ZnO} /$ graphene composite) and transmittance (over $97.7 \%$ for a single layer graphene, which maximizes UV-light absorption), allowing a reduction in response and recovery time, and increasing the photocurrent gain [174]. Duan et al. [174] was able to produce a $\mathrm{ZnO}$ UV sensor with responsivity of $0.039 \mathrm{~A} \mathrm{~W}^{-1}$, extremely short response and decay time of $37 \mu \mathrm{s}$ and $330 \mu \mathrm{s}$, respectively.

Zinc oxide is a biocompatible material, with high isoelectric point $\left(\mathrm{IEP}_{\mathrm{ZnO}} \approx 9.5\right)$, high surface activity and electron communication feature [176, 177]. For these reasons, $\mathrm{ZnO}$ can be functionalized with a wide range of biological materials with low IEP values, through electrostatic interaction, such as enzymes (like glucose oxidase and cholesterol 
oxidase), antibodies or even DNA [176, 178, 179]. Several reports have demonstrated the application of $\mathrm{ZnO}$ as biosensors, i.e. in DNA immobilization [180], in glucose level detection [176, 177, 181], for cardiac biomarker detection [179, 182, 183] and also for cancer diagnostic $[178,184,185]$.

Probably the application of $\mathrm{ZnO}$ for glucose detection is one of the most studied biosensors. For glucose levels detection, $\mathrm{ZnO}$ biosensors are produced by immobilization of glucose oxidase enzyme onto $\mathrm{ZnO}$ nanostructures [176]. The high $\mathrm{IEP}_{\mathrm{ZnO}}$ value will promote the formation of zinc oxide/ glucose oxidase complexes during functionalization (glucose oxidase are negatively charged molecules, that will be readily attracted and immobilized onto positively charged zinc oxide).

The detection of glucose by the functionalized electrodes can be described by the following electrochemical reactions: glucose oxidase enzyme oxidizes glucose and as a result $\delta$-gluconolactone and $\mathrm{H}_{2} \mathrm{O}_{2}$ are produced [181]. Finally, with the oxygen consumption and $\mathrm{H}_{2} \mathrm{O}_{2}$ oxidation, it is possible to evaluate the amperometric response of the biosensor [176, 181]. The use of $\mathrm{ZnO}$ nanostructures, with high surface-to-volume, in glucose biosensors, will provide a large specific surface area for glucose oxidase adsorption.

Gallay et al. [176] was able to produce a $\mathrm{ZnO}$ nanowire-based glucose sensor capable of detecting very low glucose concentrations of about $9 \mu \mathrm{M}$. Wahab et al. [181] used $\mathrm{ZnO}$ nanorods for the detection of glucose with concentration ranging from $1 \mu \mathrm{M}$ to $10 \mathrm{mM}$. Wang et al. [177] synthesized $\mathrm{ZnO}$ nanocombs, forming a highly porous structure, that were then immobilized with glucose oxidase, showing a detection limit of $0.02 \mathrm{mM}$.

One of the most key areas of investigation is the development of rapid systems for the diagnostic of cancer. Researchers have found that some biomolecules like DNA 
molecules, human serum albumin and angiotensin II molecules can be effectively immobilized just by modifying the $\mathrm{ZnO}$ nanostructures surface [184]. Viter et al. [178] have demonstrated that by using photoluminescence properties of $\mathrm{ZnO}$ nanorods, it was possible to develop a cancer cell recognition system. By immobilization of SSEA-4 antibodies on $\mathrm{ZnO}$ nanorods that were then deposited on the cell probe, it was possible to record photoluminescence spectra that increased when compared with the signal of control samples. Moreover, it was possible to observe that the intensity was correlated with the extent of malignancy in target cell population [178]. Another method for the detection of cancer cells was presented by Rui et al. [185]. By adsorbing Cytochrome $c$ (Cyt.c) onto $\mathrm{ZnO}$ surface, this latter study used $\mathrm{ZnO}$ nanosheets to detect $\mathrm{H}_{2} \mathrm{O}_{2}$ from living cancer cells. Cyt.c was found to promote direct electron transfer at the electrode surface [186].

For cardiovascular disease diagnosis, it was possible to develop a sensor that may detect specific concentration ranges of biomarkers that are associated with those diseases. The presence of cardiac troponin (cTnT and cTnI biomarkers) in blood circulation is an indicative of cardiovascular disease [179, 182]. Shanmugam et al. [182] developed a flexible and disposable electrochemical sensor capable of detecting very low concentrations of target analyte cTnT with only $20 \mu \mathrm{L}$ of solution. The limit of detection was identified at $0.1 \mathrm{ng} \mathrm{L^{-1 }}$. Tan et al. [183] produced a biosensor based on $\mathrm{ZnO}$ nanoparticles that was capable of converting the biological interaction of cTnI into an electrical signal. This study also detected the cTnI biomarker in a concentration range of $1 \mathrm{ng} \mathrm{mL} L^{-1}$ to $10 \mu \mathrm{g} \mathrm{mL}^{-1}$, withdetection limit of $2.191 \mathrm{ng} \mathrm{ml}^{-1}$ and sensitivity of $15.8 \mathrm{nA}$ $(\mathrm{g} / \mathrm{mL})^{-1}$. 


\subsection{Titanium dioxide}

$\mathrm{TiO}_{2}$ is a $n$-type semiconductor usually appearing in an amorphous state or as three crystalline phases: the tetragonal phases, anatase and rutile, and an orthorhombic phase, brookite [187]. Rutile is the most stable phase, in which both anatase and brookite are metastable, transforming to rutile when heated [188]. It has been reported that phase transformation of the amorphous state to anatase occurs from 300 to $500{ }^{\circ} \mathrm{C}$, and further transformation to rutile occurs at $600-1000{ }^{\circ} \mathrm{C}[103,189]$.

Rutile and anatase tetragonal structures contain six and twelve atoms per unit cell, respectively. For both phases, each $\mathrm{Ti}$ atom is coordinated to six $\mathrm{O}$ atoms and each $\mathrm{O}$ atom is coordinated to three $\mathrm{Ti}$ atoms. The $\mathrm{TiO}_{6}$ octahedron is slightly distorted, with two Ti-O bonds somewhat greater than the other four, having some of the O-Ti-O bond angles distorted from $90^{\circ}$ (greater distortion in anatase than rutile). The structures of rutile and anatase crystals consist of chains of $\mathrm{TiO}_{6}$ octahedra, sharing four edges in anatase and two in rutile. In the case of brookite, it has distorted $\mathrm{TiO}_{6}$ octahedra sharing three edges. Moreover, brookite has eight formula units in the orthorhombic cell, in which the interatomic distances and $\mathrm{O}-\mathrm{Ti}-\mathrm{O}$ bond angles are similar to those of rutile and anatase, nevertheless it has six different Ti-O bonds [190, 191]. Rutile, anatase and brookite unit cells are presented in Figure 10.
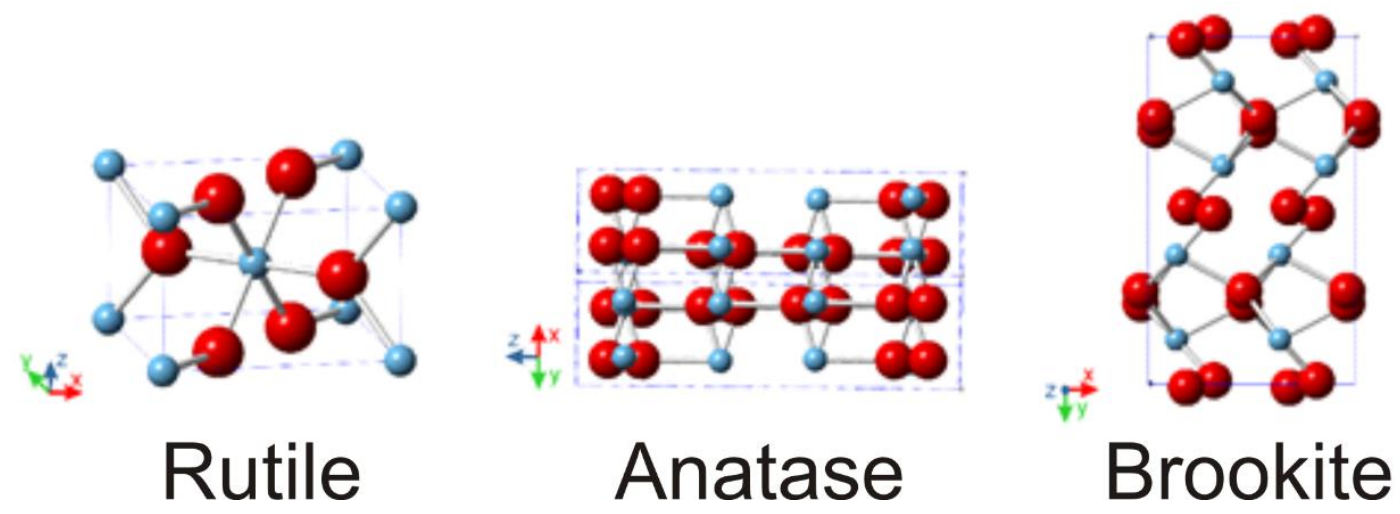

Figure 10. Unit cells of $\mathrm{TiO}_{2}$ rutile, anatase and brookite [192]. Reproduced with permission of Intech. 
$\mathrm{TiO}_{2}$ is a wide energy band gap material, typically displaying optical band gaps of 3.0 and $3.2 \mathrm{eV}$ for rutile and anatase, respectively [193], and varying from 3.13 to $3.40 \mathrm{eV}$ $[188,193]$ for brookite. Nevertheless, its optical bang gap for nanostructured materials can be engineered by adding structural defects or doping with non-metal and metal elements also to narrow its band gap [194-196]. $\mathrm{TiO}_{2}$ has a high refractive index (2.71 for rutile, 2.53 for anatase and 2.64 for brookite [191]), high dielectric constant $\left(\mathrm{TiO}_{2}\right.$ thin films ranging from 40 to 86 [197, 198]) and high resistivity extending to $10^{8} \Omega$.cm [199]. The lattice parameters for rutile $\left(P 4_{2} / \mathrm{mnm}\right)$ are $a=0.4594 \mathrm{~nm}$ and $c=0.2958 \mathrm{~nm}$, while anatase $\left(I 4_{1} /\right.$ amd $)$ has lattice parameters of $a=0.3785 \mathrm{~nm}$ and $c=0.9515 \mathrm{~nm}$, and brookite (Pbca) has lattice parameters of $a=0.9184 \mathrm{~nm}, b=0.5447 \mathrm{~nm}$, and $c=0.5145 \mathrm{~nm}[191$, 200].

Several techniques have been reported to produce $\mathrm{TiO}_{2}$ nanostructures or thin films including sol-gel method [201], wet-chemical techniques [202, 203], thermal evaporation [204], sputtering [205], electrodeposition [206], hydrothermal and solvothermal synthesis [207-210], microwave irradiation [10, 192], amongst others. Various and distinct structures have been reported for $\mathrm{TiO}_{2}$ nanomaterials, especially as nanoparticles, including nanowires, nanorods, nanotubes, nanobelts, nanowhiskers, nanospheres and others [10, 203, 211-213].

$\mathrm{TiO}_{2}$ is known to be an inexpensive material, earth abundant, chemically stable, nontoxic, biocompatible, and environmentally friendly [203, 214], which makes it prone to be applied in numerous fields, including solar cells [25, 215, 216], self-cleaning [217, 218], photocatalysis [9, 10, 192], $\mathrm{H}_{2}$ production [219], $\mathrm{CO}_{2}$ reduction [220, 221], sensors [222-224], among others. Anatase is the preferred phase for solar cell integration since it has high electron mobility, low dielectric constant and lower density [225, 226]. $\mathrm{TiO}_{2}$ has been widely investigated for photocatalytic $\mathrm{H}_{2}$ evolution, photoelectrochemical water 
splitting, reduction of $\mathrm{CO}_{2}$ to hydrocarbons, and pollutant degradation for many years. In terms of photocatalytic activity, anatase is expected to exhibit an indirect band gap that is smaller than its direct band gap. Rutile presents a direct band gap or an indirect band gap that is comparable to the direct one. It is known that semiconductors with indirect band gap generally exhibit longer charge carrier life times and thus longer electron-hole pair life would facilitate charge carriers participation in surface reactions [227]. Nevertheless, it has been reported that the mixture of both phases displayed higher photocatalytic activity than pure phases [228]. In the case of brookite, this material is the least investigated $\mathrm{TiO}_{2}$ polymorph, however it has been reported to display higher photocatalytic activity than anatase or rutile [229].

In terms of sensors, and as previously mentioned, a high-quality sensor is expected to have greater sensitivity, high detection limit, response/recovery time and stability and longer life cycles. These parameters are related to characteristics of the sensing material, such as grain size and microstructure, which directly influence the sensor's sensitivity [199]. In this sense, nanostructured materials have been extensively used in sensors over the years, including nanostructured $\mathrm{TiO}_{2}$ materials that have enhanced chemical stability allowing low temperature operation. This materials has inert characteristics, and is resistance to harsh atmospheric conditions, despite being low-cost in terms of production and compatible with wet-chemical synthesis routes [230].

$\mathrm{TiO}_{2}$ has been widely used as photoactive layer of gas sensors, where $\mathrm{TiO}_{2}$-based gas sensors are typically chemiresistive, having the working principle of typical $n$-type semiconductor gas sensor materials based on its conductance change mechanism due to adsorption/desorption process of oxidizing and reducing gases [231].

Liu et.al. [232] reported the hydrothermal synthesis of $\mathrm{TiO}_{2}$ nanocrystals with various percentages of exposed $\{001\}$ facets displaying $p$-type and $n$-type sensing responses 
towards ethanol (Figure 11 (a)). In another study, $\mathrm{TiO}_{2}$ nanowire sensors revealed excellent selectivity and high sensitivity down to $100 \mathrm{ppm} \mathrm{NO}_{2}$ at room temperature with response and recovery times of $10 \mathrm{~s}$ and $19 \mathrm{~s}$, respectively. Furthermore, the nanowires displayed good repeatability and selectivity against various interfering gases such as $\mathrm{NH}_{3}$, $\mathrm{H}_{2}$, and $\mathrm{CH}_{4}$ [233]. $\mathrm{TiO}_{2}$ nanostructured films composed of different morphologies, nanoparticles and nanotubes were synthesized by hydrothermal method and it has been shown that sensing films composed of nanotubes demonstrated a high sensor response to toluene [234].

It is also known that well-ordered porous metal oxide structures are highly efficient for improving gas sensing, in which this porosity increases surface area of the material, enhancing its interaction with the gaseous species [231]. $\mathrm{TiO}_{2}$ spongy layers with doublescale porosity at the meso and nano-scale have been reported and exhibited sensitivity of $44 \mathrm{ppm}$ to ethanol at $250^{\circ} \mathrm{C}$. Moreover, response of the material was demonstrated to be independent of ambient humidity with a response time as low as $~ 10 \mathrm{~s}$ [235].

Another approach that has been widely used is doping with small metal clusters. Doping will have a significant effect for the metal oxides which are dominated by defect chemistry (via oxygen vacancies). Oxygen vacancies are considered important reactive agents for several adsorbates, in such a way that surface reactions are influenced by this type of point defect [49]. Ruiz et al. [236] reported the effect of doping $\mathrm{TiO}_{2}$ with chromium, in which it has been observed that the addition of $\mathrm{Cr}$ retarded the anatase-torutile $\mathrm{TiO}_{2}$ transformation, moreover these materials revealed to be sensitive to $1000 \mathrm{ppm}$ CO, but also to $\mathrm{NO}_{2}$. In another study, it has been described $\mathrm{TiO}_{2}$ sol-gel films doped with gold nanoparticles used as both optical and conductometric sensors for the detection of $\mathrm{CO}$ and $\mathrm{H}_{2}$ [237]. The combination of different oxides has also been reported to surpass limitations of each metal oxide material. Carney et al. [238] produced $\mathrm{TiO}_{2}-\mathrm{SnO}_{2}$ 
nanofiber-structured films that were tested for sensing $\mathrm{H}_{2}$. This combination allowed to increase $\mathrm{TiO}_{2}$ gas sensitivity and supress $\mathrm{SnO}_{2}$ sensors limitations that utilize lowtemperature chemisorption (under $400{ }^{\circ} \mathrm{C}$ ) of gases on the surface. Above $400{ }^{\circ} \mathrm{C}$, $\mathrm{SnO}_{2}$ exhibits poor sensing performance, while $\mathrm{TiO}_{2}$ is stable at higher temperatures.

In terms of humidity sensors, $\mathrm{TiO}_{2}$ is known to have superior humidity sensitivity with the preferably hydrophilic property resulting from the surface defects, i.e. the $\mathrm{Ti}^{3+}$ defect sites or oxygen vacancies sites, that can adsorb water molecules in the atmosphere [239]. Nevertheless, reported $\mathrm{TiO}_{2}$-based humidity sensors usually display limited sensitivity resultant of low surface/volume ratio, high resistance or poor charge transfer process of single phased $\mathrm{TiO}_{2}$ material. Thus, several approaches have been designed to overcome these limitations. Ultrathin $2 \mathrm{D} \mathrm{TiO}_{2}$ nanosheets with high specific surface area and surface oxygen vacancy defects have been reported as having ultrahigh humidity sensing performance. These nanostructured sensors revealed significant impedance variation from RH $11 \%$ to $95 \%$, short response time $(3 \mathrm{~s})$ and recovery time (50 s), as well as small hysteresis $\sim 4.6 \%$ (Figure 11 (b)) [239]. Lin et al. [240] reported a humidity sensor based on graphene/ $\mathrm{TiO}_{2}$ that at $12-90 \%$ relative humidity, exhibited a sensing response $(S=151)$ and humidity hysteresis value of $<0.39 \%$. In another study, flexible sensors based on $\mathrm{TiO}_{2}$ and conducting polymers have been described. These humidity sensors demonstrated hysteresis (range of 30-90\% RH) of $2 \% \mathrm{RH}$, with response time of $30 \mathrm{~s}$, and recovery time of $45 \mathrm{~s}$ [241]. Doping $\mathrm{TiO}_{2}$ was also considered for producing enhanced humidity sensors. Zare et al. [242] reported the effect of doping $\mathrm{TiO}_{2}$ with silver in terms of humidity sensitivity, while Buvailo et al. [243] showed $\mathrm{TiO}_{2-}$ based nanomaterial doped with $\mathrm{LiCl}$ to produce conducting thin film sensors. The latter sensors were measured in the RH range of 5-95\% and revealed 0.75 and $1 \mathrm{~s}$ for sensor response and recovery time, respectively. 
Recently, $\mathrm{TiO}_{2}$ has been considered as a good alternative for the most common used UV sensors, i.e. silicon-based sensors [244], as $\mathrm{TiO}_{2}$ is highly photoactive and stable under UV irradiation due to its band gap [67, 245, 246]. Highly oriented rutile $\mathrm{TiO}_{2}$ nanorod arrays were synthesized by hydrothermal method and tested as UV sensors achieving a photocurrent of $12.87 \mu \mathrm{A} \mathrm{cm}^{-2}$ under $365 \mathrm{~nm}$ UV light exposure [224]. In another study, anodic $\mathrm{TiO}_{2}$ anatase nanotube arrays were tested as UV sensors showing high responsivity of $13 \mathrm{~A} \mathrm{~W}^{-1}$ under $\lambda=312 \mathrm{~nm}$ and fast response with rise time and decay time of 0.5 and $0.7 \mathrm{~s}$, respectively [247]. Epitaxial $\mathrm{TiO}_{2}$ thin films were fabricated on $\mathrm{LaAlO}_{3}$ single crystal substrates by RF magnetron sputtering, and the sensor exhibited a maximum photoresponse of $3.63 \mathrm{~A} \mathrm{~W}^{-1}$ at $310 \mathrm{~nm}$ and ultrahigh response speed $(\sim 90$ ns) [248]. Nano-branched $\mathrm{TiO}_{2}$ arrays were integrated on self-powered UV sensors. The photosensitivity increased from 0.03 to $0.22 \mathrm{~A} \mathrm{~W}^{-1}$ exhibiting excellent spectral selectivity and fast response (0.05 s decay time) [249]. 

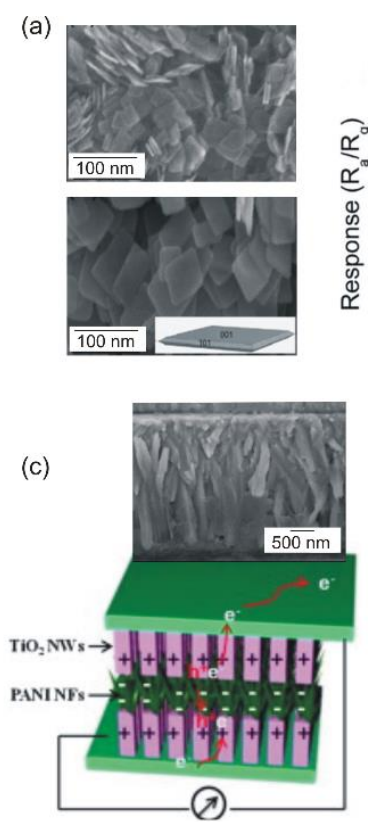
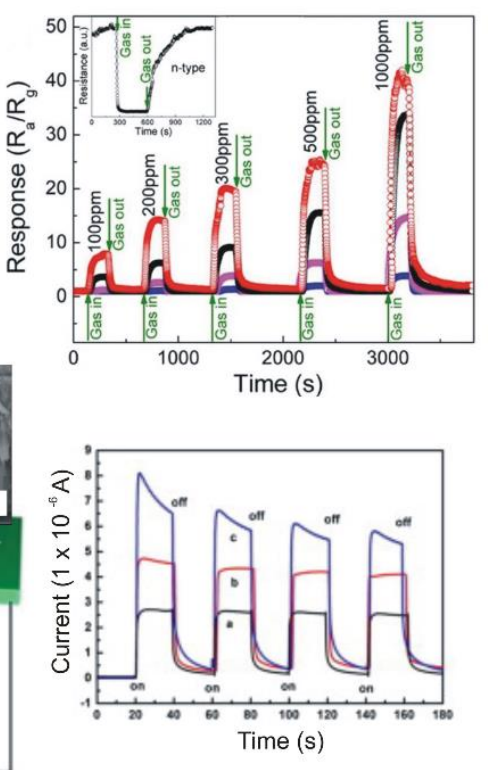

(b)
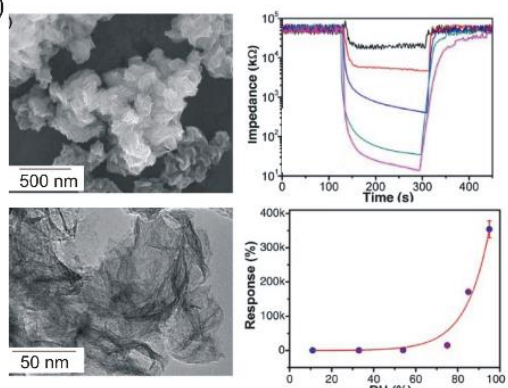

(d)
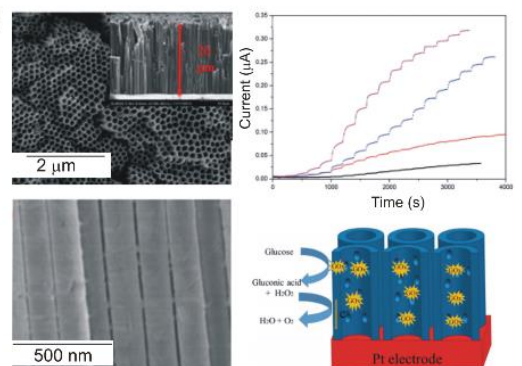

Figure 11. (a) $\mathrm{SEM}$ images of $\mathrm{TiO}_{2}$ nanosheets together with the response and recovery curves of the sensors as a function of ethanol concentration [232]. (b) SEM and TEM images of $\mathrm{TiO}_{2}$ nanosheets for humidity sensors together with the transient responding dynamics of the impedance of $\mathrm{TiO}_{2}$ nanosheetsbased sensor and calibration curve [239]. (c) SEM images of $\mathrm{TiO}_{2}$ nanowires/ $\mathrm{PANI} / \mathrm{TiO}_{2}$ nanowires heterostructured arrays to be used as UV photodetectors together with the time responses of photocurrents under UV light [250]. (d) SEM and schematic diagram of glucose detection on mesoporous $\mathrm{GO} / \mathrm{TiO}_{2}$ nanotubes. The graph showed the current responses with successive injections of glucose [251]. Reproduced with permission of Elsevier, [232], [239] and [250], and Royal Society of Chemistry (2018) [251].

D. Nunes et al. [246] reported the microwave synthesis $\mathrm{TiO}_{2}$ nanostructured films grown on bacterial nanocellulose (BNC), tracing paper and polyester film substrates to produce flexible and disposable UV sensors (Figure 12). The UV devices showed responsivities of $0.33 \mu \mathrm{A} \mathrm{W} \mathrm{W}^{-1}, 0.16 \mu \mathrm{A} \mathrm{W}^{-1}$ and $0.07 \mu \mathrm{A} \mathrm{W} \mathrm{W}^{-1}$ for $\mathrm{TiO}_{2}$ films grown on BNC, tracing paper and polyester substrates, respectively. The structural characteristics of the $\mathrm{TiO}_{2}$ films and substrates were correlated to differences in the UV photodetection. 

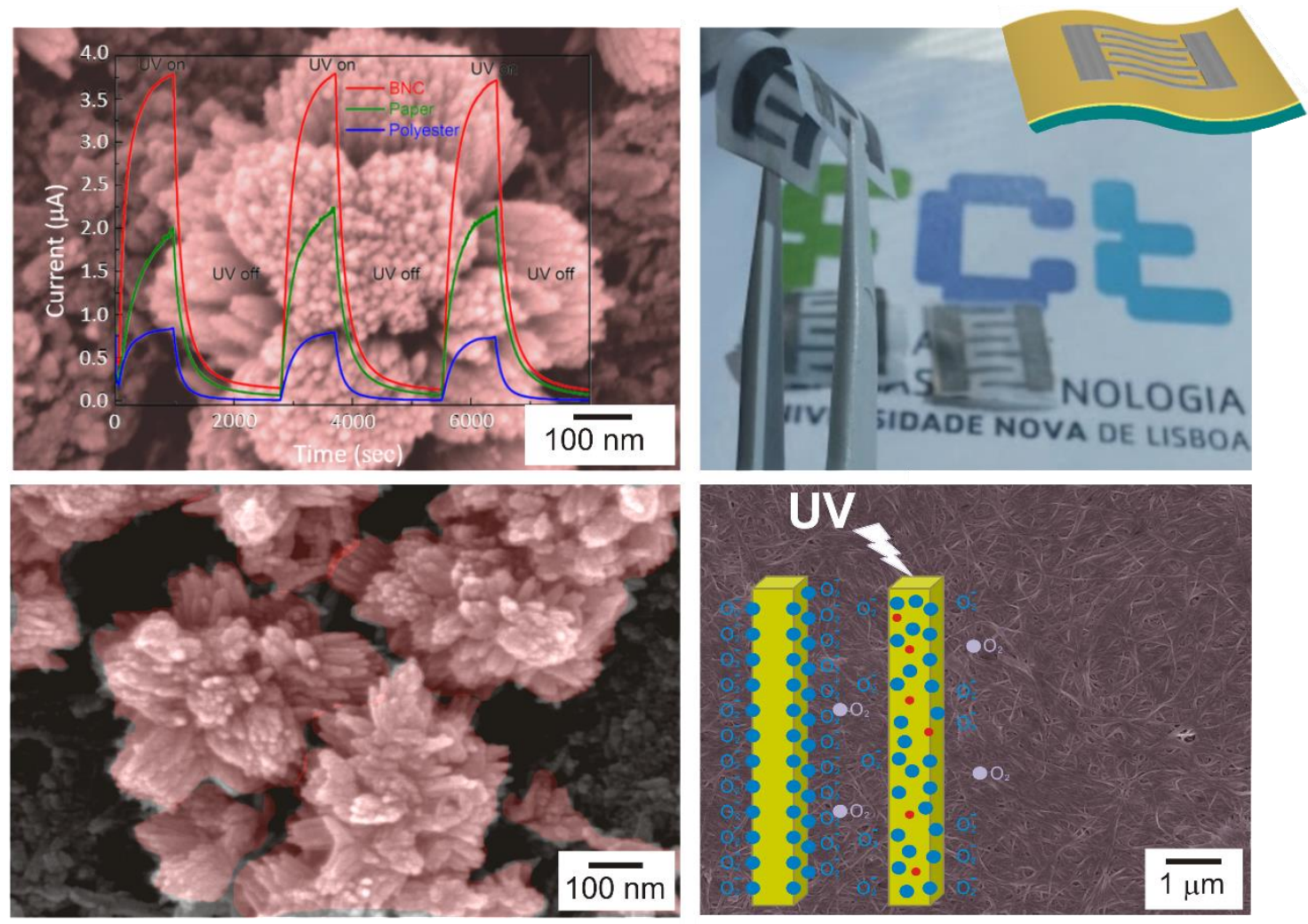

Figure 12. $\mathrm{TiO}_{2}$ nanostructured films composed by nanorod flower-like structures to be integrated as the photoactive layer of flexible UV sensors. The films were grown on tracing paper, bacterial nanocellulose and polyester substrates. The cycling behaviour of the photodetectors at $10 \mathrm{~V}$ and under a $360 \mathrm{~nm} \mathrm{UV}$ source were investigated. The schematic diagrams of dark and UV irradiation processes are presented. Images reproduced with permission of Springer Nature (2018) [246].

Another solution proposed to reduce electron-hole recombination is production of metal-doped $\mathrm{TiO}_{2}$ materials. It has been reported that $\mathrm{Au}$ nanoparticles deposited on $\mathrm{TiO}_{2}$ nanotubes showed good wavelength selectivity with high photocurrent as compared to pure $\mathrm{TiO}_{2}$ devices [252]. The addition of other oxides has also been addressed, for example in the case of $\mathrm{SnO}_{2}$, it possesses high electron mobility, suggesting a faster diffusion transport of photon-induced electrons to $\mathrm{TiO}_{2}$ [253]. Chen et al. [253] reported $\mathrm{SnO}_{2}-\mathrm{TiO}_{2}$ nanomace arrays exhibited responsivity of $0.145 \mathrm{~A} \mathrm{~W}^{-1}$ at $365 \mathrm{~nm}$, rising time of $0.037 \mathrm{~s}$, and decay time of $0.015 \mathrm{~s}$. $\mathrm{Zu}$ et al. [250] reported a self-powered UV photodetector based on heterostructured arrays of $\mathrm{TiO}_{2}$ nanowires/polyaniline 
nanoflowers $/ \mathrm{TiO}_{2}$ nanowires (Figure 11 (c)). The heterostructure revealed improved sensing performance when compared to bare $\mathrm{TiO}_{2}$ nanowires.

Metal oxides sensing applications, including in biosensors, is growing fast in recent years. In the case of biosensors, these devices are a rapidly expanding field in analytical chemistry, with an estimated $60 \%$ annual growth rate [254]. This impulse is coming from health-care industry, food quality and safety, but also from environmental monitoring. When comes to using $\mathrm{TiO}_{2}$ in biosensors, several studies have focused on producing 1D nanostructures forming continuous arrays [223, 251, 255, 256]. The use of $\mathrm{TiO}_{2}$ nanotube/nanorod arrays is related to large internal surface area, negative surface charge and high refractive index of these arrays allowing incorporation of biomolecules and high analyte sensitivity $[223,255]$. Mun et al. [223] reported the production of $\mathrm{TiO}_{2}$ nanotube arrays for label-free optical interferometric biosensing using a protein A capture probe and an immunoglobulin analyte [223]. Mesoporous $\mathrm{TiO}_{2}$ nanotube arrays had immobilized glucose oxidase (GO) to produce a biosensor for amperometric detection of glucose. The amperometric response of glucose on the $\mathrm{GO} / \mathrm{TiO}_{2}$ electrode was reported to be proportional to glucose concentration in the range from 0.1 to $6 \mathrm{mM}$ with a sensitivity of 0.954 $\mu \mathrm{A} \mathrm{mM}^{-1} \mathrm{~cm}^{-2}$ (Figure $\left.11(\mathrm{~d})\right)$ [251]. Hu et al. [255] produced carbon-doped $\mathrm{TiO}_{2}$ nanotube arrays for simultaneous detection of 5-hydroxytryptamine and ascorbic acid, which can also be readily regenerated photocatalytically to recover its high selectivity and sensitivity. Gao et al. [256] reported a graphene/ $/ \mathrm{TiO}_{2}$ nanorods/chitosan nanocomposite modified carbon ionic liquid electrode to produce an electrochemical DNA biosensor for detection of the transgenic soybean sequence of MON89788. The target ssDNA sequence was detected in the range from $1.0 \times 10^{-12}$ to $1.0 \times 10^{-6} \mathrm{~mol} \mathrm{~L}^{-1}$ with detection limit of 7.21 $\times 10^{-13} \mathrm{~mol} \mathrm{~L}^{-1}$. 
In another approach, $\mathrm{TiO}_{2}$ nanoparticles were used to produce a nanocomposite with graphene oxide nanosheets. The amperometric response of the glucose biosensor fabricated by the $\mathrm{TiO}_{2}$-graphene composite was linear against a concentration of glucose ranging from 0 to $8 \mathrm{mM}$ at $-0.6 \mathrm{~V}$. The highest sensitivity was shown at $6.2 \mu \mathrm{A} \mathrm{mM} \mathrm{m}^{-1} \mathrm{~cm}^{-}$ ${ }^{2}$, and the glucose biosensor based on the $\mathrm{TiO}_{2}$-graphene composite showed higher catalytic performance for glucose redox than a pure $\mathrm{TiO}_{2}$ and graphene biosensor [257]. Another study demonstrated the enzyme immobilization by amperometric biosensors with $\mathrm{TiO}_{2}$ nanoparticles to detect phenol compounds [258].

\subsection{Tungsten trioxide}

Tungsten trioxide is one of the most investigated transition metal oxide materials exhibiting a wide variety of novel properties. $\mathrm{WO}_{3}$ is a $n$-type semiconductor material with a wide energy band gap varying from 2.6 to $3.25 \mathrm{eV}[29,259] . \mathrm{WO}_{3}$ can present different crystallographic phases, such as cubic, hexagonal, monoclinic, triclinic, tetragonal and orthorhombic [260-264]. The cubic $\mathrm{WO}_{3}$ is hardly obtained experimentally, but oxygen vacancies in the $\mathrm{WO}_{3}$ lattice are capable of increasing the cell symmetry from monoclinic via tetragonal to cubic phase [265].

The most studied $\mathrm{WO}_{3}$ phases are the monoclinic $\left(P 2_{1 / n}\right)$, orthorhombic $(P b c n)$ and hexagonal $(P 6 / \mathrm{mmm})$. The monoclinic phase lattice parameter was reported to be $a=$ $0.7301 \mathrm{~nm}, b=0.7539 \mathrm{~nm}$, and $c=0.7689 \mathrm{~nm}$ [266] and consists of $\mathrm{WO}_{6}$ octahedral connected by corner sharing of oxygen atoms, connected in the $a$-, $b$ - and $c$-directions; the orthorhombic phase with lattice parameters of $a=0.7333 \mathrm{~nm}, b=0.7573 \mathrm{~nm}$, and $c=$ $0.7740 \mathrm{~nm}[267]$ is based on two octahedral, $\mathrm{WO}_{5}\left(\mathrm{H}_{2} \mathrm{O}\right)$ (with two oxygen atoms forming $\mathrm{W}=\mathrm{O}$ and $\mathrm{W}-\mathrm{OH}_{2}$ bonds) and $\mathrm{WO}_{6}$ with $\mathrm{W}-\mathrm{O}$ bonds sharing the same bond length; the hexagonal phase with cell parameters $a=0.7298 \mathrm{~nm}$ and $c=0.7798 \mathrm{~nm}$ [268] consists of $\mathrm{WO}_{6}$ octahedral structures sharing equatorial oxygen atoms, forming trigonal and 
hexagonal tunnels $[261,264]$. Both monoclinic and hexagonal phases consist of $\mathrm{WO}_{6}$ octahedral, but with different arrangements. Figure 13shows SEM images of the different morphologies and $\mathrm{WO}_{3}$ crystallographic phases.
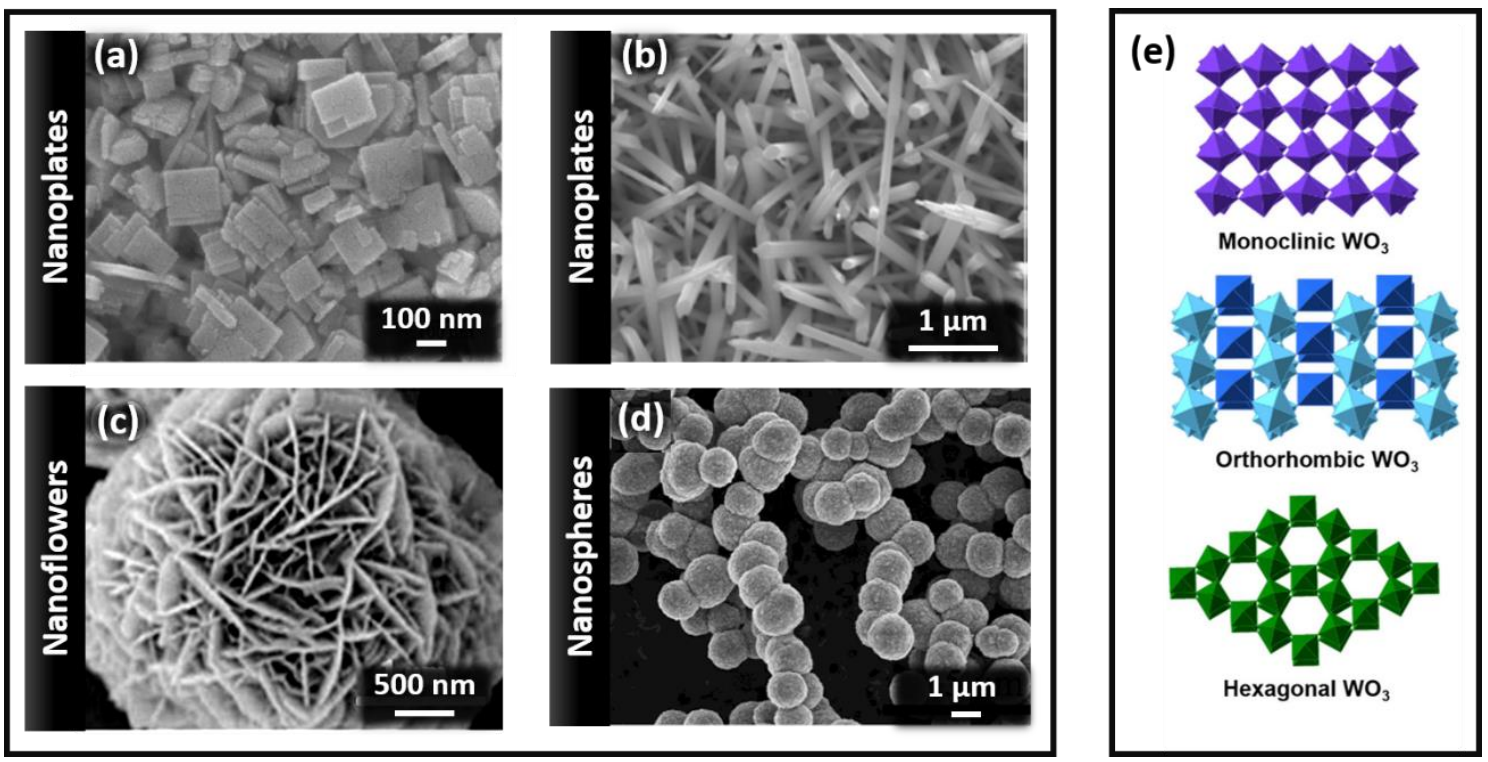

Figure 13. SEM images of $\mathrm{WO}_{3}$ (a) nanoplates produced by microwave hydrothermal method [269]; (b) nanowires produced by thermal evaporation [270]; (c) nanoflowers produced by hydrothermal method [271]; (d) microspheres produced by hydrothermal method [272]. (e) Crystallographic structures of different $\mathrm{WO}_{3}$ phases [262]. Reproduced with permission of Hindawi [269], Elsevier [270], [271], and [272], and Springer Nature (2018) [262].

Many researchers have concentrated their studies on novel and more efficient synthesis techniques for producing $\mathrm{WO}_{3}$ nanostructures, such as conventional and microwave hydrothermal/solvothermal syntheses [273-275], electrodeposition [276], chemical bath deposition [277], chemical vapour deposition [278] and electrospinning $[279,280]$. By using these different synthesis techniques, tungsten trioxide may grow with different morphologies like nanoplates [269, 281, 282], nanowires [270, 283, 284], nanorods [285, 286], nanoflowers [271, 287] and hollow nanospheres [272, 288].

Due to its thermochromic properties, $\mathrm{WO}_{3}$ is mostly used in intelligent electrochromic windows, surfaces for energy-efficient architectures and flat-panel displays [289-295]. Moreover, this material is widely used in solar photocatalysis [273, 296, 297], but it has 
also been demonstrated that this semiconductor material exhibits enhanced chemical sensing properties and is used in several sensing applications [298-301].

$\mathrm{WO}_{3}$ has been largely employed in gas sensors with remarkable gas sensing properties for the detection of $\mathrm{NO}_{2}$ [302-304]. In Ref. [303], it has been shown the $\mathrm{NO}_{2}$ response of lamellar-nanostructured $\mathrm{WO}_{3}$ particles. The gas sensor exhibited high sensor response $(S=150-280)$ to dilute $\mathrm{NO}_{2}(50-1000 \mathrm{ppb})$ in air at $200{ }^{\circ} \mathrm{C}$. Sensitive porous $\mathrm{WO}_{3}$ nanocrystalline based $\mathrm{NO}_{2}$ sensor has been reported in [304]. The sensor showed high sensitivity to low $\mathrm{NO}_{2}$ concentration in the range from 50 to $550 \mathrm{ppb}$ with relatively fast response time $(\sim 3 \mathrm{~min})$ and recovery time $(\sim 1 \mathrm{~min})$. A three-dimensional hierarchical $\mathrm{WO}_{3}$ nanostructure with nanosheet-assembled morphology has been used in gas sensors.

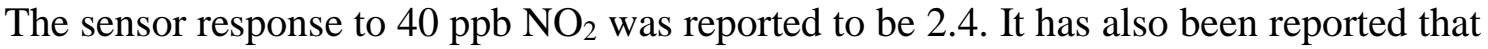
this sensor has good selectivity to $\mathrm{NO}_{2}$, as the signal was higher for this gas when compared to other oxidizing gases $\left(\mathrm{Cl}_{2}\right)$ or reducing gases $\left(\mathrm{CO}, \mathrm{H}_{2} \mathrm{~S}, \mathrm{NH}_{3}\right.$, acetone and ethanol) [305]. An et al. [306] reported $\mathrm{WO}_{3}$ nanotube sensors with responses of 144$677 \%$ in $\mathrm{NO}_{2}$ concentration range of $1-5 \mathrm{ppm}$ at $300{ }^{\circ} \mathrm{C}$.

Lin et al. [57] reported $\mathrm{WO}_{3}$ hollow-sphere gas sensors with satisfactory sensitivity to alcohol, acetone, $\mathrm{CS}_{2}, \mathrm{NH}_{3}$, and $\mathrm{H}_{2} \mathrm{~S}$. With increasing gas concentration, sensitivity of the sensors sharply increased. The sensors were more sensitive to alcohol and acetone than to other organics. Another work showed a $\mathrm{WO}_{3}$ nanowire-like structure for high sensitivity $\mathrm{NH}_{3}$ gas sensor. The $\mathrm{NH}_{3}$ gas-sensing properties of these nanowires were measured, showing maximum response of $9.7-1500 \mathrm{ppm}$ at $250{ }^{\circ} \mathrm{C}$ with response and recovery times of 7 and $8 \mathrm{~s}$, respectively [307]. $\mathrm{WO}_{3}$ nanostructures synthesized by hydrothermal method were reported in Ref. [308]. The responses for the sensors increased significantly with the increase of the acetone gas concentration. One of the sensors demonstrated increased sensitivity from 4.1 to 15.8 when the concentration of acetone 
was changed from $10 \mathrm{ppm}$ to $400 \mathrm{ppm}$. The sensing selectivity was also explored by comparing the response to acetone, ethanol, formaldehyde and ammonia gases with various concentrations.

The use of $\mathrm{WO}_{3}$ in the form of films for gas sensing was also investigated. Oriented $\mathrm{WO}_{3}$ nanoflakes array films were tested as gas sensors in Ref. [298]. The $\mathrm{WO}_{3}$ thin film sensor exhibited responses of $2.8-9.8 \%, 12.8-68.9 \%$ and $26.2 \%-85 \%$ respectively, to $0.1-$ $10 \mathrm{ppm}$ of $\mathrm{H}_{2} \mathrm{~S}$ concentration at various operating temperature such as $100{ }^{\circ} \mathrm{C}, 200{ }^{\circ} \mathrm{C}$ and $300{ }^{\circ} \mathrm{C}$, respectively. The $\mathrm{WO}_{3}$ thin film sensor showed a high response to $\mathrm{H}_{2} \mathrm{~S}$ that increased with $\mathrm{H}_{2} \mathrm{~S}$ gas concentration. Sulfur dioxide gas sensors based on $\mathrm{WO}_{3}$ screen printed thick films composed of nanopowders were demonstrated in [309]. The sensors exhibited responses to $1-10 \mathrm{ppm} \mathrm{SO}_{2}$ at $200-300{ }^{\circ} \mathrm{C}$, which has been shown to be strongly dependent on $\mathrm{WO}_{3}$ morphology. Nanoparticle $\mathrm{WO}_{3}$ films were used as gas sensors for ethanol and $\mathrm{H}_{2} \mathrm{~S}$. The working temperature of the sensor was between 150 and $250{ }^{\circ} \mathrm{C}$ and it was possible to detect $200 \mathrm{ppb}$ of ethanol and $20 \mathrm{ppb}$ of $\mathrm{H}_{2} \mathrm{~S}$ [310].

Different approaches have been designed to efficiently enhance the gas sensing characteristics of $\mathrm{WO}_{3}$, including doping with noble elements, other metal oxides (forming of $p-n$ heterojunction) or carbon-based materials. Au nanoparticle modified $\mathrm{WO}_{3}$ nanorods were tested as $\mathrm{H}_{2}$ sensors, exhibiting larger response to $\mathrm{H}_{2}$, i.e. $50 \mathrm{ppm}$ and recovery time lower than $10 \mathrm{~s}$ [311]. In another study, Pt nanoparticles were functionalized on $\mathrm{WO}_{3}$ hybrid nanorods to be used as gas sensor. The gas sensing to varied concentrations $(1,5,20,100$ and $200 \mathrm{ppm})$ of ethanol and methanol at $220{ }^{\circ} \mathrm{C}$ were demonstrated, with better performance than pure $\mathrm{WO}_{3}$ [312]. In Ref. [313], Cr-doped $\mathrm{WO}_{3}$ nanofibers were reported to have high response towards $100 \mathrm{ppm}$ xylene and long term stability. Ag doped $\mathrm{WO}_{3}$-based powder sensors for detection of $\mathrm{NO}$ gas in air were reported in Ref. [314], demonstrating a sensitivity of 38.3 at $250{ }^{\circ} \mathrm{C}$. This value was 
compared to the sensor without Ag doping. 3D hierarchical monoclinic-type structural Sb-doped $\mathrm{WO}_{3}$ gas sensing material was described in Ref. [315]. The results of gas sensor measurements indicated that the 3D material has superior sensitivity $(S=122)$ and high selectivity to ppm-level $\mathrm{NO}_{2}$ at $30{ }^{\circ} \mathrm{C}$. It has been demonstrated that abundant structural defects derived from $\mathrm{Sb}$ doping modification, reduced band gap, and 3D hierarchical microstructure played a key role on the $\mathrm{NO}_{2}$ gas sensing performance.

Ref. [316], reports $\mathrm{CuO} / \mathrm{WO}_{3}$ heterostructured nanocubes that were used to sense $\mathrm{H}_{2} \mathrm{~S}$ gas in a concentration as low as $50 \mathrm{ppb}$. By combining these with electric modulation, the sensors simultaneously exhibited fast recovery and ultrahigh sensitivity for detecting $\mathrm{H}_{2} \mathrm{~S}$ gas at low temperature. Nanocrystalline $\mathrm{TiO}_{2}: \mathrm{WO}_{3}$-based hydrogen sensors were reported in Ref. [317]. The sensitivity to $\mathrm{H}_{2}$ was observed to be 0.91 and 0.94 at $200{ }^{\circ} \mathrm{C}$ depending on the amount of Pd doping, with a response time of 1 min. Kumar et al. [318] reported a sensor based on the $\mathrm{Pd} / \mathrm{WO}_{3}-\mathrm{ZnO}$ nanocomposite showing remarkably improved $\mathrm{H}_{2}$ sensing performance, good stability and excellent selectivity when compared to that of pure $\mathrm{WO}_{3}$ and $\mathrm{ZnO}$, at a relatively lower operating temperature $\left(200{ }^{\circ} \mathrm{C}\right)$ and with a low detection range of 10-1000 ppm. The $\mathrm{Pd} / \mathrm{WO}_{3}-\mathrm{ZnO}$ composite sensor exhibited a stable response over 20 cycles towards $100 \mathrm{ppm}$ of $\mathrm{H}_{2}$ at $200{ }^{\circ} \mathrm{C}$. The response and recovery time achieved were $16 \mathrm{~s}$ and $62 \mathrm{~s}$, respectively, towards $100 \mathrm{ppm} \mathrm{H}_{2}$ at $200{ }^{\circ} \mathrm{C}$. Shouli et al. [319] reported $\mathrm{WO}_{3}-\mathrm{SnO}_{2}$ nanocomposites to act as $\mathrm{NO}_{2}$ sensors. The sensor exhibited the highest response for 186 to $200 \mathrm{ppm}$ of $\mathrm{NO}_{2}$ at operating temperature of $200{ }^{\circ} \mathrm{C}$, with an increased response when $\mathrm{Zn}$ or $\mathrm{MgO}$ were added (responses of 251 and 418, respectively).

Zhang et al. [279] produced pure $\mathrm{WO}_{3}$ and graphene oxide- $\mathrm{WO}_{3}$ composite nanofibers to be applied as gas sensors. The graphene oxide- $\mathrm{WO}_{3}$ composite nanofibers displayed the highest response of $35.9-100 \mathrm{ppm}$ acetone at $375^{\circ} \mathrm{C}$, which is 4.3 times 
higher than that of pristine $\mathrm{WO}_{3}$ nanofibers. Good selectivity and stability to acetone were also demonstrated for the composite nanofibers (Figure 14 (a)). $\mathrm{WO}_{3}$ nanorods/graphene nanocomposites to act as $\mathrm{NO}_{2}$ sensors were described in [320], and their gas sensing performance was compared to pure $\mathrm{WO}_{3}$ nanorods. The response of $\mathrm{WO}_{3}$ nanorods/graphene to $25 \mathrm{ppb}, 100 \mathrm{ppb}, 500 \mathrm{ppb}$ and 1 ppm $\mathrm{NO}_{2}$ were 13, 25, 40 and 61, respectively, while those of $\mathrm{WO}_{3}$ nanorods were 2.6, 3.3, 5 and 5.3, respectively. In Ref. [321], Pd- $\mathrm{WO}_{3} /$ reduced graphene oxide ( $\mathrm{rGO}$ ) hierarchical nanostructures were used as efficient hydrogen gas sensors. These materials were sensitive to $20 \mathrm{ppm}$ of hydrogen gas at room temperature, and the best operating temperature in terms of sensitivity $\left(10^{2}\right)$ was $100{ }^{\circ} \mathrm{C}$ with responses of $<1 \mathrm{~min}$.

The relation between humidity and gas sensing was also explored. In Ref. [322], the effect of relative humidity on $\mathrm{NO}_{2}$ sensitivity of a $\mathrm{SnO}_{2} / \mathrm{WO}_{3}$ heterojunction gas sensor was investigated. The sensor showed high sensitivity and a pseudo-linear response to $\mathrm{NO}_{2}$ in the range $0-5 \mathrm{ppm}$ in dry air. Response to variations in relative humidity was reported to be small at $\mathrm{RH}$ levels below $40 \%$, with the sensor becoming saturated at higher values of RH. Strong interference effects were observed, with sensitivity to $\mathrm{NO}_{2}$ decreasing rapidly as the $\mathrm{RH}$ of the atmosphere increased. Hybrid sensors were developed from Fe-doped $\mathrm{WO}_{3}$ film and reduced graphene oxide top layer. The sensors were tested towards different concentrations of $\mathrm{NO}_{2}$ and relative humidity at different temperatures ranging from $25{ }^{\circ} \mathrm{C}$ to $100{ }^{\circ} \mathrm{C}$, showing fast dynamics to humidity when compared to $\mathrm{NO}_{2}$. A response time of 6.7, 6.6 and $4.9 \mathrm{~min}$ and $6.54,5.9$ and $5.47 \mathrm{~min}$ to $10 \% \mathrm{RH}$ and $50 \% \mathrm{RH}$, respectively at temperatures of 25,50 and $100{ }^{\circ} \mathrm{C}$ were obtained [323].

The humidity-sensing process is generally based on the adsorption of water molecules and structure defects play a key role in this process. $\mathrm{WO}_{3}$ is an interesting alternative as 
a humidity sensing material since it has a variety of nonstoichiometric defects and oxygen vacancies [324]. Several approaches have been developed to increase $\mathrm{WO}_{3}$ humidity sensitivity. In Ref. [325], the effect of Ni doping was studied, in which the humidity sensing properties of pure $\mathrm{WO}_{3}$ were significantly improved by $\mathrm{Ni}$ dopant. This was justified with the high surface area and smaller band gap energy of $\mathrm{Ni}-\mathrm{WO}_{3}$. The sensitivity was improved with the increase in relative humidity. A $\mathrm{Li} / \mathrm{K}$ co-doped 3D ordered material (3DOM) $\mathrm{WO}_{3}$ humidity sensor was presented in Ref. [324] (Figure 14 (b)). The sensor response and recovery times were 15 and $10 \mathrm{~s}$, respectively, with the maximum hysteresis of $3 \% \mathrm{RH}$ for 11 to $95 \% \mathrm{RH}$, indicating good sensor reliability. The enhanced humidity sensing behaviour was attributed to structural defects, adsorbed oxygen and the coeffect of $\mathrm{Li} / \mathrm{K}$. Moreover, to access the interaction of this material with other gaseous species that might be present in ambient air, its gas sensing performance was evaluated.

Several other studies reported the humidity sensing of $\mathrm{WO}_{3}$ materials and when in association with other materials. In Ref. [326], the photoelectric responses of nanocrystalline $\mathrm{WO}_{3}$ film to humidity under UV light irradiation were investigated in humidity range of 20-80 \% $\mathrm{RH}$ at room temperature. Dong et al. [327] reported a $\mathrm{WO}_{3}$ film deposited on silicon nanoporous pillar arrays to be used in capacitive humidity sensors. With relative humidity changing from $11 \%$ to $95 \%$ sensitivity over $16000 \%$ at an optimal measuring frequency of $1000 \mathrm{~Hz}$, has been reported. The response and recovery times were determined to be $\sim 104$ and $\sim 94 \mathrm{~s}$, respectively, with maximum humidity hysteresis $\sim 5.3 \%$ at $65 \%$ RH. Patil et al. [328] reported on the humidity sensing properties of $\operatorname{poly}(2,5$-dimethoxyaniline $) / \mathrm{WO}_{3}$ composites. The sensor demonstrated to change linearly over an humidity range of $23-84 \%$ with maximum percentage response factor of $\sim 651$ at $87 \% \mathrm{RH}$, as well as quick response (humidification, 
$27 \mathrm{~s}$ and desiccation, $136 \mathrm{~s})$ and narrow hysteresis $(\sim 5 \%)$. In another study, $\mathrm{WO}_{3}-\mathrm{ZnO}$ nanocomposites were produced and their humidity sensitivity tested. It has been shown that when \% RH increases, there is a decrease in the resistance for the humidity range from $15 \%$ to $95 \%$. The sensor showed a maximum sensitivity of $16.42 \mathrm{M} \Omega / \% \mathrm{RH}$ and narrow hysteresis $(1.09 \%)$ [329].

$\mathrm{WO}_{3}$ has also the potential to be integrated in UV photodetectors/sensors since it has an indirect large energy band gap $(3.3 \mathrm{eV})$. Lately, $\mathrm{WO}_{3}$ nanostructures have been used to overcome limitations reported for $\mathrm{WO}_{3}$-based $\mathrm{UV}$ sensors, such as slow response times (> $1 \mathrm{~min}$ ) [330]. $\mathrm{WO}_{3}$ nanosheets were used as high-performance UV photodetectors/sensors, showing excellent optoelectronic performance with high sensitivity (293 $\left.\mathrm{A} \mathrm{W}^{-1}\right)$, fast response speed (40 ms), high on/off ratios (2000) and high external quantum efficiency $\left(997 \%\right.$ ) [331]. Li et al. [332] reported $\mathrm{WO}_{3}$ nanowires synthesized on carbon papers to be used as UV photodetectors/sensors (Figure 14 (c). These $\mathrm{WO}_{3}$ hierarchical sensors demonstrated response and decay times of about $3 \mathrm{~s}$ and $20 \mathrm{~s}$, respectively. In another study, hexagonal $\mathrm{WO}_{3}$ nanowires were also tested as UV photodetectors. An increase of more than two orders of magnitude in conductance was obtained under UV illumination at $312 \mathrm{~nm}$ with a photoconductivity gain of $4.6 \times 10^{3}$ [333]. In Ref. [334], $\mathrm{WO}_{3}$ nanobelts were produced via electrospinning for application as UV photodetectors. The sensor's photocurrent increased to $\sim 12 \mathrm{nA}$ and then rapidly decreased to its initial value (12 pA) once the light is turned off, suggesting high sensitivity of the photodetector with photo-dark current ratio up to 1000. A responsivity and external quantum efficiency up to $2.6 \times 10^{5} \mathrm{~A} \mathrm{~W}^{-1}$ and $8.1 \times 10^{7} \%$, respectively, have also been demonstrated. Shao et al. [335] reported 3D $\mathrm{WO}_{3}$ nanoshale structured materials synthesized using hydrothermal synthesis. The UV photodetector fabricated with $3 \mathrm{D} \mathrm{WO}_{3}$ nanoshale showed good photoresponsivity $\left(5.1 \mathrm{~A} \mathrm{~W}^{-1}\right)$, which was 
attributed to the internal gain introduced by surface oxygen adsorption-desorption process, as well as high surface to volume ratio of the 3D nanoshale structure. In Ref. [330], an ultraviolet photodetector was fabricated from $\mathrm{WO}_{3}$ nanodiscs and reduced graphene oxide composite material. A maximum photoresponsivity of $6.4 \mathrm{~A} \mathrm{~W}^{-1}$ at 347 nm was observed under $20 \mathrm{~V}$ bias. The rise time (as measured from $10 \%$ to $90 \%$ ) and fall time (from $90 \%$ to $10 \%$ ) of the photodetector were reported to be 13 and $16 \mathrm{~ms}$, respectively.

UV photodetectors/sensors with $\mathrm{WO}_{3}$ in the form of films were also explored. Cook et al. [336] reported $\mathrm{WO}_{3}$ films produced by inkjet printing to be used as UV photodetectors. Large on/off ratio of 3538 and high responsivity up to $2.70 \mathrm{~A} \mathrm{~W}^{-1}$ at $5 \mathrm{~V}$ bias $\left(0.54 \mathrm{~A} \mathrm{~W}^{-1} \mathrm{~V}^{-1}\right)$ were obtained. In another study, a monolayer $\mathrm{WO}_{3}$-based UVA photodetector was reported. The sensor has demonstrated fast response time of less than $40 \mu$ s and photoresponsivity reaching $\sim 0.329 \mathrm{~A} \mathrm{~W}^{-1}$. Long-term stability exceeding more than 200 cycles without any visible degradation was also showed [337].

In terms of biosensors, the remarkable properties of $\mathrm{WO}_{3}$ that include reversible change of conductivity, high sensitivity, selectivity and biocompatibility, make this material suitable for integration in biosensors [338]. Deng et al. [339] reported direct electron transfer of cytochrome $c$ at $\mathrm{WO}_{3}$ nanostructures. A combination of direct electrochemistry of cytochrome $c$ at the nanostructured $\mathrm{WO}_{3}$ surface and enzymatic catalytic activity of cytochrome $c$ towards $\mathrm{H}_{2} \mathrm{O}_{2}$ resulted in a third-generation $\mathrm{H}_{2} \mathrm{O}_{2}$ biosensor with high selectivity. The biosensor demonstrated a wide linear detection range from $3 \times 10^{-7}$ to $3 \times 10^{-4} \mathrm{M}$, low-detection limit $\left(2.4 \times 10^{-7} \mathrm{M}\right)$ and short response time of $5 \mathrm{~s}$. Liu et al. [340] reported $\mathrm{WO}_{3}$ nanowires with high length-diameter ratio that were used to immobilize hemoglobin to fabricate a mediator-free nitrite biosensor. The biosensors displayed superior performance for detection of nitrite with a wide linear range 
of 1 to $4200 \mu \mathrm{M}$, as well as an extremely low detection limit of $0.28 \mu \mathrm{M}$ (Figure 14 (d)). Anithaa et al. [341] reported $\mathrm{WO}_{3}$ nanoparticles with monoclinic $(\gamma)$ and orthorhombic $(\beta)$ structures synthesized by simple microwave irradiation to be applied for mediatorfree dopamine detection. The $\gamma-\mathrm{WO}_{3}$ modified glassy carbon electrode exhibited a linear response over a wide concentration range of $0.1 \mu \mathrm{mol} \mathrm{L}-1-600 \mu \mathrm{mol} \mathrm{L} \mathrm{L}^{-1}$ of dopamine with lowest detection limit of $24 \mathrm{nmol} \mathrm{L}{ }^{-1}$. The dopamine sensor showed excellent antiinterference ability against electroactive species and metal ions with good stability and reproducibility. In Ref. [342], polyethylene glycol assisted $\mathrm{WO}_{3}$ nanoparticles were used for L-dopa bio-sensing applications. The detection limit to L-dopa was demonstrated to be $120 \mathrm{nM}$.

(a)

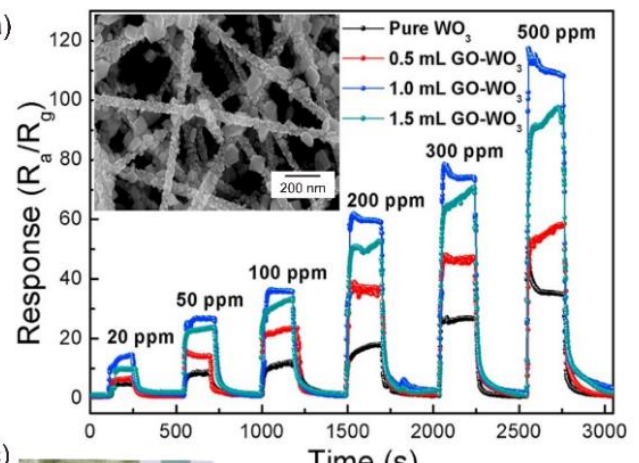

(c)

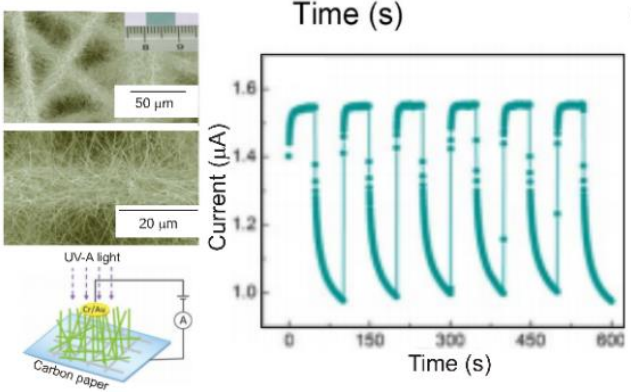

(b)

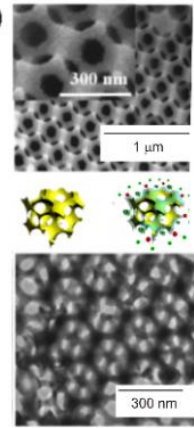

(d)

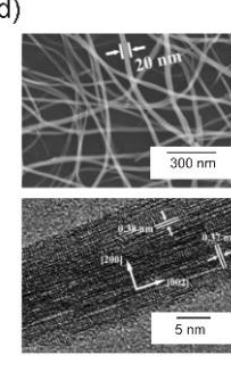

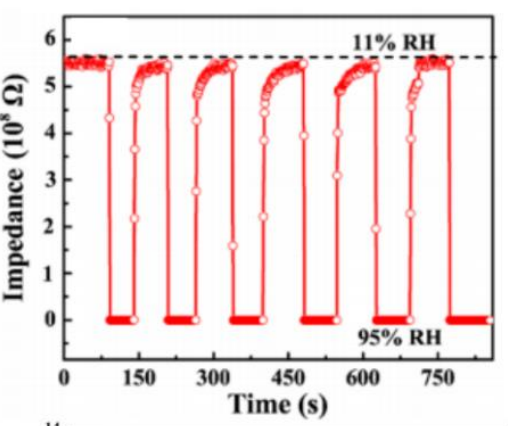

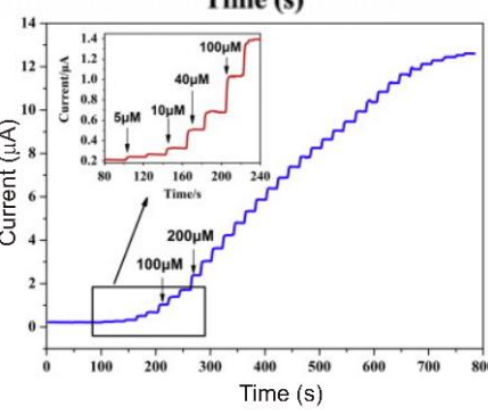

Figure 14. (a) Graphene oxide- $\mathrm{WO}_{3}$ composite nanofibers and dynamic gas sensing curves of the sensors as a function of acetone concentration [279], (b) SEM and TEM image of a Li/K co-doped 3D ordered material to be used as $\mathrm{WO}_{3}$ humidity sensor [324] and realtime impedance under different RH. (c) SEM images of $\mathrm{WO}_{3}$ nanowires and the scheme of the UV photodetector with its corresponding light switching "ON" and "OFF" curve [332]. (c) SEM and TEM images of $\mathrm{WO}_{3}$ nanowires and the graph shows the current-time response of the Nafion/hemoglobin/ $\mathrm{WO}_{3}$ nanowires/glassy carbon electrode [340]. Reproduced with permission of Elsevier [279] and [340], ACS publications "Copyright (2018) American Chemical Society" [324], and Royal Society of Chemistry (2018) [332]. 
In Ref. [343], bovine hemoglobin was electrostatically immobilized on $\mathrm{WO}_{3}$ nanoparticles, multiwalled carbon nanotubes were added and this was applied to modify a carbon paste electrode. The fabricated biosensor showed suitable electrocatalytical properties in the simultaneous determination of levodopa (L-DOPA), folic acid, and uric acid. Santos et al. [338] reported the synthesis of $\mathrm{WO}_{3}$ nanoparticles by hydrothermal method with different structures (Figure 15) to be used as nitrite biosensors. In this study, $\mathrm{c} c \mathrm{NiR}$ was chosen as model enzyme due to its high catalytic activity towards nitrite reduction, and $\mathrm{c} c \mathrm{NiR}$ modified $\left(\mathrm{c} c \mathrm{NiR} / \mathrm{WO}_{3} / \mathrm{ITO}\right)$ electrodes were produced. The biosensors demonstrated sensitivities of $2143 \mathrm{~mA} \mathrm{M}^{-1} \mathrm{~cm}^{-2}$.

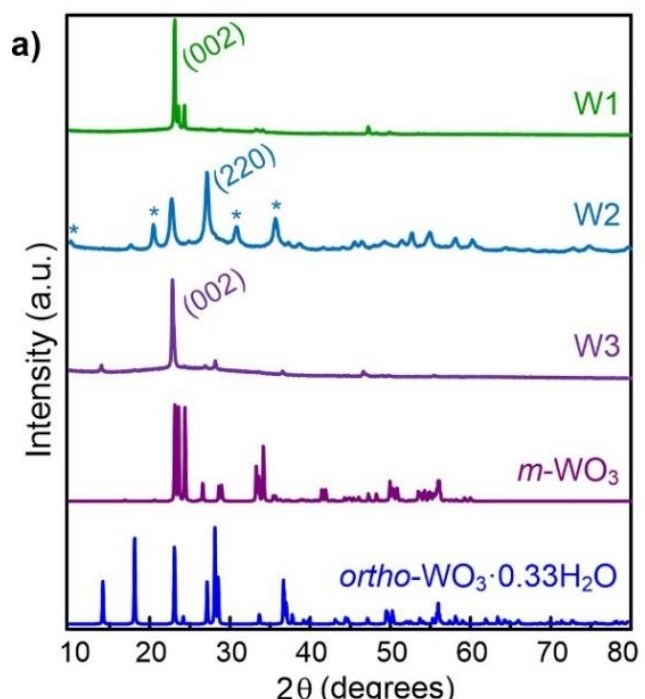

b) $m-\mathrm{WO}_{3}$

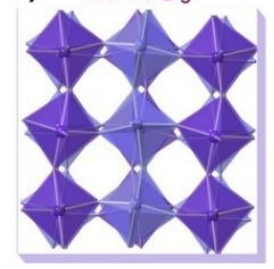

c) ortho- $\mathrm{WO}_{3} \cdot 0.33 \mathrm{H}_{2} \mathrm{O}$

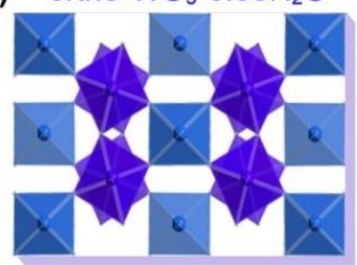

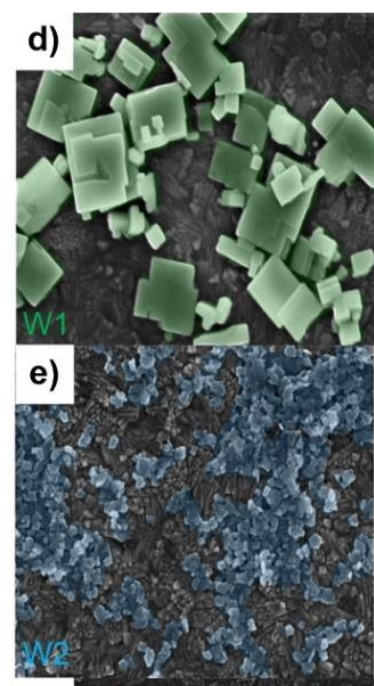

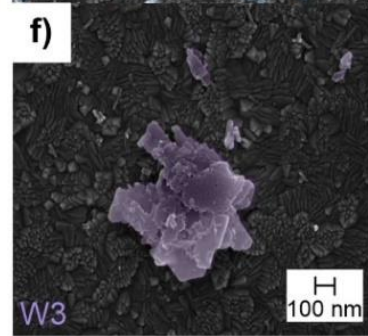

g)

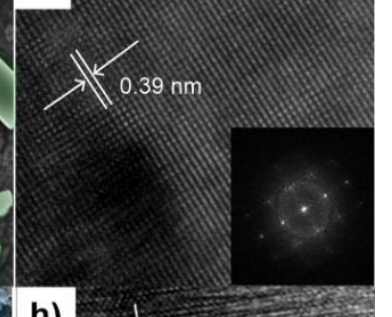

Figure 15. (a) to (i) $\mathrm{XRD}, \mathrm{SEM}$ and TEM measurements of hydrothermally synthesized $\mathrm{WO}_{3}$ powders to be used as nitrite biosensor [338]. Reproduced with permission of Elsevier (2018).

Marques et al. [262] reported $\mathrm{WO}_{3}$ nanoparticles synthesized by microwave assisted hydrothermal synthesis which were used to impregnate non-treated regular office paper substrates. This allowed the production of a paper-based colorimetric sensor (Figure 16 (a)) able to detect electrochemically active bacteria in different growing stages 
by electrochromic reaction. A colorimetric relation between the growing stage of bacteria and $\mathrm{WO}_{3}$ nanoparticles concentration was presented with RGB analyses (Figure 16 (b)).

(a)

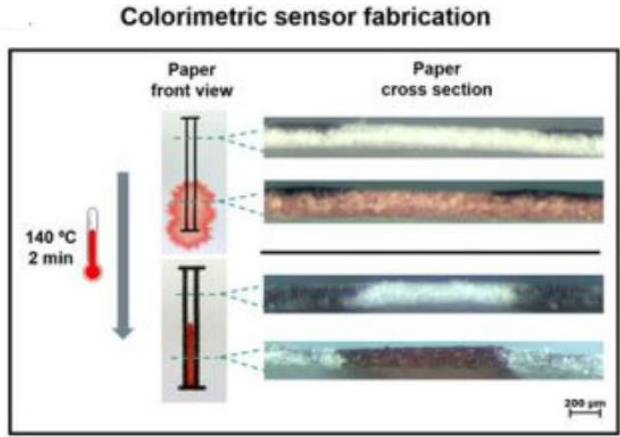

(b)

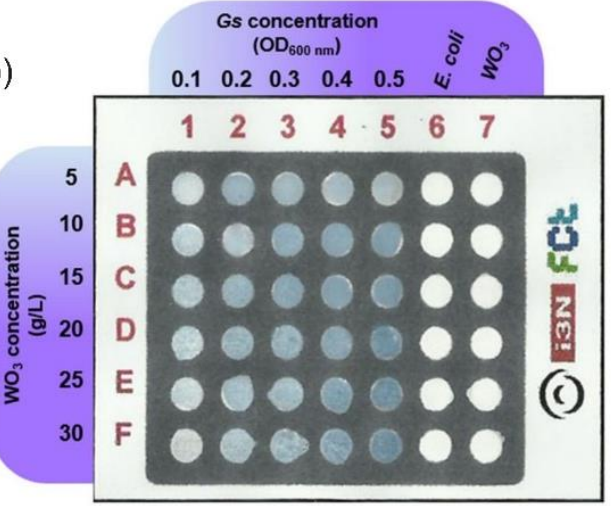

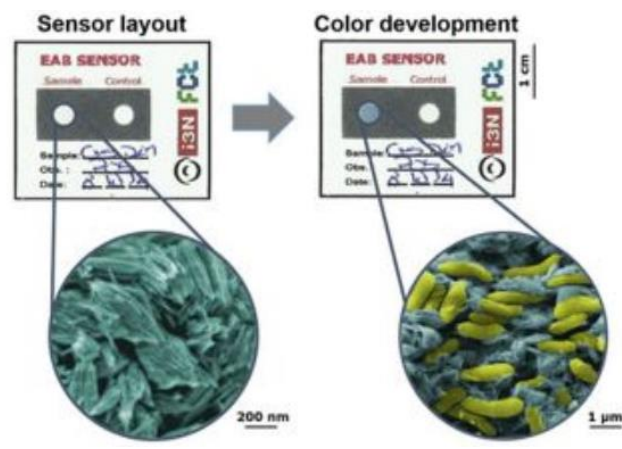

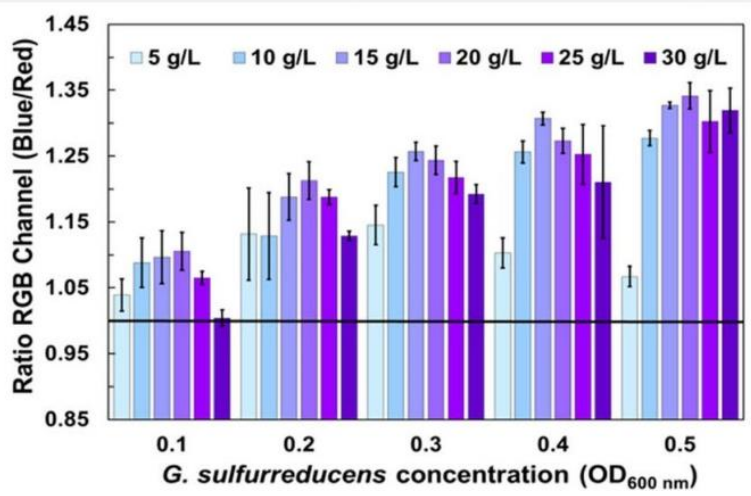

Figure 16. (a) Scheme of the colorimetric sensor fabrication with the hydrophobic barriers formation together with the photograph of paper-based sensor photograph of the Colorimetric assays of h$\mathrm{WO}_{3}$ nanoparticles at different concentrations, and (b) RGB analyses of $h$-WO3 nanoparticles at $15 \mathrm{~g} / \mathrm{L}$ in contact with Geobacter sulfurreducens cells, with the negative control E. coli and a blank test [262]. Reproduced with permission of Springer Nature (2018).

Righettoni et al. [344] reported $\mathrm{Si}: \mathrm{WO}_{3}$ sensors for highly selective detection of acetone for easy diagnosis of diabetes by breath analysis. The biosensor was able to detect low acetone concentrations (down to $20 \mathrm{ppb}$ ) with high signal-to-noise ratio in ideal (dry air) and realistic (up to $90 \% \mathrm{RH}$ ) conditions. At $90 \% \mathrm{RH}$, healthy humans ( $\leq 900 \mathrm{ppb}$ acetone) and diabetes patients ( $\geq 1800 \mathrm{ppb}$ ) could be distinguished by a gap of $40 \%$ in sensor response. In Ref. [345], 3D graphene network and $\mathrm{WO}_{3}$ nanowire composites were demonstrated to produce a multifunctional colorimetric and electrochemical biosensing platform. The peroxidase-like activity of composite was investigated to colorimetrically 
detect $\mathrm{H}_{2} \mathrm{O}_{2}$. Moreover, the produced biosensor showed an ultrahigh sensitivity of 1.306 $\mathrm{mA} \mathrm{mM}^{-1} \mathrm{~cm}^{-2}$ to dopamine and linear range up to $150 \mu \mathrm{M}$, as well as low detection limit $(238 \mathrm{nM})$ and response time (4 s). Li et al. [346] reported $\mathrm{WO}_{3}-\mathrm{TiO}_{2}$ hybrid films prepared on ITO electrodes for multi-functionalized biosensors. Electrochemical oxidation and reduction of of norepinephrine and riboflavin (Vitamin B2) was demonstrated. In another study, an universal photoelectrochemical sensing platform was fabricated based on the composition of protoporphyrin $\mathrm{IX}, \mathrm{WO}_{3}$ and reduced graphene oxide on ITO electrode for detecting cysteine in aqueous solution. The biosensor for detection of cysteine showed linear range of 0.1 to $100 \mu \mathrm{M}$ and the detection limit was $25 \mathrm{nM}$ [347]. Santos et al. [348] reported $\mathrm{WO}_{3}$ nanoparticle-based conformable pH sensors compatible with wearable biomedical devices, since $\mathrm{pH}$ is a vital physiological parameter that can be used for disease diagnosis and treatment as well as in monitoring other biological processes. These sensors showed sensitivity of $-56.7 \pm 1.3 \mathrm{mV} / \mathrm{pH}$ in a wide $\mathrm{pH}$ range of 9 to 5 .

\subsection{Copper oxides}

Copper oxides are abundant materials, eco-friendly, non-toxic and are compatible with wet-chemical synthesis routes that originate low-cost devices $[11,349,350]$. The most common copper oxides are copper(I) oxide or cuprous oxide $\left(\mathrm{Cu}_{2} \mathrm{O}\right)$, reddish material, and copper(II) oxide or cupric oxide ( $\mathrm{CuO})$, black material. Both copper oxides are $p$-type semiconductors displaying a bulk direct band gap from 2-2.17 eV in the case of $\mathrm{Cu}_{2} \mathrm{O}[351,352]$ and a narrow bandgap of $1.2 \mathrm{eV}$ (bulk) for $\mathrm{CuO}$, that is controversial regarding being direct or indirect $[353,354]$. The $p$-type character of both oxides is usually attributed to the presence of negatively charged $\mathrm{Cu}$ vacancies [355-357]. $\mathrm{Cu}_{2} \mathrm{O}$ possesses high carrier mobility of about $100 \mathrm{~cm}^{2} \mathrm{~V}^{-1} \mathrm{~s}^{-1}$ at room temperature and long 
carrier diffusion length ranging up to several micrometers [358]. Upon photoexcitation, the excitons of $\mathrm{Cu}_{2} \mathrm{O}$ are found to be long-lived (10 $\mu$ s) [351].

$\mathrm{Cu}_{2} \mathrm{O}$ crystallizes as in a cubic structure with space group Pn3m (224) and lattice parameter of $0.42696 \mathrm{~nm}$ [350]. Its unit cell contains six atoms, in which four copper atoms are positioned in a face-centred cubic lattice and the two oxygen atoms forming a body-centred cubic sublattice a face-centered cubic (fcc) sublattice. The oxygen atoms occupy tetrahedral interstitial positions in respect to the copper sublattice, in a way that oxygen is tetrahedrally coordinated by copper, while copper is linearly coordinated by two adjacent oxygens $[350,359]$. $\mathrm{CuO}$ has a complex monoclinic tenorite crystallographic structure, and it belongs to the $C 2 / c$ (15) space group with lattice parameters $a=0.46833 \mathrm{~nm}, b=0.34208$ and $c=0.51294 \mathrm{~nm}[360,361]$. Each $\mathrm{Cu}$ is coordinated to four coplanar $\mathrm{O}$ at the corners of a nearly rectangular parallelogram $\left(\mathrm{CuO}_{4}-\right.$ plaquettes) [362]. The oxygen is coordinated to four $\mathrm{Cu}$ at the corners of a distorted tetrahedron. The six nearest $\mathrm{O}$ to each $\mathrm{Cu}$ complete a strongly distorted octahedron. The $\mathrm{CuO}_{4}$ parallelograms form ribbons along [110] direction altering to [010] direction. Each ribbon is linked to adjacent chains of other groups by sharing corners $[360,361]$. The structure can be considered as being based on two types of zig-zag $\mathrm{Cu}-\mathrm{O}$ chains running

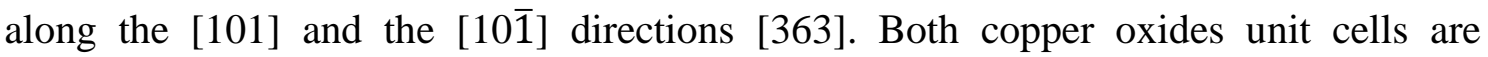
represented in Figure 17.
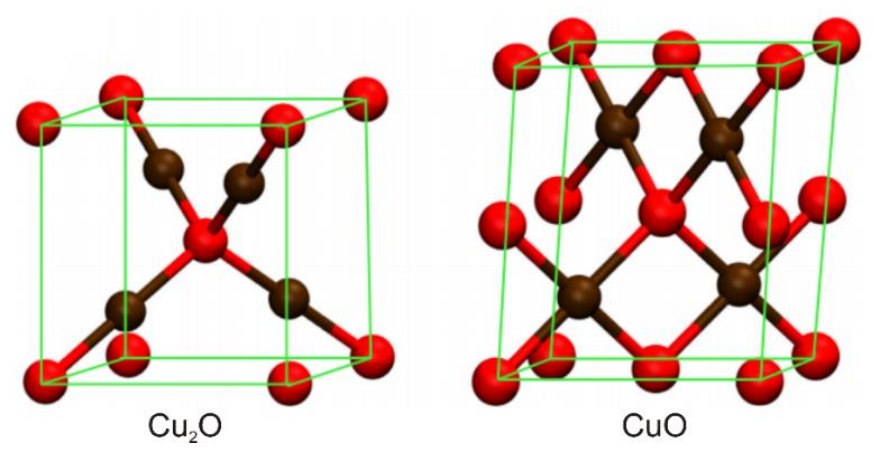

Figure 17. Unit cells of cuprous oxide $\mathrm{Cu}_{2} \mathrm{O}$ and cupric oxide $\mathrm{CuO}$ [364]. Reproduced with permission of Elsevier (2018). 
The thermal oxidation of metallic copper into both $\mathrm{Cu}_{2} \mathrm{O}$ and $\mathrm{CuO}$ has been largely reported [11, 349, 365-371], as copper displays high oxygen affinity [372]. The oxide phase formation starting from copper by thermal oxidation can be described as follows: $\mathrm{Cu} \rightarrow \mathrm{Cu}+\mathrm{Cu}_{2} \mathrm{O} \rightarrow \mathrm{Cu}_{2} \mathrm{O} \rightarrow \mathrm{Cu}_{2} \mathrm{O}+\mathrm{CuO} \rightarrow \mathrm{CuO} . \quad \mathrm{Cu}_{2} \mathrm{O} \quad$ oxidation occurs at temperatures as low as $100{ }^{\circ} \mathrm{C}$ [372]. In contrary, $\mathrm{CuO}$ formation is slow and is considered a product of $\mathrm{Cu}_{2} \mathrm{O}$ oxidation $\left(\mathrm{CuO}\right.$ starts at $300{ }^{\circ} \mathrm{C}$ [373]). Its formation is possible above a certain critical thickness of a $\mathrm{Cu}_{2} \mathrm{O}$ layer on the metal surface, thus $\mathrm{Cu}_{2} \mathrm{O}$ serves as precursor to $\mathrm{CuO}$ [372]. The reactions involved can be summarized as follows [366]:

$$
\begin{aligned}
& 4 \mathrm{Cu}+\mathrm{O}_{2} \rightarrow 2 \mathrm{Cu}_{2} \mathrm{O} \\
& 2 \mathrm{Cu}_{2} \mathrm{O}+\mathrm{O}_{2} \rightarrow 4 \mathrm{CuO}
\end{aligned}
$$

Thermal oxidation of copper, is an attractive technique due to its simplicity, highquality and low-cost, nevertheless it is a time consuming route [374]. Besides thermal oxidation, several other techniques have been used to produce copper oxides, including hydrothermal synthesis [367, 375], microwave irradiation [376] and microwave oxidation [11], sol-gel method [377, 378], spray pyrolysis [25, 379], electrodeposition [380, 381], sputtering $[382,383]$, among others.

Several structures at the nano/micrometer scales have been reported for both $\mathrm{Cu}_{2} \mathrm{O}$ and $\mathrm{CuO}$ materials, such as nanowires [384-386], nanorods [387, 388], nanobelts [389, 390], nanowhiskers [391, 392], nanocubes [55, 393, 394], octahedral nanostructures [395, 396], nanospheres [349, 397-400], hierarchical nanostructures [401], and others (Figure 18). 

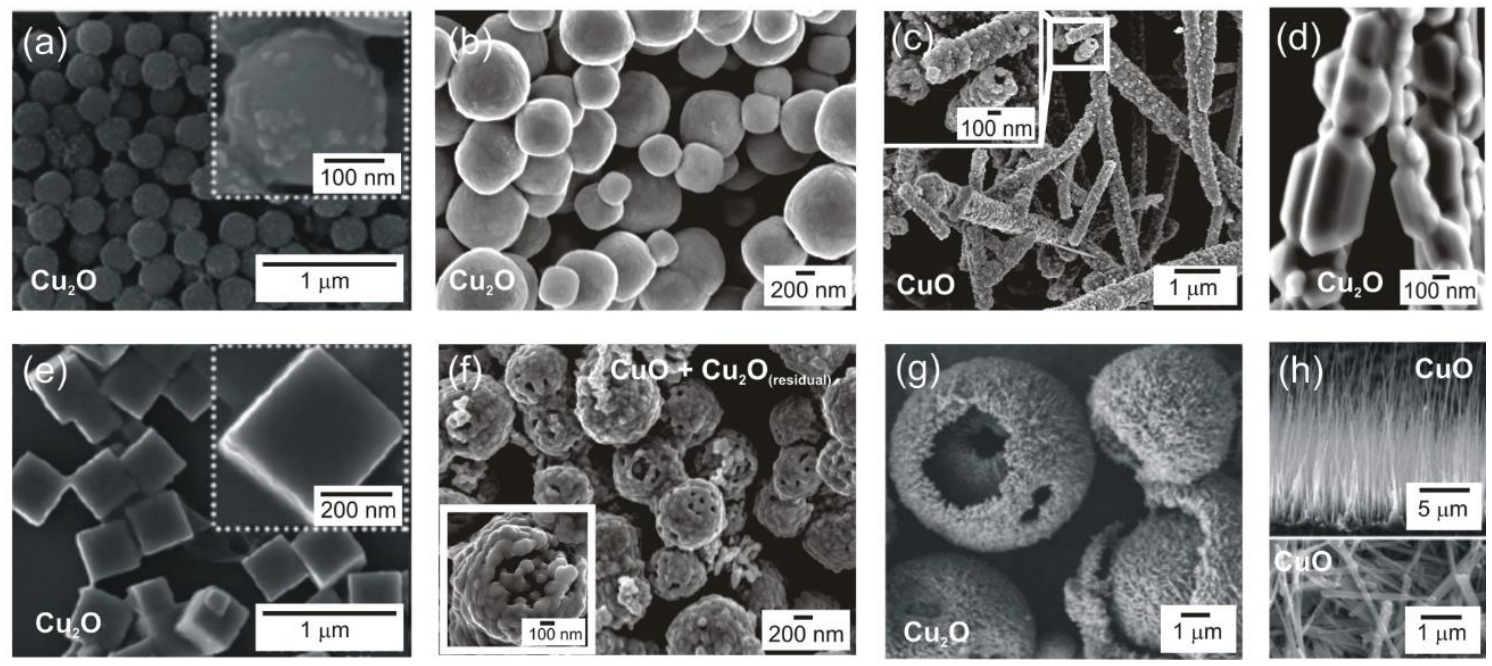

Figure 18. $\mathrm{SEM}$ images of $\mathrm{Cu}_{2} \mathrm{O}$ spheres in (a) [55] and (b) [349], (c) $\mathrm{CuO}$ nanotubes, (d) $\mathrm{Cu}_{2} \mathrm{O}$ nanowires [11], (e) $\mathrm{Cu}_{2} \mathrm{O}$ nanocubes, (f) $\mathrm{CuO}$ nanospheres [349], (g) hierarchical hollow $\mathrm{Cu}_{2} \mathrm{O}$ microspheres [401] (h) $\mathrm{CuO}$ nanowires [386]. Reproduced with permission of Royal Society of Chemistry [55] and [11], Materials Research Society [349], John Wiley and Sons [401], and Elsevier (2018) [386].

$\mathrm{Cu}_{2} \mathrm{O}$ and $\mathrm{CuO}$ have been proposed for several applications over the years, including photocatalysis [402, 403], solar cells [404, 405], electrodes in lithium ion batteries [406, 407], thin-film transistors [368], sensors [375, 408, 409], among others. With emphasis to the latter application, integration of both materials in sensors has been extensively investigated over the years, due to their intrinsic $p$-type properties [410]. The application of $\mathrm{Cu}_{2} \mathrm{O}$ in gas sensors is much less studied than for $\mathrm{CuO}$ [55]. $\mathrm{Cu}_{2} \mathrm{O}$ nanowires were tested as gas sensors towards $\mathrm{H}_{2}$, showing a response of $33.3 \%$ and recovery time of $\sim 10 \mathrm{~min}$ [411]. Tang et al. [412] reported on the gas sensing performance of $\mathrm{Cu}_{2} \mathrm{O}$ nanocages towards gasoline. In another study, sensitivity of hierarchical $\mathrm{Cu}_{2} \mathrm{O}$ microspheres toward $100 \mathrm{ppm}$ ethanol was estimated to be 8.2 , which is much higher than the value of 1.5 measured for solid $\mathrm{Cu}_{2} \mathrm{O}$ microspheres [401]. The gas sensitivity of $\mathrm{Cu}_{2} \mathrm{O}$ nanocubes and nanospheres were tested for ethanol vapor, with clear sensitivity differences regarding particle size and morphology [55]. Sensors based on $\mathrm{Cu}_{2} \mathrm{O}$ films have also been reported, demonstrating high sensitivity, fast response time, and fast recovery time for methane gas at an operation temperature as low as $180{ }^{\circ} \mathrm{C}$. At a $2.5 \%$ 
$\mathrm{CH}_{4}$ concentration, the films demonstrated sensitivity around $70 \%$. The fast and high response of $\mathrm{Cu}_{2} \mathrm{O}$ sensor for methane was justified by the increase of resistance in intrinsic $p$-type $\mathrm{Cu}_{2} \mathrm{O}$ in the presence of methane gas [413].

$\mathrm{CuO}$ nanostructures have been integrated in gas sensors for detection of a variety of reducing as well as oxidizing gases including acetone, ethanol, propanol, $\mathrm{H}_{2} \mathrm{~S}, \mathrm{CO}, \mathrm{O}_{3}$, $\mathrm{NO}_{\mathrm{x}}$, methanol, formaldehyde, $\mathrm{H}_{2}$, toluene and ammonia [414]. Kim et al. [386] reported $\mathrm{CuO}$ nanowire gas sensors for air quality control in automotive cabin, showing a resistance decrease upon exposure to 30-100 ppm $\mathrm{NO}_{2}$, and increase upon contact with $\leq 5 \mathrm{ppm} \mathrm{NO}_{2}$. Yang et al. [415] reported on the synthesis of $\mathrm{CuO} 3 \mathrm{D}$ flower- and 2D branching sheet-like $\mathrm{CuO}$ nanostructures exhibiting an enhanced gas response to the five gases. At $1000 \mathrm{ppm}$, the $\mathrm{CuO}$ flower sensor demonstrated responses to ethyl-acetate (4.6), ethanol (4.0), acetone (3.8), xylene (3.6) and toluene (2.8). The sheet-like structures resulted in lower responses. The gas-sensing mechanism of $p$-type $\mathrm{CuO}$ semiconductor was explained by the change in resistance caused by the adsorption/desorption and reactions of gas molecules at the semiconductor surface. In another study, $\mathrm{CuO}$ nanoparticles were used for ethanol sensing showing fast response and recovery times below $10 \mathrm{~s}$ and responses greater than 2.3 at $100 \mathrm{ppm}$ of ethanol at $200{ }^{\circ} \mathrm{C}$ (Figure 19 (a)) [416]. Flower-like $\mathrm{CuO}$ nanostructures with porous nanosheets demonstrated good $\mathrm{H}_{2} \mathrm{~S}$ gas sensing performance with maximum responses between 2.10 and 2.15 for five consecutive sensing cycles at $1 \mathrm{ppm}$, showing good reproducibility. The flower-like $\mathrm{CuO}$ nanostructured sensor was exposed to other types of gases $\left(\mathrm{NO}_{2}, \mathrm{H}_{2}, \mathrm{CO}, \mathrm{C}_{2} \mathrm{H}_{5} \mathrm{OH}\right.$ and $\mathrm{NH}_{3}$ ) and for $100 \mathrm{ppm}$ of $\mathrm{NH}_{3}$, the sensor showed a response sensitivity of 1.42 [417]. $\mathrm{CuO}$ nanowires were integrated as ethanol gas sensors, showing responses of 1.06, $1.11,1.14,1.18,1.24$, and 1.27 for ethanol gas concentration of 25, 50, 100, 200, 500, 
and $1000 \mathrm{ppm}$, respectively [418]. $\mathrm{CuO}$ wormlike structures were also tested as gas sensors towards ethanol [419].

When it comes to gas sensors with films, Choi et al. [420] reported on the direct printing synthesis of $\mathrm{CuO}$ hollow spheres to form a film. This film based on $\mathrm{CuO}$ hollow spheres exhibited a high, stable response of $\sim 2$ to $\mathrm{H}_{2} \mathrm{~S}$, while for $\mathrm{C}_{2} \mathrm{H}_{5} \mathrm{OH}$, the response was $\sim 3$, which was 2 times higher than that $(\sim 1.5)$ of $\mathrm{CuO}$ powder. $\mathrm{CuO}$ thin films were also reported for gas sensing applications. The gas sensitivity was demonstrated to increase up to 5.1 in the presence of $\mathrm{CO}_{2}$ gas at $160^{\circ} \mathrm{C}$, while in the presence of $\mathrm{N}_{2}$ gas, it reached only 1.43 even at $200{ }^{\circ} \mathrm{C}$ [421].

It has also been reported combinations of metal oxide materials to obtain a $p-/ n$ heterojunction. In Ref. [422], flower-like $p-\mathrm{CuO} / n-\mathrm{ZnO}$ nanorods heterojunction was produced showing response of 98.8to $100 \mathrm{ppm}$ ethanol, which was 2.5 times that of $\mathrm{ZnO}$ material, with response and recovery time of $7 \mathrm{~s}$ and $9 \mathrm{~s}$, respectively. Good selectivity and long-term stability were also reported with response to low concentration of ethanol (1 ppm) of 9.68 using the flower-like $p$-CuO/n-ZnO heterojunction nanorods. In another study, sensors based on $\mathrm{ZnO} / \mathrm{CuO}$ nanostructures were tested as gas sensors and had investigated their $\mathrm{H}_{2} \mathrm{~S}$-sensing properties, with sensor response of 2.7, and response time within $37 \mathrm{~s}$ [423]. $\mathrm{CuO}-\mathrm{MnO}_{2}$ nanocomposites were also reported, with response time of $120 \mathrm{~s}$ and recovery within $600 \mathrm{~s}$ [424]. Sensors based on mixtures of $\mathrm{Cu}_{2} \mathrm{O}$ and $\mathrm{CuO}$ has also been reported. Meng et al. [425] showed $\mathrm{Cu}_{2} \mathrm{O} / \mathrm{CuO}$ submicrosphere based sensors with responses up to $2.1-50 \mathrm{ppb}$ of $\mathrm{H}_{2} \mathrm{~S}$ gas at $95{ }^{\circ} \mathrm{C}$, with recovery time of about $76 \mathrm{~s}$. Zhou et al. [426] reported porous $\mathrm{Cu}_{2} \mathrm{O} / \mathrm{CuO}$ cubes with enhanced gas sensing properties. For acetone concentrations of 50, 100, 200, 400, $500 \mathrm{ppm}$, the obtained responses were 3.0, 4.4, 6.5, 9.0 and 9.9, respectively. $\mathrm{Cu}_{2} \mathrm{O}$ and 
$\mathrm{CuO}$ were also mixed with metal nanoparticles, forming a hierarchical hollow nanostructure that was applied for CO sensing [427].

The mixture of copper oxides to carbon-based materials has also been addressed. In Ref. [428], CuO-reduced graphene oxide sandwiched nanostructure was investigated to determine its hydrogen sensing characteristics. In another study, reduced graphene oxide conjugated $\mathrm{Cu}_{2} \mathrm{O}$ nanowire mesocrystals demonstrated higher sensitivity toward $\mathrm{NO}_{2}$ at room temperature, surpassing the performance of $\mathrm{Cu}_{2} \mathrm{O}$ nanowires networks and $\mathrm{rGO}$ sheets. This composite showed sensitivity of $67.8 \%$ at $2 \mathrm{ppm}$ and calculated limits of detection of $82 \mathrm{ppb}$ [429].

Humidity-sensing studies of $p$-type semiconducting materials are scarce. Hsueh et al. [430] reported on the fabrication of humidity sensors by growing $\mathrm{CuO}$ nanowires on glass substrates. These sensors demonstrated that resistance of the $\mathrm{CuO}$ nanowires increased with the increase of relative humidity $(52-90 \%)$ due to the $p$-type nature of $\mathrm{CuO}$. In another study, nanostructured $\mathrm{Cu}_{2} \mathrm{O}$ porous films were exposed to humidity. The increase of resistance with increasing $\mathrm{RH}$ values is a characteristic response of $p$-type metal oxides, in which holes are the majority charge carriers. Up to $48 \% \mathrm{RH}$, the linear increase of response percentage has been reported. The average response and recovery time evaluated for low RH were $151 \pm 6$ and $145 \pm 18 \mathrm{~s}$, respectively, with a maximum rate of $4.38 \pm 0.16 \% / \mathrm{RH}$ [431]. Wang et al. [432] reported on $\mathrm{CuO}$ nanowire humidity sensors, that show steady state currents of about $2.44,2.32,2.23$, and $2.15 \mu$ Awhen measured with $20,40,60$, and $80 \%$ relative humidity, respectively.

A blend of $\mathrm{Cu}_{2} \mathrm{O}$ nanopowder and poly-N-epoxypropylcarbazole was also tested as humidity sensor, with an abrupt decrease of resistance at $30 \% \mathrm{RH}$ [433]. In another study, the electronic conduction and capacitance of an $\mathrm{Au} / \mathrm{CuO} / \mathrm{Cu}_{2} \mathrm{O} / \mathrm{Cu}$ sandwich structure was investigated and revealed to be dependent on humidity [434]. Yuan et al. [435] 
reported highly sensitive humidity sensors based on $\mathrm{CuO}$ inorganic-organic hybrid nanowires. Ref. [436] showed an urchinlike $\mathrm{CuO}$ modified by rGO composite that was integrated in humidity sensors revealing much higher impedance than pure $\mathrm{CuO}$ (Figure 19 (b)). The mixture of metal oxides was also investigated, in which moisture sensing of $\mathrm{Cu}_{2} \mathrm{O}$ doped $\mathrm{ZnO}$ nanocomposites was reported by Pandey et al. [437], with the response and recovery time of this material shown to be 76 and 296 s, respectively.

Copper oxides based UV/near-UV sensors have also been reported, but in this case composing a heterojunction to enhance their performance due to an additional charge separation effect [438]. Wang and Cho [438] reported $p$-CuO nanowire/n- $\mathrm{ZnO}$ nanosheet heterojunctions and its application for near-ultraviolet light detection. Under different illumination conditions, the photocurrent detection limit was around $16.8 \mathrm{~mW} \mathrm{~mm}$. Hong et al. [439] demonstrated n-silicon nanowire arrays with a layer of $\mathrm{CuO}$ nanoflakes to be applied as photodetectors/sensors highly sensitive to visible and near-infrared light irradiation. The photocurrent obtained for this device was $0.96 \mu \mathrm{A}$ at $0.48 \mathrm{~W} \mathrm{~cm}^{-2}$ for a $405 \mathrm{~nm}$ laser, $4.41 \mu \mathrm{A}$ at $5 \mathrm{~W} \mathrm{~cm}^{-2}$ for a $532 \mathrm{~nm}$ laser and $4.92 \mu \mathrm{A}$ at $5.5 \mathrm{~W} \mathrm{~cm}^{-2}$ for a $1064 \mathrm{~nm}$ laser (Figure 19 (c)). In another study, $\mathrm{CuO}$ nanowires were used to produce a $p$ - $\mathrm{CuO} / n-\mathrm{ZnO}$ heterojunction nanostructured photodetector/UV sensor. The responsivity was reported to be $0.040 \mathrm{~A} \mathrm{~W}^{-1}$ for $350 \mathrm{~nm}$ and an applied bias of $1 \mathrm{~V}$ and for a $2 \mathrm{~V}$ bias it increased to $0.123 \mathrm{~A} \mathrm{~W}^{-1}$ [440]. Ok et al. [441] demonstrated UV photodetectors/sensors based on $p-\mathrm{Cu}_{2} \mathrm{O}$ thin film and $n-\mathrm{ZnO}$ nanowires for formation of a $p-n$ heterojunction. These named all-oxide UV devices resulted in a responsivity of $\sim 50 \mathrm{~A} \mathrm{~W}^{-1}$ at $360 \mathrm{~nm}$.

Several studies reported the integration of copper oxides in biosensors [442-446]. Liu et al. [442] reported a sensor for the detection of glucose and hydrogen peroxide based on $\mathrm{Cu}_{2} \mathrm{O}$ nanocubes wrapped by graphene nanosheets. A linear response over glucose 
concentration range of 0.3 to $3.3 \mathrm{mM}$ was reported, with a detection limit of $3.3 \mu \mathrm{M}$, high selectivity and short response time $(<9 \mathrm{~s})$. The enzymeless sensor also exhibited good response toward $\mathrm{H}_{2} \mathrm{O}_{2}$, with the linear response ranging from 0.3 to $7.8 \mathrm{mM}$ at $-0.4 \mathrm{~V}$ and detection limit of $20.8 \mu \mathrm{M} . \mathrm{Cu}_{2} \mathrm{O}$ shuriken-like nanostructures produced by hydrothermal synthesis were tested as nonenzymatic glucose biosensors. The glucose sensors exhibited wide linear detection range (from $0.01 \mu \mathrm{M}$ to $11.0 \mathrm{mM}$ ), ultra-low detection limit $(0.035 \mu \mathrm{M})$ and high sensitivity $\left(0.933 \mathrm{~mA} \mathrm{mM}^{-1} \mathrm{~cm}^{-2}\right)$ [444]. In another study, carbon quantum dots/octahedral $\mathrm{Cu}_{2} \mathrm{O}$ nanocomposites were tested as nonenzymatic glucose and hydrogen peroxide amperometric sensors. Amperometric sensing of glucose was realized with linear response range from 0.02 to $4.3 \mathrm{mM}$ and showed a detection limit of $8.4 \mu \mathrm{M}$. The nonenzymatic sensor revealed an electrocatalytic reduction of $\mathrm{H}_{2} \mathrm{O}_{2}$ with linear response range from $5 \mu \mathrm{M}$ to $5.3 \mathrm{mM}$ and detection limit of $2.8 \mu \mathrm{M}$ [447]. Ref. [446] showed leaf-like $\mathrm{CuO}$ nanoparticles for detecting glucose. This sensor exhibited high sensitivity (246 $\mathrm{mA} \mathrm{mM}^{-1} \mathrm{~cm}^{-2}$ ), short response time (within $5 \mathrm{~s}$ ), linear dynamic range of 1.0 to $170 \mathrm{mM}$ and low limit of detection (0.91 mM). In Ref. [448], $\mathrm{CuO}$ nanotube arrays were used as biosensors for glucose detection showing sensitivity of $1.89 \mathrm{~mA} \mathrm{mM}^{-1} \mathrm{~cm}^{-2}$ and linear range from $5 \mu \mathrm{M}$ to $3.0 \mathrm{mM}$.

Copper oxides were also tested as biosensors in film form. Inkjet-printed $\mathrm{CuO}$ nanoparticles to produce films were integrated in nonenzymatic glucose biosensors. The sensors showed high and reproducible sensitivity of $2762.5 \mu \mathrm{Am} \mathrm{M}^{-1} \mathrm{~cm}^{-2}$ with wide linear-detecting range of $0.05-18.45 \mathrm{mM}$ and detection limit of $\sim 0.5 \mu \mathrm{M}$ [449]. A nonenzymatic glucose biosensor based on printed $\mathrm{CuO}$ nanoparticles film was also demonstrated in [450]. The biosensor showed linear response toward glucose in the range of 0.1 to $6.5 \mathrm{mM}$ at a lower detection limit of $0.5 \mu \mathrm{M}$ glucose. $\mathrm{CuO}$ thin film based uric acid biosensor has been reported to have good linearity over a wide uric acid 
concentration range of $0.05 \mathrm{mM}$ to $1.0 \mathrm{mM}$ with enhanced response of $2.7 \mathrm{~mA} \mathrm{mM}^{-1}$ and long shelf life (> 14 weeks) [445].

Two metal oxides were also employed in biosensors. In Ref. [451], a $\mathrm{ZnO}-\mathrm{CuO}$ composite matrix based biosensor was demonstrated for detection of total cholesterol, for which sensitivity was reported to be $680 \mu \mathrm{A} \mathrm{mM}^{-1} \mathrm{~cm}^{-2}$ and $760 \mu \mathrm{A} \mathrm{mM} \mathrm{m}^{-1} \mathrm{~cm}^{-2}$ towards free cholesterol and total cholesterol respectively with response time of $5 \mathrm{~s}$, with long shelf life. Vertically-aligned $\mathrm{ZnO}$ nanorods decorated with $\mathrm{CuO}$ were produced and integrated in high-performance nonenzymatic glucose sensors. The fabricated electrodes exhibited high sensitivity $\left(2961.7 \mu \mathrm{A} \mathrm{mM}^{-1} \mathrm{~cm}^{-2}\right)$, linear range up to $8.45 \mathrm{mM}$, low limit of detection $(0.40 \mu \mathrm{M})$ and short response time $<2$ s (Figure $19(\mathrm{~d}))$ [443].

(a)

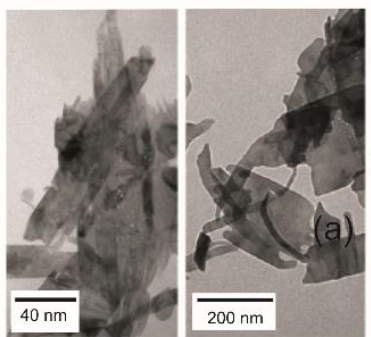

(c)

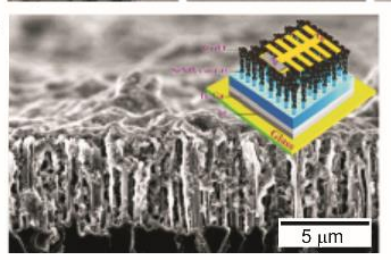

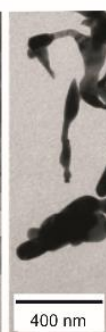

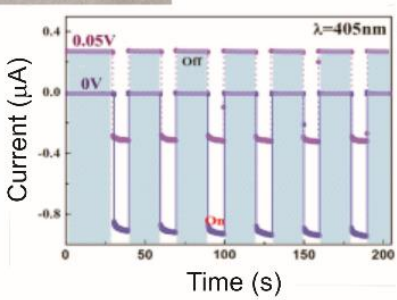

(b)

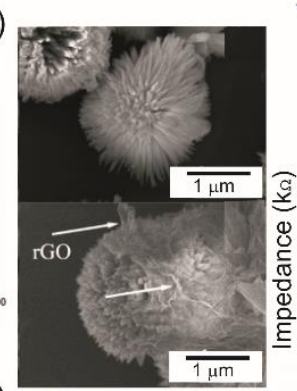

(d)

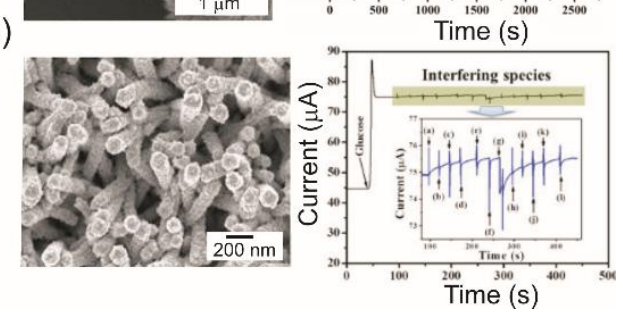

Figure 19. (a) TEM images of $\mathrm{CuO}$ nanoparticles for ethanol gas sensing [416], (b) SEM images of $\mathrm{CuO} / \mathrm{rGO}$ composites for humidity sensors [436]. (c) $p-n$ Heterojunctions of $\mathrm{CuO} / \mathrm{Si}$ Nanowire Array to be used as photodectors/UV sensors [439]. (d) $\mathrm{CuO}$ modified $\mathrm{ZnO}$ nanorods to produce highly efficient non-enzymatic glucose sensors [443]. The graphs represent the sensors' response, resistance, current and impedance variations. Reproduced with permission of ACS publications "Copyright (2019) American Chemical Society” [416], “Copyright (2018) American Chemical Society” [436] and [439], and Springer Nature (2018) [443]. 


\subsection{Tin oxide}

There are two well-known tin oxide compounds, i.e. tin (IV) oxide or stannic oxide $\left(\mathrm{SnO}_{2}\right)$ and tin (II) monoxide or stannous oxide $(\mathrm{SnO}) . \mathrm{SnO}_{2}$ is a $n$-type semiconductor, with a wide energy band gap ( $E g \sim 3.6 \mathrm{eV}$ for bulk at room temperature). $\mathrm{SnO}_{2}$ has a tetragonal structure $(a=b=0.4737 \mathrm{~nm}$ and $c=0.3186 \mathrm{~nm})$, similar to the rutile structure [452, 453] with space group $P 4_{2} / m n m$ (136) [454]. SnO is a $p$-type semiconductor with a direct band gap of 2.5-3.0 eV and an indirect band gap of 0.5-0.7 eV [455-458]. The origin of $p$-type conductivity of $\mathrm{SnO}$ is mainly attributed to $\mathrm{Sn}$ vacancies and $\mathrm{O}$ interstitials [355]. Moreover, the native $p$-type character of $\mathrm{SnO}$ has been reported to result in more effective hole transport path and higher hole mobility due to the closer position of Sn-5s and O-2p components $[458,459]$. SnO also has tetragonal structure $(a=b=0.37986 \mathrm{~nm}, c=0.48408 \mathrm{~nm})$ with space group P4/nmm (129) [460].

The $\mathrm{SnO}_{2}$ unit cell consists of two metal atoms and four oxygen atoms. Each $\mathrm{Sn}$ atom is placed at the center of six $\mathrm{O}$ atoms, nearly forming the corners of a regular octahedron. Oxygen atoms are surrounded by three $\mathrm{Sn}$ atoms that approximate the corners of an equilateral triangle [461]. In the case of $\mathrm{SnO}$, this material has a layered structure with Sn-O-Sn layered pyramids, where oxygen atoms are tetrahedrally bonded to tin atoms. The Sn atoms are situated at the apex of regular square-based pyramids that are based on $\mathrm{O}$ atoms [355]. The unit cells of tetragonal $\mathrm{SnO}_{2}$ and $\mathrm{SnO}$ are represented in Figure 20.

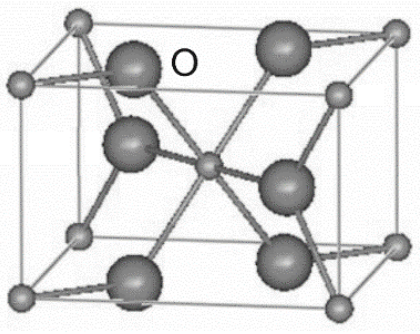

$\mathrm{SnO}_{2}$

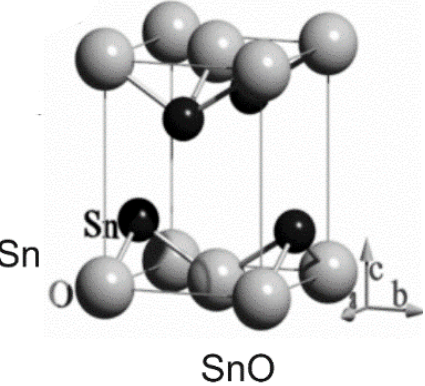

$\mathrm{SnO}$

Figure 20. Unit cells of both $\mathrm{SnO}_{2}$ [462] and $\mathrm{SnO}$ [463]. Reproduced with permission of MDPI [462] and APS Physics (2018) [463]. 
$\mathrm{SnO}$ is formed at the initial stage of Sn oxidation and it is a metastable phase that converts to $\mathrm{SnO}_{2}$ even in the absence of oxygen if exposed to a certain temperature. The specific temperature to convert $\mathrm{SnO}$ to $\mathrm{SnO}_{2}$ is unclear, varying from 250 to $600{ }^{\circ} \mathrm{C}$ and depends on several factors, such as deposition method, initial oxygen concentration, annealing temperature and humidity [464]. Nevertheless, it is accepted that $\mathrm{SnO}$ is unstable above $270{ }^{\circ} \mathrm{C}$ in comparison with $\mathrm{SnO}_{2}$, which makes it frequently known as precursor or intermediate phase in the production of $\mathrm{SnO}_{2}$ nanostructures [457].

Several techniques have been reported to yield $\mathrm{SnO}$ and $\mathrm{SnO}_{2}$ nanostructures and thin films, including hydrothermal synthesis [465-467], microwave irradiation [468, 469], precipitation method [470, 471], sol-gel technique [472-474], rf magnetron sputtering $[475,476]$, spray pyrolysis $[477,478]$, among others. $\mathrm{SnO}_{2}$-doped material plays an important role as transparent conductive oxide material with remarkable electrical and optical properties in the form of thin films [453]. Antimony, indium and fluorine are examples of doping elements. The electrical properties of the $\mathrm{SnO}_{2}$ films are critically depend upon its oxygen stoichiometry [477]. When passing to nanostructures, several nano- and microstructures have been reported for both $\mathrm{SnO}$ and $\mathrm{SnO}_{2}$, such as nanoparticles [479, 480], nanorods [468, 481], nanobelts [482, 483], nanowhiskers [484, 485], nanowires [486-488], nanoflowers [489, 490], spheres [491, 492], among others.

Both $\mathrm{SnO}$ and $\mathrm{SnO}_{2}$ have been used in numerous applications, such as thin film transistors [475], anodes for Li-ion batteries [493-495], water splitting for production of hydrogen [496], photocatalysis [497, 498] and sensors. In the latter application, $\mathrm{SnO}_{2}$ has been extensively applied, with emphasis on gas sensing. In fact, $\mathrm{SnO}_{2}$ is one of the most used materials as gas sensors [499]. Several $\mathrm{SnO}_{2}$ nanostructures have been investigated for the detection of different gases, such as ethanol, $\mathrm{H}_{2}, \mathrm{O}_{2}, \mathrm{CO}, \mathrm{NO}, \mathrm{NO}_{2}$ and $\mathrm{NH}_{3}$ at moderate temperature, due to its fast-response speed, high exciton binding energy, high 
chemical stability, prominent selectivity, and low cost [500-503]. In Ref. [503], it has been shown ethanol gas sensors based on nanosheets-assembled $\mathrm{SnO}_{2}$ hollow spheres showing responses from 2.4 to 23.5 for $10-500 \mathrm{ppm}$ ethanol, and at the ppb level, showed a response of 1.1 toward $500 \mathrm{ppb}$ of ethanol. The sensor response time was about $5 \mathrm{~s}$ (Figures 21 (a) and (b)). $\mathrm{SnO}_{2}$ nanoparticles were also produced using the hydrothermal synthesis with conventional oven (Figure 21 (c)). Huang et al. [504] reported porous flower-like $\mathrm{SnO}_{2}$ nanostructures for gas sensors (Figure 21 (d)). The sensor responses to $100 \mathrm{ppm}$ ethanol and n-butanol were 42.6 and 77.2 , respectively, at a working temperature of $240{ }^{\circ} \mathrm{C}$. In addition, these sensors also exhibited a good response to methanol, 2-propanol, and acetone. Ref. [497] demonstrated hierarchical $\mathrm{SnO}_{2}$ based ultrathin nanosheets that were tested as gas sensors for ethanol, ammonia, benzene, acetone, toluene, methanol and diethyl ether. The sensor sensitivity to $5 \mathrm{ppm}$ ethanol is around 5.13 which increases to 183.8 for $500 \mathrm{ppm}$ ethanol. The response and recovery time of hierarchical nanostructures to $100 \mathrm{ppm}$ of ethanol were 1 and $2 \mathrm{~s}$, respectively. The responses of this sensor to eight gases were also compared and the largest response was observed only for ethanol with a value of up to 44.7, implying good selectivity of the sensor for ethanol (Figure 21 (e)). In another study, square-shaped $\mathrm{SnO}_{2}$ nanowires forming a sphere-like superstructure were tested as gas sensors. These sensors showed sensitivity of 5.5 for acetone concentration as low as $20 \mathrm{ppm}$, and the response and recovery times were 7 and $10 \mathrm{~s}$, respectively [505]. $\mathrm{SnO}_{2}$ nanorod sensors were also reported in Ref. [506] exhibiting sensitivity of 31.4 for 300 ppm of ethanol with both response and recovery time around 1 s. Liu et al. [507] reported tubular $\mathrm{SnO}_{2}$ nanomembranes fabricated by rolled-up technology. The sensor exhibited a highly stable response to acetone detection at $20 \mathrm{ppm}$. Kuang et al. [508] reported hierarchical $\mathrm{SnO}_{2}$ nanostructures composed of numerous one-dimensional nanorods and tested as gas 
sensors. The responses of sensors with six different ethanol concentrations $(5,10,25,50$, 75 and $100 \mathrm{ppm}$ ) were 7, 13, 32, 44, 59 and 72, respectively (Figure 21 (f)).
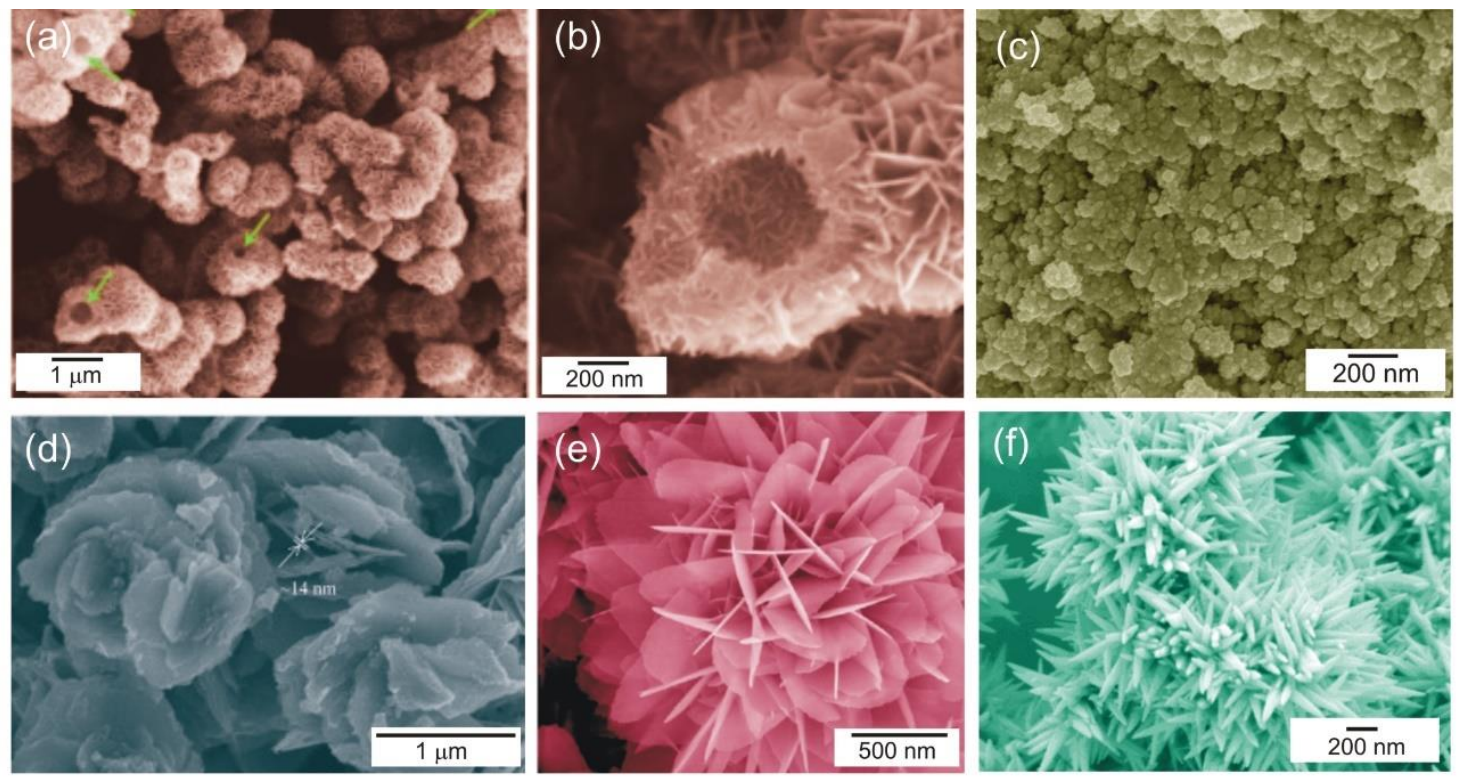

Figure 21. SEM images of (a-b) nanosheets-assembled $\mathrm{SnO}_{2}$ hollow spheres for ethanol gas sensor [503],

(c) $\mathrm{SnO}_{2}$ nanoparticles produced at CENIMAT using hydrothermal synthesis, (d) porous flower-shaped $\mathrm{SnO}_{2}$ nanostructures [504], (e) hierarchical $\mathrm{SnO}_{2}$ based ultrathin nanosheets [497], and (f) hierarchical $\mathrm{SnO}_{2}$ nanostructures made of superfine nanorods [508]. Reproduced with permission of Elsevier [503], [504] and [508] and ACS publications "Copyright (2018) American Chemical Society" [497],

Choi et al. [509] reported a $\mathrm{SnO}_{2}$ nanowire-based gas sensor for detecting $\mathrm{NO}_{2}$. The sensitivity was determined to be 18 and 180 when $\mathrm{NO}_{2}$ concentration was 0.5 and 5 ppm, respectively (at $200{ }^{\circ} \mathrm{C}$ ). Suman et al. [510] reported a sensor based on $\mathrm{SnO}$ microdisks, showing a response of $\sim 13$ to $100 \mathrm{ppb}$ of $\mathrm{NO}_{2}$, and selectivity against potential interferent gases such as $\mathrm{H}_{2}, \mathrm{CO}$ and $\mathrm{CH}_{4}$ was also demonstrated. In another study, $\mathrm{SnO}$, $\mathrm{SnO}_{2}$ and $\mathrm{Sn}_{3} \mathrm{O}_{4}$ nanobelts had their efficiency as gas sensors compared. $\mathrm{SnO}$ and $\mathrm{Sn}_{3} \mathrm{O}_{4}$ exhibited higher sensitivity and selectivity relative to potential interferent gases $\left(\mathrm{H}_{2}, \mathrm{CO}\right.$ and $\mathrm{CH}_{4}$ ) than $\mathrm{SnO}_{2}$ nanobelts (Figure 22 (a)) [511].

Doping elements, such as, $\mathrm{Ag}, \mathrm{Au}, \mathrm{Pd}, \mathrm{Pt}$, and other metal oxides are used to enhance the sensing properties, such as, sensitivity, response time and reproducibility for 
a specific gas [502]. Kolmakov et al. [486] reported the sensing ability toward oxygen and hydrogen of individual $\mathrm{SnO}_{2}$ nanowires and nanobelts before and after functionalization with $\mathrm{Pd}$ catalyst particles. $\mathrm{Sb}$-doped $\mathrm{SnO}_{2}$ nanowires were tested as gas sensors and resulted in sensitivity of 1.76 upon exposure to $10 \mathrm{ppm}$ ethanol and recovery time of about $5 \mathrm{~s}$ [512]. Reduced graphene oxide was also explored with tin oxides for gas sensors. Wei et al. [513] reported the gas-sensing of a silver-decorated tin oxide/reduced graphene oxide $\left(\mathrm{Ag} / \mathrm{SnO}_{2} / \mathrm{rGO}\right)$ composite with a sensitivity to $400 \mathrm{ppm}$ ethanol of 95.3 at optimum operating temperature $\left(280{ }^{\circ} \mathrm{C}\right)$. The $\mathrm{SnO}_{2} / \mathrm{rGO}$ sensor was also tested demonstrating a lower sensitivity of 55.3. A hierarchical $\mathrm{SnO}_{2} / \mathrm{rGO}$ nanostructure was described in Ref. [514], with sensitivity of 78 to $10 \mathrm{ppm}_{2} \mathrm{~S}$ at $100{ }^{\circ} \mathrm{C}$ and response time of 7 s. $\mathrm{NH}_{3}$ gas sensors based on $\mathrm{Pd}, \mathrm{SnO}_{2}$ and $\mathrm{rGO}$ ternary nanocomposite was demonstrated in Ref. [515], with response and recovery time of 7 and $50 \mathrm{~min}$, respectively, at $\mathrm{NH}_{3}$ testing concentration of $100 \mathrm{ppm}$.

The combination of different metal oxides has also been widely addressed in gas sensing. Core-shell $\mathrm{WO}_{3}-\mathrm{SnO}_{2}$ nanofibers have been synthesized via a coaxial electrospinning approach. The sensors exhibited good response to ethanol (5.09 at $10 \mathrm{ppm})$ and short response/recovery time (18.5 s and $282 \mathrm{~s})$ [516]. A sensor based on $\mathrm{ZnO} / \mathrm{SnO}_{2}$ composites with a hollow nanostructure was reported in Ref. [517]. The sensitivity to $30 \mathrm{ppm}$ ethanol was shown to be 34.8 , which was about seven times higher than the sensor based on pristine $\mathrm{SnO}_{2}$ hollow spheres (the response was 5.1). The sensor exhibited response to ppb-level ethanol and response time was $1 \mathrm{~s}$. In another study, gas sensors fabricated from $\mathrm{SnO}_{2}-\mathrm{SnO}$ nanocomposite with $p$ - $n$ heterojunctions exhibited an enhanced sensing performance for $\mathrm{NO}_{2}$ gas detection, with limit of detection and sensitivity of $0.1 \mathrm{ppm}$ and $0.26 \mathrm{ppm}^{-1}$, respectively [518]. Another $p$ - $n$ heterojunction was demonstrated with $\mathrm{CuO}-\mathrm{SnO}_{2}$ gas sensors for $\mathrm{CO}$ gas [519]. A sensor based on a 
hierarchical $\mathrm{CoO} / \mathrm{SnO}_{2}$ heterojunction demonstrated response up to 145 when exposed to $100 \mathrm{ppm}$ ethanol gas. This sensor was demonstrated to be effectively higher when compared to $\mathrm{SnO}_{2}$ only sensors (13.5 for $\mathrm{SnO}_{2}$ ) [520]. Gas sensors based on $\mathrm{SnO}_{2}$ decorated $\mathrm{NiO}$ nanostructures demonstrated excellent sensitivity and selectivity towards toluene, with response of 66.2-100 ppm, which was 50 times higher than that of pure $\mathrm{NiO}$ nanospheres (1.3-100 ppm). Additionally, the sensor had surpassingly low detection limit (ppb-level), showing response of 1.2-10 ppb toluene [521].

Similarly to copper oxides, integration of $p$-type materials, i.e. $\mathrm{SnO}$, in humidity sensors is diminished. However, as observed for gas sensors, there are several studies demonstrating the use of $\mathrm{SnO}_{2}$ in such sensors. Parthibavarman et al. [522] reported humidity sensors based on $\mathrm{SnO}_{2}$ nanoparticles produced under microwave irradiation. This sensor showed fast response time (32 s) and recovery time (25 s) with relative humidity range of 5-95\% in air at room temperature. Kuang et al. [92] reported the production of $\mathrm{SnO}_{2}$ humidity nanodevice using a single $\mathrm{SnO}_{2}$ nanowire as the sensing unit. The response time and recovery time of this sensor was 120-170 and 20-60 s, respectively. Ordered $\mathrm{SnO}_{2}$ nanostructures were used as humidity sensors, showing a response and recovery time of $32 \mathrm{~s}$ and $42 \mathrm{~s}$ for $11-96 \% \mathrm{RH}$, respectively. The hysteresis for the $\mathrm{SnO}_{2}$ nanostructured sensor was $<5 \%$ [523]. $\mathrm{SnO}_{2}$ and $\mathrm{Li}^{+}$-doped $\mathrm{SnO}_{2}$ porous nanofibers were fabricated via electrospinning and tested as humidity sensors. The doped materials demonstrated better performance than the $\mathrm{SnO}_{2}$ nanofiber-based sensor, in which an ultrafast response and recovery time within $1 \mathrm{~s}$ has been reported for the dopedsensor at a relative humidity level of $85 \%$ [524]. Another study described humidity sensors based on ion-doped $\mathrm{SnO}_{2}$ nanofibers $(\mathrm{KCl})$ developed by screen-printing. It has been shown that impedance of the sensor decreased by more than five orders of magnitude 
with increasing relative humidity from $11 \%$ to $95 \%$, with response and recovery time of 5 and 6 s, respectively [525].

Several studies also demonstrated humidity sensors based on different metal oxides. In Ref. [526], $\mathrm{SnO}_{2} / \mathrm{ZnO}$ heterojunction nanostructured films demonstrated remarkable humidity-sensing performance exhibiting sensitivity of 90.56 to humidity. Nanostructured $\mathrm{TiO}_{2}-\mathrm{SnO}_{2}$ thin films produced by sol-gel process showed over three orders change in the resistance during relative humidity variation from 20 to $90 \%$ [527]. Hybrid nanomaterials have also been described. Zhang et al. [528] reported a $\mathrm{MoS}_{2} / \mathrm{SnO}_{2}$ hybrid film sensor with ultrafast response/recovery behaviours. Three distinct nanocomposites based on $\mathrm{SnO}_{2}-\mathrm{CuO}, \mathrm{SnO}_{2}-\mathrm{Fe}_{2} \mathrm{O}_{3}$ and $\mathrm{SnO}_{2}-\mathrm{SbO}_{2}$ and their humidity sensing performance were described in Ref. [529]. It has been shown that when relative humidity increases, the resistance of the nanomaterials decreases. of Amongst all other composites, $\mathrm{SnO}_{2}-\mathrm{SbO}_{2}$ showed maximum sensitivity for humidity (12 M $\left.\mathrm{M} / \% \mathrm{RH}\right)$. Humidity sensors based on reduced graphene oxide and tin oxide $\left(\mathrm{rGO}-\mathrm{SnO}_{2}\right)$ nanocomposites were also reported [530]. These sensors demonstrated stability over 30 days at $95 \%$ RH (Figure 22 (b)).

As $\mathrm{SnO}_{2}$ is wide bandgap material with consequent transparency in the visible spectral region, it has been reported for UV sensing. Huang et al. [72] reported single-crystalline $\mathrm{SnO}_{2}$ nanobelt with amorphous embedded $\mathrm{Sn}$ nanodots , to produce an individual nanobelt-based UV photodetector/sensor. The responsivity value of the nanobelt photodetector excited by $300 \mathrm{~nm}$-light was $56 \mathrm{~A} \mathrm{~W}^{-1}$. This sensor also demonstrated high external quantum efficiency (EQE) $\left(\sim 2.3 \times 10^{4}\right)$, fast response time (less than $0.3 \mathrm{~s}$ ) and high on/off current ratio $\left(\sim 2.75 \times 10^{3}\right)$. The photoresponse of $\mathrm{SnO}_{2}$ nanobelts has been investigated under UV light in Ref. [531], and shown that the source-drain current increased to $\sim 80 \mu \mathrm{A}$ in air and up to $\sim 900 \mu \mathrm{A}$ in vacuum, demonstrating $\mathrm{SnO}_{2}$ nanobelts 
potentialities as UV sensors. $\mathrm{SnO}_{2}$ nanowires were tested as UV photodetectors in [532], with the photoelectric current exhibiting rapid photo-response as an UV lamp was switched on and off. In another study, photodetectors based on thin $\mathrm{SnO}_{2}$ nanowires have been reported. These exhibited excellent light selectivity and stability and high EQE value of $1.32 \times 10^{7}$ [533]. $\mathrm{SnO}_{2}$ hollow nanospheres have been used as an active material to fabricate UV photodetectors. The UV sensor exhibited peak UV responsivity of $2680 \mathrm{~A}$ $\mathrm{W}^{-1}$ and high external quantum efficiency of $9.8 \times 10^{5} \%$ [534]. Lu et al. [535] reported ultrahigh gain in photodetectors based on single $\mathrm{SnO}_{2}$ nanowires with ferromagnetic $\mathrm{Ni}$ electrodes.

$\mathrm{SnO}_{2}$ has been also combined with other metal oxides to produce UV photodetectors/sensors. Xie et al. [536] reported UV photodetectors based on $\mathrm{CuO} / \mathrm{SnO}_{2} p-n$ nanoscale heterojunctions. The responsivity for the single $\mathrm{SnO}_{2}$ nanodevice was $1.9 \mathrm{~A} \mathrm{~W}^{-1}$ while for the $p-n$ heterojunction it was $10.3 \mathrm{~A} \mathrm{~W}^{-1}$. The wavelength-dependent photocurrent-to-dark current ratio was estimated to be $\sim 592$ for the $\mathrm{CuO} / \mathrm{SnO}_{2}$ photodetector at $290 \mathrm{~nm} . \mathrm{ZnO}-\mathrm{SnO}_{2}$ nanowire arrays were synthesized by a near-field electrospinning method for flexible ultraviolet photodetectors application. These sensors exhibited excellent photoresponse properties to $300 \mathrm{~nm}$ ultraviolet light illumination including high $I_{\text {on }} / I_{\text {off }}$ ratios (up to $10^{3}$ ), good stability and reproducibility [537]. Another work described fully transparent photodetectors produced from electrospun $\mathrm{ZnO}-\mathrm{SnO}_{2}$ heterojunction nanofibers. This photodetector exhibited excellent operating characteristics, including high UV-sensitivity and photo-dark current ratio, and fast response speed [538]. $\mathrm{TiO}_{2} / \mathrm{SnO}_{2}$ branched heterojunction nanostructures with $\mathrm{TiO}_{2}$ branches on electrospun $\mathrm{SnO}_{2}$ nanofiber were developed for self-powered UV photodetector. Under UV irradiation, the self-powered UV photodetector exhibited responsivity of $0.6 \mathrm{~A} \mathrm{~W}^{-1}$, high on/off ratio of 4550 , rise time of $0.03 \mathrm{~s}$ and decay time of 
$0.01 \mathrm{~s}$ [539]. $\mathrm{SnO}_{2}$ nanosheet films with branched $\mathrm{TiO}_{2}$ nanoneedles on $\mathrm{SnO}_{2}$ nanosheets, forming a heterojunction core-shell structure have been used to integrate UV photodetectors/sensors. These UV photodetectors showed responsivity of $0.6 \mathrm{~A} \mathrm{~W}^{-}$ ${ }^{1}$, high on/off ratio (440,563\%), fast response for rise time $0.02 \mathrm{~s}$ and decay time $0.004 \mathrm{~s}$ [540]. A self-powered UV photodetector based on $\mathrm{TiO}_{2}$ coated $\mathrm{SnO}_{2}$ mesoporous spheres has been described in Ref. [541]. Under UV irradiation, this sensor displayed high on/off ratio of 11519 , fast rise time of $0.007 \mathrm{~s}$ and decay time of $0.006 \mathrm{~s}$.

Tin oxides are also largely present in biosensors. In Ref. [542], $\mathrm{SnO}_{2}$ nanorod arrays have been tested as $\mathrm{H}_{2} \mathrm{O}_{2}$ biosensors. This sensor demonstrated sensitivity of 379 $\mu \mathrm{A} \mathrm{mM}^{-1} \mathrm{~cm}^{-2}$, low detection limit $(0.2 \mu \mathrm{M})$ and high selectivity with apparent Michaelis-Menten constant estimated to be as small as $33.9 \mu \mathrm{M}$. Nanostructured $\mathrm{SnO}_{2}$ thin films were presented as glucose sensors. These sensors exhibited higher response, fast rise time $8 \mathrm{~s}$ and suitable recovery time $53 \mathrm{~s}$ upon working at room temperature with a glucose concentration between 50-200 $\mathrm{mg} \mathrm{L}^{-1}$ [543].

As mentioned previously, tin oxides have been doped or combined with other elements or metal oxide materials, including for biosensing. A mediator-free horseradish peroxidase-based $\mathrm{H}_{2} \mathrm{O}_{2}$ biosensor was constructed with $\mathrm{Sb}$-doped $\mathrm{SnO}_{2}$ nanowires as immobilization matrix for enzymes. The sensor showed sensitivity of $100 \mathrm{~mA} \mathrm{M}{ }^{-1} \mathrm{~cm}^{-2}$, and detection limit of $0.8 \mu \mathrm{M}$ at a signal-to-noise ratio of 3. The Michaelis-Menten constant was calculated to be $0.76 \mathrm{mM}$ and the sensor demonstrated long-term stability [544]. Hydrogen peroxide biosensors based on $\mathrm{Ni}$ doped $\mathrm{SnO}_{2}$ nanoparticles has been reported [545]. A horseradish peroxidase/ $\mathrm{Ni}-\mathrm{SnO}_{2}$ nanocomposite has been studied exhibiting a linearity range from $1.0 \times 10^{-7}$ to $3.0 \times 10^{-4} \mathrm{M}$ with detection limit of $43 \mathrm{nM}$. The apparent Michaelis-Menten constant of horseradish peroxidase on the nano-Ni$\mathrm{SnO}_{2}$ was estimated as $0.221 \mathrm{mM}$. Cr-doped $\mathrm{SnO}_{2}$ nanoparticles based biosensors for 
selective determination of riboflavin in pharmaceuticals has been described in [546]. This sensor responded linearly to riboflavin over a concentration range of $0.2 \times 10^{-6}$ to $1.0 \times$ $10^{-4} \mathrm{M}$ with detection limit of $107 \mathrm{nM}$. Shen et al. [547] reported the synthesis of $\mathrm{Au}-\mathrm{SnO}_{2}$ hybrid nanospheres with enhanced photoelectrochemical biosensing performance. The biosensor displayed suitable analytical performance for detection of cysteine with a broad linear range (from $0.4 \mathrm{mM}$ to $12 \mathrm{mM}$ ) and low detection limit (0.1 mM). In Ref. [548], $\mathrm{ZnO} / \mathrm{SnO}_{2}$ heterostructured nanomaterials were explored to build a biosensing platform for detecting $\mathrm{H}_{2} \mathrm{O}_{2}$ by immobilizing hemoglobin with chitosan. The biosensor sensitivity was $52.8 \mathrm{~mA} \mathrm{~cm}^{-2} \mathrm{M}^{-1}$, with linear range from $2.0 \times 10^{-6}$ to $3.7 \times 10^{-4} \mathrm{M}$. The detection limit of $\mathrm{H}_{2} \mathrm{O}_{2}$ was $4.6 \times 10^{-7} \mathrm{M}$ when signal-to-noise ratio was 3 .

The incorporation of carbon-based materials in tin oxides for biosensing has also been investigated. Zhu et al. [549] reported graphene/ $\mathrm{SnO}_{2}$ composite nanosheets loaded with noble metal nanoparticles to be applied as biosensors for nonenzymatic glucose detection. The amperometric response has been shown to be linear for glucose concentrations ranging from 2 to $20 \mathrm{mM}$ with sensitivity of $20.3 \mu \mathrm{A} \mathrm{mM}{ }^{-1}$. Multiwalled carbon nanotubes-SnO $2-\mathrm{Au}$ composite was tested as glucose biosensor by absorbing glucose oxidase on the hybrid material. The glucose biosensor demonstrated linear range from 4.0 to $24.0 \mathrm{mM}$, high stability with its voltammetric response remaining stable after 50 cycles [550]. A sensitive amperometric acetylcholinesterase biosensor, based on $\mathrm{SnO}_{2}$ nanoparticles, carboxylic graphene and nafion for the detection of methyl parathion and carbofuran has been developed in Ref. [551]. The biosensor showed favourable affinity to acetylthiocholine chloride with an apparent Michaelis-Menten constant of $131 \mu \mathrm{M}$, detecting methyl parathion in a linear range from $10^{-13}$ to $10^{-10} \mathrm{M}$ and from $10^{-10}$ to $10^{-8}$ M. This device detected carbofuran in a linear range from $10^{-12}$ to $10^{-10} \mathrm{M}$ and from $10^{-10}$ to $10^{-8} \mathrm{M}$. The detection limits of methyl parathion and carbofuran were $5 \times 10^{-14} \mathrm{M}$ and 
$5 \times 10^{-13} \mathrm{M}$, respectively. Another study demonstrated amperometric acetylcholinesterase biosensors based on a nanocomposite of multi-walled carbon nanotubes, $\mathrm{SnO}_{2}$ nanoparticles and chitosan. These biosensors exhibited a wide linear range from 0.05 to $1.0 \times 10^{5} \mu \mathrm{g} / \mathrm{L}$ with detection limit for chlorpyrifos of $0.05 \mu \mathrm{g} / \mathrm{L}$. Based on the inhibition of pesticides, using chlorpyrifos as model pesticide, the biosensor exhibited a wide range, low detection limit, good reproducibility, and high stability. Using cabbages, lettuces, leeks and pakchois, acceptable recovery of 98.7-105.2\% was reported [552]. In Ref. [553], a carboxylated multiwalled carbon nanotubes- $\mathrm{SnO}_{2}$ nanoparticles-graphenechitosan composite was demonstrated as an amperometric biosensor (Figure 22 (d)). Lysine oxidase enzyme was immobilized covalently on the surface of the composite. The biosensor exhibited wide linear range $\left(9.9 \times 10^{-7} \mathrm{M}-1.6 \times 10^{-4} \mathrm{M}\right)$, low detection limit $\left(1.5 \times 10^{-7} \mathrm{M}\right)$, high sensitivity $\left(55.20 \mu \mathrm{A} \mathrm{mM} \mathrm{mm}^{-1} \mathrm{~cm}^{-2}\right)$ and fast amperometric response $(<25 \mathrm{~s})$. 
(a)

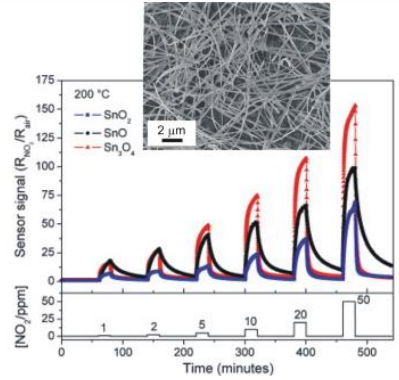

(c)
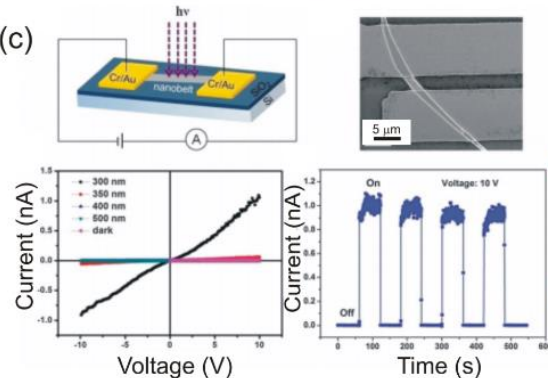

(b)
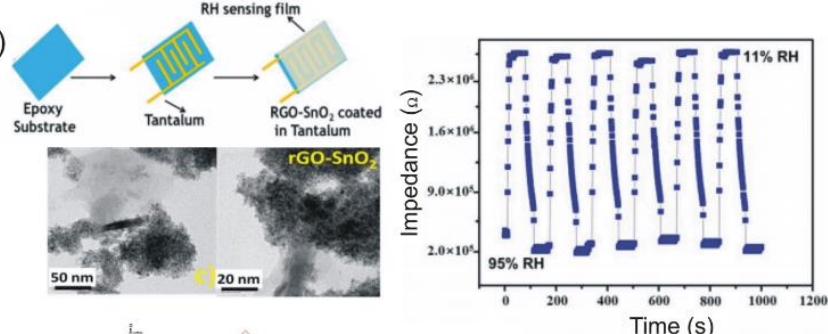

(d)

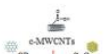

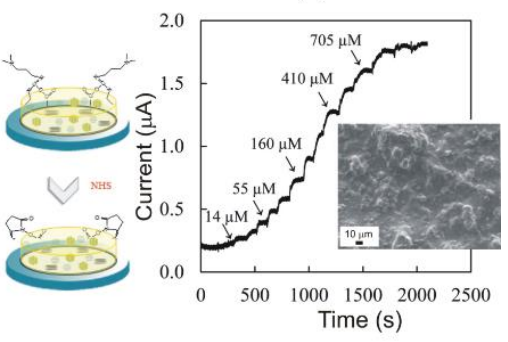

Figure 22. (a) SEM image of $\mathrm{SnO}_{2}$ nanobelts. The graph showed the sensitivities of the gas sensor under exposure to $\mathrm{NO}_{2}$, with concentrations ranging from 1 to $50 \mathrm{ppm}$ of $\mathrm{NO}_{2}$ [511]. (b) Schematic diagram of the $\mathrm{rGO}-\mathrm{SnO}_{2}$ humidity sensor [530], and the nanocomposite morphology. The graph shows the long-term stability of the rGO-SnO 2 sensor after being exposed to $95 \%$ RH for 30 days. (c) Schematic illustration of a Sn-embedded $\mathrm{SnO}_{2}$ nanobelt photodetector, and corresponding SEM image. The $I-V$ curves of the photodetector exposed to light with different wavelengths and under dark conditions, with the timedependent response of the photodetector [72]. (d) Production scheme of the carboxylated multiwalled carbon nanotubes-SnO 2 nanoparticles-graphene-chitosan composite biosensor together with its currenttime response to successive addition of L-lysine into a stirred solution of $0.025 \mathrm{M}$ [553]. Reproduced with permission of MDPI [530], Royal Society of Chemistry [72], and Elsevier (2018) [511] and [553].

\subsection{Vanadium oxide}

Vanadium oxide is a $3 \mathrm{~d}$ transition metal compound which may display different valence states, ranging from $+\mathrm{II}$ to $+\mathrm{V}$, and form a variety of oxides such as $\mathrm{V}_{2} \mathrm{O}_{5}$ (orthorhombic phase), $\mathrm{V}_{2} \mathrm{O}_{3}$ (rhombohedra phase), $\mathrm{V}_{3} \mathrm{O}_{7}$ (monoclinic phase), $\mathrm{V}_{4} \mathrm{O}_{9}$ (orthorhombic phase), $\mathrm{V}_{6} \mathrm{O}_{13}$ (monoclinic phase) and also $\mathrm{VO}_{2}$ [554-557].

The allotropic phases of $\mathrm{VO}_{2}$ systems may include $\mathrm{VO}_{2}(\mathrm{R})$ (tetragonal/rutile phase, $P 4_{2} / m n m$ ), $\mathrm{VO}_{2}(\mathrm{M})$ (monoclinic phase, $P 2_{1} / c$ ), $\mathrm{VO}_{2}(\mathrm{~B})$ (monoclinic phase, $C 2 / m$ ) and $\mathrm{VO}_{2}(\mathrm{~A})$ (tetragonal phase, $P 4_{2} / \mathrm{ncm}$ ) [558-561], however the most stable is $\mathrm{VO}_{2}(\mathrm{R})$ 
phase. Crystal structure of these four $\mathrm{VO}_{2}$ polymorphs, is based on bcc oxygen lattice, with a somewhat regular oxygen octahedra, and vanadium in octahedral sites . In $\mathrm{VO}_{2}(\mathrm{R})$ and $\mathrm{VO}_{2}(\mathrm{M})$, the oxygen octahedra is aligned along two perpendicular directions, while for $\mathrm{VO}_{2}(\mathrm{~B})$ and $\mathrm{VO}_{2}(\mathrm{~A})$ the oxygen octahedra is aligned along just one direction [559]. Despite having the same chemical formula, the crystalline and electronic structures are very distinct, exhibiting different electrical and optical properties $[560,562]$. On table 1 , the crystallographic parameters of the different vanadium oxide phases are shown.

Table 1. Space group and lattice parameter of the different vanadium oxide phases [563-568].

\begin{tabular}{|c|c|c|c|c|}
\hline \multirow{2}{*}{ Crystallographic phase } & \multirow{2}{*}{ Space group } & \multicolumn{3}{|c|}{ Lattice parameter $(\AA)$} \\
\hline & & $A$ & $B$ & $c$ \\
\hline $\mathrm{VO}_{2}$ Monoclinic & $\mathrm{P} 2{ }_{1} / c$ & 5.753 & 4.753 & 5.383 \\
\hline $\mathrm{VO}_{2}$ Monoclinic & $\mathrm{C} 2 / m$ & 12.03 & 3.693 & 6.42 \\
\hline $\mathrm{VO}_{2}$ Tetragonal & $\mathrm{P} 4_{2} / n c m$ & 8.440 & 8.440 & 7.680 \\
\hline $\mathrm{VO}_{2}$ Tetragonal/Rutile & $\mathrm{P} 4_{2} / m n m$ & 4.554 & 4.554 & 2.856 \\
\hline $\mathrm{V}_{2} \mathrm{O}_{3}$ Rhombohedral & $\mathrm{D} 3 d$ & 4.9517 & 14.005 & 2.8283 \\
\hline $\mathrm{V}_{2} \mathrm{O}_{5}$ Orthorhombic & Pmmn & 11.510 & 3.563 & 4.369 \\
\hline $\mathrm{V}_{3} \mathrm{O}_{7}$ Monoclinic & $\mathrm{C} 2 / c$ & 18.626 & 3.622 & 13.719 \\
\hline $\mathrm{V}_{4} \mathrm{O}_{9}$ Orthorhombic & $\mathrm{Cmcm}$ & 10.356 & 8.174 & 16.559 \\
\hline $\mathrm{V}_{6} \mathrm{O}_{13}$ Monoclinic & $\mathrm{Cm}$ & 11.900 & 3.680 & 10.200 \\
\hline
\end{tabular}

$\mathrm{VO}_{2}(\mathrm{~A})$ and $\mathrm{VO}_{2}(\mathrm{~B})$ are thermodynamically metastable phases that present a layered structure similar to $\mathrm{V}_{2} \mathrm{O}_{5}$ [569]. $\mathrm{VO}_{2}$ (A) was reported as an intermediate phase in the transformation $\mathrm{VO}_{2}(\mathrm{~B}) \rightarrow \mathrm{VO}_{2}(\mathrm{R})$ [569]. Moreover, when heated to temperatures around $68{ }^{\circ} \mathrm{C}$, the $\mathrm{VO}_{2}(\mathrm{M})$ phase presents a Mott metal-insulator transition that is characterized by a change in crystal structure from semiconductor phase $\left(P 2_{1} / c\right)$ to metallic phase $\mathrm{VO}_{2}(\mathrm{R})\left(P 4_{2} / \mathrm{mnm}\right)[558,569]$. Figure 23 shows a schematic representation of the unit cell of each oxidation phases of vanadium oxides. 

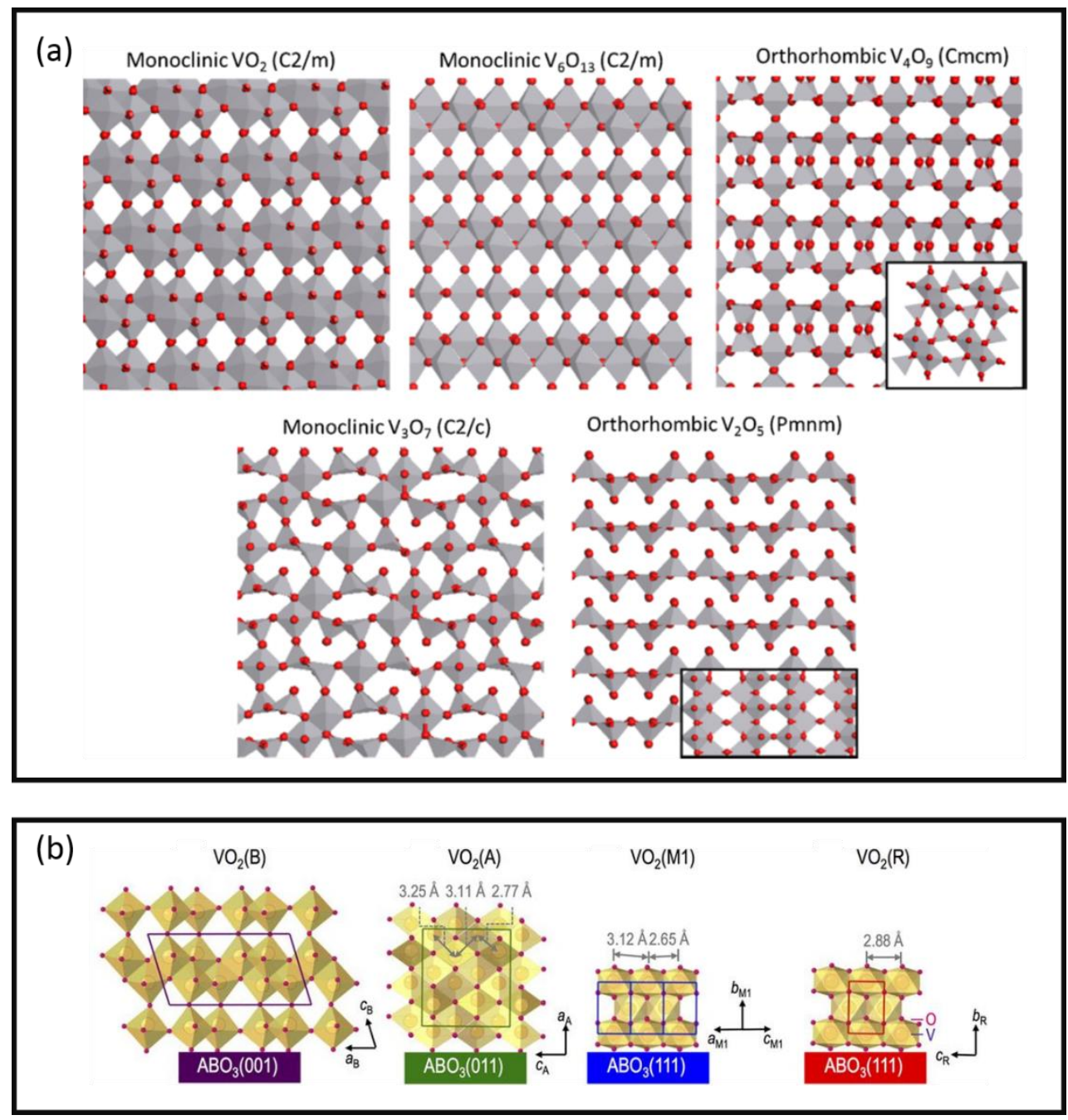

Figure 23. Schematic representation of (a) the $a$-axis of the lattice of $\mathrm{VnO}_{2 n+1}$ for $n=2,3,4$ and 6 [556] and (b) $\mathrm{VO}_{2}(\mathrm{~B}), \mathrm{VO}_{2}(\mathrm{~A}), \mathrm{VO}_{2}(\mathrm{M})$ and $\mathrm{VO}_{2}(\mathrm{R})$ phases [560]. Reproduced with permission of John Wiley and Sons [556] and Springer Nature (2018) [560].

Due to their electronic and structural properties this class of oxides can be used in a vast number of applications, from catalysis [570], environmental pollution control optoelectronics $[571,572]$, in smart thermochromic and electrochromic windows [556, $573,574]$, optical switches $[575,576]$ and in energy storage $[577,578]$. In terms of sensing applications, reports have shown that the most used phases are $\mathrm{VO}_{2}(\mathrm{R})$ and $\mathrm{V}_{2} \mathrm{O}_{5}$, due to their metal to insulator transition at relatively low temperature that may alter resistivity by three orders of magnitude [560]. 
Different nanostructures can be synthesized via hydrothermal/solvothermal method [571, 572, 579], chemical bath [555], chemical vapor deposition [580], thermal evaporation [570], electrodeposition [578, 581, 582] and electrospinning [583]. With these production methods, it is possible to obtain different vanadium oxide morphologies, such as spheres [572], nanotubes [584, 585], nanorods [571], nanobelts [579], nanowires [570]. On Figure 24, it is possible to observe some of the vanadium oxide nanostructures reported.
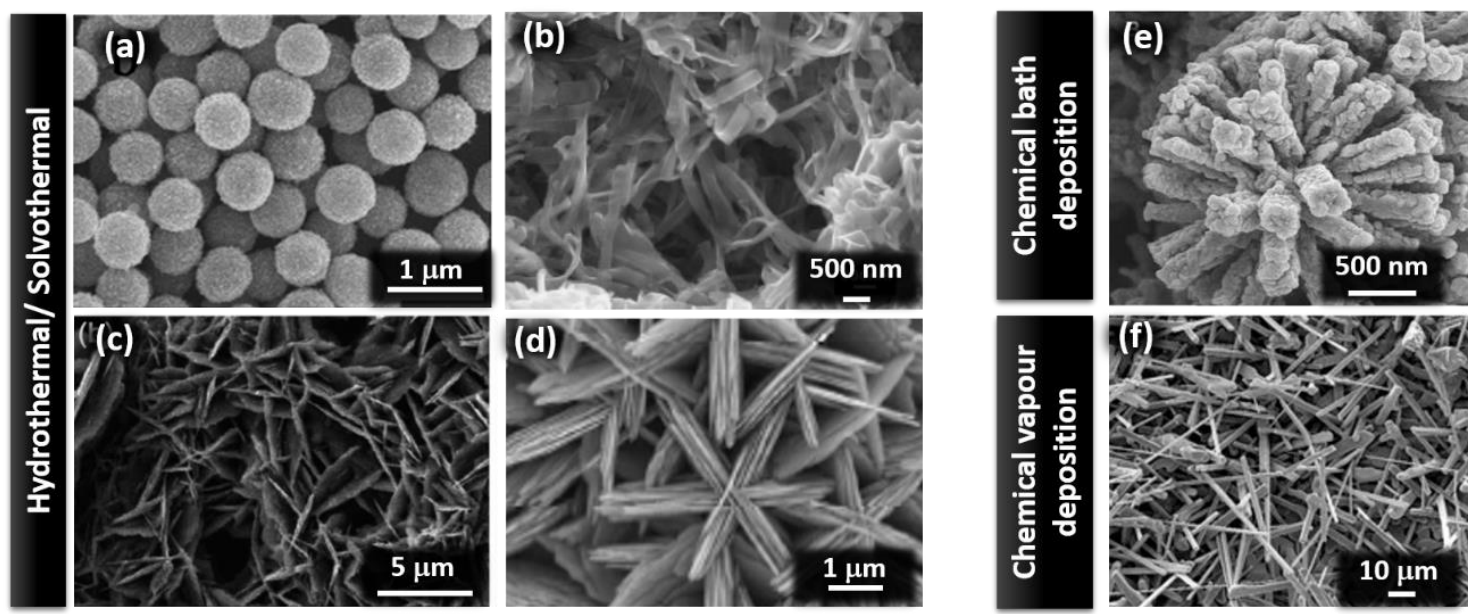

Figure 24. (a) $\mathrm{V}_{2} \mathrm{O}_{5}$ hollow spheres [572]; (b) $\mathrm{V}_{2} \mathrm{O}_{5}$ nanobelts [579]; (c) $\mathrm{VO}_{2}$ (M) nanoflowers [558]; (d) $\mathrm{VO}_{2}$ carambola shaped nanostructure on graphene [586], reproduced with permission of Royal Society of Chemistry (2018); (e) $\mathrm{V}_{2} \mathrm{O}_{5}$ urchin-like structures [555], and (f) $\mathrm{VO}_{2}$ nanorods [580]. Reproduced with permission of Royal Society of Chemistry [572] and [586], Wiley and Sons [579] and [558]; Springer Nature [555] and Elsevier (2018) [580].

Gas sensors based on nanostructured vanadium pentoxide, $\mathrm{V}_{2} \mathrm{O}_{5}$, are the most used for detection of combustible gases $[572,579]$. Wu et al. [572] synthesized $\mathrm{V}_{2} \mathrm{O}_{5}$ hollow spheres and suggested that by using this type of nanostructures, gas sensing properties would by greatly improved due to their high ratio of volume to surface area. When $\mathrm{V}_{2} \mathrm{O}_{5}$ nanostructures are exposed to reducing gases, $\mathrm{V}^{5+}$ species are partially reduced to $\mathrm{V}^{4+}$, originating formation of oxygen vacancies thus increasing conductivity of the sensor (this phenomena can be optically observed due to a material colour change 
from yellow to dark blue) $[572,584]$. Wu was able to detect trimethylamine (one of the toxic gases released by the decomposition of fish and other seafood) with detection limit of $10 \mathrm{ppb}$, response of 1.283 and maximum recovery time of $150 \mathrm{~s}$ at a working temperature of $370{ }^{\circ} \mathrm{C}$ [572]. Griogorieva et al. [571] produced $\mathrm{V}_{2} \mathrm{O}_{5}$ nanorods that showed stable response to trimethylamine (detecting $10 \mathrm{ppm}$ with sensor response of 1 to $3 \%$ ), but weak response to carbon monoxide (only $0.3 \%$ at $180^{\circ} \mathrm{C}$ ), with short response time of $32 \mathrm{~s}$. For the detection of ethanol, Liu et al. [579] used $\mathrm{V}_{2} \mathrm{O}_{5}$ nanobelts synthesized via hydrothermal method. These sensors were tested in a temperature range between 150 and $400{ }^{\circ} \mathrm{C}$, with an increasing concentration from 10 to $100 \mathrm{ppm}$ of ethanol. The lowest detection limit was about $5 \mathrm{ppm}$, with response and recovery time of 30 to $50 \mathrm{~s}$ [579]. Also, Liu et al. [555] used $\mathrm{V}_{2} \mathrm{O}_{5}$ urchin-like structures and nanorods not only for detection of acetone, but also of isopropanol and ammonia, with detection range of 10 to $1000 \mathrm{ppm}$ and recovery time of 200 to $500 \mathrm{~s}$.

Another interesting approach was presented by Liang et al. [580] that investigated sensing properties of $\mathrm{VO}_{2}$ decorated with gold nanoparticles to $\mathrm{NO}_{2}$ gas. It was found that $\mathrm{VO}_{2}$ nanowires decorated with the smallest $\mathrm{Au}$ nanoparticles exhibit sensitivity to $\mathrm{NO}_{2}$ of 0.5 to $5 \mathrm{ppm}$. Liang attributed this response enhancement to a "spillover effect" and to changes in the depletion layer caused by the presence of Au nanoparticles [580]. The small particle size and high number of particles accelerate dissociation and adsorption of oxygen at $\mathrm{VO}_{2}$ surface and thus improve the sensor response from 1.14 to 3.22. This report also showed that $\mathrm{VO}_{2}$ decorated with $\mathrm{Au}$ was also sensitive to acetone, ethanol, isopropanol and $\mathrm{NH}_{3}$, with response of $1.04,1.08,1.12$ and 1.05, respectively [580].

Vanadium oxide nanostructures have been widely used in the detection of toxic and flammable gases, however the high working temperature necessary to achieve good sensitivity, still remains a major challenge. Schneider et al. [587] developed 
nanostructured $\mathrm{V}_{2} \mathrm{O}_{5}$ films for detection of hydrogen, methane and propane, with a good response (0.2) in the presence of 5 to $300 \mathrm{ppm}$ of gas at $200{ }^{\circ} \mathrm{C}$ (Figure 25 (a)).

Some authors have reported the use of vanadium oxide as humidity sensor. Yin et al. [558] reported on the hydrothermal synthesis of $\mathrm{VO}_{2}(\mathrm{~B})$ nanoflowers and their heattransformation into $\mathrm{VO}_{2}(\mathrm{M})$, as well as their humidity sensing characteristics. Both sensors presented fast response and recovery time, with good stability and reproducibility. It was found that $\mathrm{VO}_{2}(\mathrm{M})$ nanostructures were more sensitive at high $\mathrm{RH}$ while $\mathrm{VO}_{2}(\mathrm{~B})$ nanostructures presented higher sensitivity at low RH values [558].

In semiconductor nanomaterials, oxygen vacancies and oxygen ions adsorbed at the surface are active sites, thus water vapour is ionized to $\mathrm{OH}^{-}$and $\mathrm{H}^{+}[558,588]$. Subsequently, another $\mathrm{H}_{2} \mathrm{O}$ molecule is adsorbed to the $\mathrm{H}^{+}$bond between two neighbouring $\mathrm{OH}^{-}$groups. In the presence of high humidity levels, $\mathrm{H}_{2} \mathrm{O}$ layers are formed at $\mathrm{VO}_{2}(\mathrm{M})$ surface that may be dissociated into $\mathrm{H}_{3} \mathrm{O}^{+}$. This will cause the depletion layer to decrease, promoting an increase in surface conductivity. In metallic $\mathrm{VO}_{2}(\mathrm{~B})$ phase, with a lower resistance, the dominant charge carriers are electrons, $\mathrm{e}^{-}$. For high humidity values and due to the polarity of $\mathrm{H}_{2} \mathrm{O}$ molecules, some of these $\mathrm{e}^{-}$are electrostatically attached to positively charged $\mathrm{H}^{+}$forming hydrogen bonds [26]. The density of free electrons at $\mathrm{VO}_{2}(\mathrm{~B})$ surface decreases, increasing materials' resistance with humidity increase [558].

To improve the sensors' response to RH variation, some authors have reported on the use of some additive or the formation of hybrid composites, such as $\mathrm{VO}_{2}-$ carbon nanotubes composites [589]. Doping with other semiconductor materials induces additional atomic defects modifying sensing properties [583]. Araújo et al. [583] doped $\mathrm{TiO}_{2} / \mathrm{WO}_{3}$ composites with different percentages of $\mathrm{V}_{2} \mathrm{O}_{5}$ that demonstrated a change in impedance of an order of magnitude when detecting RH ranging from 40 to $100 \%$. 
Moreover, Evans et al. [589] produced humidity sensors based on $\mathrm{VO}_{2}-$ carbon nanotubes composites. These nanocomposites presented high response to water vapour, with sensitivity between 2.7 and 3.6, when increasing the RH to $50 \%$. Devices resistance was reduced by incorporation of carbon nanotubes, CNTs, suggesting that these significantly contribute to the increased composites' conductivity [589] (Figure 25 (b)).

The use of vanadium oxides in UV sensing is not common, nevertheless some reports show that this semiconductor presents a good responsivity to UV radiation. Zhai et. al. [590] reported on the photoconductive of centimeter-long $\mathrm{V}_{2} \mathrm{O}_{5}$ nanowires produced by hydrothermal method. These nanowires presented responsivity of $\sim 482 \mathrm{~A}$ $\mathrm{W}^{-1}$ and $\mathrm{EQE} \sim 132800 \%$ at $450 \mathrm{~nm}$ and $1.0 \mathrm{~V}$. Wu et al. [591] demonstrated responsivity of a single microwire to UV radiation. Photoconductor made of a single nano/microwire can yield much higher sensitivity and responsivity than the bulk material. The $\mathrm{VO}_{2}$ microwire photodetector presented responsivity of $7069 \mathrm{~A} \mathrm{~W}^{-1}$ and response time of $\approx 126 \mathrm{~ms}$ (Figure 25 (c)).

One interesting approach is using the $\mathrm{V}_{2} \mathrm{O}_{5}$ nanostructures as photochromic UV detectors. Miyazaki et al. [592] produced a $\mathrm{V}_{2} \mathrm{O}_{5}$ based composite that exhibit photochromic properties when irradiated with UV light. These showed multichromism, changing from yellow to green and to pale blue with good reversible photochromic properties when placed in the dark. Miyazaki assumed that UV irradiation is responsible for $\mathrm{V}_{2} \mathrm{O}_{5}$ reducing from +5 to +4 states and associated colour change. Optical band gap increased with UV irradiation due to increase in carrier concentration (Figure 25 (d)).

Other studies reported doping of vanadium oxides with other metal oxides to increase responsivity, response and recovery time of UV sensors. Vanadium oxide doping exhibited an enhancement in luminescence and in photo-sensing properties. These properties arise from formation of defect states within the bandgap, which traps and de- 
traps electrons. Srivastava et al. [593] reported substitution of some vanadium atoms in $\mathrm{ZnO}$, which lead to an increase in UV sensitivity and responsivity, which was attributed to trapping and de-trapping of electrons at $\mathrm{V}^{4+}$ and $\mathrm{V}^{5+}$-related defect states. Whereas the $\mathrm{V}^{5+}$ state is empty, the $\mathrm{V}^{4+}$ state has an extra available electron that when illuminated by UV irradiation will move to the conduction band and increase photocurrent. This study also showed that sensor responsivity increased for $1.76 \%$ of vanadium content to $120 \mu \mathrm{A}$ $\mathrm{W}^{-1}$ when compared to undoped material $(4 \mu \mathrm{A})$.

The use of vanadium oxide semiconductor in biosensing applications is rather rare. Nevertheless, being a biocompatibility material, $\mathrm{V}_{2} \mathrm{O}_{5}$ have attracted much attention for the fabrication of bio-electrodes, due to their high catalytic properties and also to their high electron transfer [594]. Suresh et al. [595] doped $\mathrm{V}_{2} \mathrm{O}_{5}$ with $\mathrm{Ni}$ for determination of dopamine (an electroactive neurotransmitter vital in the central nervous system) at nanomolar level. The doped nanoparticles showed a good response to dopamine in concentrations ranging from 6.6 to $96.4 \mu \mathrm{M}$, with sensitivity of $132 \mathrm{nA} \mu \mathrm{M}^{-1}$ and limit of detection of $28 \mathrm{nM}$. Suresh suggested that $\mathrm{Ni}-\mathrm{V}^{5+}{ }_{2} \mathrm{O}_{5}$ causes oxidation of dopamine and is then electrochemically reduced to $\mathrm{Ni}-\mathrm{V}^{4+}{ }_{2} \mathrm{O}_{5}$. and after donation of an electron to the carbon electrode is regenerated to $\mathrm{Ni}-\mathrm{V}^{5+}{ }_{2} \mathrm{O}_{5}$.

Most of existing reports are related with the use of $\mathrm{V}_{2} \mathrm{O}_{5}$ nanocomposites. Yang et al. [596] produced an electrochemiluminescence (ECL) aptasensor for the detection of mucin 1 (a biomarker associated to breast and pancreatic cancer) using $\mathrm{V}_{2} \mathrm{O}_{5}$ nanospheres as peroxidade mimics. $\mathrm{V}_{2} \mathrm{O}_{5}$ was synthesized and added to ABEI ( $N$-(4-aminobuthyl)- $N$ (ethylisoluminol)), functionalized with silver nanoparticles, thus forming a nanocomposite that was applied to the sensor electrode. The produced sensors' signal increased by about 2.7 times. Yang suggested that $\mathrm{V}_{2} \mathrm{O}_{5}$ nanospheres are responsible for loading a large number of luminuphores with an enhanced ECL signal. This approach 
displayed detection range of $10 \mathrm{fg} \mathrm{mL}^{-1}$ to $10 \mathrm{ng} \mathrm{mL}^{-1}$, with a limit of detection down to $3.33 \mathrm{fg} \mathrm{mL}^{-1}[596]$.

Other composites using $\mathrm{V}_{2} \mathrm{O}_{5}$ nanostructures and carbon nanotubes were reported. These nanocomposites were used to improve sensing properties. Xiaobing et al. [597] reported the development of carbon nanotubes $/ \mathrm{V}_{2} \mathrm{O}_{5} /$ chitosan nanocomposite for detection of ciprofloxacin (an antibiotic widely used in health and agricultural industries, which the residues may cause skin infections and respiratory infections). This sensor combines the biocompatibility of $\mathrm{V}_{2} \mathrm{O}_{5}$, the efficient electron transfer of carbon nanotubes and the effective fil-forming strength presented by chitosan. Moreover, it presented good selectivity and low limit of ciprofloxacin detection $\left(0.5 \mathrm{ng} \mathrm{mL}^{-1}\right)$ on milk, with a recovery rate of $94.5-97.87 \%$ (Figure 25 (e)) [597].

Sun et al. [598] also used this nanocomposite (nanotubes $/ \mathrm{V}_{2} \mathrm{O}_{5} /$ chitosan) for fabrication of electrodes for immobilization of single-stranded DNA. The experiments performed by Sun suggested that the synergistic effect of $\mathrm{V}_{2} \mathrm{O}_{5} /$ Carbon nanotubes leads to increased amount of single-stranded DNA being adsorbed onto the electrode's surface, thus increasing the electrochemical response. The biosensor produced by Sun et al. was able to detect concentrations in the range of $1.0 \times 10^{-11}$ to $1.0 \times 10^{-6} \mathrm{~mol} \mathrm{~L}^{-1}$, with detection limit of $1.76 \times 10^{-12} \mathrm{~mol} \mathrm{~L}^{-1}$.

Another biosensor based on these types of nanocomposites electrodes was reported by Alagappan et al. [594] for detection of methylglyoxal, which is responsible for complications in diabetic patients. This bioelectrode was able to measure concentrations of methyglyxal in par-boiled rice ranging from 0.1 to $100 \mu \mathrm{M}$, with sensitivity of $1130.86 \mu \mathrm{A} \mathrm{cm} \mathrm{cm}^{-2}$, limit of detection of $2 \mathrm{nM}$ and response time $<18 \mathrm{~s}$. Vanadium oxide has an isoelectric point of 3 which allows electrostatic attraction of the glutathione cofactor, that has a high isoelectric point (5.93). In the absence of 
methyglyxal, glutathione will oxidize to hemithioacetal at $-2.74 \mathrm{mV}$, while in the presence of $0.1 \mu \mathrm{M}$ of methyglyxal the the required potential is $-32.29 \mathrm{mV}$ [594].

(a)
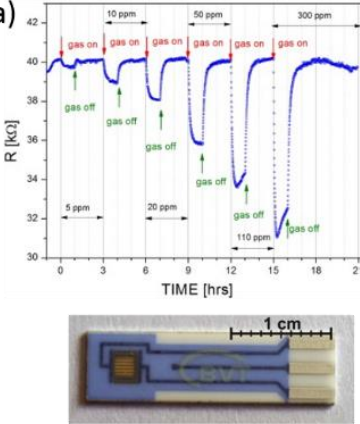

(c)

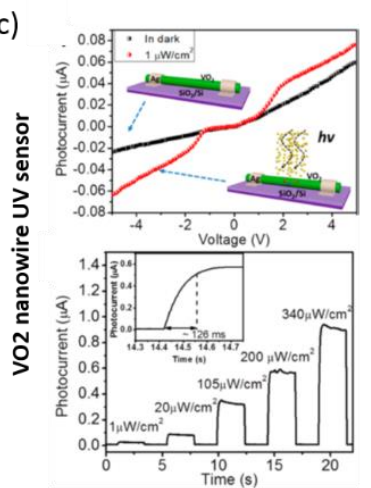

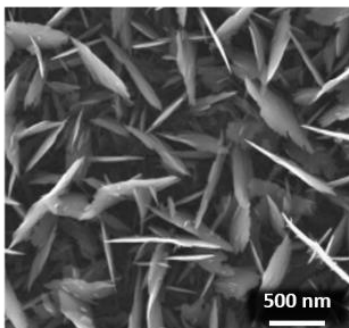

(d)

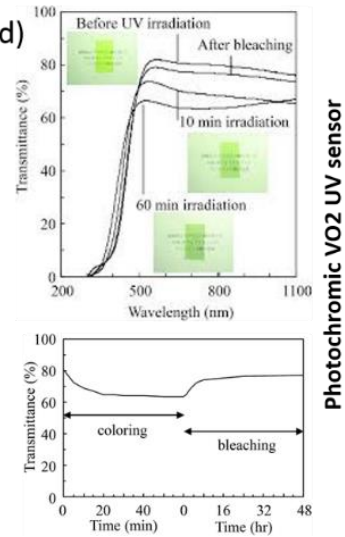

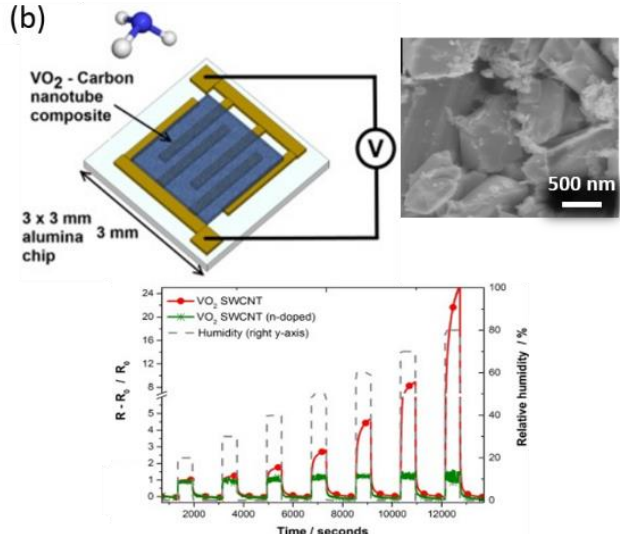

(e)

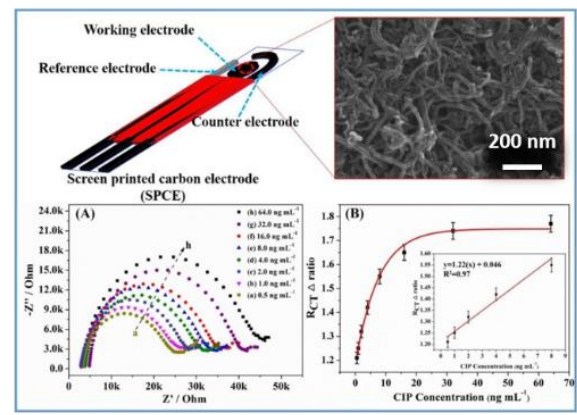

Figure 25. (a) $\mathrm{V}_{2} \mathrm{O}_{5}$ nanostructured film for hydrogen gas sensing application [587]; (b) $\mathrm{VO}_{2}$-carbon nanotube composite for humidity sensor [589]; (c) $\mathrm{VO}_{2}$ microwire UV photodetectors and the correspondent photocurrent at $4 \mathrm{~V}$ under different UV illumination intensities (the inset show the response time) [591]; (d) UV-VIS spectra of the $\mathrm{V}_{2} \mathrm{O}_{5}$ nanostructured photodetector when irradiated with UV light and their time dependence of the transmittance when coloring and bleaching [592]; (e) Schematic, SEM image and Nyquist plots of the carbon nanotube $/ \mathrm{V}_{2} \mathrm{O}_{5}$ electrodes used in biosensing application [597]. Reproduced with permission of Elsevier (2018) [587], [589] and [597]; ACS publishing "Copyright (2018) American Chemical Society” [591]; and Royal Society of Chemistry (2018) [592].

\section{Overview of the metal oxide sensors performance}

This section describes the comparison between all the different metal oxides discussed above, organized by sensor device type. Table 2 summarizes different metal 
oxide nanostructures employed as gas sensors. Metal oxides have been largely integrated in gas sensors over the years and several types of gases, including $\mathrm{NO}_{2}, \mathrm{H}_{2}$ to $\mathrm{C}_{2} \mathrm{H}_{5} \mathrm{OH}$ and $\mathrm{NH}_{3}$, have been evaluated at different concentrations. The temperature at which sensing experiments are carried out, is also imperative. As can be seen from Table 2, the used temperatures are widely diverse and even if some sensors work at room temperature (RT), which enables low cost devices and improves long-term stability, most of the nanostructures investigated show working/operating temperatures from 200 to $500{ }^{\circ} \mathrm{C}$. This range of temperatures is too high from a practical use point-of-view and leads to energy waste and emissions increase, which enhances danger of explosion when dealing with flammable gases.

In terms of metal oxides used, $\mathrm{ZnO}$ and $\mathrm{TiO}_{2}$ are largely employed as gas sensors due to their high chemical stability, simple and cost effective production, easy surface oxygen adsorption, amongst others factors [233, 599]. Nevertheless, operation temperatures of both sensors are still high which limits their integration in real-time gas monitoring devices. The response/recovery times, especially for $\mathrm{ZnO}$ nanostructures, need deeper investigation for reaching fast responses, which may include surface modification, additive doping or light activation. $\mathrm{WO}_{3}$ is considered a promising material for gas sensors having extensive application for environment and safety monitoring. $\mathrm{WO}_{3}$ is an abundant material and can be synthesized by low-cost wet-chemical routes. However, in terms of gas sensing, this material has a drawback of intersecting sensitivity, which limits distinction of two gases in a mixture [600]. Nevertheless, sensitivity of $\mathrm{WO}_{3}$ to several gases has been tested and in some cases low detection limits (in the order of ppb) were achieved, especially for $\mathrm{NO}_{2}$ (Table 2). The operation temperature is also lower ( $<300{ }^{\circ} \mathrm{C}$ for the presented nanostructured sensors) when compared to $\mathrm{ZnO}$ and $\mathrm{TiO}_{2}$, presenting fast response/recovery times. 
Copper oxide-based gas sensors have been reported over the years, especially to form $p$ - $n$ - heterojunctions. Copper oxides have $p$-type characters, besides being eco-friendly, non-toxic and compatible with wet-chemical synthesis routes. However, $\mathrm{Cu}_{2} \mathrm{O}$ phase is unstable and easily converts to $\mathrm{CuO}$. This thermal instability can influence the gas sensors behaviour, especially since $\mathrm{Cu}_{2} \mathrm{O}$ demonstrates gas sensing activity at $\sim 200{ }^{\circ} \mathrm{C}$ [400]. From Table 2, it is possible to observe that the operation temperature of copper oxidebased nanostructured devices is also lower than $300{ }^{\circ} \mathrm{C}$ and that the response/recovery times are expressively different depending on the nanostructure or composite/mixture used. $\mathrm{SnO}$ is also thermally unstable and converts to $\mathrm{SnO}_{2}$ when heated, which limits its utilization as gas sensors. On the other hand, $\mathrm{SnO}_{2}$ is widely used in gas sensors [499] for detection of different gases, like ethanol, $\mathrm{H}_{2}, \mathrm{O}_{2}, \mathrm{CO}, \mathrm{NO}, \mathrm{NO}_{2}$ and $\mathrm{NH}_{3}$, due to its fastresponse speed, high chemical stability, selectivity and low cost. Moreover, the presented nanostructured sensors work at temperatures $<300{ }^{\circ} \mathrm{C}$, with low detection limits (ppm) and fast response/recovery times. Vanadium oxides have recently been considered for gas sensing. $\mathrm{V}_{2} \mathrm{O}_{5}$ has been reported for combustible gases detection due to its good chemical and thermal stability. Nevertheless, the operation temperature, response/recovery times and detection limits of these sensors vary expressively depending on nanostructure used and vanadium oxide phase. 
Table 2. Summary of overall performance of nanostructured metal oxides-based gas sensors.

\begin{tabular}{|c|c|c|c|c|c|c|c|}
\hline $\begin{array}{c}\text { Metal oxide } \\
\text { nanostructure }\end{array}$ & Gas & $\begin{array}{c}\text { Temperature } \\
\left({ }^{\circ} \mathrm{C}\right)\end{array}$ & $\begin{array}{c}\text { Detection } \\
\text { limit }\end{array}$ & $\begin{array}{c}\text { Response } \\
\text { time }(s)\end{array}$ & $\begin{array}{l}\text { Recovery } \\
\text { time (s) }\end{array}$ & RH \% & Ref. \\
\hline $\begin{array}{l}\mathrm{ZnO} \text { nanowires, } \\
\text { nanobelts and } \\
\text { tetrapodes }\end{array}$ & $\begin{array}{l}\mathrm{H}_{2} \mathrm{~S} \text { and } \\
\mathrm{NO}\end{array}$ & RT & $\begin{array}{c}200 \mathrm{ppb} \mathrm{H}_{2} \mathrm{~S} \\
1 \mathrm{ppm} \mathrm{NO}\end{array}$ & - & - & - & [146] \\
\hline $\begin{array}{l}\mathrm{ZnO} \text { cloudy-like } \\
\text { nanoparticles, } \\
\text { isotropic } \\
\text { nanoparticles }\end{array}$ & $\begin{array}{c}\mathrm{CO} \\
\mathrm{C}_{3} \mathrm{H}_{8} \\
\text { and } \mathrm{NH}_{3}\end{array}$ & $\begin{array}{c}340,400, \text { and } \\
500\end{array}$ & $\begin{array}{c}100 \mathrm{ppm} \mathrm{CO} \\
100 \mathrm{ppm} \mathrm{C}_{3} \mathrm{H}_{8} \\
19 \mathrm{ppm} \mathrm{NH}_{3}\end{array}$ & - & - & 50 & {$[150]$} \\
\hline $\mathrm{ZnO}$ nanobelts & $\mathrm{NO}_{2}$ & $300-350$ & $0.51 \mathrm{ppm}$ & - & - & - & {$[151]$} \\
\hline $\mathrm{ZnO}$ nanorods & $\mathrm{NO}_{2}$ & $300-450$ & $1 \mathrm{ppm}$ & 180 & - & - & [152] \\
\hline $\begin{array}{l}\text { Au-doped } \mathrm{ZnO} \\
\text { nanostructures }\end{array}$ & $\mathrm{NO}_{2}$ & 300 and 550 & $0.5 \mathrm{ppm}$ & 450 & $\begin{array}{l}587 \_300^{\circ} \mathrm{C} \\
1020 \_550^{\circ} \mathrm{C}\end{array}$ & - & {$[154]$} \\
\hline $\begin{array}{l}\mathrm{ZnO} \text { nanorod arrays } \\
\text { with } \mathrm{NiO} \text { nanosheets } \\
\text { Nanoheterojunctions }\end{array}$ & $\mathrm{C}_{2} \mathrm{H}_{5} \mathrm{OH}$ & 200 & 100 ppm & 55 & 70 & - & {$[155]$} \\
\hline $\mathrm{TiO}_{2}$ nanowires & $\mathrm{NO}_{2}$ & RT & $100 \mathrm{ppm}$ & 10 & 19 & - & [233] \\
\hline $\mathrm{TiO}_{2}$ spongy layers & $\mathrm{C}_{2} \mathrm{H}_{5} \mathrm{OH}$ & 350 & $44 \mathrm{ppm}$ & 10 & - & 40 & [235] \\
\hline Cr-doped $\mathrm{TiO}_{2}$ films & $\begin{array}{c}\mathrm{CO} \\
\mathrm{NO}_{2}\end{array}$ & 500 & $\begin{array}{l}1000 \mathrm{ppm} \mathrm{CO}, \\
2 \mathrm{ppm} \mathrm{NO}\end{array}$ & - & - & $\begin{array}{l}30 \text { and } \\
50 \text { for } \\
\mathrm{NO}_{2}\end{array}$ & [236] \\
\hline Au-doped $\mathrm{TiO}_{2}$ films & $\begin{array}{l}\mathrm{CO} \\
\mathrm{H}_{2}\end{array}$ & 300 & $\begin{array}{l}5 \mathrm{ppm} \mathrm{CO} \\
8.5 \mathrm{ppm} \mathrm{H}_{2}\end{array}$ & $\begin{array}{l}15 \mathrm{CO} \\
480 \mathrm{H}_{2}\end{array}$ & $\begin{array}{l}10 \mathrm{CO} \\
9.6 \mathrm{H}_{2}\end{array}$ & dry & [237] \\
\hline $\begin{array}{c}\mathrm{TiO}_{2}-\mathrm{SnO}_{2} \\
\text { nanostructures }\end{array}$ & $\mathrm{H}_{2}$ & 400 & - & $60-120$ & $300-420$ & - & [238] \\
\hline $\begin{array}{c}\text { Lamellar- } \\
\text { nanostructured } \mathrm{WO}_{3} \\
\text { particles }\end{array}$ & $\mathrm{NO}_{2}$ & 200 & $50-1000 \mathrm{ppb}$ & - & - & - & [303] \\
\hline $\begin{array}{c}\text { Porous } \mathrm{WO}_{3} \\
\text { nanocrystalline }\end{array}$ & $\mathrm{NO}_{2}$ & 300 & $50-550 \mathrm{ppb}$ & 180 & 60 & - & [304] \\
\hline $\begin{array}{c}\text { Three-dimensional } \\
\text { hierarchical } \mathrm{WO}_{3} \\
\text { nanostructures }\end{array}$ & $\mathrm{NO}_{2}$ & $120 \_800$ ppm & $40-800 \mathrm{ppb}$ & $\begin{array}{c}\text { 120_800 } \\
\text { ppm }\end{array}$ & 41_800 ppm & - & [305] \\
\hline $\mathrm{WO}_{3}$ nanotubes & $\mathrm{NO}_{2}$ & 300 & $1-5 \mathrm{ppm}$ & $15-40$ & $70-100$ & - & [306] \\
\hline $\begin{array}{c}\mathrm{WO}_{3} \text { nanowire-like } \\
\text { structures }\end{array}$ & $\mathrm{NH}_{3}$ & 250 & $9.7-1500 \mathrm{ppm}$ & 7 & 8 & - & {$[307]$} \\
\hline $\begin{array}{c}\text { Pt- } \mathrm{WO}_{3} \text { hybrid } \\
\text { nanorods }\end{array}$ & $\begin{array}{c}\mathrm{C}_{2} \mathrm{H}_{5} \mathrm{OH} \\
\text { and } \\
\mathrm{CH}_{3} \mathrm{OH}\end{array}$ & 220 & $\begin{array}{l}1,5,20,100 \\
\text { and } 200 \mathrm{ppm}\end{array}$ & 9 & - & - & [312] \\
\hline $\begin{array}{l}\mathrm{Pd}-\mathrm{WO}_{3} / \text { reduced } \\
\text { graphene oxide } \\
\text { Hierarchical } \\
\text { nanostructures }\end{array}$ & $\mathrm{H}_{2}$ & 100 & $20 \mathrm{ppm}$ & 60 & - & - & [321] \\
\hline $\mathrm{Cu}_{2} \mathrm{O}$ nanowires & $\mathrm{H}_{2}$ & 200 & $1000 \mathrm{ppm}$ & - & 600 & dry & [411] \\
\hline $\begin{array}{l}\mathrm{CuO} 3 \mathrm{D} \text { flower- } \\
\text { nanostructures }\end{array}$ & $\mathrm{C}_{2} \mathrm{H}_{5} \mathrm{OH}$ & 260 & $10-1000$ ppm & 5 & 15 & - & [415] \\
\hline $\begin{array}{l}\mathrm{CuO} \text { flower-like } \\
\text { nanostructures }\end{array}$ & $\mathrm{H}_{2} \mathrm{~S}$ & RT & $\begin{array}{l}100 \mathrm{ppb}- \\
20 \mathrm{ppm}\end{array}$ & $240-480$ & $900-3300$ & dry & [417] \\
\hline $\begin{array}{l}\mathrm{CuO} / \mathrm{ZnO} \text { nanorod } \\
\text { heterojunction }\end{array}$ & $\mathrm{C}_{2} \mathrm{H}_{5} \mathrm{OH}$ & 300 & $1 \mathrm{ppm}$ & 7 & 9 & - & [422] \\
\hline $\begin{array}{c}\mathrm{CuO}-\mathrm{MnO}_{2} \\
\text { nanocomposite }\end{array}$ & $\mathrm{NH}_{3}$ & - & $100 \mathrm{ppm}$ & 120 & 600 & - & [424] \\
\hline $\begin{array}{l}\mathrm{Cu}_{2} \mathrm{O} / \mathrm{CuO} \text { sub- } \\
\text { microspheres }\end{array}$ & $\mathrm{H}_{2} \mathrm{~S}$ & 95 & $50 \mathrm{ppb}$ & - & 76 & - & {$[425]$} \\
\hline $\begin{array}{c}\text { Porous } \mathrm{Cu}_{2} \mathrm{O} / \mathrm{CuO} \\
\text { cubes }\end{array}$ & $\mathrm{C}_{3} \mathrm{H}_{6} \mathrm{O}$ & 150 & 500 ppm & 1 & 25 & - & {$[426]$} \\
\hline
\end{tabular}




\begin{tabular}{|c|c|c|c|c|c|c|c|}
\hline $\begin{array}{c}\text { Nanosheets- } \\
\text { assembled } \\
\mathrm{SnO}_{2} \text { hollow spheres }\end{array}$ & $\mathrm{C}_{2} \mathrm{H}_{5} \mathrm{OH}$ & 350 & $500 \mathrm{ppb}$ & - & 5 & - & {$[503]$} \\
\hline $\begin{array}{l}\text { Porous } \mathrm{SnO}_{2} \\
\text { nanoflowers }\end{array}$ & $\mathrm{C}_{2} \mathrm{H}_{5} \mathrm{OH}$ & 240 & 100 ppm & 2 & 15 & dry & {$[504]$} \\
\hline $\begin{array}{c}\text { Hierarchical } \\
\mathrm{SnO}_{2} \text { based ultrathin } \\
\text { nanosheets }\end{array}$ & $\mathrm{C}_{2} \mathrm{H}_{5} \mathrm{OH}$ & - & 100 ppm & 1 & 2 & - & [497] \\
\hline $\begin{array}{c}\text { Square-shaped } \mathrm{SnO}_{2} \\
\text { nanowires }\end{array}$ & $\mathrm{C}_{3} \mathrm{H}_{6} \mathrm{O}$ & 290 & $20 \mathrm{ppm}$ & 7 & 10 & - & {$[505]$} \\
\hline $\begin{array}{l}\text { SnO disk-like } \\
\text { structures }\end{array}$ & $\mathrm{NO}_{2}$ & 200 & $100 \mathrm{ppb}$ & - & - & - & {$[510]$} \\
\hline $\begin{array}{c}\mathrm{Sb} \text {-doped } \\
\mathrm{SnO}_{2} \text { nanowires }\end{array}$ & $\mathrm{C}_{2} \mathrm{H}_{5} \mathrm{OH}$ & 300 & $10 \mathrm{ppm}$ & 1 & 5 & - & {$[512]$} \\
\hline $\begin{array}{c}\text { Hierarchical } \mathrm{SnO}_{2} / \mathrm{rGO} \\
\text { nanostructure }\end{array}$ & $\mathrm{H}_{2} \mathrm{~S}$ & 100 & $10 \mathrm{ppm}$ & 7 & - & - & {$[514]$} \\
\hline $\begin{array}{c}\mathrm{WO}_{3-} \\
\mathrm{SnO}_{2} \text { nanofibers }\end{array}$ & $\mathrm{C}_{2} \mathrm{H}_{5} \mathrm{OH}$ & - & $10 \mathrm{ppm}$ & 18.5 & 282 & - & {$[516]$} \\
\hline $\begin{array}{c}\mathrm{SnO}_{2} \text {-decorated } \\
\mathrm{NiO} \text { nanostructures }\end{array}$ & $\mathrm{C}_{7} \mathrm{H}_{8}$ & 250 & $1.2-10 \mathrm{ppb}$ & - & - & $\begin{array}{c}15- \\
90 / / 10 \\
\mathrm{ppm}\end{array}$ & {$[521]$} \\
\hline $\mathrm{V}_{2} \mathrm{O}_{5}$ hollow spheres & $\begin{array}{l}\text { Trimethy } \\
\text { lamine }\end{array}$ & 370 & $10 \mathrm{ppb}$ & - & 150 & - & {$[572]$} \\
\hline $\mathrm{V}_{2} \mathrm{O}_{5}$ nanorods & $\begin{array}{l}\text { Trimethy } \\
\text { lamine }\end{array}$ & 175 & $10 \mathrm{ppm}$ & 32 & 330 & - & {$[571]$} \\
\hline $\mathrm{V}_{2} \mathrm{O}_{5}$ nanobelts & $\mathrm{C}_{2} \mathrm{H}_{5} \mathrm{OH}$ & 200 & $5 \mathrm{ppm}$ & 30 & 50 & - & [579] \\
\hline $\begin{array}{l}\mathrm{V}_{2} \mathrm{O}_{5} \text { urchin-like and } \\
\text { rod structures }\end{array}$ & $\mathrm{C}_{3} \mathrm{H}_{6} \mathrm{O}$ & 150 & $10-1000$ ppm & - & 200 and 500 & 30 & {$[555]$} \\
\hline $\begin{array}{l}\mathrm{VO}_{2} \text { decorated with } \\
\text { gold nanoparticles }\end{array}$ & $\mathrm{NO}_{2}$ & $25-100$ & $0.5-5 \mathrm{ppm}$ & - & - & - & {$[580]$} \\
\hline $\begin{array}{c}\text { Nanostructured } \mathrm{V}_{2} \mathrm{O}_{5} \\
\text { film }\end{array}$ & $\begin{array}{l}\mathrm{H}_{2}, \mathrm{CH}_{4}, \\
\text { and } \mathrm{C}_{3} \mathrm{H}_{8}\end{array}$ & 200 & $5-300 \mathrm{ppm}$ & - & - & - & [587] \\
\hline
\end{tabular}

Nanostructured metal oxides-based humidity sensors that can detect humidity changes in a vast range of values, between 0 and $100 \% \mathrm{RH}$, have been reported for all the discussed metal oxide materials (see Table 3). $\mathrm{ZnO}$ presents a good detection range, however it has the disadvantage of being hydrophobic, which limits sensitivity improvement. On the other hand, $\mathrm{TiO}_{2}$ often presents superior humidity sensitivity due to its hydrophilic properties, which arise from surface defects. This material presents fast response times but longer recovery times. Moreover, the use of $\mathrm{TiO}_{2}$ may lead to low long-term stability. $\mathrm{WO}_{3}$ is also an interesting alternative for humidity sensors due to its high sensitivity, which is generally attributed to structural defects. The use of copper, tin and vanadium oxides as a humidity sensor is not so common, nevertheless they all present fast response and recovery time and good long-term stability. 
Table 3. Summary of overall performance of nanostructured metal oxides-based humidity sensors.

\begin{tabular}{|c|c|c|c|c|c|}
\hline $\begin{array}{c}\text { Metal oxide } \\
\text { nanostructure }\end{array}$ & $\begin{array}{c}\text { Detection } \\
\text { range }(\% \mathrm{RH})\end{array}$ & $\begin{array}{c}\text { Response } \\
\text { time (s) }\end{array}$ & $\begin{array}{l}\text { Recovery time } \\
\text { (s) }\end{array}$ & $\begin{array}{c}\text { Hysteresis } \\
(\%)\end{array}$ & Ref. \\
\hline $\mathrm{ZnO}$ & $15-95$ & 7 & 14 & 1.8 & [157] \\
\hline $\mathrm{ZnO}$ nanoparticles & $0-80$ & 5 & - & 8.6 & [158] \\
\hline $\mathrm{ZnO} / \mathrm{SnO}_{2}$ & $11-95$ & 50 & 100 & 2 & {$[160]$} \\
\hline $\mathrm{ZnO} / \mathrm{TiO}_{2}$ & $11-95$ & 774.9 & 19.7 & - & [161] \\
\hline $\mathrm{TiO}_{2}$ nanosheets & $11-95$ & 3 & 50 & 4.6 & [239] \\
\hline $\mathrm{TiO}_{2} /$ graphene & $12-90$ & 121 & $68-128$ & $<0.39$ & [240] \\
\hline $\begin{array}{c}\mathrm{TiO}_{2} / \text { conducting } \\
\text { polymer }\end{array}$ & $30-90$ & 30 & 45 & 2 & {$[241]$} \\
\hline $\mathrm{TiO}_{2}: \mathrm{LiCl}$ & $5-95$ & 0.75 & 1 & - & [243] \\
\hline $\mathrm{WO}_{3}: \mathrm{Li}: \mathrm{K}$ & $1-95$ & 15 & 10 & 3 & [324] \\
\hline $\begin{array}{c}\mathrm{WO}_{3} \text { on } \\
\text { nanoporous silicon }\end{array}$ & $11-95$ & 104 & 94 & 5.3 & [327] \\
\hline $\begin{array}{c}\mathrm{WO}_{3} / \text { Poly }(2,5- \\
\text { dimethoxyaniline })\end{array}$ & $23-84$ & 27 & 136 & 5 & [328] \\
\hline $\mathrm{WO}_{3}: \mathrm{ZnO}$ & $15-95$ & 65 & 360 & 1.09 & [329] \\
\hline $\mathrm{CuO}$ nanowires & $52-90$ & - & - & - & [430] \\
\hline $\mathrm{Cu}_{2} \mathrm{O}$ porous film & Up to 58 & 151 & 145 & 4.38 & [431] \\
\hline $\mathrm{CuO}: \mathrm{ZnO}$ & $10-90$ & 76 & 296 & 2.30 & [437] \\
\hline $\mathrm{SnO}_{2}$ nanoparticles & $5-95$ & 32 & 25 & - & [522] \\
\hline $\begin{array}{c}\mathrm{SnO}_{2} \text { ordered } \\
\text { nanostructures }\end{array}$ & $5-96$ & 32 & 42 & $<5$ & [523] \\
\hline $\mathrm{SnO}_{2}$ nanofiber & Up to 85 & 1 & 1 & - & [524] \\
\hline $\begin{array}{c}\text { Ion doped } \mathrm{SnO}_{2} \\
\text { nanofiber }\end{array}$ & $11-95$ & 5 & 6 & - & {$[525]$} \\
\hline $\mathrm{VO}_{2}$ & Up to $92 \%$ & $5-8$ & $2-3$ & 7 & {$[558]$} \\
\hline $\mathrm{TiO}_{2} / \mathrm{WO}_{3} / \mathrm{V}_{2} \mathrm{O}_{5}$ & $40-100$ & - & - & - & [583] \\
\hline
\end{tabular}

Table 4 shows that $\mathrm{ZnO}, \mathrm{WO}_{3}$ and $\mathrm{SnO}_{2}$ are largely employed as UV sensors/photodetectors, while other metal oxides, such as $\mathrm{CuO} / \mathrm{Cu}_{2} \mathrm{O}$, are used to produce $p$ - $n$ - heterojunctions. On the other hand, the use of $\mathrm{TiO}_{2}$ and vanadium oxides in such devices is not widespread, nevertheless some studies have reported their behaviour as photoactive layers for UV sensors. The photocurrents, $I_{o n} / I$ off, responsivity and response/recovery times vary expressively for each sensor, largely depending on the metal oxide and even nanostructure used. Moreover, sensor behaviour is widely influenced by substrate, UV lamp and the environment where the measurements are carried out. Nevertheless, comparing metal oxides, it can be seen that $\mathrm{ZnO}$ shows the highest values of photocurrent and $I_{o n} / I$ off, and for that reason it is largely investigated for UV sensor applications. ZnO 1D nanostructures are especially interesting due to large 
surface to volume ratio, which increases the photoresponse. $\mathrm{WO}_{3}$ and $\mathrm{SnO}_{2}$ also display acceptable $I_{\text {on }} / I$ off values, which make them interesting to be integrated in UV sensors. Moreover, the presented $\mathrm{WO}_{3}$ nanostructures revealed fast response/recovery times. Vanadium oxides and $\mathrm{TiO}_{2}$, on the other hand, show lower photocurrent and $I_{o n} / I_{\text {off }}$.

Table 4. Summary of overall performance of nanostructured metal oxides-based UV photodetectors.

\begin{tabular}{|c|c|c|c|c|c|c|c|}
\hline $\begin{array}{c}\text { Metal oxide } \\
\text { nanostructure }\end{array}$ & Photocurrent & $\begin{array}{c}\text { Dark } \\
\text { current }\end{array}$ & $\begin{array}{c}\text { On/off ratio } \\
\left(I_{o n} / I_{\text {off }}\right)\end{array}$ & $\mathbf{R}\left(\mathrm{A} \mathrm{W}^{-1}\right)$ & $\begin{array}{c}\text { Response } \\
\text { time (s) }\end{array}$ & $\begin{array}{c}\text { Recovery } \\
\text { time (s) }\end{array}$ & Ref. \\
\hline $\mathrm{ZnO}$ nanowire & $\begin{array}{c}12.22 \mathrm{~mA} \text { (rigid } \\
\text { substrate) } \\
14.1 \mathrm{~mA} \\
\text { (flexible } \\
\text { substrate) } \\
(3 \mathrm{~V})\end{array}$ & - & $\begin{array}{l}8.2 \times 10^{3} \\
1.2 \times 10^{4}\end{array}$ & - & - & - & [171] \\
\hline $\begin{array}{c}\mathrm{ZnO} \text { nanorod } \\
\text { arrays } \\
\text { (glass substrate) }\end{array}$ & $\begin{array}{l}5 \mathrm{~mA} \\
(5 \mathrm{~V})\end{array}$ & $90 \mu \mathrm{A}$ & 55 & $4 \times 10^{-4}$ & 60 & - & {$[71]$} \\
\hline $\begin{array}{l}\mathrm{ZnO} \text { nanorod } \\
\text { arrays (cellulose } \\
\text { substrate) }\end{array}$ & $\begin{array}{c}10.36 \mu \mathrm{A} \\
(10 \mathrm{~V})\end{array}$ & $0.76 \mu \mathrm{A}$ & 13.63 & $1.19 \times 10^{-6}$ & & & [13] \\
\hline $\begin{array}{c}\mathrm{ZnO} \\
\text { ultraporous } \\
\text { nanoparticle } \\
\text { networks }\end{array}$ & $\begin{array}{l}1.2 \mathrm{~mA} \\
(5 \mathrm{~V})\end{array}$ & $3.61 \mathrm{nA}$ & $3.4 \times 10^{5}$ & - & $\sim 250$ & $\sim 150$ & {$[172]$} \\
\hline $\mathrm{ZnO}$ nanorods & - & - & $1.09 \times 10^{4}$ & 55.5 & 3.1 & 1.25 & [164] \\
\hline $\begin{array}{c}\mathrm{TiO}_{2} \text { nanorod } \\
\text { arrays }\end{array}$ & $\begin{array}{l}249.68 \mu \mathrm{A} \\
(2.5 \mathrm{~V})\end{array}$ & - & - & 13 & - & - & [247] \\
\hline $\begin{array}{l}\mathrm{TiO}_{2} \text { nanorod } \\
\text { flower-like } \\
\text { structure } \\
\text { (cellulose } \\
\text { substrate) }\end{array}$ & $\begin{array}{c}3.78 \mu \mathrm{A} \\
(10 \mathrm{~V})\end{array}$ & $0.15 \mu \mathrm{A}$ & 25.2 & $3.310^{-7}$ & - & - & [246] \\
\hline $\mathrm{WO}_{3}$ nanosheets & $2.5 \times 10^{-5} \mathrm{~A}$ & - & $2 \times 10^{3}$ & 293 & 0.04 & $\sim 0.08$ & [331] \\
\hline $\mathrm{WO}_{3}$ nanowires & $\begin{array}{c}0.1 \mathrm{nA} \\
(1 \mathrm{~V})\end{array}$ & $17.2 \mathrm{nA}$ & 172 & - & $\sim 70$ & $\sim 140$ & [333] \\
\hline $\mathrm{WO}_{3}$ nanobelts & $\begin{array}{l}12 \mathrm{nA} \\
(5 \mathrm{~V})\end{array}$ & $12 \mathrm{~Pa}$ & $1 \times 10^{3}$ & $2.6 \times 10^{5}$ & - & - & [334] \\
\hline $\begin{array}{c}3 \mathrm{D} \\
\mathrm{WO}_{3} \text { nanoshale }\end{array}$ & $\begin{array}{l}4.5 \mu \mathrm{A} \\
(20 \mathrm{~V})\end{array}$ & - & - & 5.1 & 6.3 & 0.5 & [335] \\
\hline $\begin{array}{c}\mathrm{WO}_{3} \\
\text { nanodiscs/rGO }\end{array}$ & $\begin{array}{c}\sim 1.1 \mu \mathrm{A} \\
(20 \mathrm{~V})\end{array}$ & - & - & 6.4 & 0.013 & 0.016 & [330] \\
\hline $\begin{array}{c}\mathrm{CuO} / \mathrm{Si} \\
\text { nanowire array } \\
\text { heterojunction }\end{array}$ & $\begin{array}{c}0.96 \mu \mathrm{A} \\
(0 \mathrm{~V})\end{array}$ & - & - & $3.89 \times 10^{-4}$ & $6 \times 10^{-5}$ & $8 \times 10^{-5}$ & [439] \\
\hline $\begin{array}{c}\mathrm{CuO} \\
\text { nanowire/ZnO } \\
\text { branched } \\
\text { nanowires } \\
\text { heterojuntion }\end{array}$ & $\begin{array}{c}\sim 1.7 \mathrm{~mA} \\
\quad(1 \mathrm{~V})\end{array}$ & $\sim 0.7 \mathrm{~mA}$ & 2.43 & 0.123 & - & - & [440] \\
\hline $\begin{array}{c}\mathrm{Cu}_{2} \mathrm{O} \text { film } / \mathrm{ZnO} \\
\text { nanowire }\end{array}$ & $\begin{array}{c}\sim 0.5 \mu \mathrm{A} \\
(2 \mathrm{~V})\end{array}$ & - & - & $\sim 50$ & - & - & [441] \\
\hline $\mathrm{SnO}_{2}$ nanowire & $\begin{array}{c}2.1 \mu \mathrm{A} \\
(1 \mathrm{~V})\end{array}$ & $19.4 \mathrm{nA}$ & 108 & - & - & - & [533] \\
\hline
\end{tabular}




\begin{tabular}{|c|c|c|c|c|c|c|c|}
\hline $\begin{array}{c}\mathrm{SnO}_{2} \text { nanowire } \\
\text { arrays }\end{array}$ & $\begin{array}{c}130 \mu \mathrm{A} \\
(12 \mathrm{~V})\end{array}$ & $77 \square \mathrm{A}$ & 1.69 & - & - & - & {$[532]$} \\
\hline $\begin{array}{c}\mathrm{SnO}_{2} \text { hollow } \\
\text { nanospheres }\end{array}$ & $0.01 \mathrm{~A}$ & - & - & 2680 & 38 & 137 & {$[534]$} \\
\hline $\begin{array}{c}\mathrm{SnO}_{2} \text { nanobelts- } \\
\mathrm{Sn} \text { nanodots }\end{array}$ & $\begin{array}{c}1.1 \mathrm{nA} \\
(10 \mathrm{~V})\end{array}$ & $\begin{array}{c}4 \times 10^{-4} \\
\mathrm{nA}\end{array}$ & $2.75 \times 10^{3}$ & 56 & $<0.3$ & $<0.3$ & {$[72]$} \\
\hline $\begin{array}{c}\mathrm{CuO} / \mathrm{SnO}_{2} p-n \\
\text { nanoscale } \\
\text { heterojunctions }\end{array}$ & - & - & - & 10.3 & - & - & {$[536]$} \\
\hline $\begin{array}{c}\mathrm{TiO}_{2} \text { branches } \\
\text { on electrospun } \\
\mathrm{SnO}_{2} \text { nanofibers }\end{array}$ & - & - & 4550 & 0.6 & 0.03 & 0.01 & {$[539]$} \\
$\begin{array}{c}\mathrm{V}_{2} \mathrm{O}_{5} \\
\text { centimeter-long } \\
\text { nanowires }\end{array}$ & $\begin{array}{c}25.8 \mathrm{nA} \\
(1 \mathrm{~V})\end{array}$ & $12.5 \mathrm{nA}$ & 2.06 & $\sim 482$ & - & - & {$[590]$} \\
\hline $\mathrm{VO}_{2}$ microwire & - & - & - & 7069 & 0.126 & - & {$[591]$} \\
\hline
\end{tabular}

By analysing Table 5, it is possible to observe that $\mathrm{ZnO}$ and $\mathrm{WO}_{3}$ nanostructures are largely employed in biosensing applications. On the other hand, vanadium oxides are mostly combined with other nanostructures, such as graphene or carbon nanotubes, to form composites, and thus enhance their sensitivity. Zinc oxide is mostly used for detection of glucose, as its high IEP promotes glucose oxidase adhesion. Copper oxides are also highly investigated for glucose detection, presenting high sensitivities and low detection limits. $\mathrm{WO}_{3}$ nanostructured biosensors can detect very low concentrations of analyte and presents high sensitivity to different analytes. Also, $\mathrm{WO}_{3}$ presents chromogenic properties, which enable its use in colorimetric sensors thus allowing production of low-cost disposable biosensors, using cellulose as substrate. Although $\mathrm{TiO}_{2}$ can be used in biosensing applications, the sensitivity presented by this type of nanostructures is very low, showing a very low detection limit. $\mathrm{SnO}_{2}$ nanostructures are used in biosensing when doped or combined with other elements, presenting high sensitivity and low detection limit. 
Table 5. Summary of overall performance of nanostructured metal oxides-based biosensors.

\begin{tabular}{|c|c|c|c|c|c|}
\hline $\begin{array}{c}\text { Metal oxide } \\
\text { nanostructures }\end{array}$ & Analyte & $\begin{array}{c}\text { Analyte } \\
\text { concentration }\end{array}$ & Detection limit & Sensitivity & Ref. \\
\hline $\mathrm{ZnO}$ nanowires & Glucose & 0.03 to $1.52 \mathrm{mM}$ & $9 \mu \mathrm{M}$ & $\begin{array}{c}17 \mu \mathrm{A} / \\
\mathrm{cm}^{2} \mathrm{mM}\end{array}$ & [176] \\
\hline $\mathrm{ZnO}$ nanocombs & Glucose & 0.02 to $4.5 \mathrm{mM}$ & $0,02 \mathrm{mM}$ & $\begin{array}{c}15.33 \\
\mu \mathrm{A} / \mathrm{cm}^{2} \mathrm{mM}\end{array}$ & {$[177]$} \\
\hline $\mathrm{ZnO}$ nanorods & SSEA-4 antibodies & $2 \mathrm{mM}$ & Optical detection & - & [178] \\
\hline $\mathrm{ZnO}$ nanosheetes & Cytochrome $c$ & 1 to $1000 \mu \mathrm{M}$ & $0.1 \mu \mathrm{M}$ & - & [185] \\
\hline $\mathrm{ZnO}$ & $\mathrm{cTnT}$ & 1 to $100 \mathrm{ng} / \mathrm{mL}$ & $0.1 \mathrm{ng} / \mathrm{L}$ & - & [182] \\
\hline $\mathrm{ZnO}$ nanoparticles & cTnI & $\begin{array}{c}1 \mathrm{ng} / \mathrm{mL}-10 \\
\mu \mathrm{g} / \mathrm{mL}\end{array}$ & $2.191 \mathrm{ng} / \mathrm{mL}$ & $\begin{array}{c}15.8 \\
\mathrm{nA}(\mathrm{g} / \mathrm{mL})^{-1}\end{array}$ & [183] \\
\hline $\begin{array}{c}\mathrm{TiO}_{2} \text { nanotubes } \\
\text { arrays }\end{array}$ & immunoglobulin & $115 \mathrm{mg} / \mathrm{mL}$ & $14 \mathrm{ng} / \mathrm{mL}$ & & [223] \\
\hline $\mathrm{TiO}_{2}$ nanotubes & Glucose oxidase & $0.1-6 \mathrm{mM}$ & - & $\begin{array}{c}0.954 \\
\mu \mathrm{A} / \mathrm{cm}^{2} \mathrm{mM}\end{array}$ & [251] \\
\hline $\begin{array}{c}\text { Carbon-doped } \mathrm{TiO}_{2} \\
\text { nanotubes arrays }\end{array}$ & $\begin{array}{l}5- \\
\text { hydroxytryptamine } \\
\text { and ascorbic acid }\end{array}$ & 5 to $150 \mu \mathrm{M}$ & $4.1 \times 10^{-8} \mathrm{M}$ & - & [255] \\
\hline $\begin{array}{l}\text { graphene/ } \mathrm{TiO}_{2} \text { nano } \\
\text { rods/chitosan }\end{array}$ & $\begin{array}{c}\text { Transgenic soybean } \\
\text { sequence of } \\
\text { MON89788 }\end{array}$ & $\begin{array}{c}1.0 \times 10^{-12} \text { to } \\
1.0 \times 10^{-6} \mathrm{~mol} \mathrm{~L}^{-1}\end{array}$ & $\begin{array}{c}7.21 \times 10^{-13} \\
\mathrm{~mol} / \mathrm{L}\end{array}$ & - & [256] \\
\hline $\begin{array}{c}\text { Graphene } \\
\text { nanosheets } / \mathrm{TiO}_{2}\end{array}$ & Glucose oxidase & 0 to $8 \mathrm{mM}$ & - & $\begin{array}{c}6.2 \mu \mathrm{A} / \mathrm{cm}^{2} \\
\mathrm{mM}\end{array}$ & {$[257]$} \\
\hline $\mathrm{TiO}_{2}$ nanoparticles & Laccase & 0.075 to $150 \mu \mathrm{M}$ & $0.75 \mu \mathrm{M}$ & $\begin{array}{c}2.6 \\
\mu \mathrm{A} / \mathrm{cm}^{2} \mu \mathrm{M}\end{array}$ & {$[258]$} \\
\hline $\mathrm{WO}_{3}$ nanoparticles & $\mathrm{c} c \mathrm{NiR}$ & 5 to $50 \mu \mathrm{M}$ & $5 \mu \mathrm{M}$ & $\begin{array}{c}2143 \mathrm{~mA} / \mathrm{cm} \\
{ }^{2} \mathrm{mM}\end{array}$ & [338] \\
\hline $\mathrm{WO}_{3}$ nanoparticles & cytochrome & $\begin{array}{l}3 \times 10^{-7} \text { to } \\
3 \times 10^{-4} \mathrm{M}\end{array}$ & $2.4 \times 10^{-7} \mathrm{M}$ & $\begin{array}{c}63.51 \\
\mathrm{~mA} / \mathrm{cm}^{2} \mathrm{M}\end{array}$ & [339] \\
\hline $\mathrm{WO}_{3}$ nanowires & hemoglobin & 1 to $4200 \mu \mathrm{M}$ & $0.28 \mu \mathrm{M}$ & - & [340] \\
\hline $\mathrm{WO}_{3}$ nanoparticles & dopamine & 0.1 to $600 \mu \mathrm{M}$ & $24 \mathrm{nM}$ & - & [341] \\
\hline $\mathrm{WO}_{3}$ nanoparticles & L-dopa & 0.1 to $1 \mu \mathrm{M}$ & $120 \mathrm{nM}$ & - & [342] \\
\hline $\begin{array}{c}\mathrm{WO}_{3} \\
\text { nanoparticles/carbo } \\
\text { n nanotubes }\end{array}$ & hemoglobin & 60 to $1280 \mu \mathrm{M}$ & $0.07 \mu \mathrm{M}$ & - & [343] \\
\hline $\mathrm{WO}_{3}$ nanoparticles & $\begin{array}{c}\text { Geobacter } \\
\text { Sulfurreducens } \\
\text { cells }\end{array}$ & $15 \mathrm{~g} / \mathrm{L}$ & Optical detection & & [262] \\
\hline Graphene/ $/ \mathrm{WO}_{3}$ & peroxidase & $150 \mu \mathrm{M}$ & $238 \mathrm{nM}$ & $\begin{array}{c}1.306 \\
\mathrm{~mA} / \mathrm{cm}^{2} \mathrm{mM}\end{array}$ & [345] \\
\hline $\begin{array}{l}\mathrm{WO}_{3} \text {-reduced } \\
\text { graphene }\end{array}$ & cysteine & 0.1 to $100 \mu \mathrm{M}$ & $25 \mathrm{nM}$ & - & [347] \\
\hline $\begin{array}{c}\mathrm{Cu}_{2} \mathrm{O} \\
\text { nanocubes/graphen } \\
\text { e nanosheets }\end{array}$ & glucose & 0.3 to $3.3 \mathrm{mM}$ & $3.3 \mu \mathrm{M}$ & - & [442] \\
\hline $\begin{array}{c}\mathrm{Cu}_{2} \mathrm{O} \text { shuriken-like } \\
\text { nanostructures }\end{array}$ & glucose & $\begin{array}{c}0.01 \mu \mathrm{M} \text { to } \\
11.0 \mathrm{mM}\end{array}$ & $0.035 \mu \mathrm{M}$ & $\begin{array}{c}0.933 \mathrm{~mA} / \mathrm{c} \\
\mathrm{m}^{2} \mathrm{mM}\end{array}$ & [444] \\
\hline $\begin{array}{l}\mathrm{Cu}_{2} \mathrm{O} / \text { carbon } \\
\text { quantum dots }\end{array}$ & glucose & 0.02 to $4.3 \mathrm{mM}$ & $8.4 \mu \mathrm{M}$ & - & [447] \\
\hline $\mathrm{CuO}$ & glucose & 1.0 to $170 \mathrm{mM}$ & $0.91 \mathrm{mM}$ & $\begin{array}{c}246 \\
\mathrm{~mA} / \mathrm{cm}^{2} \mathrm{mM}\end{array}$ & [446] \\
\hline $\mathrm{CuO}$ nanotubes & glucose & $5 \mu \mathrm{M}$ to $3.0 \mathrm{mM}$ & $0.1 \mu \mathrm{M}$ & $\begin{array}{c}1.89 \\
\mathrm{~mA} / \mathrm{cm}^{2} \mathrm{mM}\end{array}$ & [448] \\
\hline $\mathrm{CuO}$ nanoparticles & glucose & $0.05-18.45 \mathrm{mM}$ & $\sim 0.5 \mu \mathrm{M}$ & $\begin{array}{c}2762.5 \\
\mu \mathrm{A} / \mathrm{cm}^{2} \mathrm{mM}\end{array}$ & [449] \\
\hline $\mathrm{CuO}$ nanoparticles & glucose & 0.1 to $6.5 \mathrm{mM}$ & $0.5 \mu \mathrm{M}$ & $\begin{array}{c}2419.8 \\
\mu \mathrm{A} / \mathrm{cm}^{2} \mathrm{mM}\end{array}$ & {$[450]$} \\
\hline
\end{tabular}




\begin{tabular}{|c|c|c|c|c|c|}
\hline $\mathrm{CuO}$ nanoparticles & Uric acid & $0.05 \mathrm{mM}$ to $1.0 \mathrm{mM}$ & $0.14 \mathrm{mM}$ & $\begin{array}{c}2.7 \mathrm{~mA} / \mathrm{cm}^{2} \\
\mathrm{mM}\end{array}$ & [445] \\
\hline $\mathrm{ZnO}-\mathrm{CuO}$ & cholosterol & 0.12 to $12.93 \mathrm{mM}$ & - & $\begin{array}{c}680 \mu \mathrm{A} / \mathrm{cm}^{2} \\
\mathrm{mM}\end{array}$ & [451] \\
\hline $\mathrm{ZnO}-\mathrm{CuO}$ & glucose & up to $8.45 \mathrm{mM}$ & $0.40 \mu \mathrm{M}$ & $\begin{array}{c}2961.7 \mu \mathrm{A} / \mathrm{c} \\
\mathrm{m}^{2} \mathrm{mM}\end{array}$ & [443] \\
\hline $\mathrm{SnO}_{2}$ nanorods & $\mathrm{H}_{2} \mathrm{O}_{2}$ & 50 to $200 \mathrm{mg} / \mathrm{L}$ & $0.2 \mu \mathrm{M}$ & $\begin{array}{c}379 \\
\mu \mathrm{A} / \mathrm{cm}^{2} \mathrm{mM}\end{array}$ & {$[542]$} \\
\hline $\mathrm{SnO}_{2}: \mathrm{Sb}$ nanowires & $\mathrm{H}_{2} \mathrm{O}_{2}$ & - & $0.8 \mu \mathrm{M}$ & $\begin{array}{c}100 \\
\mathrm{~mA} / \mathrm{cm}^{2} \mathrm{M}\end{array}$ & {$[544]$} \\
\hline $\begin{array}{c}\mathrm{ZnO} / \mathrm{SnO}_{2} \\
\text { heterostructured }\end{array}$ & $\mathrm{H}_{2} \mathrm{O}_{2}$ & $\begin{array}{l}2.0 \times 10^{-6} \text { to } \\
3.7 \times 10^{-4} \mathrm{M}\end{array}$ & $0.46 \mu \mathrm{M}$ & $\begin{array}{c}52.8 \\
\mathrm{~mA} / \mathrm{cm}^{2} \mathrm{M}\end{array}$ & {$[548]$} \\
\hline $\begin{array}{c}\text { Graphene/SnO2 } \\
\text { nanosheets }\end{array}$ & Glucose & 2 to $20 \mathrm{mM}$ & - & $\begin{array}{c}20.3 \\
\mu \mathrm{A} / \mathrm{cm}^{2} \mathrm{mM}\end{array}$ & [549] \\
\hline $\begin{array}{c}\text { Carbon } \\
\text { nanotubes } / \mathrm{SnO}_{2} / \text { gra } \\
\text { phene/chitosan }\end{array}$ & $\begin{array}{l}\text { Lysine oxidase } \\
\text { enzyme }\end{array}$ & 0.99 to $160 \mu \mathrm{M}$ & $0.15 \mu \mathrm{M}$ & $\begin{array}{c}55.20 \\
\mu \mathrm{A} / \mathrm{cm}^{2} \mathrm{mM}\end{array}$ & {$[553]$} \\
\hline $\mathrm{V}_{2} \mathrm{O}_{5}: \mathrm{Ni}$ & dopamine & 6.6 to $96.4 \mu \mathrm{M}$ & $28 \mathrm{nM}$ & $\begin{array}{c}132 \\
\mathrm{nA} / \mathrm{cm}^{2} \mu \mathrm{M}\end{array}$ & {$[595]$} \\
\hline $\begin{array}{c}\mathrm{V}_{2} \mathrm{O}_{5} \text { fuctionalized } \\
\text { with } \mathrm{Ag}\end{array}$ & Mucin1 & $\begin{array}{c}10 \mathrm{fg} / \mathrm{mL} \text { to } 10 \\
\mathrm{ng} / \mathrm{mL}\end{array}$ & $3.33 \mathrm{fg} / \mathrm{mL}$ & - & [596] \\
\hline $\begin{array}{c}\text { Chitosan } / \mathrm{V}_{2} \mathrm{O}_{5} / \text { carb } \\
\text { on nanotubes }\end{array}$ & DNA & $\begin{array}{l}1.0 \times 10^{-11} \text { to } \\
1.0 \times 10^{-6} \mathrm{M}\end{array}$ & $1.76 \times 10^{-12} \mathrm{M}$ & - & [598] \\
\hline $\begin{array}{c}\text { Chitosan } / \mathrm{V}_{2} \mathrm{O}_{5} / \text { carb } \\
\text { on nanotubes }\end{array}$ & methyglyxal & 0.1 to $100 \mu \mathrm{M}$ & $2 \mathrm{nM}$ & $\begin{array}{r}1130.86 \\
\mu \mathrm{A} / \mathrm{cm}^{2} \mathrm{M} \\
\end{array}$ & [594] \\
\hline
\end{tabular}

\section{Field-effect transistor structures for sensing applications}

\subsection{Advantages and challenges of sensing with (oxide nanostructure) field-effect transistors}

While the oxide nanostructures exposed in the previous sections enable by themselves remarkable sensing performance, potential for miniaturization, parallel sensing, faster response time, improved selectivity and sensitivity and seamless integration with electronic manufacturing processes can be greatly enhanced when sensing is based on field-effect transistors (FETs) [601, 602]. In fact, and considering that oxide nanostructures can be grown on or transferred to FETs at low temperatures, the FET sensing approach seems to be perfectly tailored for the so-called system-on-foil concepts, combining the advantages of both "More Moore" (small size, high speed) and "More than Moore" (multifunctional) paths [603].

The great advantage of nanostructures compared to thin films of bulk materials for sensing was already extensively demonstrated throughout this review paper and naturally 
these advantages are also extended to FET structures. Nanowires have been the selected nanostructure for most of the FET sensors reported so far. From a device point of view, two main reasons can be pointed out for this: first, they enable the confinement of charge transport essentially along one direction of the nanostructure, assuring improved electrical properties [604]; second, due to their 1D shape nanowires are easier to integrate between two electrodes (source and drain) [603].

Fabrication of FET sensors involves more processing steps than conventional conductometric sensors, requiring integration of an extra terminal (gate), electrically insulated from the oxide semiconductor nanostructure by a gate dielectric. As in conventional nanowire FETs, different device structures can be conceived for FET sensors, such as back-gate, top-gate, horizontal or vertical surrounding-gate [605]. The back-gate nanowire FET, depicted in Figure 26, is the most widely explored FET structure for sensing. While it potentiates an inefficient gate control of the drain-to-source current (IDS) across the nanowire due to non-uniform electrostatic contact of a nanowire with a planar dielectric, this structure has at least two great advantages for sensing applications: first, its straightforward fabrication. In fact, considering the simpler approach, the FET sensors can be fabricated by drop-casting a solution containing dispersed nanostructures in a solvent on a highly-doped $\mathrm{Si}$ substrate (gate) having a thermally grown $\mathrm{SiO}_{2}$ layer. Then, source-drain electrodes can be defined on the edges of a single nanowire following a pick-and-place approach, e.g., using photolithography and e-beam evaporation; second, a back-gate configuration enables the nanowire surface to be readily exposed to the surrounding ambient, which is crucial to explore most of the sensing mechanisms. 


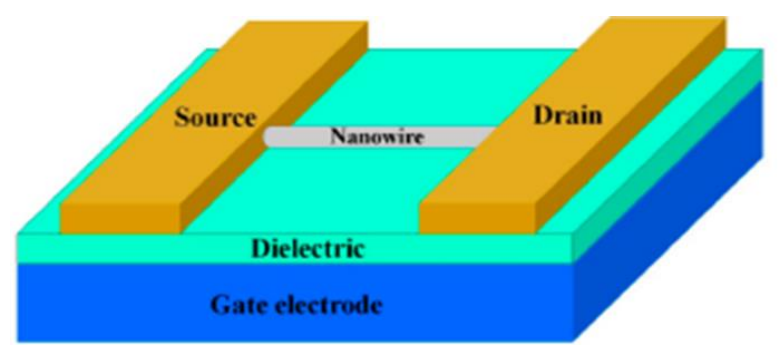

Figure 26. Schematic cross section of a back-gate nanowire FET. Reproduced with permission of MDPI (2018) [602].

This last argument brings a very interesting comparison to nanowire FETs used for electronic applications, which is particularly relevant when considering oxide nanostructures as the heart of these sensors: while on "electronic FETs" intense research has been carried out to block the interaction between oxide nanostructure surface and the surrounding environment, as it is well known that this can greatly affect device performance [606], in sensing FETs the nanowire's surface is intentionally left to interact with the ambient. Nevertheless, one should naturally understand that for both types of nanowire FETs the control of existing surface defect states by routes as doping, annealing or ozone treatments is a crucial requirement to establish stable and reliable platforms to work with [607, 608].

Many successful attempts to use FETs sensors based on oxide nanostructures have been reported during the last decades. While a detailed review on this topic would constitute an extensive document on its own and is thus out of the scope of the present review article, oxide nanostructure-based FETs are too relevant to be left out of any comprehensive review on oxide sensors. As such the next subsection presents major considerations on what has been perhaps the most active research area regarding sensing with oxide nanowire FETs: gas sensors. The reason for narrowing the discussion to a single type of sensors is that most of the concepts exposed can be the eadily applied to other types, where sensing also relies on interactions at the oxide nanostructure surface, given that those interactions will eventually affect carrier concentration which is one key 
aspect governing the properties measured on a FET. Based on this concept, significantly improved sensing performance when FET structures are used have been shown for humidity, UV and biosensors [92, 609, 610].

\subsection{Gas sensing with oxide nanowire field-effect transistors}

FETs for gas sensing have been studied for more than four decades. Back in 1975, Lundstrom et al. demonstrated hydrogen sensing on a Si-based metal oxide semiconductor FET (MOSFET), demonstrating that the threshold voltage $\left(\mathrm{V}_{\mathrm{T}}\right)$ of the device was a function of hydrogen partial pressure [611]. At this point it is worth noticing that MOSFET gas sensors reported by many other researchers since this initial report work under a different principle compared to the oxide nanowire-based FET sensors under discussion in this section. While MOSFET gas sensors rely on catalytic interaction between a metal gate and gas molecules, which results in a measurable change of IDS within the Si channel of a conventional MOSFET, oxide nanowire-based FET sensors rely on the direct interaction between the oxide semiconductor and the gas. This interaction (adsorption or desorption of gas molecules) leads to multiple measurable changes on device characteristics, such as $I_{D S}, V_{T}$, mobility $(\mu)$ and subthreshold swing (S) $[602,612,613]$. These effects are a consequence of variation of the carrier concentration within the nanowire as the gas-nanowire interactions occur. Considering an n-type oxide nanowire (e.g., $\mathrm{SnO}_{2}, \mathrm{ZnO}, \mathrm{In}_{2} \mathrm{O}_{3}$ ), oxidizing and reducing gas environments will result in decreased and increased carrier concentration, respectively. While this is also seen on two-terminal oxide nanowire-based conductometric gas sensors, the gate-tosource voltage $\left(\mathrm{V}_{\mathrm{GS}}\right)$ in FET gas sensors can significantly enhance these effects, i.e., taking the device to operate with a specific $\mathrm{V}_{\mathrm{GS}}$ can result in very large sensor sensitivity. This arises as a consequence of the free carrier concentration modulation by $\mathrm{V}_{\mathrm{GS}}$, which in turn affects the rate and extent of oxidation/reduction reactions taking place at the oxide 
nanowire surface $[614,615]$. By operating the FET sensor at its subthreshold regime these effects are maximized, given that channel carriers are substantially depleted and thus, conductance changes caused by gas adsorption become much more significant [612].

The effect of $V_{G S}$ on the carrier concentration also brings another advantage to FETbased gas sensors, which is the ability to operate at considerably lower temperatures than conductometric gas sensors: the latter are typically operated at $200-500{ }^{\circ} \mathrm{C}$ to decrease response and recovery times, given that gas adsorption/desorption are thermally-activated processes. As these response/recovery times are carrier concentration dependent, FETbased gas sensors can even operate at room temperature, as demonstrated with several $n$ type oxide semiconductor nanowires [612]. For instance, while the reported limits of $\mathrm{NO}_{2}$ detection for individual $\mathrm{In}_{2} \mathrm{O}_{3}$ nanowire resistor sensors are $\approx 500 \mathrm{ppb}$ at an operating temperature of $400{ }^{\circ} \mathrm{C}, \operatorname{In}_{2} \mathrm{O}_{3}$ nanowire FET sensors exhibit limits of detection of $20 \mathrm{ppb}$ at room temperature $[615,616]$, which is even lower than the $53 \mathrm{ppb}$ required for monitoring of air quality standards $[613,615]$. This brings significant advantages, such as low power consumption, longer device lifetime and reduced explosion hazards [612, $614]$.

Despite the proven advantage of $\mathrm{V}_{\mathrm{GS}}$ control for sensing performance, other methods have also been used to enhance nanowire FET gas sensors. The most striking examples are nanoparticle decoration of the nanowire, local heating and light irradiation.

$\mathrm{Pd}, \mathrm{Pt}, \mathrm{Ag}, \mathrm{Au}, \mathrm{ZnO}$ and $\mathrm{NiO}$ nanoparticles have been used to modify the surface of oxide nanowires, resulting in improved sensitivity of FET sensors [617]. Two examples are shown in the figure below, one for $\mathrm{NiO}$-functionalized $\mathrm{SnO}_{2}$ nanowires used for $\mathrm{CO}$ detection [618] and another for Pd-coated $\mathrm{SnO}_{2}$ nanowires used for $\mathrm{H}_{2}$ detection [619]. The proposed mechanisms for these significant improvements are based on the created heterojunctions or Schottky barrier-type junctions (nanowire-nanoparticle), resulting in 
the formation of depletion regions or even purely chemical catalytic effect when considering nanoparticles of noble metals [612].
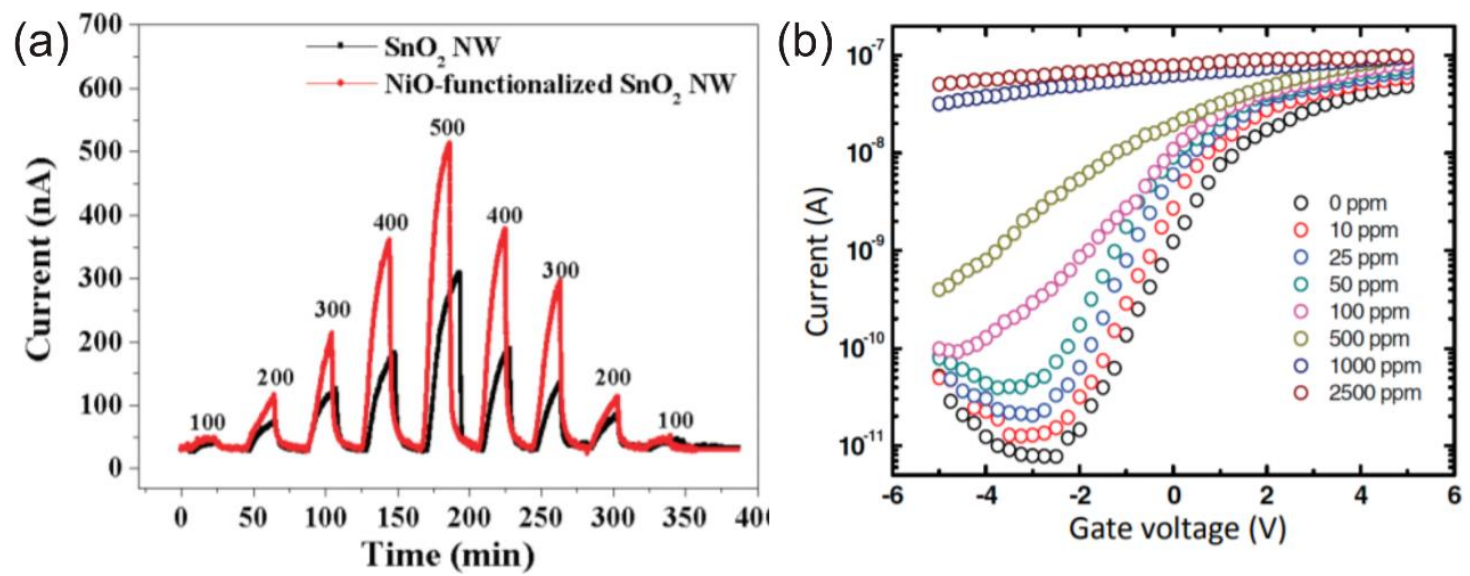

Figure 27. Enhancements on FET gas sensor sensitivity by functionalization of $\mathrm{SnO}_{2}$ nanowires: (a) response curve for pure and $\mathrm{NiO}$-functionalized $\mathrm{SnO}_{2}$ nanowire-based sensor to $\mathrm{CO}$, for a concentration of detected gas between 100 and $500 \mathrm{ppm}$, and operation temperature of $250{ }^{\circ} \mathrm{C}$; (b) transfer characteristics of $\mathrm{Pd}$-functionalized $\mathrm{SnO}_{2}$ nanowire channel under different $\mathrm{H}_{2}$ partial pressures, for operation temperature of $100{ }^{\circ} \mathrm{C}$. Reproduced with permission of ACS publishing "Copyright (2018) American Chemical Society" [618] and Wiley [619].

A good example on how gas selectivity can be enhanced using the combined effect of $\mathrm{V}_{\mathrm{GS}}$ and local heating was given by Dattoli et al. [620] with $\mathrm{SnO}_{2}$ nanowire FET sensors and volatile organic compound analytes. By treating temperature- and gatedependent analyte response variations as an identifying "fingerprint", an average recognition rate of $98 \%$ was achieved using a statistical pattern recognition procedure. This value dropped to $76.7 \%$ for measurements with gate in the grounded state.

The effect of light irradiation can also be quite relevant to achieve faster FET gas sensors. For instance, this was demonstrated already in 2002 for $\mathrm{SnO}_{2}$ nanobelt FETs, by illumination with UV light with energy near the $\mathrm{SnO}_{2}$ bandgap. Law et al. [621] concluded that the UV-generated carriers accelerated desorption velocity of $\mathrm{NO}_{2}$ on the device . Similar effects were reported when using $\operatorname{In}_{2} \mathrm{O}_{3}$ nanowires [615]. 
An extensive list of oxide nanowire FET sensors based on $\mathrm{SnO}_{2}, \mathrm{ZnO}, \mathrm{In}_{2} \mathrm{O}_{3}, \mathrm{Ga}_{2} \mathrm{O}_{3}$ or $\mathrm{Fe}_{2} \mathrm{O}_{3}$ using the advantages of FET structures for sensing mentioned above have been demonstrated for detection of several gas molecules, such as $\mathrm{NO}_{2}, \mathrm{NH}_{3}, \mathrm{CO}, \mathrm{H}_{2}, \mathrm{H}_{2} \mathrm{~S}$, $\mathrm{CH}_{4}$ and $\mathrm{O}_{2}$. In some cases, limits of detection in ppb range and response/recovery times of few seconds, were possible to achieve thus enabling real-time monitoring,. Detailed reviews on this can be found for instance in $[612,614,622]$.

A last note should be considered regarding the feasibility of bringing these oxide nanowire FET sensors to large-scale manufacturing. The pick-and-place methodology used to prepare most of the nano-FET structures reported in literature is indeed a serious limitation, requiring selection of a single wire for deposition/patterning of source-drain electrodes. A process enabling direct growth of oxide semiconductor nanowires with controlled density on a receiver substrate, without requiring any transfer methods, would surely be desirable to overcome this limitation. A good example on how to achieve this was reported by Zhang et al. [615]. The authors used $\mathrm{Si} / \mathrm{SiO}_{2}$ substrates with tuned catalytic particle density to grow $\operatorname{In}_{2} \mathrm{O}_{3}$ nanowires by laser ablation. With this a network with multiple wires was obtained, which could then be contacted using standard photolithography and metal deposition, as shown in the figure below. Besides the simplified fabrication process and compatibility with large-scale manufacturing, these multiwire gas sensors also offer improved sensitivity to $\mathrm{NO}_{2}$ and selectivity between $\mathrm{NO}_{2}$ and $\mathrm{NH}_{3}$ than single wire devices (Figures $28 \mathrm{c}$ and d). Selectivity reached $5 \mathrm{ppb}$, as compared to $20 \mathrm{ppb}$ of single wire FETs, which was tentatively attributed to the formation of nanowire/nanowire junctions within the network, with associated depletion layers. Regarding selectively, it was associated with the possibility of having conductance changes in opposite directions upon exposure to $\mathrm{NH}_{3}$ owing to a specific doping level distribution within the network. 

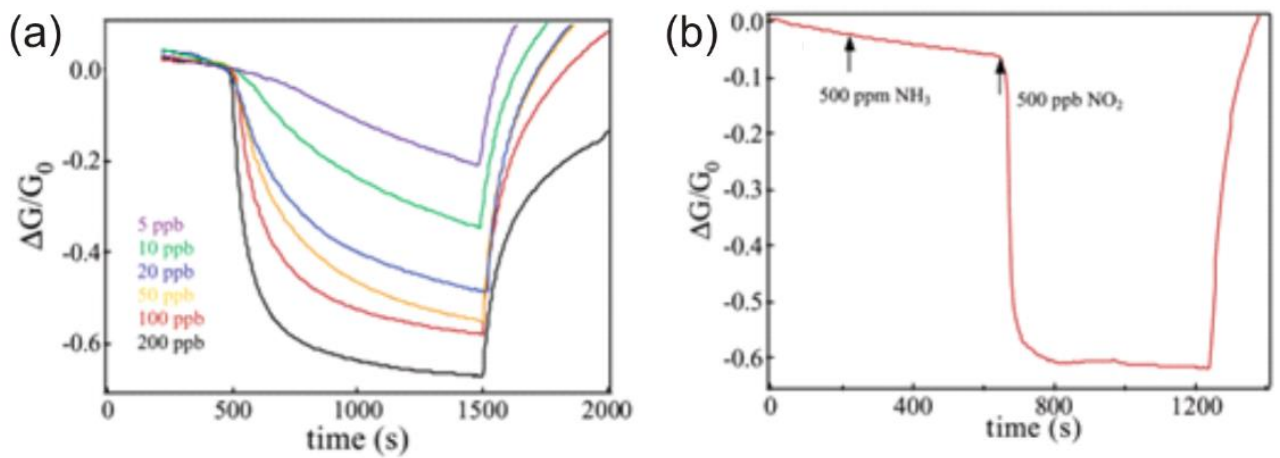

(c)

(d)
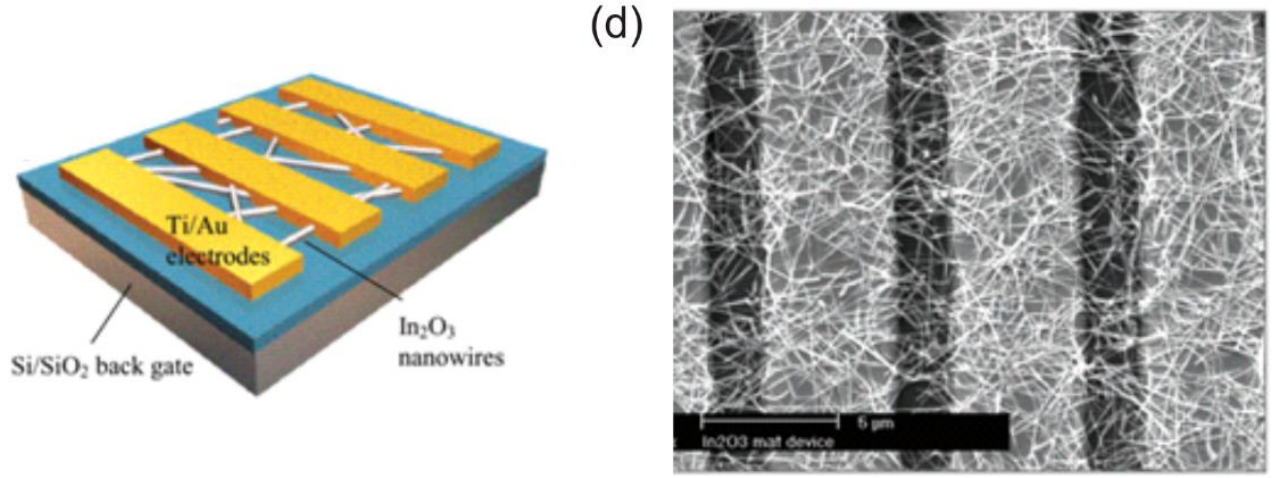

Figure 28. Multiwire $\operatorname{In}_{2} \mathrm{O}_{3}$ FET gas sensor: (a) schematic of device structure; (b) top-view scanning electron microscope image of the device; (c) sensing cycles corresponding to $\mathrm{NO}_{2}$ concentrations between 5 and $200 \mathrm{ppb}$; (d) selective sensing to $\mathrm{NH}_{3}$ and $\mathrm{NO}_{2}$. Reproduced with permission of ACS publishing “Copyright (2018) American Chemical Society” [615].

Nonetheless, for integration in low-temperature and even flexible substrates, reliable transfer or direct growth methods of oxide nanowires that are compatible with the low thermal budgets need to be implemented. This is still one of the major bottlenecks inhibiting advances of flexible oxide nanoelectronics [603].

\section{Conclusions and future perspectives}

This review presented and summarized the latest advances in sensing technologies, focusing in four types of sensors, i.e. gas, humidity, UV and biosensors. This work was centered in semiconductor metal oxides at the nanoscale, which potentiates sensors performance due to nanomaterials intrinsic properties such as, high surface-to-volume ratios and high surface reaction activity. The selected metal oxides have in common the fact that these are earth abundant, low-cost, nontoxic and compatible with wet-chemical 
synthesis routes. The sensing mechanisms of the presented sensors and the general properties of the selected metal oxides have been discussed in detail. It has been demonstrated that distinct nanostructures, such as nanowires, nanotubes, core-shell nanostructures, nanosheets, nanofibers, nanocubes, nanospheres, amongst others, are the path for novel and enhanced sensor materials. The main limitations of the current sensors have been addressed, and several approaches to increase materials' sensitivity and general sensor behaviour have been discussed, which included the effect of doping and combination with other metal oxides to produce nanocomposites or carbon-based materials. A last section on FET-based sensing showed that the extra gate electrode of these structures compared to two-terminal sensors enables significant improvements on sensor performance, namely on sensitivity, selectivity and response/recovery time. However, large scale manufacturing of oxide nanostructure FET sensors on flexible substrates still requires major advances on reliable routes to obtain controlled density of high-quality networks of nanostructures on those substrates.

In terms of future perspectives, the scientific community has been focused on the development of innovative synthesis strategies capable of specifically tuning the metal oxide structures at the nanoscale, as well as their intrinsic properties. For example, this could be observed in the evolution of UV sensors with single 1D nanostructures that originated high performance devices. These nanostructures are expected to diminish defect density and thus facilitate transport of carriers in the nanostructures, which enables high external quantum efficiency and fast response time.

Miniaturization of sensors maintaining or increasing sensor sensitivity and selectivity is also one of the major concerns of researchers nowadays, as well the production of flexible and low-priced systems. The use of inexpensive, lightweight, abundant, recyclable, and environmentally friendly substrates, such as polymer and paper-based 
materials, is a reliable way to produce the next generation sensing devices expected to be highly adaptable, disposable, eco-friendly, sustainable and recyclable smart products. Moreover, these substrates allow large-scale production of devices and can be easily associated to printing methods.

In the near future, it is expected flexible sensing devices capable of being incorporated into opto-electronic smart devices such as solar cells, in a way that all these technologies can emerge into a broad range of low-cost and disposable consumer products to our everyday life. The flexibility and conformability of this new generation of sensors will allow them to become part of the Internet of Things (IoT) revolution, providing wellbeing, satisfaction and comfort to the final users.

\section{Acknowledgments}

This work was supported by FEDER funds, through the COMPETE 2020 Program, and national funds, through the Fundação para Ciência e Tecnologia (FCT), under the projects POCI-01-0145-FEDER-007688 (Reference UID/CTM/50025). The authors also acknowledge funding from the European Commission through the projects 1D-NEON (H2020-NMP-2015, grant 685758-21D) and BET-EU (H2020-TWINN-2015, grant 692373), as well as from the European Research Council through the Starting Grant given to P. Barquinha (TREND, grant 716510). The work was also partially funded by the Nanomark collaborative project between INCM (Imprensa Nacional - Casa da Moeda) and CENIMAT/i3N. D. Nunes and A. Pimentel acknowledge funding from FCT through the grants SFRH/BPD/84215/2012 and SFRH/BPD/76992/2011, respectively. 


\section{References}

[1] Li J-Y, Xu Q, Li G, Yin Y-X, Wan L-J and Guo Y-G 2017 Research progress regarding Si-based anode materials towards practical application in high energy density Li-ion batteries Materials Chemistry Frontiers 1 1691-708

[2] Nunes D, Vilarigues M, Correia J B and Carvalho P A 2012 Nickel-carbon nanocomposites: Synthesis, structural changes and strengthening mechanisms Acta Materialia $60737-47$

[3] Khan I, Saeed K and Khan I 2017 Nanoparticles: Properties, applications and toxicities Arabian Journal of Chemistry

[4] Zhang Q, Zhang K, Xu D, Yang G, Huang H, Nie F, Liu C and Yang S 2014 CuO nanostructures: Synthesis, characterization, growth mechanisms, fundamental properties, and applications Progress in Materials Science 60 208-337

[5] Vaseem M, Umar A and Hahn Y-B 2010 ZnO nanoparticles: growth, properties, and applications Metal oxide nanostructures and their applications 5 1-36

[6] Roduner E 2006 Size matters: why nanomaterials are different Chemical Society Reviews 35 583-92

[7] Pitkethly M J 2004 Nanomaterials - the driving force Materials Today 7 20-9

[8] Yu R, Lin Q, Leung S-F and Fan Z 2012 Nanomaterials and nanostructures for efficient light absorption and photovoltaics Nano Energy 1 57-72

[9] Nunes D, Pimentel A, Santos L, Barquinha P, Fortunato E and Martins R 2017 Photocatalytic $\mathrm{TiO} 2$ Nanorod Spheres and Arrays Compatible with Flexible Applications Catalysts 760

[10] Nunes D, Pimentel A, Pinto J V, Calmeiro T R, Nandy S, Barquinha P, Pereira L, Carvalho P A, Fortunato E and Martins R 2016 Photocatalytic behavior of TiO2 films synthesized by microwave irradiation Catalysis Today 278, Part 2 262-70 
[11] Nunes D, Pimentel A, Barquinha P, Carvalho P A, Fortunato E and Martins R $2014 \mathrm{Cu} 2 \mathrm{O}$ polyhedral nanowires produced by microwave irradiation J. Mater. Chem. C 2 6097-103

[12] Wu H B, Chen J S, Hng H H and Wen Lou X 2012 Nanostructured metal oxidebased materials as advanced anodes for lithium-ion batteries Nanoscale 4 252642

[13] Pimentel A, Samouco A, Nunes D, Araújo A, Martins R and Fortunato E 2017 Ultra-Fast Microwave Synthesis of ZnO Nanorods on Cellulose Substrates for UV Sensor Applications Materials 101308

[14] Pimentel A, Rodrigues J, Duarte P, Nunes D, Costa F M, Monteiro T, Martins R and Fortunato E 2015 Effect of solvents on $\mathrm{ZnO}$ nanostructures synthesized by solvothermal method assisted by microwave radiation: a photocatalytic study Journal of Materials Science $\mathbf{5 0} 5777-87$

[15] Kolmakov A and Moskovits M 2004 Chemical sensing and catalysis by onedimensional metal-oxide nanostructures Annu. Rev. Mater. Res. 34 151-80

[16] Devan R S, Patil R A, Lin J-H and Ma Y-R 2012 One-Dimensional Metal-Oxide Nanostructures: Recent Developments in Synthesis, Characterization, and Applications Advanced Functional Materials 22 3326-70

[17] Yu X, Marks T J and Facchetti A 2016 Metal oxides for optoelectronic applications Nat Mater 15 383-96

[18] Fernández-García M and Rodriguez J A 2011 Encyclopedia of Inorganic and Bioinorganic Chemistry: John Wiley \& Sons, Ltd)

[19] Guo T, Yao M-S, Lin Y-H and Nan C-W 2015 A comprehensive review on synthesis methods for transition-metal oxide nanostructures CrystEngComm 17 $3551-85$ 
[20] Walia S, Balendhran S, Nili H, Zhuiykov S, Rosengarten G, Wang Q H, Bhaskaran M, Sriram S, Strano M S and Kalantar-zadeh K 2013 Transition metal oxides - Thermoelectric properties Progress in Materials Science 58 1443-89

[21] Wang C, Yin L, Zhang L, Xiang D and Gao R 2010 Metal Oxide Gas Sensors: Sensitivity and Influencing Factors Sensors 102088

[22] Phanichphant S 2014 Semiconductor Metal Oxides as Hydrogen Gas Sensors Procedia Engineering 87 795-802

[23] Lin J, Heo Y-U, Nattestad A, Sun Z, Wang L, Kim J H and Dou S X 2014 3D hierarchical rutile $\mathrm{TiO} 2$ and metal-free organic sensitizer producing dyesensitized solar cells 8.6\% conversion efficiency Scientific reports 45769

[24] Kardarian K, Nunes D, Sberna P M, Ginsburg A, Keller D A, Pinto J V, Deuermeier J, Anderson A Y, Zaban A and Martins R 2016 Effect of Mg doping on $\mathrm{Cu} 2 \mathrm{O}$ thin films and their behavior on the $\mathrm{TiO} 2 / \mathrm{Cu} 2 \mathrm{O}$ heterojunction solar cells Solar Energy Materials and Solar Cells 147 27-36

[25] Pavan M, Rühle S, Ginsburg A, Keller D A, Barad H-N, Sberna P M, Nunes D, Martins R, Anderson A Y and Zaban A 2015 TiO 2/Cu 2 O all-oxide heterojunction solar cells produced by spray pyrolysis Solar Energy Materials and Solar Cells 132 549-56

[26] Fukai Y, Kondo Y, Mori S and Suzuki E 2007 Highly efficient dye-sensitized $\mathrm{SnO} 2$ solar cells having sufficient electron diffusion length Electrochemistry Communications 9 1439-43

[27] Dinh N N, Oanh N T T, Long P D, Bernard M C and Hugot-Le Goff A 2003 Electrochromic properties of $\mathrm{TiO} 2$ anatase thin films prepared by a dipping solgel method Thin Solid Films $\mathbf{4 2 3}$ 70-6 
[28] Santos L, Wojcik P, Pinto J V, Elangovan E, Viegas J, Pereira L, Martins R and Fortunato E 2015 Structure and Morphologic Influence of WO3 Nanoparticles on the Electrochromic Performance of Dual-Phase a-WO3/WO3 Inkjet Printed Films Advanced Electronic Materials 1 1400002-n/a

[29] Santos L, Neto J, Crespo A, Baião P, Barquinha P, Pereira L, Martins R and Fortunato E 2015 Electroplating of Nanostructures: InTech)

[30] Park M S, Wang G X, Kang Y M, Wexler D, Dou S X and Liu H K 2007 Preparation and electrochemical properties of $\mathrm{SnO} 2$ nanowires for application in lithium-ion batteries Angewandte Chemie 119 764-7

[31] Liu Y and Yang Y 2016 Recent Progress of TiO2-Based Anodes for Li Ion Batteries Journal of Nanomaterials 201615

[32] Wang X, Cao X, Bourgeois L, Guan H, Chen S, Zhong Y, Tang D M, Li H, Zhai T and Li L 2012 N-Doped Graphene-SnO2 Sandwich Paper for HighPerformance Lithium-Ion Batteries Advanced Functional Materials 22 2682-90

[33] Subalakshmi P and Sivashanmugam A $2017 \mathrm{CuO}$ nano hexagons, an efficient energy storage material for Li- ion battery application Journal of Alloys and Compounds 690 523-31

[34] Nakata K and Fujishima A 2012 TiO2 photocatalysis: Design and applications Journal of Photochemistry and Photobiology C: Photochemistry Reviews 13 16989

[35] Schneider J, Matsuoka M, Takeuchi M, Zhang J, Horiuchi Y, Anpo M and Bahnemann D W 2014 Understanding TiO2 Photocatalysis: Mechanisms and Materials Chemical Reviews 114 9919-86 
[36] Jin X, Xu J, Wang X, Xie Z, Liu Z, Liang B, Chen D and Shen G 2014 Flexible TiO2/cellulose acetate hybrid film as a recyclable photocatalyst RSC Advances 4 $12640-8$

[37] Sunada K, Kikuchi Y, Hashimoto K and Fujishima A 1998 Bactericidal and Detoxification Effects of TiO2 Thin Film Photocatalysts Environmental Science \& Technology 32 726-8

[38] Vukoje I, Kovač T, Džunuzović J, Džunuzović E, Lončarević D, Ahrenkiel S P and Nedeljković J M 2016 Photocatalytic Ability of Visible-Light-Responsive TiO2 Nanoparticles The Journal of Physical Chemistry C 120 18560-9

[39] Bai J and Zhou B 2014 Titanium Dioxide Nanomaterials for Sensor Applications Chemical Reviews 114 10131-76

[40] Bernacka-Wojcik I, Senadeera R, Wojcik P J, Silva L B, Doria G, Baptista P, Aguas H, Fortunato E and Martins R 2010 Inkjet printed and “doctor blade” TiO2 photodetectors for DNA biosensors Biosensors and Bioelectronics 25 1229-34

[41] Zhang J, Liu J, Peng Q, Wang X and Li Y 2006 Nearly monodisperse Cu2O and $\mathrm{CuO}$ nanospheres: preparation and applications for sensitive gas sensors Chemistry of materials 18 867-71

[42] Raible I, Burghard M, Schlecht U, Yasuda A and Vossmeyer T 2005 V2O5 nanofibres: novel gas sensors with extremely high sensitivity and selectivity to amines Sensors and Actuators B: Chemical 106 730-5

[43] Ansari A A, Alhoshan M, Alsalhi M and Aldwayyan A 2010 Biosensors: InTech)

[44] Tiemann M 2007 Porous Metal Oxides as Gas Sensors Chemistry - A European Journal $138376-88$

[45] Chen Z and Lu C 2005 Humidity sensors: a review of materials and mechanisms Sensor letters $3274-95$ 
[46] Liu Z, Li F, Li S, Hu C, Wang W, Wang F, Lin F and Wang H 2015 Fabrication of UV photodetector on TiO2/diamond film Scientific reports 5

[47] Solanki P R, Kaushik A, Agrawal V V and Malhotra B D 2011 Nanostructured metal oxide-based biosensors Npg Asia Materials 317

[48] Liu A 2008 Towards development of chemosensors and biosensors with metaloxide-based nanowires or nanotubes Biosensors and Bioelectronics 24 167-77

[49] Dey A 2018 Semiconductor metal oxide gas sensors: A review Materials Science and Engineering: B 229 206-17

[50] Huang J and Wan Q 2009 Gas sensors based on semiconducting metal oxide onedimensional nanostructures Sensors 9 9903-24

[51] Afzal A, Cioffi N, Sabbatini L and Torsi L 2012 NOx sensors based on semiconducting metal oxide nanostructures: progress and perspectives Sensors and Actuators B: Chemical 171 25-42

[52] Liu X, Cheng S, Liu H, Hu S, Zhang D and Ning H 2012 A Survey on Gas Sensing Technology Sensors 129635

[53] Mishra S, Ghanshyam C, Ram N, Bajpai R P and Bedi R K 2004 Detection mechanism of metal oxide gas sensor under UV radiation Sensors and Actuators B: Chemical 97 387-90

[54] Wan Q, Li Q, Chen Y, Wang T-H, He X, Li J and Lin C 2004 Fabrication and ethanol sensing characteristics of $\mathrm{ZnO}$ nanowire gas sensors Applied Physics Letters 84 3654-6

[55] Wan X, Wang J, Zhu L and Tang J 2014 Gas sensing properties of $\mathrm{Cu} 2 \mathrm{O}$ and its particle size and morphology-dependent gas-detection sensitivity Journal of Materials Chemistry A 2 13641-7 
[56] Tang H, Prasad K, Sanjines R and Levy F 1995 TiO2 anatase thin films as gas sensors Sensors and Actuators-B-Chemical Biochemical Sensors 26 71-5

[57] Li X-L, Lou T-J, Sun X-M and Li Y-D 2004 Highly sensitive WO3 hollow-sphere gas sensors Inorganic chemistry $\mathbf{4 3} 5442-9$

[58] Seal S and Shukla S 2002 Nanocrystalline SnO gas sensors in view of surface reactions and modifications JOM 54 35-8

[59] Raj A D, Pazhanivel T, Kumar P S, Mangalaraj D, Nataraj D and Ponpandian N 2010 Self assembled V2O5 nanorods for gas sensors Current Applied Physics 10 $531-7$

[60] Staerz A, Berthold C, Russ T, Wicker S, Weimar U and Barsan N 2016 The oxidizing effect of humidity on WO3 based sensors Sensors and Actuators B: Chemical 237 54-8

[61] Zhang J, Qin Z, Zeng D and Xie C 2017 Metal-oxide-semiconductor based gas sensors: screening, preparation, and integration Physical Chemistry Chemical Physics 19 6313-29

[62] Wetchakun K, Samerjai T, Tamaekong N, Liewhiran C, Siriwong C, Kruefu V, Wisitsoraat A, Tuantranont A and Phanichphant S 2011 Semiconducting metal oxides as sensors for environmentally hazardous gases Sensors and Actuators B: Chemical $160580-91$

[63] Steele J J, Taschuk M T and Brett M J 2008 Nanostructured Metal Oxide Thin Films for Humidity Sensors IEEE Sensors Journal 8 1422-9

[64] Su P-G and Huang L-N 2007 Humidity sensors based on $\mathrm{TiO} 2$ nanoparticles/polypyrrole composite thin films Sensors and Actuators B: Chemical 123 501-7 
[65] Farahani H, Wagiran R and Hamidon M N 2014 Humidity sensors principle, mechanism, and fabrication technologies: a comprehensive review Sensors $\mathbf{1 4}$ $7881-939$

[66] Yang M-Z, Dai C-L and Wu C-C 2014 Sol-Gel Zinc Oxide Humidity Sensors Integrated with a Ring Oscillator Circuit On-a-Chip Sensors 1420360

[67] Chen Z, Xiaohong W, Xuanlin K and Sixing X 2016 High performance flexible ultraviolet photodetectors based on $\mathrm{TiO} 2$ /graphene hybrid for irradiation monitoring applications Journal of Micromechanics and Microengineering 26 075003

[68] Tian W, Lu H and Li L 2015 Nanoscale ultraviolet photodetectors based on onedimensional metal oxide nanostructures Nano Research 8 382-405

[69] Alsultany F H, Hassan Z and Ahmed N M 2016 A high-sensitivity, fast-response, rapid-recovery UV photodetector fabricated based on catalyst-free growth of $\mathrm{ZnO}$ nanowire networks on glass substrate Optical Materials 60 30-7

[70] Fu Y and Cao W 2006 Preparation of transparent TiO2 nanocrystalline film for UV sensor Chinese Science Bulletin 51 1657-61

[71] Pimentel A, Ferreira S, Nunes D, Calmeiro T, Martins R and Fortunato E 2016 Microwave Synthesized ZnO Nanorod Arrays for UV Sensors: A Seed Layer Annealing Temperature Study Materials 9299

[72] Huang Y, Lin J, Li L, Xu L, Wang W, Zhang J, Xu X, Zou J and Tang C 2015 High performance UV light photodetectors based on Sn-nanodot-embedded $\mathrm{SnO} 2$ nanobelts Journal of Materials Chemistry C 3 5253-8

[73] Liu K, Sakurai M and Aono M 2010 ZnO-Based Ultraviolet Photodetectors Sensors 108604 
[74] Mohanty S P and Kougianos E 2006 Biosensors: a tutorial review IEEE Potentials $2535-40$

[75] Martins T D, Ribeiro A C C, de Camargo H S, da Costa Filho P A, Cavalcante H P M and Dias D L 2013 State of the Art in Biosensors-General Aspects: InTech)

[76] Hasanzadeh M, Shadjou N and de la Guardia M 2015 Iron and iron-oxide magnetic nanoparticles as signal-amplification elements in electrochemical biosensing TrAC Trends in Analytical Chemistry 72 1-9

[77] Arya S K, Wong C C, Jeon Y J, Bansal T and Park M K 2015 Advances in Complementary-Metal-Oxide-Semiconductor-Based Integrated Biosensor Arrays Chemical Reviews 115 5116-58

[78] Mehrotra P 2016 Biosensors and their applications - A review Journal of Oral Biology and Craniofacial Research 6 153-9

[79] Vigneshvar S, Sudhakumari C C, Senthilkumaran B and Prakash H 2016 Recent Advances in Biosensor Technology for Potential Applications - An Overview Frontiers in Bioengineering and Biotechnology 4

[80] Van P T H, Dai D D, Van Duy N, Hoa N D and Van Hieu N 2016 Ultrasensitive NO2 gas sensors using tungsten oxide nanowires with multiple junctions selfassembled on discrete catalyst islands via on-chip fabrication Sensors and Actuators B: Chemical 227 198-203

[81] Alenezi M R, Henley S J and Silva S R P 2015 On-chip Fabrication of High Performance Nanostructured ZnO UV Detectors Scientific Reports 58516

[82] Sun Y-F, Liu S-B, Meng F-L, Liu J-Y, Jin Z, Kong L-T and Liu J-H 2012 Metal Oxide Nanostructures and Their Gas Sensing Properties: A Review Sensors 12 2610 
[83] Shankar P and Rayappan J B B 2015 Gas sensing mechanism of metal oxides: The role of ambient atmosphere, type of semiconductor and gases-A review Sci. Lett. J 4126

[84] Nag P and Sujatha Devi P 2015 SnO2 Based Ceramics for Hydrogen Sensors: Current Status and Perspectives Transactions of the Indian Ceramic Society 74 $129-47$

[85] Hua Z, Li Y, Zeng Y and Wu Y 2018 A theoretical investigation of the powerlaw response of metal oxide semiconductor gas sensors I: Schottky barrier control Sensors and Actuators B: Chemical 255 1911-9

[86] Geistlinger H 1993 Electron theory of thin-film gas sensors Sensors and Actuators B: Chemical 17 47-60

[87] Morrison S R 1987 Mechanism of semiconductor gas sensor operation Sensors and Actuators $11283-7$

[88] Hung C M, Le D T T and Van Hieu N 2017 On-chip growth of semiconductor metal oxide nanowires for gas sensors: A review Journal of Science: Advanced Materials and Devices $263-85$

[89] Comini E, Faglia G and Sberveglieri G 2008 Solid State Gas Sensing: Springer US)

[90] Morimoto T, Nagao M and Tokuda F 1969 Relation between the amounts of chemisorbed and physisorbed water on metal oxides The Journal of Physical Chemistry 73 243-8

[91] Boyle J F and Jones K A 1977 The effects of CO, water vapor and surface temperature on the conductivity of a $\mathrm{SnO} 2$ gas sensor Journal of Electronic Materials 6 717-33 
[92] Kuang Q, Lao C, Wang Z L, Xie Z and Zheng L 2007 High-Sensitivity Humidity Sensor Based on a Single SnO2 Nanowire Journal of the American Chemical Society $1296070-1$

[93] Qian J, Peng Z, Shen Z, Zhao Z, Zhang G and Fu X 2016 Positive impedance humidity sensors via single-component materials Scientific Reports 625574

[94] Yang H, Ye Q, Zeng R, Zhang J, Yue L, Xu M, Qiu Z-J and Wu D 2017 Stable and Fast-Response Capacitive Humidity Sensors Based on a $\mathrm{ZnO}$ Nanopowder/PVP-RGO Multilayer Sensors (Basel, Switzerland) 172415

[95] Wang Z, Gu Y, Qi J, Lu S, Li P, Lin P and Zhang Y 2015 Size dependence and UV irradiation tuning of the surface potential in single conical $\mathrm{ZnO}$ nanowires RSC Advances 5 42075-80

[96] Soci C, Zhang A, Xiang B, Dayeh S A, Aplin D, Park J, Bao X, Lo Y-H and Wang D $2007 \mathrm{ZnO}$ nanowire UV photodetectors with high internal gain Nano letters 7 1003-9

[97] Kind H, Yan H, Messer B, Law M and Yang P 2002 Nanowire Ultraviolet Photodetectors and Optical Switches Advanced Materials 14 158-60

[98] Tian W, Zhang C, Zhai T, Li S-L, Wang X, Liu J, Jie X, Liu D, Liao M, Koide Y, Golberg D and Bando Y 2014 Flexible Ultraviolet Photodetectors with Broad Photoresponse Based on Branched $\mathrm{ZnS}-\mathrm{ZnO}$ Heterostructure Nanofilms Advanced Materials 26 3088-93

[99] Fang X, Bando Y, Liao M, Zhai T, Gautam U K, Li L, Koide Y and Golberg D 2010 An Efficient Way to Assemble ZnS Nanobelts as Ultraviolet-Light Sensors with Enhanced Photocurrent and Stability Advanced Functional Materials 20 $500-8$ 
[100] Grieshaber D, MacKenzie R, Vörös J and Reimhult E 2008 Electrochemical Biosensors - Sensor Principles and Architectures Sensors (Basel, Switzerland) 8 $1400-58$

[101] Li B and Logan B E 2004 Bacterial adhesion to glass and metal-oxide surfaces Colloids and Surfaces B: Biointerfaces 36 81-90

[102] Vicente A T, Araújo A, Gaspar D, Santos L, Marques A C, Mendes M J, Pereira L, Fortunato E and Martins R 2017 Nanostructured Solar Cells: InTech)

[103] Yanagisawa K and Ovenstone J 1999 Crystallization of Anatase from Amorphous Titania Using the Hydrothermal Technique: Effects of Starting Material and Temperature The Journal of Physical Chemistry B 103 7781-7

[104] Vicente A, Araujo A, Mendes M J, Nunes D, Oliveira M J, Sanchez-Sobrado O, Ferreira M P, Aguas H, Fortunato E and Martins R 2018 Multifunctional cellulose-paper for light harvesting and smart sensing applications Journal of Materials Chemistry C 6 3143-81

[105] Coleman V A and Jagadish C 2006 Zinc Oxide Bulk, Thin Films and Nanostructures, (Oxford: Elsevier Science Ltd) pp 1-20

[106] Baruah S and Dutta J 2009 Hydrothermal growth of $\mathrm{ZnO}$ nanostructures Science and Technology of Advanced Materials 10013001

[107] Kumar R, Umar A, Kumar G, Nalwa H S, Kumar A and Akhtar M S 2017 Zinc oxide nanostructure-based dye-sensitized solar cells Journal of Materials Science 52 4743-95

[108] Wen B, Huang Y and Boland J J 2008 Controllable Growth of ZnO Nanostructures by a Simple Solvothermal Process The Journal of Physical Chemistry C 112 106-11 
[109] Alenezi M R, Alshammari A S, Jayawardena K D G I, Beliatis M J, Henley S J and Silva S R P 2013 Role of the Exposed Polar Facets in the Performance of Thermally and UV Activated ZnO Nanostructured Gas Sensors The Journal of Physical Chemistry C 117 17850-8

[110] Tong Y, Liu Y, Dong L, Zhao D, Zhang J, Lu Y, Shen D and Fan X 2006 Growth of $\mathrm{ZnO}$ Nanostructures with Different Morphologies by Using Hydrothermal Technique The Journal of Physical Chemistry B $11020263-7$

[111] Chang J and Waclawik E R 2012 Facet-controlled self-assembly of ZnO nanocrystals by non-hydrolytic aminolysis and their photodegradation activities CrystEngComm 14 4041-8

[112] Zeng J H, Jin B B and Wang Y F 2009 Facet enhanced photocatalytic effect with uniform single-crystalline zinc oxide nanodisks Chemical Physics Letters 472 905

[113] Manthina V and Agrios A G 2016 Single-pot ZnO nanostructure synthesis by chemical bath deposition and their applications Nano-Structures \& Nano-Objects $71-11$

[114] Shaikh S K, Inamdar S I, Ganbavle V V and Rajpure K Y 2016 Chemical bath deposited $\mathrm{ZnO}$ thin film based UV photoconductive detector Journal of Alloys and Compounds $664242-9$

[115] Chaaya A A, Bechelany M, Balme S and Miele P 2014 ZnO 1D nanostructures designed by combining atomic layer deposition and electrospinning for UV sensor applications Journal of Materials Chemistry A 2 20650-8

[116] Preda N, Evanghelidis A, Enculescu M, Florica C and Enculescu I 2015 Zinc oxide electroless deposition on electrospun PMMA fiber mats Materials Letters $138238-42$ 
[117] Di Mauro A, Fragalà M E, Privitera V and Impellizzeri G 2017 ZnO for application in photocatalysis: From thin films to nanostructures Materials Science in Semiconductor Processing 69 44-51

[118] Skompska M and Zarębska K 2014 Electrodeposition of ZnO Nanorod Arrays on Transparent Conducting Substrates-a Review Electrochimica Acta 127 467-88

[119] CATAÑO F A, ALLENDE L W and GÓMEZ H 2015 ELECTRODEPOSITION OF ZnO NANOROD ARRAYS FOR APPLICATION IN PEROVSKITE BASED SOLAR CELLS Journal of the Chilean Chemical Society 60 2940-3

[120] Rodrigues J, Mata D, Pimentel A, Nunes D, Martins R, Fortunato E, Neves A J, Monteiro T and Costa F M 2015 One-step synthesis of ZnO decorated CNT buckypaper composites and their optical and electrical properties Materials Science and Engineering: B 195 38-44

[121] Rodrigues J, Cerqueira A F R, Sousa M G, Santos N F, Pimentel A, Fortunato E, da Cunha A F, Monteiro T and Costa F M 2016 Exploring the potential of laser assisted flow deposition grown $\mathrm{ZnO}$ for photovoltaic applications Materials Chemistry and Physics 177 322-9

[122] Pimentel A, Nunes D, Duarte P, Rodrigues J, Costa F M, Monteiro T, Martins R and Fortunato E 2014 Synthesis of Long ZnO Nanorods under Microwave Irradiation or Conventional Heating The Journal of Physical Chemistry C 118 $14629-39$

[123] Yang J, Lin Y, Meng Y and Liu Y 2012 A two-step route to synthesize highly oriented $\mathrm{ZnO}$ nanotube arrays Ceramics International 38 4555-9

[124] Zhu L, Li J, Ye Z, He H, Chen X and Zhao B 2008 Photoluminescence of Gadoped $\mathrm{ZnO}$ nanorods prepared by chemical vapor deposition Optical Materials $31237-40$ 
[125] Bai S, Chen S, Zhao Y, Guo T, Luo R, Li D and Chen A 2014 Gas sensing properties of $\mathrm{Cd}$-doped $\mathrm{ZnO}$ nanofibers synthesized by the electrospinning method Journal of Materials Chemistry A 2 16697-706

[126] Mahpeykar S M, Koohsorkhi J and Ghafoori-fard H 2012 Ultra-fast microwaveassisted hydrothermal synthesis of long vertically aligned $\mathrm{ZnO}$ nanowires for dyesensitized solar cell application Nanotechnology 23165602

[127] Jia Y, Yu X-Y, Luo T, Zhang M-Y, Liu J-H and Huang X-J 2013 PEG aggregation templated porous $\mathrm{ZnO}$ nanostructure: room temperature solution synthesis, pore formation mechanism, and their photoluminescence properties CrystEngComm $153647-53$

[128] Xu F, Lu Y, Xie Y and Liu Y 2009 Controllable morphology evolution of electrodeposited $\mathrm{ZnO}$ nano/micro-scale structures in aqueous solution Materials \& Design 30 1704-11

[129] Khajavi M R, Blackwood D J, Cabanero G and Tena-Zaera R 2012 New insight into growth mechanism of $\mathrm{ZnO}$ nanowires electrodeposited from nitrate-based solutions Electrochimica Acta 69 181-9

[130] Shi R, Yang P, Wang J, Zhang A, Zhu Y, Cao Y and Ma Q 2012 Growth of flowerlike $\mathrm{ZnO}$ via surfactant-free hydrothermal synthesis on ITO substrate at low temperature CrystEngComm 14 5996-6003

[131] Pimentel A, Fortunato E, Gonçalves A, Marques A, Águas H, Pereira L, Ferreira I and Martins R 2005 Polycrystalline intrinsic zinc oxide to be used in transparent electronic devices Thin Solid Films $\mathbf{4 8 7} 212-5$

[132] Fortunato E M C, Barquinha P M C, Pimentel A C M B G, Gonçalves A M F, Marques A J S, Pereira L M N and Martins R F P 2005 Fully Transparent ZnO 
Thin-Film Transistor Produced at Room Temperature Advanced Materials $590-4$

[133] Byeong-Yun O, Young-Hwan K, Hee-Jun L, Byoung-Yong K, Hong-Gyu P, JinWoo H, Gi-Seok H, Tae-Won K, Kwang-Young K and Dae-Shik S 2011 Highperformance $\mathrm{ZnO}$ thin-film transistor fabricated by atomic layer deposition Semiconductor Science and Technology 26085007

[134] Zong X and Zhu R 2017 Zinc oxide nanorod field effect transistor for long-time cellular force measurement Scientific Reports 743661

[135] Pauporté T 2018 The Future of Semiconductor Oxides in Next-Generation Solar Cells: Elsevier) pp 3-43

[136] Fang J, Fan H, Tian H and Dong G 2015 Morphology control of ZnO nanostructures for high efficient dye-sensitized solar cells Materials Characterization 108 51-7

[137] Duan J, Xiong Q, Wang H, Zhang J and Hu J 2017 ZnO nanostructures for efficient perovskite solar cells Journal of Materials Science: Materials in Electronics 28 60-6

[138] Wang Z L and Song J 2006 Piezoelectric nanogenerators based on zinc oxide nanowire arrays Science 312 242-6

[139] Nour E S, Nur O and Willander M 2017 Zinc oxide piezoelectric nano-generators for low frequency applications Semiconductor Science and Technology 32064005

[140] Opoku C, Dahiya A S, Oshman C, Cayrel F, Poulin-Vittrant G, Alquier D and Camara N 2015 Fabrication of ZnO Nanowire Based Piezoelectric Generators and Related Structures Physics Procedia 70 858-62 
[141] Guo M Y, Fung M K, Fang F, Chen X Y, Ng A M C, Djurišić A B and Chan W $\mathrm{K} 2011 \mathrm{ZnO}$ and $\mathrm{TiO} 2$ 1D nanostructures for photocatalytic applications Journal of Alloys and Compounds $\mathbf{5 0 9}$ 1328-32

[142] Man M T, Kim J-H, Jeong M S, Do A-T T and Lee H S 2017 Oriented ZnO nanostructures and their application in photocatalysis Journal of Luminescence $18517-22$

[143] Pimentel A, Araújo A, Coelho B, Nunes D, Oliveira M, Mendes M, Águas H, Martins R and Fortunato E 2017 3D ZnO/Ag Surface-Enhanced Raman Scattering on Disposable and Flexible Cardboard Platforms Materials 101351

[144] Andreia A, Ana P, Maria João O, Manuel J M, Ricardo F, Elvira F, Hugo Á and Rodrigo M 2017 Direct growth of plasmonic nanorod forests on paper substrates for low-cost flexible 3D SERS platforms Flexible and Printed Electronics 2 014001

[145] Asif M, Danielsson B and Willander M 2015 ZnO Nanostructure-Based Intracellular Sensor Sensors 1511787

[146] Gupta S K, Joshi A and Kaur M 2010 Development of gas sensors using ZnO nanostructures Journal of Chemical Sciences 122 57-62

[147] Basyooni M A, Shaban M and El Sayed A M 2017 Enhanced Gas Sensing Properties of Spin-coated Na-doped ZnO Nanostructured Films Scientific Reports 741716

[148] Iversen K J and Spencer M J S 2013 Effect of ZnO Nanostructure Morphology on the Sensing of H2S Gas The Journal of Physical Chemistry C 117 26106-18

[149] Spencer M J S and Yarovsky I 2010 ZnO Nanostructures for Gas Sensing: Interaction of $\mathrm{NO} 2, \mathrm{NO}, \mathrm{O}$, and $\mathrm{N}$ with the $\mathrm{ZnO}(10 \overline{0})$ Surface The Journal of Physical Chemistry C 114 10881-93 
[150] Jońca J, Ryzhikov A, Kahn M L, Fajerwerg K, Chaudret B, Chapelle A, Menini P and Fau P 2014 Shape-controlled ZnO Nanostructures for Gas Sensing Applications Procedia Engineering 87 907-10

[151] Sadek A Z, Choopun S, Wlodarski W, Ippolito S J and Kalantar-zadeh K 2007 Characterization of $\mathrm{ZnO}$ Nanobelt-Based Gas Sensor for <span class="roman" $>\mathrm{H}</$ span $>\langle$ sub $>2</$ sub $>, \quad<$ span class="roman" $>\mathrm{NO}</$ span $><$ sub $>2</$ sub $>$, and Hydrocarbon Sensing IEEE Sensors Journal 7 919-24

[152] Cho P-S, Kim K-W and Lee J-H 2006 NO2 sensing characteristics of ZnO nanorods prepared by hydrothermal method Journal of Electroceramics 17 975-8

[153] Galstyan V, Comini E, Baratto C, Faglia G and Sberveglieri G 2015 Nanostructured ZnO chemical gas sensors Ceramics International 41 14239-44

[154] Dilonardo E, Penza M, Alvisi M, Di Franco C, Palmisano F, Torsi L and Cioffi N 2016 Evaluation of gas-sensing properties of $\mathrm{ZnO}$ nanostructures electrochemically doped with $\mathrm{Au}$ nanophases Beilstein Journal of Nanotechnology 7 22-31

[155] Li D, Zhang Y, Liu D, Yao S, Liu F, Wang B, Sun P, Gao Y, Chuai X and Lu G 2016 Hierarchical core/shell $\mathrm{ZnO} / \mathrm{NiO}$ nanoheterojunctions synthesized by ultrasonic spray pyrolysis and their gas-sensing performance CrystEngComm $\mathbf{1 8}$ $8101-7$

[156] Wang C, Cui X, Liu J, Zhou X, Cheng X, Sun P, Hu X, Li X, Zheng J and Lu G 2016 Design of Superior Ethanol Gas Sensor Based on Al-Doped NiO NanorodFlowers ACS Sensors 1 131-6 
[157] Ghanem S, Telia A, Boukaous C and Aida M S 2015 Humidity sensor characteristics based on $\mathrm{ZnO}$ nanostructure grown by sol-gel method International Journal of Nanotechnology 12 697-707

[158] Herrán J, Fernández I, Ochoteco E, Cabañero G and Grande H 2014 The role of water vapour in $\mathrm{ZnO}$ nanostructures for humidity sensing at room temperature Sensors and Actuators B: Chemical 198 239-42

[159] 2015 High-performance self-powered/active humidity sensing of Fe-doped $\mathrm{ZnO}$ nanoarray nanogenerator Sensors and Actuators B: Chemical 213382

[160] Yuan Q, Li N, Tu J, Li X, Wang R, Zhang T and Shao C 2010 Preparation and humidity sensitive property of mesoporous $\mathrm{ZnO}-\mathrm{SiO} 2$ composite Sensors and Actuators B: Chemical 149 413-9

[161] Gu L, Zheng K, Zhou Y, Li J, Mo X, Patzke G R and Chen G 2011 Humidity sensors based on $\mathrm{ZnO} / \mathrm{TiO} 2$ core/shell nanorod arrays with enhanced sensitivity Sensors and Actuators B: Chemical 159 1-7

[162] Montesperelli G, Pumo A, Traversa E, Gusmano, Bearzotti A, Montenero A and Gnappi G 1995 Sol—gel processed TiO2-based thin films as innovative humidity sensors Sensors and Actuators B: Chemical 25 705-9

[163] Kim H K, Dattatraya Sathaye S, Hwang Y K, Jhung S H, Hwang J S, Kwon S H, Park S-E and Chang J 2005 Humidity Sensing Properties of Nanoporous TiO2SnO2 Ceramic Sensors vol 26

[164] Park T, Lee K E, Kim N, Oh Y, Yoo J-K and Um M-K 2017 Aspect ratiocontrolled $\mathrm{ZnO}$ nanorods for highly sensitive wireless ultraviolet sensor applications Journal of Materials Chemistry C 5 12256-63 
[165] Dong M, Wang Y, Li Z, Weng Z and Yu N 2018 Simple Fabrication of Homogeneous ZnO Core/Shell Nanorod Arrays for Ultraviolet Photodetectors Journal of Nanoscience and Nanotechnology 18 5686-91

[166] Makhlouf H, Karam C, Lamouchi A, Tingry S, Miele P, Habchi R, Chtourou R and Bechelany M 2018 Analysis of ultraviolet photo-response of $\mathrm{ZnO}$ nanostructures prepared by electrodeposition and atomic layer deposition Applied Surface Science $\mathbf{4 4 4}$ 253-9

[167] Shewale P S, Lee S H and Yu Y S 2018 UV sensitive pulsed laser deposited ZnO thin films: Influence of growth temperature Journal of Alloys and Compounds $\mathbf{7 4 4}$ $849-58$

[168] Yi N, Zhiming Z, Feng T and Xiaosheng F 2018 Novel Transparent and SelfPowered UV Photodetector Based on Crossed ZnO Nanofiber Array Homojunction Small 141703754

[169] Dalvand R, Mahmud S and Shabannia R 2018 Fabrication of UV photodetector using needle-shaped $\mathrm{ZnO}$ nanostructure arrays prepared on porous silicon substrate by a facile low-temperature method Journal of Materials Science: Materials in Electronics 29 4999-5008

[170] Kenanakis G, Vernardou D, Koudoumas E, Kiriakidis G and Katsarakis N 2007 Ozone sensing properties of $\mathrm{ZnO}$ nanostructures grown by the aqueous chemical growth technique Sensors and Actuators B: Chemical 124 187-91

[171] Suo B, Weiwei W, Yong Q, Nuanyang C, J. B D and Xudong W 2011 HighPerformance Integrated ZnO Nanowire UV Sensors on Rigid and Flexible Substrates Advanced Functional Materials 21 4464-9 
[172] Noushin N, Renheng B, Fan W, Lan F and Antonio T 2015 Ultraporous ElectronDepleted ZnO Nanoparticle Networks for Highly Sensitive Portable Visible-Blind UV Photodetectors Advanced Materials 27 4336-43

[173] AlZoubi T, Qutaish H, Al-Shawwa E a and Hamzawy S 2018 Enhanced UV-light detection based on $\mathrm{ZnO}$ nanowires/graphene oxide hybrid using cost-effective low temperature hydrothermal process Optical Materials 77 226-32

[174] Duan L, He F, Tian Y, Sun B, Fan J, Yu X, Ni L, Zhang Y, Chen Y and Zhang W 2017 Fabrication of Self-Powered Fast-Response Ultraviolet Photodetectors Based on Graphene/ZnO:Al Nanorod-Array-Film Structure with Stable Schottky Barrier ACS Applied Materials \& Interfaces 9 8161-8

[175] Liu H, Sun Q, Xing J, Zheng Z, Zhang Z, Lü Z and Zhao K 2015 Fast and Enhanced Broadband Photoresponse of a $\mathrm{ZnO}$ Nanowire Array/Reduced Graphene Oxide Film Hybrid Photodetector from the Visible to the Near-Infrared Range ACS Applied Materials \& Interfaces 7 6645-51

[176] Gallay P, Tosi E, Madrid R, Tirado M and Comedi D 2016 Glucose biosensor based on functionalized $\mathrm{ZnO}$ nanowire/graphite films dispersed on a Pt electrode Nanotechnology 27425501

[177] Wang J X, Sun X W, Wei A, Lei Y, Cai X P, Li C M and Dong Z L 2006 Zinc oxide nanocomb biosensor for glucose detection Applied Physics Letters $\mathbf{8 8}$ 233106

[178] Viter R, Jekabsons K, Kalnina Z, Poletaev N, Hsu S H and Riekstina U 2016 Bioanalytical system for detection of cancer cells with photoluminescent $\mathrm{ZnO}$ nanorods Nanotechnology 27465101 
[179] Shanmugam N R, Muthukumar S and Prasad S 2017 A review on ZnO-based electrical biosensors for cardiac biomarker detection Future Science OA 3 FSO196

[180] Mohammed A M, Ibraheem I J, Obaid A S and Bououdina M 2017 Nanostructured ZnO-based biosensor: DNA immobilization and hybridization Sensing and Bio-Sensing Research 15 46-52

[181] Wahab H A, Salama A A, El Saeid A A, Willander M, Nur O and Battisha I K 2018 Zinc oxide nano-rods based glucose biosensor devices fabrication Results in Physics 9 809-14

[182] Shanmugam N R, Muthukumar S and Prasad S 2016 Ultrasensitive and lowvolume point-of-care diagnostics on flexible strips - a study with cardiac troponin biomarkers Scientific Reports 633423

[183] Tan C M, Arshad M K M, Fathil M F M, Adzhri R, N M N M, Ruslinda A R, Ibau C and Hashim U 2016 Interdigitated Electrodes integrated with zinc oxide nanoparticles for Cardiac Troponin I biomarker detection. In: 2016 IEEE International Conference on Semiconductor Electronics (ICSE), pp 220-3

[184] Bhat S S, Qurashi A and Khanday F A 2017 ZnO nanostructures based biosensors for cancer and infectious disease applications: Perspectives, prospects and promises TrAC Trends in Analytical Chemistry 86 1-13

[185] Rui Q, Komori K, Tian Y, Liu H, Luo Y and Sakai Y 2010 Electrochemical biosensor for the detection of $\mathrm{H} 2 \mathrm{O} 2$ from living cancer cells based on $\mathrm{ZnO}$ nanosheets Analytica Chimica Acta 670 57-62

[186] Negahdary M, Rezaei-Zarchi S, Rousta N and Samei Pour S 2012 Direct Electron Transfer of Cytochrome c on ZnO Nanoparticles Modified Carbon Paste Electrode ISRN Biophysics 20126 
[187] Rathee D, Arya S and Kumar M 2011 Analysis of TiO2 for microelectronic applications: effect of deposition methods on their electrical properties Frontiers of Optoelectronics in China 4 349-58

[188] Di Paola A, Bellardita M and Palmisano L 2013 Brookite, the least known TiO2 photocatalyst Catalysts 3 36-73

[189] Zhang H, Finnegan M and Banfield J F 2001 Preparing Single-Phase Nanocrystalline Anatase from Amorphous Titania with Particle Sizes Tailored by Temperature Nano Letters 1 81-5

[190] Allen N S, Mahdjoub N, Vishnyakov V, Kelly P J and Kriek R J The effect of crystalline phase (anatase, brookite and rutile) and size on the photocatalytic activity of calcined polymorphic titanium dioxide (TiO2) Polymer Degradation and Stability

[191] Rocquefelte X, Goubin F, Koo H-J, Whangbo M-H and Jobic S 2004 Investigation of the Origin of the Empirical Relationship between Refractive Index and Density on the Basis of First Principles Calculations for the Refractive Indices of Various TiO2 Phases Inorganic Chemistry $432246-51$

[192] Pimentel A, Nunes D, Pereira S, Martins R and Fortunato E 2016 Semiconductor Photocatalysis - Materials, Mechanisms and Applications, ed W Cao (Rijeka: InTech) p Ch. 03

[193] Reyes-Coronado D, Rodríguez-Gattorno G, Espinosa-Pesqueira M, Cab C, De Coss R and Oskam G 2008 Phase-pure TiO2 nanoparticles: anatase, brookite and rutile Nanotechnology 19145605

[194] Khan M M, Ansari S A, Pradhan D, Ansari M O, Han D H, Lee J and Cho M H 2014 Band gap engineered $\mathrm{TiO} 2$ nanoparticles for visible light induced 
photoelectrochemical and photocatalytic studies Journal of Materials Chemistry A 2 637-44

[195] George S, Pokhrel S, Ji Z, Henderson B L, Xia T, Li L, Zink J I, Nel A E and Mädler L 2011 Role of Fe Doping in Tuning the Band Gap of TiO2 for the PhotoOxidation-Induced Cytotoxicity Paradigm Journal of the American Chemical Society 133 11270-8

[196] Umebayashi T, Yamaki T, Itoh H and Asai K 2002 Band gap narrowing of titanium dioxide by sulfur doping Applied Physics Letters 81 454-6

[197] Dueñas S, Castán H, García H, Andrés E S, Toledano-Luque M, Mártil I, González-Díaz G, Kukli K, Uustare T and Aarik J 2005 A comparative study of the electrical properties of $\mathrm{TiO} 2$ films grown by high-pressure reactive sputtering and atomic layer deposition Semiconductor Science and Technology 201044

[198] Wypych A, Bobowska I, Tracz M, Opasinska A, Kadlubowski S, KrzywaniaKaliszewska A, Grobelny J and Wojciechowski P 2014 Dielectric Properties and Characterisation of Titanium Dioxide Obtained by Different Chemistry Methods Journal of Nanomaterials 20149

[199] Maziarz W, Kusior A and Trenczek-Zajac A 2016 Nanostructured TiO2-based gas sensors with enhanced sensitivity to reducing gases Beilstein journal of nanotechnology 71718

[200] Mo S-D and Ching W Y 1995 Electronic and optical properties of three phases of titanium dioxide: Rutile, anatase, and brookite Physical Review B 51 13023-32

[201] Antonelli D M and Ying J Y 1995 Synthesis of hexagonally packed mesoporous TiO2 by a modified sol-gel method Angewandte Chemie International Edition in English 34 2014-7 
[202] Xiang L and Zhao X 2017 Wet-Chemical Preparation of TiO(2)-Based Composites with Different Morphologies and Photocatalytic Properties Nanomaterials 7310

[203] Verma R, Gangwar J and Srivastava A K 2017 Multiphase TiO 2 nanostructures: a review of efficient synthesis, growth mechanism, probing capabilities, and applications in bio-safety and health RSC Advances 7 44199-224

[204] Wu J-M, Shih H C, Wu W-T, Tseng Y-K and Chen I C 2005 Thermal evaporation growth and the luminescence property of $\mathrm{TiO} 2$ nanowires Journal of Crystal Growth $281384-90$

[205] Boyadzhiev S, Georgieva V and Rassovska M 2010 Characterization of reactive sputtered TiO2 thin films for gas sensor applications. In: Journal of Physics: Conference Series: IOP Publishing) p 012040

[206] Jiang L C and Zhang W D 2009 Electrodeposition of TiO2 nanoparticles on multiwalled carbon nanotube arrays for hydrogen peroxide sensing Electroanalysis 21 988-93

[207] Lee D, Rho Y, Allen F I, Minor A M, Ko S H and Grigoropoulos C P 2013 Synthesis of hierarchical $\mathrm{TiO} 2$ nanowires with densely-packed and omnidirectional branches Nanoscale 5 11147-52

[208] Yu J, Wang Y and Xiao W 2013 Enhanced photoelectrocatalytic performance of SnO2/TiO2 rutile composite films Journal of Materials Chemistry A 1 10727-35

[209] Zhao X, Liu M and Zhu Y 2007 Fabrication of porous TiO2 film via hydrothermal method and its photocatalytic performances Thin Solid Films $\mathbf{5 1 5}$ 7127-34

[210] Chen Q, Qian Y, Chen Z, Wu W, Chen Z, Zhou G and Zhang Y 1995 Hydrothermal epitaxy of highly oriented $\mathrm{TiO} 2$ thin films on silicon Applied Physics Letters 66 1608-10 
[211] Li G, Wang G and Hong J 1999 Synthesis and characterization of rutile TiO 2 nanowhiskers Journal of materials research 14 3346-54

[212] Zhang X, Wang Y, Liu B, Sang Y and Liu H 2017 Heterostructures construction on TiO2 nanobelts: A powerful tool for building high-performance photocatalysts Applied Catalysis B: Environmental 202 620-41

[213] Yang H G and Zeng H C 2004 Preparation of Hollow Anatase TiO2 Nanospheres via Ostwald Ripening The Journal of Physical Chemistry B 108 3492-5

[214] Ovenstone J and Yanagisawa K 1999 Effect of Hydrothermal Treatment of Amorphous Titania on the Phase Change from Anatase to Rutile during Calcination Chemistry of Materials 11 2770-4

[215] Panigrahi S, Jana S, Calmeiro T, Nunes D, Martins R and Fortunato E 2017 Imaging the Anomalous Charge Distribution Inside $\mathrm{CsPbBr} 3$ Perovskite Quantum Dots Sensitized Solar Cells ACS Nano 11 10214-21

[216] Mor G K, Shankar K, Paulose M, Varghese O K and Grimes C A 2006 Use of highly-ordered TiO2 nanotube arrays in dye-sensitized solar cells Nano letters 6 215-8

[217] Guan K 2005 Relationship between photocatalytic activity, hydrophilicity and self-cleaning effect of TiO2/SiO2 films Surface and Coatings Technology 191 $155-60$

[218] Bozzi A, Yuranova T and Kiwi J 2005 Self-cleaning of wool-polyamide and polyester textiles by $\mathrm{TiO} 2-$-rutile modification under daylight irradiation at ambient temperature Journal of Photochemistry and Photobiology A: Chemistry $17227-34$ 
[219] Ni M, Leung M K, Leung D Y and Sumathy K 2007 A review and recent developments in photocatalytic water-splitting using $\mathrm{TiO} 2$ for hydrogen production Renewable and Sustainable Energy Reviews 11 401-25

[220] Yu J, Low J, Xiao W, Zhou P and Jaroniec M 2014 Enhanced photocatalytic CO2reduction activity of anatase $\mathrm{TiO} 2$ by coexposed $\{001\}$ and $\{101\}$ facets Journal of the American Chemical Society $1368839-42$

[221] Liu L, Zhao H, Andino J M and Li Y 2012 Photocatalytic CO2 reduction with $\mathrm{H} 2 \mathrm{O}$ on $\mathrm{TiO} 2$ nanocrystals: Comparison of anatase, rutile, and brookite polymorphs and exploration of surface chemistry Acs Catalysis 2 1817-28

[222] Ferroni M, Guidi V, Martinelli G, Faglia G, Nelli P and Sberveglieri G 1996 Characterization of a nanosized TiO2 gas sensor Nanostructured materials 7 70918

[223] Mun K-S, Alvarez S D, Choi W-Y and Sailor M J 2010 A stable, label-free optical interferometric biosensor based on TiO2 nanotube arrays ACS Nano 4 2070-6

[224] Cao C, Hu C, Wang X, Wang S, Tian Y and Zhang H 2011 UV sensor based on TiO2 nanorod arrays on FTO thin film Sensors and Actuators B: Chemical 156 $114-9$

[225] Luttrell T, Halpegamage S, Tao J, Kramer A, Sutter E and Batzill M 2014 Why is anatase a better photocatalyst than rutile? - Model studies on epitaxial $\mathrm{TiO}(2)$ films Scientific Reports 44043

[226] Kyu R D, Seok C W, Hoon A S, Harim J and Hak K J 2013 One-step Synthesis of Vertically Aligned Anatase Thornbush-like TiO2 Nanowire Arrays on Transparent Conducting Oxides for Solid-State Dye-Sensitized Solar Cells ChemSusChem 6 1384-91 
[227] Luttrell T, Halpegamage S, Tao J, Kramer A, Sutter E and Batzill M 2014 Why is anatase a better photocatalyst than rutile? - Model studies on epitaxial TiO2 films Scientific Reports 44043

[228] Nakajima H, Mori T, Shen Q and Toyoda T 2005 Photoluminescence study of mixtures of anatase and rutile $\mathrm{TiO} 2$ nanoparticles: Influence of charge transfer between the nanoparticles on their photoluminescence excitation bands Chemical Physics Letters 409 81-4

[229] Wang Y, Li L, Huang X, Li Q and Li G 2015 New insights into fluorinated TiO2 (brookite, anatase and rutile) nanoparticles as efficient photocatalytic redox catalysts RSC Advances 5 34302-13

[230] Xie T, Sullivan N, Steffens K, Wen B, Liu G, Debnath R, Davydov A, Gomez R and Motayed A 2015 UV-assisted room-temperature chemiresistive NO2 sensor based on TiO2 thin film Journal of Alloys and Compounds $\mathbf{6 5 3} 255-9$

[231] Galstyan V 2017 Porous TiO2-Based Gas Sensors for Cyber Chemical Systems to Provide Security and Medical Diagnosis Sensors 172947

[232] Liu C, Lu H, Zhang J, Gao J, Zhu G, Yang Z, Yin F and Wang C 2018 Crystal facet-dependent p-type and n-type sensing responses of $\mathrm{TiO} 2$ nanocrystals Sensors and Actuators B: Chemical 263 557-67

[233] Zhu Z, Lin S-J, Wu C-H and Wu R-J 2018 Synthesis of TiO2 nanowires for rapid NO2 detection Sensors and Actuators A: Physical 272 288-94

[234] Seo M-H, Yuasa M, Kida T, Huh J-S, Shimanoe K and Yamazoe N 2009 Gas sensing characteristics and porosity control of nanostructured films composed of TiO2 nanotubes Sensors and Actuators B: Chemical 137 513-20

[235] Alberti A, Renna L, Sanzaro S, Smecca E, Mannino G, Bongiorno C, Galati C, Gervasi L, Santangelo A and La Magna A 2018 Innovative spongy TiO2 layers 
for gas detection at low working temperature Sensors and Actuators B: Chemical $259658-67$

[236] Ruiz A M, Sakai G, Cornet A, Shimanoe K, Morante J R and Yamazoe N 2003 Cr-doped TiO2 gas sensor for exhaust NO2 monitoring Sensors and Actuators B: Chemical 93 509-18

[237] Dario B, Michael P, Carlo C, Paul M and 2Alessandro M 2008 Gold NanoparticleDoped TiO2 Semiconductor Thin Films: Gas Sensing Properties Advanced Functional Materials 18 3843-9

[238] Carney C M, Yoo S and Akbar S A 2005 TiO2-SnO2 nanostructures and their $\mathrm{H} 2$ sensing behavior Sensors and Actuators B: Chemical 108 29-33

[239] Gong M, Li Y, Guo Y, Lv X and Dou X 2018 2D TiO2 nanosheets for ultrasensitive humidity sensing application benefited by abundant surface oxygen vacancy defects Sensors and Actuators B: Chemical 262 350-8

[240] Lin W-D, Liao C-T, Chang T-C, Chen S-H and Wu R-J 2015 Humidity sensing properties of novel graphene/TiO2 composites by sol-gel process Sensors and Actuators B: Chemical 209 555-61

[241] Su P-G and Wang C-P 2008 Flexible humidity sensor based on TiO2 nanoparticles-polypyrrole-poly-[3-(methacrylamino)propyl] trimethyl ammonium chloride composite materials Sensors and Actuators B: Chemical 129 $538-43$

[242] Ali Hooshiar Z and Somayye M 2011 Silver Doped Titanium Dioxide Humidity Sensor IOP Conference Series: Materials Science and Engineering 17012015

[243] Buvailo A I, Xing Y, Hines J, Dollahon N and Borguet E 2011 TiO2/LiCl-Based Nanostructured Thin Film for Humidity Sensor Applications ACS Applied Materials \& Interfaces 3 528-33 
[244] Monroy E, Omnès F and Calle F 2003 Wide-bandgap semiconductor ultraviolet photodetectors Semiconductor Science and Technology 18 R33

[245] Yu X, Zhao Z, Zhang J, Guo W, Qiu J, Li D, Li Z, Mou X, Li L and Li A 2016 Rutile Nanorod/Anatase Nanowire Junction Array as Both Sensor and Power Supplier for High-Performance, Self-Powered, Wireless UV Photodetector Small $122759-67$

[246] Nunes D, Pimentel A, Araujo A, Calmeiro T, Panigrahi S, Pinto J, Barquinha P, Gama M, Fortunato E and Martins R Enhanced UV Flexible Photodetectors and Photocatalysts Based on TiO 2 Nanoplatforms Topics in Catalysis 1-16

[247] Zou J, Zhang Q, Huang K and Marzari N 2010 Ultraviolet Photodetectors Based on Anodic TiO2 Nanotube Arrays The Journal of Physical Chemistry C 114 10725-9

[248] Jie X, Huiyun W, Er-Jia G and Fang Y 2011 Highly sensitive fast-response UV photodetectors based on epitaxial TiO 2 films Journal of Physics D: Applied Physics 44375104

[249] Yanru X, Lin W, Qinghao L, Yanxue C, Shishen Y, Jun J, Guolei L and Liangmo M 2014 High-performance self-powered UV photodetectors based on TiO 2 nanobranched arrays Nanotechnology 25075202

[250] Zu X, Wang H, Yi G, Zhang Z, Jiang X, Gong J and Luo H 2015 Self-powered UV photodetector based on heterostructured $\mathrm{TiO} 2$ nanowire arrays and polyaniline nanoflower arrays Synthetic Metals 200 58-65

[251] Wang J, Xu G, Zhang X, Lv J, Zhang X, Zheng Z and Wu Y 2015 Electrochemical performance and biosensor application of $\mathrm{TiO} 2$ nanotube arrays with mesoporous structures constructed by chemical etching Dalton Transactions $\mathbf{4 4} 7662-72$ 
[252] Noothongkaew S, Han J K, Lee Y B, Thumthan O and An K-S 2017 Au NPs decorated $\mathrm{TiO} 2$ nanotubes array candidate for UV photodetectors Progress in Natural Science: Materials International 27 641-6

[253] Chen D, Wei L, Meng L, Wang D, Chen Y, Tian Y, Yan S, Mei L and Jiao J 2018 High-Performance Self-Powered UV Detector Based on SnO2-TiO2 Nanomace Arrays Nanoscale Research Letters 1392

[254] Viticoli M, Curulli A, Cusma A, Kaciulis S, Nunziante S, Pandolfi L, Valentini F and Padeletti G 2006 Third-generation biosensors based on TiO2 nanostructured films Materials Science and Engineering: C 26 947-51

[255] Hu L, Huo K, Chen R, Gao B, Fu J and Chu P K 2011 Recyclable and HighSensitivity Electrochemical Biosensing Platform Composed of Carbon-Doped TiO2 Nanotube Arrays Analytical Chemistry 83 8138-44

[256] Hongwei G, Min S, Chao L and Shubai W 2012 Electrochemical DNA Biosensor Based on Graphene and TiO2 Nanorods Composite Film for the Detection of Transgenic Soybean Gene Sequence of MON89788 Electroanalysis 24 2283-90

[257] Jang H D, Kim S K, Chang H, Roh K-M, Choi J-W and Huang J 2012 A glucose biosensor based on TiO2-Graphene composite Biosensors and Bioelectronics 38 $184-8$

[258] Romero-Arcos M, Garnica-Romo M G, Martinez-Flores H E, Vázquez-Marrufo G, Ramírez-Bon R, González-Hernández J and Barbosa-Cánovas G V 2016 Enzyme Immobilization by Amperometric Biosensors with $\mathrm{TiO} 2$ Nanoparticles Used to Detect Phenol Compounds Food Engineering Reviews 8 235-50

[259] Coronado J M, Fresno F, Hernández-Alonso M D and Portela R 2013 Design of Advanced Photocatalytic Materials for Energy and Environmental Applications: Springer London) 
[260] Ramana C V, Utsunomiya S, Ewing R C, Julien C M and Becker U 2006 Structural Stability and Phase Transitions in WO3 Thin Films The Journal of Physical Chemistry B 110 10430-5

[261] Wang L, Huang M, Chen Z, Yang Z, Qiu M, Wang K and Zhang W 2016 pHcontrolled assembly of three-dimensional tungsten oxide hierarchical nanostructures for catalytic oxidation of cyclohexene to adipic acid CrystEngComm 18 8688-95

[262] Marques A C, Santos L, Costa M N, Dantas J M, Duarte P, Gonçalves A, Martins R, Salgueiro C A and Fortunato E 2015 Office Paper Platform for Bioelectrochromic Detection of Electrochemically Active Bacteria using Tungsten Trioxide Nanoprobes Scientific Reports 59910

[263] Li P, Li X, Zhao Z, Wang M, Fox T, Zhang Q and Zhou Y 2016 Correlations among structure, composition and electrochemical performances of WO3 anode materials for lithium ion batteries Electrochimica Acta 192 148-57

[264] Yang J, Li W, Li J, Sun D and Chen Q 2012 Hydrothermal synthesis and photoelectrochemical properties of vertically aligned tungsten trioxide (hydrate) plate-like arrays fabricated directly on FTO substrates Journal of Materials Chemistry 22 17744-52

[265] Fang Z, Jiao S, Wang B, Yin W, Liu S, Gao R, Liu Z, Pang G and Feng S 2017 Synthesis of reduced cubic phase WO3-x nanosheet by direct reduction of H2WO4·H2O Materials Today Energy 6 146-53

[266] Pokhrel S, Birkenstock J, Dianat A, Zimmermann J, Schowalter M, Rosenauer A, Ciacchi L C and Madler L 2015 In situ high temperature X-ray diffraction, transmission electron microscopy and theoretical modeling for the formation of WO3 crystallites CrystEngComm 17 6985-98 
[267] Vogt T, Woodward P M and Hunter B A 1999 The High-Temperature Phases of WO3 Journal of Solid State Chemistry 144 209-15

[268] Solonin Y M, Khyzhun O Y and Graivoronskaya E A 2001 Nonstoichiometric Tungsten Oxide Based on Hexagonal WO3 Crystal Growth \& Design 1 473-7

[269] Sungpanich J, Thongtem T and Thongtem S 2014 Photocatalysis of WO3 Nanoplates Synthesized by Conventional-Hydrothermal and MicrowaveHydrothermal Methods and of Commercial WO3 Nanorods Journal of Nanomaterials 20148

[270] Luo J Y, Gong L, Tan H D, Deng S Z, Xu N S, Zeng Q G and Wang Y 2012 Study of the catalyst poisoning and reactivation of $\mathrm{Pt}$ nanoparticles on the surface of WO3 nanowire in gasochromic coloration Sensors and Actuators B: Chemical 171-172 1117-24

[271] Yu Y, Zeng W and Zhang H 2016 Hydrothermal synthesis of assembled WO3.H2O nanoflowers with enhanced gas sensing performance Materials Letters 171 162-5

[272] Tong H, Xu Y, Cheng X, Zhang X, Gao S, Zhao H and Huo L 2016 One-pot solvothermal synthesis of hierarchical WO3 hollow microspheres with superior lithium ion battery anode performance Electrochimica Acta 210 147-54

[273] Vasudevan V, Thangavel S, Nallamuthu G, Kirubakaran K, Ramasubramanian P A and Venugopal G 2018 Enhanced Photocatalytic Properties of Nanostructured WO3 Semiconductor-Photocatalyst Prepared via Hydrothermal Method Journal of Nanoscience and Nanotechnology 18 3320-8

[274] Nayak A K and Pradhan D 2018 Microwave-Assisted Greener Synthesis of Defect-Rich Tungsten Oxide Nanowires with Enhanced Photocatalytic and 

3183-93

[275] Seung-Myung R and Chunghee N Adsorption Characteristics of Methylene Blue on WO3 Nanorods Prepared by Microwave-Assisted Hydrothermal Methods physica status solidi (a) 01700996

[276] Yun G, Arunachalam M, Kim H-S, Ahn K-S and Kang S H 2018 Role of WO3 Layers Electrodeposited on $\mathrm{SnO} 2$ Inverse Opal Skeletons in Photoelectrochemical Water Splitting The Journal of Physical Chemistry C 122 9729-

[277] Raudoniene J, Laurikenas A, Kaba M M, Sahin G, Morkan A U, Brazinskiene D, Asadauskas S, Seidu R, Kareiva A and Garskaite E 2018 Textured WO3 and WO3:Mo films deposited from chemical solution on stainless steel Thin Solid Films 653 179-87

[278] Cai Z, Liu B, Zou X and Cheng H-M 2018 Chemical Vapor Deposition Growth and Applications of Two-Dimensional Materials and Their Heterostructures Chemical Reviews

[279] Zhang J, Lu H, Yan C, Yang Z, Zhu G, Gao J, Yin F and Wang C 2018 Fabrication of conductive graphene oxide-WO3 composite nanofibers by electrospinning and their enhanced acetone gas sensing properties Sensors and Actuators B: Chemical $264128-38$

[280] Kai S, Fengmei G, Weiyou Y, Enyan W, Zhenxia W and Huilin H 2018 WO3 Mesoporous Nanobelts towards Efficient Photoelectrocatalysts for Water Splitting ChemElectroChem 5 322-7 
[281] Deliang C, Xianxiang H, Hejing W, Yu W, Hailong W, Xinjian L, Rui Z, Hongxia L, Hongliang X, Shaokang G, Jing S and Lian G 2010 The enhanced alcoholsensing response of ultrathin WO 3 nanoplates Nanotechnology 21035501

[282] Xu M, Zeng W, Yang F and Chen L 2015 Controllability of assemblage from WO3 $\cdot \mathrm{H} 2 \mathrm{O}$ nanoplates to nanoflowers with the assistance of oxalic acid Journal of Materials Science: Materials in Electronics 26 6676-82

[283] Kunquan H, Maohai X and Huasheng W 2006 Tungsten oxide nanowires synthesized by a catalyst-free method at low temperature Nanotechnology 17 4830

[284] Huanjun C, Ningsheng X, Shaozhi D, Dongyu L, Zhenglin L, Jun Z and Jun C 2007 Gasochromic effect and relative mechanism of WO 3 nanowire films Nanotechnology 18205701

[285] Jerry Y, Liu Y, Hao W, Mahnaz S, Matthew Richard F, Jia L, Jin Y, Zhi Fu L, Wojtek W, Nunzio M, Yong Xiang L, Gengmin Z, Kourosh K-z and Peter To L 2013 Hydrothermally formed functional niobium oxide doped tungsten nanorods Nanotechnology 24495501

[286] Chih-Hao L, Min Hsiung H, Chi-Yun K and Ing-Chi L 2014 Preparation of WO 3 nanorods by a hydrothermal method for electrochromic device Japanese Journal of Applied Physics 53 06JG8

[287] Hu W, Zhao Y, Liu Z, Dunnill C W, Gregory D H and Zhu Y 2008 Nanostructural Evolution: From One-Dimensional Tungsten Oxide Nanowires to ThreeDimensional Ferberite Flowers Chemistry of Materials 20 5657-65

[288] Wang C, Feng C, Wang M, Li X, Cheng P, Zhang H, Sun Y, Sun P and Lu G 2015 One-pot synthesis of hierarchical WO3 hollow nanospheres and their gas sensing properties RSC Advances 5 29698-703 
[289] Li Y, McMaster W A, Wei H, Chen D and Caruso R A 2018 Enhanced Electrochromic Properties of WO3 Nanotree-like Structures Synthesized via a Two-Step Solvothermal Process Showing Promise for Electrochromic Window Application ACS Applied Nano Materials

[290] He X, Li X, Bi Z, Chen Y, Xu X and Gao X 2018 Dual-functional electrochromic and energy-storage electrodes based on tungsten trioxide nanostructures Journal of Solid State Electrochemistry

[291] Shen L, Luo G, Zheng J and Xu C 2018 Effect of pH on the electrochromic and photoluminescent properties of Eu doped WO3 film Electrochimica Acta 278 $263-70$

[292] Lee-Sie E A, Ming T A W, Xing C, Shlomo M and See L P 2018 Recent Advances in Flexible Electrochromic Devices: Prerequisites, Challenges, and Prospects Energy Technology 6 33-45

[293] Wojcik P J, Santos L, Pereira L, Martins R and Fortunato E 2015 Tailoring nanoscale properties of tungsten oxide for inkjet printed electrochromic devices Nanoscale 7 1696-708

[294] Wojcik P J, Cruz A S, Santos L, Pereira L, Martins R and Fortunato E 2012 Microstructure control of dual-phase inkjet-printed a-WO3/TiO2/WOX films for high-performance electrochromic applications Journal of Materials Chemistry 22 $13268-78$

[295] Pedro B, Sónia P, Luís P, Pawel W, Paul G, Rodrigo M and Elvira F 2015 Flexible and Transparent WO3 Transistor with Electrical and Optical Modulation Advanced Electronic Materials 11500030 
[296] Zhang J, Fu X, Hao H and Gan W 2018 Facile synthesis 3D flower-like Ag@WO3 nanostructures and applications in solar-light photocatalysis Journal of Alloys and Compounds 757 134-41

[297] Sajjad A K L, Sajjad S, Iqbal A and Ryma N-u-A 2018 ZnO/WO3 nanostructure as an efficient visible light catalyst Ceramics International 44 9364-71

[298] Poongodi S, Kumar P S, Mangalaraj D, Ponpandian N, Meena P, Masuda Y and Lee C 2017 Electrodeposition of WO3 nanostructured thin films for electrochromic and $\mathrm{H} 2 \mathrm{~S}$ gas sensor applications Journal of Alloys and Compounds 719 71-81

[299] Ponnusamy R, Gangan A, Chakraborty B and Rout C S 2018 Tuning the pure monoclinic phase of WO3 and WO3-Ag nanostructures for non-enzymatic glucose sensing application with theoretical insight from electronic structure simulations Journal of Applied Physics 123024701

[300] Ponnusamy R, Chakraborty B and Rout C S 2018 Pd-Doped WO3 Nanostructures as Potential Glucose Sensor with Insight from Electronic Structure Simulations The Journal of Physical Chemistry B 122 2737-46

[301] Sone B T, Nkosi S S, Nkosi M M, Coetsee-Hugo E, Swart H C and Maaza M 2018 Self-assembled micro-/nanostructured WO3 thin films by aqueous chemical growth and their applications in $\mathrm{H} 2$ and $\mathrm{CO} 2$ sensing AIP Conference Proceedings 1962040003

[302] Wang C, Sun R, Li X, Sun Y, Sun P, Liu F and Lu G 2014 Hierarchical flowerlike WO3 nanostructures and their gas sensing properties Sensors and Actuators B: Chemical 204 224-30 
[303] Kida T, Nishiyama A, Yuasa M, Shimanoe K and Yamazoe N 2009 Highly sensitive NO2 sensors using lamellar-structured WO3 particles prepared by an acidification method Sensors and Actuators B: Chemical 135 568-74

[304] Wang S-H, Chou T-C and Liu C-C 2003 Nano-crystalline tungsten oxide NO2 sensor Sensors and Actuators B: Chemical 94 343-51

[305] Wang C, Li X, Feng C, Sun Y and Lu G 2015 Nanosheets assembled hierarchical flower-like WO3 nanostructures: Synthesis, characterization, and their gas sensing properties Sensors and Actuators B: Chemical $21075-81$

[306] An S, Park S, Ko H and Lee C 2014 Fabrication of WO3 nanotube sensors and their gas sensing properties Ceramics International 40 1423-9

[307] Hieu N V, Quang V V, Hoa N D and Kim D 2011 Preparing large-scale WO3 nanowire-like structure for high sensitivity $\mathrm{NH} 3$ gas sensor through a simple route Current Applied Physics 11 657-61

[308] Zhang H, Liu Z, Yang J, Guo W, Zhu L and Zheng W 2014 Temperature and acidity effects on WO3 nanostructures and gas-sensing properties of WO3 nanoplates Materials Research Bulletin 57 260-7

[309] Boudiba A, Zhang C, Bittencourt C, Umek P, Olivier M-G, Snyders R and Debliquy M 2012 SO2 Gas Sensors based on WO3 Nanostructures with Different Morphologies Procedia Engineering 47 1033-6

[310] Ionescu R, Hoel A, Granqvist C G, Llobet E and Heszler P 2005 Low-level detection of ethanol and $\mathrm{H} 2 \mathrm{~S}$ with temperature-modulated WO3 nanoparticle gas sensors Sensors and Actuators B: Chemical 104 132-9

[311] Xiang Q, Meng G F, Zhao H B, Zhang Y, Li H, Ma W J and Xu J Q 2010 Au Nanoparticle Modified WO3 Nanorods with Their Enhanced Properties for 
Photocatalysis and Gas Sensing The Journal of Physical Chemistry C 114 204955

[312] Liu X, Zhang J, Yang T, Guo X, Wu S and Wang S 2011 Synthesis of Pt nanoparticles functionalized WO3 nanorods and their gas sensing properties Sensors and Actuators B: Chemical 156 918-23

[313] Li F, Ruan S, Zhang N, Yin Y, Guo S, Chen Y, Zhang H and Li C 2018 Synthesis and characterization of Cr-doped WO3 nanofibers for conductometric sensors with high xylene sensitivity Sensors and Actuators B: Chemical 265 355-64

[314] Chen L and Tsang S C 2003 Ag doped WO3-based powder sensor for the detection of NO gas in air Sensors and Actuators B: Chemical 89 68-75

[315] Qi J, Chen K, Xing Y, Fan H, Zhao H, Yang J, Li L, Yan B, Zhou J, Guo L and Yang S 2018 Application of 3D hierarchical monoclinic-type structural Sb-doped WO3 towards NO2 gas detection at low temperature Nanoscale 10 7440-50

[316] Yu W, Sun Y, Zhang T, Zhang K, Wang S, Chen X and Dai N 2015 CuO/WO3 Hybrid Nanocubes for High-Responsivity and Fast-Recovery H2S Sensors Operated at Low Temperature Particle \& Particle Systems Characterization 33 $15-20$

[317] Chaudhari G N, Bende A M, Bodade A B, Patil S S and Sapkal V S 2006 Structural and gas sensing properties of nanocrystalline TiO2:WO3-based hydrogen sensors Sensors and Actuators B: Chemical 115 297-302

[318] Kumar A, Sanger A, Kumar A and Chandra R 2017 Porous silicon filled with $\mathrm{Pd} / \mathrm{WO} 3-\mathrm{ZnO}$ composite thin film for enhanced $\mathrm{H} 2$ gas-sensing performance $R S C$ Advances 7 39666-75 
[319] Bai S, Li D, Han D, Luo R, Chen A and Chung C L 2010 Preparation, characterization of WO3-SnO2 nanocomposites and their sensing properties for NO2 Sensors and Actuators B: Chemical 150 749-55

[320] An X, Yu J C, Wang Y, Hu Y, Yu X and Zhang G 2012 WO3 nanorods/graphene nanocomposites for high-efficiency visible-light-driven photocatalysis and NO2 gas sensing Journal of Materials Chemistry 22 8525-31

[321] Esfandiar A, Irajizad A, Akhavan O, Ghasemi S and Gholami M R 2014 PdWO3/reduced graphene oxide hierarchical nanostructures as efficient hydrogen gas sensors International Journal of Hydrogen Energy 39 8169-79

[322] Ling M and Leach C 2004 The Effect of Relative Humidity on the NO2 Sensitivity of a SnO2/WO3 Heterojunction Gas Sensor vol 102

[323] Piloto C, Shafiei M, Khan H, Gupta B, Tesfamichael T and Motta N 2018 Sensing performance of reduced graphene oxide-Fe doped WO3 hybrids to NO2 and humidity at room temperature Applied Surface Science 434 126-33

[324] Wang Z, Fan X, Li C, Men G, Han D and Gu F 2018 Humidity-Sensing Performance of 3DOM WO3 with Controllable Structural Modification ACS Applied Materials \& Interfaces $103776-83$

[325] Ramkumar S and Rajarajan G 2017 A comparative study of humidity sensing and photocatalytic applications of pure and nickel (Ni)-doped WO3 thin films Applied Physics A 123401

[326] Zou Z, Qiu Y, Xu J, Guo P and Luo Y 2017 High performance photoelectric responses of nanocrystalline WO3 film to humidity irradiated by UV light Journal of Materials Science: Materials in Electronics 28 15618-24

[327] Dong Y F, Li L Y, Jiang W F, Wang H Y and Li X J 2009 Capacitive humiditysensing properties of electron-beam-evaporated nanophased WO3 film on silicon 
nanoporous pillar array Physica E: Low-dimensional Systems and Nanostructures $41711-4$

[328] Patil D, Seo Y-K, Hwang Y K, Chang J-S and Patil P 2008 Humidity sensitive poly(2,5-dimethoxyaniline)/WO3 composites Sensors and Actuators B: Chemical $132116-24$

[329] Shakya V and Kumar Pandey N 2018 Structural and Moisture Sensing Properties of WO3-ZnO Nanocomposites Synthesized by a Soft Chemical Route Materials Today: Proceedings 5 9082-8

[330] Dali S, Mingpeng Y, Jie L and Shayla S 2013 An ultraviolet photodetector fabricated from WO 3 nanodiscs/reduced graphene oxide composite material Nanotechnology 24295701

[331] Liu J, Zhong M, Li J, Pan A and Zhu X 2015 Few-layer WO3 nanosheets for highperformance UV-photodetectors Materials Letters 148 184-7

[332] Li L, Zhang Y, Fang X, Zhai T, Liao M, Sun X, Koide Y, Bando Y and Golberg D 2011 WO3 nanowires on carbon papers: electronic transport, improved ultraviolet-light photodetectors and excellent field emitters Journal of Materials Chemistry 21 6525-30

[333] Huang K, Zhang Q, Yang F and He D 2010 Ultraviolet photoconductance of a single hexagonal WO3 nanowire Nano Research 3 281-7

[334] He Z, Liu Q, Hou H, Gao F, Tang B and Yang W 2015 Tailored Electrospinning of WO3 Nanobelts as Efficient Ultraviolet Photodetectors with Photo-Dark Current Ratios up to 1000 ACS Applied Materials \& Interfaces 7 10878-85

[335] Shao D, Yu M, Lian J and Sawyer S 2014 Optoelectronic properties of three dimensional WO3 nanoshale and its application for UV sensing Optical Materials 36 1002-5 
[336] Cook B, Liu Q, Butler J, Smith K, Shi K, Ewing D, Casper M, Stramel A, Elliot A and Wu J 2018 Heat-Assisted Inkjet Printing of Tungsten Oxide for HighPerformance Ultraviolet Photodetectors ACS Applied Materials \& Interfaces 10 873-9

[337] Hai Z, Akbari M K, Xue C, Xu H, Hyde L and Zhuiykov S 2017 Wafer-scaled monolayer WO3 windows ultra-sensitive, extremely-fast and stable UV-A photodetection Applied Surface Science 405 169-77

[338] Santos L, Silveira C M, Elangovan E, Neto J P, Nunes D, Pereira L, Martins R, Viegas J, Moura J J G, Todorovic S, Almeida M G and Fortunato E 2016 Synthesis of WO3 nanoparticles for biosensing applications Sensors and Actuators B: Chemical 223 186-94

[339] Deng Z, Gong Y, Luo Y and Tian Y 2009 WO3 nanostructures facilitate electron transfer of enzyme: Application to detection of $\mathrm{H} 2 \mathrm{O} 2$ with high selectivity Biosensors and Bioelectronics 24 2465-9

[340] Liu H, Duan C, Yang C, Chen X, Shen W and Zhu Z 2015 A novel nitrite biosensor based on the direct electron transfer hemoglobin immobilized in the WO3 nanowires with high length-diameter ratio Materials Science and Engineering: C 53 43-9

[341] Anithaa A C, Lavanya N, Asokan K and Sekar C 2015 WO3 nanoparticles based direct electrochemical dopamine sensor in the presence of ascorbic acid Electrochimica Acta 167 294-302

[342] Hariharan V, Radhakrishnan S, Parthibavarman M, Dhilipkumar R and Sekar C 2011 Synthesis of polyethylene glycol (PEG) assisted tungsten oxide (WO3) nanoparticles for 1-dopa bio-sensing applications Talanta 85 2166-74 
[343] Ghodsi J, Rafati A A and Shoja Y 2016 First report on hemoglobin electrostatic immobilization on WO 3 nanoparticles: application in the simultaneous determination of levodopa, uric acid, and folic acid Analytical and bioanalytical chemistry $\mathbf{4 0 8} 3899-909$

[344] Righettoni M, Tricoli A and Pratsinis S E 2010 Si:WO3 Sensors for Highly Selective Detection of Acetone for Easy Diagnosis of Diabetes by Breath Analysis Analytical Chemistry 82 3581-7

[345] Ma Y, Zhao M, Cai B, Wang W, Ye Z and Huang J 2014 3D graphene network@WO3 nanowire composites: a multifunctional colorimetric and electrochemical biosensing platform Chemical Communications 50 11135-8

[346] Li Y, Hsu P-C and Chen S-M 2012 Multi-functionalized biosensor at WO3-TiO2 modified electrode for photoelectrocatalysis of norepinephrine and riboflavin Sensors and Actuators B: Chemical 174 427-35

[347] Sun B, Zhang K, Chen L, Guo L and Ai S 2013 A novel photoelectrochemical sensor based on PPIX-functionalized WO3-rGO nanohybrid-decorated ITO electrode for detecting cysteine Biosensors and Bioelectronics $\mathbf{4 4}$ 48-51

[348] Santos L, Neto J P, Crespo A, Nunes D, Costa N, Fonseca I M, Barquinha P, Pereira L, Silva J, Martins R and Fortunato E 2014 WO3 Nanoparticle-Based Conformable pH Sensor ACS Applied Materials \& Interfaces 6 12226-34

[349] Nunes D, Santos L, Duarte P, Pimentel A, Pinto J V, Barquinha P, Carvalho P A, Fortunato E and Martins R 2014 Room Temperature Synthesis of Cu2O Nanospheres: Optical Properties and Thermal Behavior Microscopy and Microanalysis 21 108-19 
[350] K. M B, A. P, D. R, M. B, P. H, J. K P, Th. S, C. R, J. B, M. E, C. H, M. H, J. B, A. K, S. S, C. M and C. R 2012 Binary copper oxide semiconductors: From materials towards devices physica status solidi (b) 249 1487-509

[351] Ng C H B and Fan W Y 2006 Shape Evolution of Cu2O Nanostructures via Kinetic and Thermodynamic Controlled Growth The Journal of Physical Chemistry B $11020801-7$

[352] Heinemann M, Eifert B and Heiliger C 2013 Band structure and phase stability of the copper oxides $\mathrm{Cu} \$\{\}_{-}\{2\} \$ \mathrm{O}, \mathrm{CuO}$, and $\mathrm{Cu} \$\{\}_{-}\{4\} \$ \mathrm{O} \$\{\}_{-}\{3\} \$$ Physical Review B 87115111

[353] Dhineshbabu N R, Rajendran V, Nithyavathy N and Vetumperumal R 2016 Study of structural and optical properties of cupric oxide nanoparticles Applied Nanoscience $6933-9$

[354] Wang Y, Lany S, Ghanbaja J, Fagot-Revurat Y, Chen Y P, Soldera F, Horwat D, Mücklich F and Pierson J F 2016 Electronic structures of

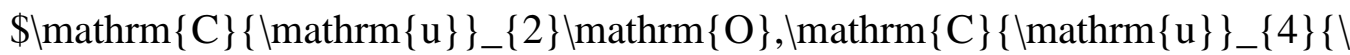
mathrm $\{\mathrm{O}\}\}_{-}\{3\}$ \$, and $\mathrm{CuO}$ : A joint experimental and theoretical study Physical Review B 94245418

[355] Barquinha P, Martins R, Pereira L and Fortunato E 2012 Transparent Oxide Electronics: From Materials to Devices: Wiley)

[356] Nolan M and Elliott S D 2006 The p-type conduction mechanism in Cu2O: a first principles study Physical Chemistry Chemical Physics 8 5350-8

[357] Murali D S, Kumar S, Choudhary R J, Wadikar A D, Jain M K and Subrahmanyam A 2015 Synthesis of $\mathrm{Cu} 2 \mathrm{O}$ from $\mathrm{CuO}$ thin films: Optical and electrical properties AIP Advances 5047143 
[358] Chatterjee S and Pal A J 2016 Introducing Cu2O Thin Films as a Hole-Transport Layer in Efficient Planar Perovskite Solar Cell Structures The Journal of Physical Chemistry C 120 1428-37

[359] Korzhavyi P A and Johansson B 2011 Literature review on the properties of cuprous oxide $\mathrm{Cu} 2 \mathrm{O}$ and the process of copper oxidation: Swedish Nuclear Fuel and Waste Management Company)

[360] Cupric oxide (CuO) crystal structure, lattice parameters: Datasheet from LandoltBörnstein - Group III Condensed Matter · Volume 41C: "Non-Tetrahedrally Bonded Elements and Binary Compounds I" in SpringerMaterials (https://dx.doi.org/10.1007/10681727_51). Springer-Verlag Berlin Heidelberg)

[361] Su D, Xie X, Dou S and Wang G $2014 \mathrm{CuO}$ single crystal with exposed $\{001\}$ facets - A highly efficient material for gas sensing and Li-ion battery applications Scientific Reports 45753

[362] Döring G, Sternemann C, Kaprolat A, Mattila A, Hämäläinen K and Schülke W 2004 Shake-up valence excitations in $\mathrm{CuO}$ by resonant inelastic $x$-ray scattering $\operatorname{vol} 70$

[363] Kuz'menko A, Van der Marel D, Van Bentum P, Tishchenko E, Presura C and Bush A 2001 Infrared spectroscopic study of CuO: Signatures of strong spinphonon interaction and structural distortion Physical Review B 63094303

[364] Gattinoni C and Michaelides A 2015 Atomistic details of oxide surfaces and surface oxidation: the example of copper and its oxides Surface Science Reports $70424-47$

[365] Kevin M, Ong W L, Lee G H and Ho G W 2011 Formation of hybrid structures: copper oxide nanocrystals templated on ultralong copper nanowires for open network sensing at room temperature Nanotechnology 22235701 
[366] Jiang X, Herricks T and Xia Y 2002 CuO Nanowires Can Be Synthesized by Heating Copper Substrates in Air Nano Letters 2 1333-8

[367] Karapetyan A, Reymers A, Giorgio S, Fauquet C, Sajti L, Nitsche S, Nersesyan M, Gevorgyan V and Marine W 2015 Cuprous oxide thin films prepared by thermal oxidation of copper layer. Morphological and optical properties Journal of Luminescence 159 325-32

[368] Figueiredo V, Pinto J V, Deuermeier J, Barros R, Alves E, Martins R and Fortunato E 2013 p-Type <formula formulatype="inline"> <img src="/images/tex/20030.gif" alt=" $\{\text { ไhbox }\{\mathrm{Cu}\}\}_{-}\{\mathrm{x}\}\{$ hhbox $\{\mathrm{O}\}\} "></$ formula $>$ Thin-Film Transistors Produced by Thermal Oxidation Display Technology, Journal of $9735-40$

[369] Figueiredo V, Elangovan E, Gonçalves G, Franco N, Alves E, Park S H K, Martins R and Fortunato E 2009 Electrical, structural and optical characterization of copper oxide thin films as a function of post annealing temperature physica status solidi (a) 206 2143-8

[370] Figueiredo V, Elangovan E, Gonçalves G, Barquinha P, Pereira L, Franco N, Alves E, Martins R and Fortunato E 2008 Effect of post-annealing on the properties of copper oxide thin films obtained from the oxidation of evaporated metallic copper Applied Surface Science 254 3949-54

[371] Nunes D, Calmeiro T R, Nandy S, Pinto J V, Pimentel A, Barquinha P, Carvalho P A, Walmsley J C, Fortunato E and Martins R 2016 Charging effects and surface potential variations of Cu-based nanowires Thin Solid Films 601 45-53

[372] Korshunov A V and Il'in A P 2009 Oxidation of copper nanopowders on heating in air Russian Journal of Applied Chemistry 82 1164-71 
[373] Singh R, Science E S D and Division T 2000 Low and High Dielectric Constant Materials: Materials Science, Processing, and Reliability Issues : Proceedings of the Fourth International Symposium : And, Thin Film Materials for Advanced Packaging Technologies : Proceedings of the Second International Symposium: Electrochemical Society)

[374] Choopun S, Hongsith N and Wongrat E 2010 Metal-oxide nanowires by thermal oxidation reaction technique

\section{INTECH}

[375] Li Y, Liang J, Tao Z and Chen J $2008 \mathrm{CuO}$ particles and plates: Synthesis and gas-sensor application Materials Research Bulletin 43 2380-5

[376] Luévano-Hipólito E, Torres-Martínez L M, Sánchez-Martínez D and Alfaro Cruz M R $2017 \mathrm{Cu} 2 \mathrm{O}$ precipitation-assisted with ultrasound and microwave radiation for photocatalytic hydrogen production International Journal of Hydrogen Energy 42 12997-3010

[377] Lim Y-F, Chua C S, Lee C J J and Chi D 2014 Sol-gel deposited Cu2O and CuO thin films for photocatalytic water splitting Physical Chemistry Chemical Physics $1625928-34$

[378] Mallick P 2014 Synthesis of Copper Oxide Nanocomposite (Cu2O/CuO) by Solgel Route vol 84

[379] Panigrahi S, Nunes D, Calmeiro T, Kardarian K, Martins R and Fortunato E 2017 Oxide-Based Solar Cell: Impact of Layer Thicknesses on the Device Performance ACS combinatorial science 19 113-20

[380] Hossain M A, Al-Gaashani R, Hamoudi H, Al Marri M J, Hussein I A, Belaidi A, Merzougui B A, Alharbi F H and Tabet N 2017 Controlled growth of Cu2O thin 
films by electrodeposition approach Materials Science in Semiconductor Processing 63 203-11

[381] Brandt I S, Tumelero M A, Pelegrini S, Zangari G and Pasa A A 2017 Electrodeposition of Cu2O: growth, properties, and applications Journal of Solid State Electrochemistry 21 1999-2020

[382] Dolai S, Dey R, Das S, Hussain S, Bhar R and Pal A K 2017 Cupric oxide (CuO) thin films prepared by reactive d.c. magnetron sputtering technique for photovoltaic application Journal of Alloys and Compounds 724 456-64

[383] Zhu H, Zhang J, Li C, Pan F, Wang T and Huang B $2009 \mathrm{Cu} 2 \mathrm{O}$ thin films deposited by reactive direct current magnetron sputtering Thin Solid Films $\mathbf{5 1 7}$ $5700-4$

[384] Filipič G and Cvelbar U 2012 Copper oxide nanowires: a review of growth Nanotechnology 23194001

[385] Chen J T, Zhang F, Wang J, Zhang G A, Miao B B, Fan X Y, Yan D and Yan P X $2008 \mathrm{CuO}$ nanowires synthesized by thermal oxidation route Journal of Alloys and Compounds $\mathbf{4 5 4}$ 268-73

[386] Kim Y-S, Hwang I-S, Kim S-J, Lee C-Y and Lee J-H 2008 CuO nanowire gas sensors for air quality control in automotive cabin Sensors and Actuators B: Chemical 135 298-303

[387] Wei M and Huo J 2010 Preparation of $\mathrm{Cu} 2 \mathrm{O}$ nanorods by a simple solvothermal method Materials Chemistry and Physics 121 291-4

[388] Kumar K and Chowdhury A 2017 Facile synthesis of $\mathrm{CuO}$ nanorods obtained without any template and/or surfactant Ceramics International 43 13943-7

[389] Zhang X, Wang G, Liu X and Wu H 2008 Synthesis and electrochemical properties of $\mathrm{CuO}$ nanobelts Materials Chemistry and Physics 112 726-9 
[390] Dan Z, Yang Y, Qin F, Wang H and Chang H 2018 Facile Fabrication of Cu2O Nanobelts in Ethanol on Nanoporous $\mathrm{Cu}$ and Their Photodegradation of Methyl Orange Materials 11446

[391] Mukherjee N, Show B, Maji S K, Madhu U, Bhar S K, Mitra B C, Khan G G and Mondal A $2011 \mathrm{CuO}$ nano-whiskers: Electrodeposition, Raman analysis, photoluminescence study and photocatalytic activity Materials Letters 65 324850

[392] Qu Y, Li X, Chen G, Zhang H and Chen Y 2008 Synthesis of Cu2O nano-whiskers by a novel wet-chemical route Materials Letters $\mathbf{6 2} 886-8$

[393] Chang I C, Chen P-C, Tsai M-C, Chen T-T, Yang M-H, Chiu H-T and Lee C-Y 2013 Large-scale synthesis of uniform $\mathrm{Cu} 2 \mathrm{O}$ nanocubes with tunable sizes by insitu nucleation CrystEngComm 15 2363-6

[394] Navale Y H, Navale S T, Galluzzi M, Stadler F J, Debnath A K, Ramgir N S, Gadkari S C, Gupta S K, Aswal D K and Patil V B 2017 Rapid synthesis strategy of $\mathrm{CuO}$ nanocubes for sensitive and selective detection of NO2 Journal of Alloys and Compounds $\mathbf{7 0 8} 456-63$

[395] Cao Y, Fan J, Bai L, Yuan F and Chen Y 2009 Morphology Evolution of Cu2O from Octahedra to Hollow Structures Crystal Growth \& Design 10 232-6

[396] Feng L, Xuan Z, Bai Y, Zhao H, Li L, Chen Y, Yang X, Su C, Guo J and Chen X 2014 Preparation of octahedral $\mathrm{CuO}$ micro/nanocrystals and electrochemical performance as anode for lithium-ion battery Journal of Alloys and Compounds $600162-7$

[397] Sun S, Zhang X, Song X, Liang S, Wang L and Yang Z 2012 Bottom-up assembly of hierarchical $\mathrm{Cu} 2 \mathrm{O}$ nanospheres: controllable synthesis, formation mechanism and enhanced photochemical activities CrystEngComm 14 3545-53 
[398] Chen W, Li L, Peng Q and Li Y 2012 Polyol synthesis and chemical conversion of $\mathrm{Cu} 2 \mathrm{O}$ nanospheres Nano Res. 5 320-6

[399] Jiang L, You T, Yin P, Shang Y, Zhang D, Guo L and Yang S 2013 Surfaceenhanced Raman scattering spectra of adsorbates on $\mathrm{Cu} 2 \mathrm{O}$ nanospheres: chargetransfer and electromagnetic enhancement Nanoscale 5 2784-9

[400] Zhang J, Liu J, Peng Q, Wang X and Li Y 2006 Nearly Monodisperse Cu2O and $\mathrm{CuO}$ Nanospheres: Preparation and Applications for Sensitive Gas Sensors Chemistry of Materials 18 867-71

[401] H. Z, Q. Z, Y. Z, Y. W, L. Z and B. Y 2007 One-Pot Synthesis and Hierarchical Assembly of Hollow Cu2O Microspheres with Nanocrystals-Composed Porous Multishell and Their Gas-Sensing Properties Advanced Functional Materials 17 2766-71

[402] Scuderi V, Amiard G, Boninelli S, Scalese S, Miritello M, Sberna P M, Impellizzeri G and Privitera V 2016 Photocatalytic activity of $\mathrm{CuO}$ and $\mathrm{Cu} 2 \mathrm{O}$ nanowires Materials Science in Semiconductor Processing 42 89-93

[403] Kumar S, Parlett C M A, Isaacs M A, Jowett D V, Douthwaite R E, Cockett M C R and Lee A F 2016 Facile synthesis of hierarchical Cu2O nanocubes as visible light photocatalysts Applied Catalysis B: Environmental 189 226-32

[404] Rai B P 1988 Cu2O solar cells: A review vol 25

[405] Anandan S, Wen X and Yang S 2005 Room temperature growth of CuO nanorod arrays on copper and their application as a cathode in dye-sensitized solar cells Materials Chemistry and Physics 93 35-40

[406] Bijani S, Gabás M, Martínez L, Ramos-Barrado J R, Morales J and Sánchez L 2007 Nanostructured $\mathrm{Cu} 2 \mathrm{O}$ thin film electrodes prepared by electrodeposition for rechargeable lithium batteries Thin Solid Films 515 5505-11 
[407] Yi-Tao X, Ying G, Hong J, Xiao-Bin X, Bo Z, Peng-Li Z, Xian-Zhu F, Rong S and Ching-Ping W 2015 Enhanced Performance of Lithium-Ion Batteries with Copper Oxide Microspheres @ Graphene Oxide Micro/Nanocomposite Electrodes Energy Technology 3 488-95

[408] Gao P and Liu D 2015 Facile synthesis of copper oxide nanostructures and their application in non-enzymatic hydrogen peroxide sensing Sensors and Actuators B: Chemical 208 346-54

[409] Steinhauer S, Brunet E, Maier T, Mutinati G C, Köck A, Freudenberg O, Gspan C, Grogger W, Neuhold A and Resel R 2013 Gas sensing properties of novel CuO nanowire devices Sensors and Actuators B: Chemical 187 50-7

[410] Zheng X, Ning H, Wenhui L, Yuzhou D, Shuyan G, Ying W, Xiaofeng W, Yingxia L and Yunfa C 2017 Facet-dependent gas sensing properties of $\mathrm{Cu} 2 \mathrm{O}$ crystals physica status solidi (a) 2141600904

[411] Şişman O, Kılınç N and Öztürk Z Z 2015 H2 Sensing Properties of Cu2O Nanowires on Glass Substrate Procedia Engineering 120 1170-4

[412] Tang N, Chen B, Xia Y, Chen D and Jiao X 2015 Facile synthesis of Cu2O nanocages and gas sensing performance towards gasoline RSC Advances 5 544338

[413] H. J A, P. S and Guo K 2009 Methane gas sensor application of cuprous oxide synthesized by thermal oxidation physica status solidi (a) $206332-7$

[414] Umar A, Alshahrani A A, Algarni H and Kumar R 2017 CuO nanosheets as potential scaffolds for gas sensing applications Sensors and Actuators B: Chemical 250 24-31 
[415] Yang C, Xiao F, Wang J and Su X 2015 3D flower- and 2D sheet-like CuO nanostructures: Microwave-assisted synthesis and application in gas sensors Sensors and Actuators B: Chemical 207 177-85

[416] Taubert A, Stange F, Li Z, Junginger M, Günter C, Neumann M and Friedrich A $2012 \mathrm{CuO}$ Nanoparticles from the Strongly Hydrated Ionic Liquid Precursor (ILP) Tetrabutylammonium Hydroxide: Evaluation of the Ethanol Sensing Activity ACS Applied Materials \& Interfaces 4 791-5

[417] Li Z, Wang J, Wang N, Yan S, Liu W, Fu Y Q and Wang Z 2017 Hydrothermal synthesis of hierarchically flower-like $\mathrm{CuO}$ nanostructures with porous nanosheets for excellent $\mathrm{H} 2 \mathrm{~S}$ sensing Journal of Alloys and Compounds $\mathbf{7 2 5}$ $1136-43$

[418] Hsueh H, Chang S, Hung F, Weng W, Hsu C, Hsueh T, Lin S and Dai B 2011 Ethanol gas sensor of crabwise $\mathrm{CuO}$ nanowires prepared on glass substrate Journal of The Electrochemical Society 158 J106-J9

[419] Liu X, Zhang J, Kang Y, Wu S and Wang S 2012 Brochantite tabular microspindles and their conversion to wormlike $\mathrm{CuO}$ structures for gas sensing CrystEngComm 14 620-5

[420] Choi Y-H, Kim D-H, Han H S, Shin S, Hong S-H and Hong K S 2014 Direct Printing Synthesis of Self-Organized Copper Oxide Hollow Spheres on a Substrate Using Copper(II) Complex Ink: Gas Sensing and Photoelectrochemical Properties Langmuir 30 700-9

[421] Samarasekara P, Kumara N T R N and Yapa N U S 2006 Sputtered copper oxide $(\mathrm{CuO})$ thin films for gas sensor devices Journal of Physics: Condensed Matter 18 2417 
[422] Zhang Y-B, Yin J, Li L, Zhang L-X and Bie L-J 2014 Enhanced ethanol gassensing properties of flower-like p-CuO/n- $\mathrm{ZnO}$ heterojunction nanorods Sensors and Actuators B: Chemical 202 500-7

[423] Li D, Qin L, Zhao P, Zhang Y, Liu D, Liu F, Kang B, Wang Y, Song H, Zhang T and Lu G 2018 Preparation and gas-sensing performances of $\mathrm{ZnO} / \mathrm{CuO}$ rough nanotubular arrays for low-working temperature H2S detection Sensors and Actuators B: Chemical 254 834-41

[424] Bhuvaneshwari S, Papachan S and Gopalakrishnan N 2017 Free standing CuO$\mathrm{MnO} 2$ nanocomposite for room temperature ammonia sensing AIP Conference Proceedings 1832050126

[425] Meng F-N, Di X-P, Dong H-W, Zhang Y, Zhu C-L, Li C and Chen Y-J 2013 Ppb $\mathrm{H} 2 \mathrm{~S}$ gas sensing characteristics of $\mathrm{Cu} 2 \mathrm{O} / \mathrm{CuO}$ sub-microspheres at lowtemperature Sensors and Actuators B: Chemical 182 197-204

[426] Zhou L-J, Zou Y-C, Zhao J, Wang P-P, Feng L-L, Sun L-W, Wang D-J and Li GD 2013 Facile synthesis of highly stable and porous $\mathrm{Cu} 2 \mathrm{O} / \mathrm{CuO}$ cubes with enhanced gas sensing properties Sensors and Actuators B: Chemical 188 533-9

[427] Liu Q, Cui Z, Zhang Q and Guo L 2014 Gold-catalytic green synthesis of $\mathrm{Cu} 2 \mathrm{O} / \mathrm{Au} / \mathrm{CuO}$ hierarchical nanostructure and application for $\mathrm{CO}$ gas sensor Chinese Science Bulletin 59 7-10

[428] Zhang D, Yin N, Jiang C and Xia B 2017 Characterization of CuO-reduced graphene oxide sandwiched nanostructure and its hydrogen sensing characteristics Journal of Materials Science: Materials in Electronics 28 2763-8

[429] Deng S, Tjoa V, Fan H M, Tan H R, Sayle D C, Olivo M, Mhaisalkar S, Wei J and Sow C H 2012 Reduced Graphene Oxide Conjugated Cu2O Nanowire 
Mesocrystals for High-Performance NO2 Gas Sensor Journal of the American Chemical Society 134 4905-17

[430] Hsueh H T, Hsueh T J, Chang S J, Hung F Y, Tsai T Y, Weng W Y, Hsu C L and Dai B T $2011 \mathrm{CuO}$ nanowire-based humidity sensors prepared on glass substrate Sensors and Actuators B: Chemical 156 906-11

[431] Dhonge B P, Ray S S and Mwakikunga B 2017 Electronic to protonic conduction switching in $\mathrm{Cu} 2 \mathrm{O}$ nanostructured porous films: the effect of humidity exposure RSC Advances 7 21703-12

[432] Wang S B, Hsiao C H, Chang S J, Lam K T, Wen K H, Young S J, Hung S C and Huang B R 2012 CuO Nanowire-Based Humidity Sensor IEEE Sensors Journal 12 1884-8

[433] Kh S K, Saleem M, Karieva Z M, Mateen A, Chani M T S and Zafar Q 2012 Humidity sensing properties of $\mathrm{Cu} 2$ O-PEPC nanocomposite films Journal of Semiconductors 33073001

[434] Necmi S, Tülay S and Basri Ü 2000 The effect of humidity on electronic conductivity of an $\mathrm{Au} / \mathrm{CuO} / \mathrm{Cu} 2 \mathrm{O} / \mathrm{Cu}$ sandwich structure Semiconductor Science and Technology 15112

[435] Conghui Y, Yiting X, Yuanming D, Nina J, Ning H and Lizong D $2010 \mathrm{CuO}$ based inorganic-organic hybrid nanowires: a new type of highly sensitive humidity sensor Nanotechnology 21415501

[436] Wang Z, Xiao Y, Cui X, Cheng P, Wang B, Gao Y, Li X, Yang T, Zhang T and Lu G 2014 Humidity-Sensing Properties of Urchinlike CuO Nanostructures Modified by Reduced Graphene Oxide ACS Applied Materials \& Interfaces 6 3888-95 
[437] Pandey N, Tiwari K and Roy A 2011 Moisture Sensing Application of $\$\{\backslash \mathrm{rm} \mathrm{Cu}\}$ _ $\{2\}\{\backslash \mathrm{rm}$ O\} \$ Doped ZnO Nanocomposites IEEE Sensors Journal $112142-8$

[438] Wang $\mathrm{X}$ and Cho $\mathrm{H} \mathrm{J} 2018$ p-CuO nanowire/n-ZnO nanosheet heterojunctionbased near-UV sensor fabricated by electroplating and thermal oxidation process Materials Letters 223 170-3

[439] Hong Q, Cao Y, Xu J, Lu H, He J and Sun J-L 2014 Self-Powered Ultrafast Broadband Photodetector Based on $\mathrm{p}-\mathrm{n}$ Heterojunctions of $\mathrm{CuO} / \mathrm{Si}$ Nanowire Array ACS Applied Materials \& Interfaces 6 20887-94

[440] Wang S-B, Hsiao C-H, Chang S-J, Jiao Z, Young S-J, Hung S-C and Huang B-R $2013 \mathrm{ZnO}$ branched nanowires and the $\mathrm{p}-\mathrm{CuO} / \mathrm{n}-\mathrm{ZnO}$ heterojunction nanostructured photodetector IEEE transactions on nanotechnology 12 263-9

[441] Ok Y H, Lee K R, Jung B O, Kwon Y H and Cho H K 2014 All oxide ultraviolet photodetectors based on a $\mathrm{p}-\mathrm{Cu} 2 \mathrm{O}$ film/n- $\mathrm{ZnO}$ heterostructure nanowires Thin Solid Films $\mathbf{5 7 0} 282-7$

[442] Liu M, Liu R and Chen W 2013 Graphene wrapped Cu2O nanocubes: Nonenzymatic electrochemical sensors for the detection of glucose and hydrogen peroxide with enhanced stability Biosensors and Bioelectronics 45 206-12

[443] Ahmad R, Tripathy N, Ahn M-S, Bhat K S, Mahmoudi T, Wang Y, Yoo J-Y, Kwon D-W, Yang H-Y and Hahn Y-B 2017 Highly efficient non-enzymatic glucose sensor based on $\mathrm{CuO}$ modified vertically-grown $\mathrm{ZnO}$ nanorods on electrode Scientific Reports 75715

[444] Khan R, Ahmad R, Rai P, Jang L-W, Yun J-H, Yu Y-T, Hahn Y-B and Lee I-H 2014 Glucose-assisted synthesis of $\mathrm{Cu} 2 \mathrm{O}$ shuriken-like nanostructures and their application as nonenzymatic glucose biosensors Sensors and Actuators B: Chemical 203 471-6 
[445] Jindal K, Tomar M and Gupta V $2012 \mathrm{CuO}$ thin film based uric acid biosensor with enhanced response characteristics Biosensors and Bioelectronics 38 11-8

[446] Li Y, Wei Y, Shi G, Xian Y and Jin L 2010 Facile Synthesis of Leaf-Like CuO Nanoparticles and Their Application on Glucose Biosensor Electroanalysis 23 497-502

[447] Li Y, Zhong Y, Zhang Y, Weng W and Li S 2015 Carbon quantum dots/octahedral $\mathrm{Cu} 2 \mathrm{O}$ nanocomposites for non-enzymatic glucose and hydrogen peroxide amperometric sensor Sensors and Actuators B: Chemical 206 735-43

[448] Xu L, Yang Q, Liu X, Liu J and Sun X 2014 One-dimensional copper oxide nanotube arrays: biosensors for glucose detection RSC Advances 4 1449-55

[449] Ahmad R, Vaseem M, Tripathy N and Hahn Y-B 2013 Wide Linear-Range Detecting Nonenzymatic Glucose Biosensor Based on CuO Nanoparticles InkjetPrinted on Electrodes Analytical Chemistry 85 10448-54

[450] Molazemhosseini A, Magagnin L, Vena P and Liu C-C 2017 Single-use nonenzymatic glucose biosensor based on $\mathrm{CuO}$ nanoparticles ink printed on thin film gold electrode by micro-plotter technology Journal of Electroanalytical Chemistry 789 50-7

[451] Batra N, Tomar $\mathrm{M}$ and Gupta V $2015 \mathrm{ZnO}-\mathrm{CuO}$ composite matrix based reagentless biosensor for detection of total cholesterol Biosensors and Bioelectronics 67 263-71

[452] Akgul F A, Gumus C, Er A O, Farha A H, Akgul G, Ufuktepe Y and Liu Z 2013 Structural and electronic properties of SnO2 Journal of Alloys and Compounds $57950-6$ 
[453] Shalan A E, Osama I, Rashad M M and Ibrahim I A 2014 An investigation on the properties of $\mathrm{SnO} 2$ nanoparticles synthesized using two different methods Journal of Materials Science: Materials in Electronics 25 303-10

[454] Dieguez A, Romano-Rodriguez A, Vila A and Morante J 2001 The complete Raman spectrum of nanometric SnO 2 particles Journal of Applied Physics 90 $1550-7$

[455] Chen P-J and Jeng H-T 2015 Phase diagram of the layered oxide SnO: GW and electron-phonon studies Scientific Reports 516359

[456] Zhou W and Umezawa N 2015 Band gap engineering of bulk and nanosheet SnO: an insight into the interlayer Sn-Sn lone pair interactions Physical Chemistry Chemical Physics 17 17816-20

[457] Shin J H, Song J Y, Kim Y H and Park H M 2010 Low temperature and selfcatalytic growth of tetragonal SnO nanobranch Materials Letters 64 1120-2

[458] Javaid K, Xie Y F, Luo H, Wang M, Zhang H L, Gao J H, Zhuge F, Liang L Y and $\mathrm{Cao} \mathrm{H}$ T 2016 The electrical properties of $\mathrm{n}-\mathrm{ZnO} / \mathrm{p}-\mathrm{SnO}$ heterojunction diodes Applied Physics Letters 109123507

[459] Liang L Y, Liu Z M, Cao H T and Pan X Q 2010 Microstructural, optical, and electrical properties of $\mathrm{SnO}$ thin films prepared on quartz via a two-step method ACS applied materials \& interfaces 2 1060-5

[460] SnO Crystal Structure: Datasheet from "PAULING FILE Multinaries Edition 2012" in SpringerMaterials (https://materials.springer.com/isp/crystallographic/docs/sd_0541683). SpringerVerlag Berlin Heidelberg \& Material Phases Data System (MPDS), Switzerland \& National Institute for Materials Science (NIMS), Japan) 
[461] Diéguez A, Romano-Rodríguez A, Vilà A and Morante J R 2001 The complete Raman spectrum of nanometric $\mathrm{SnO} 2$ particles Journal of Applied Physics 90 $1550-7$

[462] González G B 2012 Investigating the Defect Structures in Transparent Conducting Oxides Using X-ray and Neutron Scattering Techniques Materials 5818

[463] Giefers H, Koval S, Wortmann G, Sturhahn W, Alp E E and Hu M Y 2006 Phonon density of states of $\mathrm{Sn}$ in textured $\$ \backslash$ mathrm $\{\mathrm{SnO}\} \$$ under high pressure: Comparison of nuclear inelastic x-ray scattering spectra to a shell model Physical Review B 74094303

[464] Song P and Wen D 2009 Experimental Investigation of the Oxidation of Tin Nanoparticles The Journal of Physical Chemistry C 113 13470-6

[465] Cheng Y, Huang J, Li J, Cao L and Qi H 2018 Hydrothermal synthesis of shapecontrolled $\mathrm{SnO}$ as anode material for Li-ion batteries IET Micro \& Nano Letters $13257-60$

[466] Chiu H-C and Yeh C-S 2007 Hydrothermal Synthesis of SnO2 Nanoparticles and Their Gas-Sensing of Alcohol The Journal of Physical Chemistry C 111 7256-9

[467] Du F, Guo Z and Li G 2005 Hydrothermal synthesis of SnO2 hollow microspheres Materials Letters $\mathbf{5 9} 2563-5$

[468] Azam A, Habib S S, Salah N A and Ahmed F 2013 Microwave-assisted synthesis of $\mathrm{SnO}(2)$ nanorods for oxygen gas sensing at room temperature International Journal of Nanomedicine 8 3875-82

[469] Salah N, AL-Shawafi W M, Alshahrie A, Habib S S and Azam A 2017 Microwave synthesis of 2D SnO nanosheets: effects of annealing temperatures on their thermoelectric properties Journal of Materials Science: Materials in Electronics $283598-606$ 
[470] Ibarguen C A, Mosquera A, Parra R, Castro M S and Rodríguez-Páez J E 2007 Synthesis of $\mathrm{SnO} 2$ nanoparticles through the controlled precipitation route Materials Chemistry and Physics 101 433-40

[471] Rashad M M, Ibrahim I A, Osama I and Shalan A E 2014 Distinction between $\mathrm{SnO} 2$ nanoparticles synthesized using co-precipitation and solvothermal methods for the photovoltaic efficiency of dye-sensitized solar cells Bulletin of Materials Science 37 903-9

[472] Marikkannan M, Vishnukanthan V, Vijayshankar A, Mayandi J and Pearce J M 2015 A novel synthesis of tin oxide thin films by the sol-gel process for optoelectronic applications AIP Advances 5027122

[473] Zhang J and Gao L 2004 Synthesis and characterization of nanocrystalline tin oxide by sol-gel method Journal of solid state chemistry 177 1425-30

[474] Chatelon J P, Terrier C, Bernstein E, Berjoan R and Roger J A 1994 Morphology of $\mathrm{SnO} 2$ thin films obtaibed by the sol-gel technique Thin Solid Films 247 162-8

[475] Fortunato E, Barros R, Barquinha P, Figueiredo V, Park S-H K, Hwang C-S and Martins R 2010 Transparent p-type SnOx thin film transistors produced by reactive rf magnetron sputtering followed by low temperature annealing Applied Physics Letters 97052105

[476] Gubbins M A, Casey V and Newcomb S B 2002 Nanostructural characterisation of $\mathrm{SnO} 2$ thin films prepared by reactive r.f. magnetron sputtering of tin Thin Solid Films $\mathbf{4 0 5} 270-5$

[477] Nafiseh M, Mohammad R S, Elangovan E and Elvira F 2010 Characterization of $\mathrm{SnO} 2: \mathrm{F}$ thin films deposited by an economic spray pyrolysis technique physica status solidi c $72277-81$ 
[478] Patil G E, Kajale D D, Gaikwad V B and Jain G H 2012 Spray Pyrolysis Deposition of Nanostructured Tin Oxide Thin Films ISRN Nanotechnology 2012 5

[479] Jun G, Florent H, Jeremy L and Xile H 2018 Densely Packed, Ultra Small SnO Nanoparticles for Enhanced Activity and Selectivity in Electrochemical CO2 Reduction Angewandte Chemie International Edition 57 2943-7

[480] Patil G E, Kajale D D, Gaikwad V B and Jain G H 2012 Preparation and characterization of $\mathrm{SnO} 2$ nanoparticles by hydrothermal route International Nano Letters 217

[481] Xi G and Ye J 2010 Ultrathin SnO2 Nanorods: Template- and Surfactant-Free Solution Phase Synthesis, Growth Mechanism, Optical, Gas-Sensing, and Surface Adsorption Properties Inorganic Chemistry $492302-9$

[482] Orlandi M O, Leite E R, Aguiar R, Bettini J and Longo E 2006 Growth of SnO nanobelts and dendrites by a self-catalytic VLS process The Journal of Physical Chemistry B $1106621-5$

[483] Sun S H, Meng G W, Zhang G X, Gao T, Geng B Y, Zhang L D and Zuo J 2003 Raman scattering study of rutile $\mathrm{SnO} 2$ nanobelts synthesized by thermal evaporation of Sn powders Chemical Physics Letters 376 103-7

[484] Ying Z, Wan Q, Song Z T and Feng S L 2005 Controlled synthesis of branched SnO2 nanowhiskers Materials Letters 59 1670-2

[485] Jia Z-j, Zhu L-p, Liao G-h, Yu Y and Tang Y-w 2004 Preparation and characterization of SnO nanowhiskers Solid State Communications 132 79-82

[486] Kolmakov A, Klenov D O, Lilach Y, Stemmer S and Moskovits M 2005 Enhanced Gas Sensing by Individual $\mathrm{SnO} 2$ Nanowires and Nanobelts Functionalized with Pd Catalyst Particles Nano Letters 5 667-73 
[487] Nam S-H and Boo J-H 2012 Rutile structured SnO2 nanowires synthesized with metal catalyst by thermal evaporation method Journal of nanoscience and nanotechnology 12 1559-62

[488] Caraveo-Frescas J A and Alshareef H N 2013 Transparent p-type SnO nanowires with unprecedented hole mobility among oxide semiconductors Applied Physics Letters 103222103

[489] Iqbal M Z, Wang F, Zhao H, Rafique M Y, Wang J and Li Q 2012 Structural and electrochemical properties of $\mathrm{SnO}$ nanoflowers as an anode material for lithium ion batteries Scripta Materialia 67 665-8

[490] Wu M, Zeng $\mathrm{W}$ and Li Y 2013 Hydrothermal synthesis of novel SnO2 nanoflowers and their gas-sensing properties Materials Letters 104 34-6

[491] Gyger F, Hübner M, Feldmann C, Barsan N and Weimar U 2010 Nanoscale SnO2 Hollow Spheres and Their Application as a Gas-Sensing Material Chemistry of Materials 22 4821-7

[492] Hossain M A, Yang G, Parameswaran M, Jennings J R and Wang Q 2010 Mesoporous SnO2 Spheres Synthesized by Electrochemical Anodization and Their Application in CdSe-Sensitized Solar Cells The Journal of Physical Chemistry C $11421878-84$

[493] Zhu L, Yang H, Jin D and Zhu H 2007 Hydrothermal synthesis of SnO nanoflakes as anode materials for lithium-ion batteries Inorganic Materials 43 1307-12

[494] Demir-Cakan R, Hu Y-S, Antonietti M, Maier J and Titirici M-M 2008 Facile One-Pot Synthesis of Mesoporous SnO2 Microspheres via Nanoparticles Assembly and Lithium Storage Properties Chemistry of Materials 20 1227-9 
[495] Son S Y, Hong S-A, Oh S Y, Lee Y-C, Lee G-W, Kang J W, Huh Y S and Kim I T 2018 Crab-Shell Biotemplated SnO2 Composite Anodes for Lithium-Ion Batteries Journal of Nanoscience and Nanotechnology 18 6463-8

[496] Abanades S, Charvin P, Lemont F and Flamant G 2008 Novel two-step SnO2/SnO water-splitting cycle for solar thermochemical production of hydrogen International Journal of Hydrogen Energy 33 6021-30

[497] Liu Y, Jiao Y, Zhang Z, Qu F, Umar A and Wu X 2014 Hierarchical SnO2 Nanostructures Made of Intermingled Ultrathin Nanosheets for Environmental Remediation, Smart Gas Sensor, and Supercapacitor Applications ACS Applied Materials \& Interfaces 6 2174-84

[498] Haspulat B, Sarıbel M and Kamış H 2017 Surfactant assisted hydrothermal synthesis of $\mathrm{SnO}$ nanoparticles with enhanced photocatalytic activity Arabian Journal of Chemistry

[499] Das S and Jayaraman V 2014 SnO2: A comprehensive review on structures and gas sensors Progress in Materials Science 66 112-255

[500] Mei L, Chen Y and Ma J 2014 Gas Sensing of SnO2 Nanocrystals Revisited: Developing Ultra-Sensitive Sensors for Detecting the H2S Leakage of Biogas Scientific Reports 46028

[501] Li C, Lv M, Zuo J and Huang X 2015 SnO(2) Highly Sensitive CO Gas Sensor Based on Quasi-Molecular-Imprinting Mechanism Design Sensors (Basel, Switzerland) 15 3789-800

[502] Wu Q-H, Li J and Sun S-G 2010 Nano SnO2 gas sensors Current Nanoscience 6 $525-38$ 
[503] Wang B, Sun L and Wang Y 2018 Template-free synthesis of nanosheetsassembled $\mathrm{SnO} 2$ hollow spheres for enhanced ethanol gas sensing Materials Letters 218 290-4

[504] Huang J, Yu K, Gu C, Zhai M, Wu Y, Yang M and Liu J 2010 Preparation of porous flower-shaped $\mathrm{SnO} 2$ nanostructures and their gas-sensing property Sensors and Actuators B: Chemical 147 467-74

[505] Lipeng Q, Jiaqiang X, Xiaowen D, Qingyi P, Zhixuan C, Qun X and Feng L 2008 The template-free synthesis of square-shaped $\mathrm{SnO} 2$ nanowires: the temperature effect and acetone gas sensors Nanotechnology 19185705

[506] Chen Y J, Xue X Y, Wang Y G and Wang T H 2005 Synthesis and ethanol sensing characteristics of single crystalline $\mathrm{SnO} 2$ nanorods Applied Physics Letters $\mathbf{8 7}$ 233503

[507] Liu X, Ma T, Xu Y, Sun L, Zheng L, Schmidt O G and Zhang J 2018 Rolled-up SnO2 nanomembranes: A new platform for efficient gas sensors Sensors and Actuators B: Chemical 264 92-9

[508] Kuang X, Liu T, Shi D, Wang W, Yang M, Hussain S, Peng X and Pan F 2016 Hydrothermal synthesis of hierarchical $\mathrm{SnO} 2$ nanostructures made of superfine nanorods for smart gas sensor Applied Surface Science 364 371-7

[509] Young-Jin C, In-Sung H, Jae-Gwan P, Kyoung Jin C, Jae-Hwan P and Jong-Heun L 2008 Novel fabrication of an SnO 2 nanowire gas sensor with high sensitivity Nanotechnology 19095508

[510] Suman P H, Felix A A, Tuller H L, Varela J A and Orlandi M O 2013 Giant Chemo-Resistance of $\mathrm{SnO}$ disk-like structures Sensors and Actuators B: Chemical 186 103-8 
[511] Suman P H, Felix A A, Tuller H L, Varela J A and Orlandi M O 2015 Comparative gas sensor response of $\mathrm{SnO} 2, \mathrm{SnO}$ and $\mathrm{Sn} 3 \mathrm{O} 4$ nanobelts to $\mathrm{NO} 2$ and potential interferents Sensors and Actuators B: Chemical 208 122-7

[512] Wan Q and Wang T H 2005 Single-crystalline Sb-doped SnO2 nanowires: synthesis and gas sensor application Chemical Communications 3841-3

[513] Wei Y, Yi G, Xu Y, Zhou L, Wang X, Cao J, Sun G, Chen Z, Hari B and Zhang Z 2017 Synthesis, characterization, and gas-sensing properties of $\mathrm{Ag} / \mathrm{SnO} 2 / \mathrm{rGO}$ composite by a hydrothermal method Journal of Materials Science: Materials in Electronics 28 17049-57

[514] Yin L, Chen D, Cui X, Ge L, Yang J, Yu L, Zhang B, Zhang R and Shao G 2014 Normal-pressure microwave rapid synthesis of hierarchical SnO2@rGO nanostructures with superhigh surface areas as high-quality gas-sensing and electrochemical active materials Nanoscale 6 13690-700

[515] Su P-G and Yang L-Y 2016 NH3 gas sensor based on Pd/SnO2/RGO ternary composite operated at room-temperature Sensors and Actuators B: Chemical 223 202-8

[516] Li F, Gao X, Wang R and Zhang T 2018 Design of WO3-SnO2 core-shell nanofibers and their enhanced gas sensing performance based on different work function Applied Surface Science 442 30-7

[517] Liu J, Wang T, Wang B, Sun P, Yang Q, Liang X, Song H and Lu G 2017 Highly sensitive and low detection limit of ethanol gas sensor based on hollow $\mathrm{ZnO} / \mathrm{SnO} 2$ spheres composite material Sensors and Actuators B: Chemical 245 551-9

[518] Li L, Zhang C and Chen W 2015 Fabrication of SnO2-SnO nanocomposites with p-n heterojunctions for the low-temperature sensing of NO2 gas Nanoscale 7 $12133-42$ 
[519] Chen W, Li Q, Gan H and Zeng W 2014 Study of CuO-SnO2 heterojunction nanostructures for enhanced $\mathrm{CO}$ gas sensing properties Advances in Applied Ceramics 113 139-46

[520] Wang Q, Kou X, Liu C, Zhao L, Lin T, Liu F, Yang X, Lin J and Lu G 2018 Hydrothermal synthesis of hierarchical $\mathrm{CoO} / \mathrm{SnO} 2$ nanostructures for ethanol gas sensor Journal of Colloid and Interface Science $\mathbf{5 1 3}$ 760-6

[521] Gao H, Zhao L, Wang L, Sun P, Lu H, Liu F, Chuai X and Lu G 2018 Ultrasensitive and low detection limit of toluene gas sensor based on $\mathrm{SnO}$ decorated NiO nanostructure Sensors and Actuators B: Chemical 255 3505-15

[522] Parthibavarman M, Hariharan V and Sekar C 2011 High-sensitivity humidity sensor based on $\mathrm{SnO} 2$ nanoparticles synthesized by microwave irradiation method Materials Science and Engineering: C 31 840-4

[523] Li W, Liu J, Ding C, Bai G, Xu J, Ren Q and Li J 2017 Fabrication of Ordered SnO2 Nanostructures with Enhanced Humidity Sensing Performance Sensors 17 2392

[524] Yin M, Yang F, Wang Z, Zhu M, Liu M, Xu X and Li Z 2017 A Fast Humidity Sensor Based on $\mathrm{Li}(+)$-Doped $\mathrm{SnO}(2)$ One-Dimensional Porous Nanofibers Materials 10535

[525] Song X, Qi Q, Zhang T and Wang C 2009 A humidity sensor based on KCl-doped SnO2 nanofibers Sensors and Actuators B: Chemical 138 368-73

[526] Ismail A S, Mamat M H, Malek M F, Yusoff M M, Mohamed R, Sin N D M, Suriani A B and Rusop M 2018 Heterogeneous SnO2/ZnO nanoparticulate film: Facile synthesis and humidity sensing capability Materials Science in Semiconductor Processing 81 127-38 
[527] Tai W-P and Oh J-H 2002 Fabrication and humidity sensing properties of nanostructured TiO2-SnO2 thin films Sensors and Actuators B: Chemical 85 1547

[528] Zhang D, Sun Y e, Li P and Zhang Y 2016 Facile Fabrication of MoS2-Modified SnO2 Hybrid Nanocomposite for Ultrasensitive Humidity Sensing ACS Applied Materials \& Interfaces 8 14142-9

[529] Yadav B C, Sharma P and Khanna P K 2011 Morphological and humidity sensing characteristics of $\mathrm{SnO} 2-\mathrm{CuO}, \mathrm{SnO} 2-\mathrm{Fe} 2 \mathrm{O} 3$ and $\mathrm{SnO} 2-\mathrm{SbO} 2$ nanocooxides Bulletin of Materials Science $\mathbf{3 4} 689$

[530] Karthick S, Lee H-S, Kwon S-J, Natarajan R and Saraswathy V 2016 Standardization, Calibration, and Evaluation of Tantalum-Nano rGO-SnO2 Composite as a Possible Candidate Material in Humidity Sensors Sensors 162079

[531] Yujin C, Chunling Z, Maosheng C and Taihong W 2007 Photoresponse of SnO 2 nanobelts grown in situ on interdigital electrodes Nanotechnology 18285502

[532] Wu J-M and Kuo C-H 2009 Ultraviolet photodetectors made from SnO2 nanowires Thin Solid Films 517 3870-3

[533] Hu L, Yan J, Liao M, Wu L and Fang X 2011 Ultrahigh External Quantum Efficiency from Thin SnO2 Nanowire Ultraviolet Photodetectors Small 7 1012-7

[534] Sharma P and Sawyer S 2016 A high responsivity SnO2 hollow nanospheres based ultraviolet photodetector: IEEE)

[535] Lu M-L, Weng T-M, Chen J-Y and Chen Y-F 2012 Ultrahigh-gain single SnO2 nanowire photodetectors made with ferromagnetic nickel electrodes Npg Asia Materials 4 e26 
[536] Xie T, Hasan M R, Qiu B, Arinze E S, Nguyen N V, Motayed A, Thon S M and Debnath R 2015 High-performing visible-blind photodetectors based on SnO2/CuO nanoheterojunctions Applied Physics Letters 107241108

[537] Zheng L, Xiaoli Y, Haoran C and Zhongzhu L 2018 Flexible ultraviolet photodetectors based on $\mathrm{ZnO}-\mathrm{SnO} 2$ heterojunction nanowire arrays Journal of Semiconductors 39024002

[538] Tian W, Zhai T, Zhang C, Li S L, Wang X, Liu F, Liu D, Cai X, Tsukagoshi K, Golberg D and Bando Y 2013 Low-Cost Fully Transparent Ultraviolet Photodetectors Based on Electrospun $\mathrm{ZnO}-\mathrm{SnO} 2$ Heterojunction Nanofibers Advanced Materials 25 4625-30

[539] Li X, Gao C, Duan H, Lu B, Wang Y, Chen L, Zhang Z, Pan X and Xie E 2012 High-Performance Photoelectrochemical-Type Self-Powered UV Photodetector Using Epitaxial $\mathrm{TiO} 2 / \mathrm{SnO} 2$ Branched Heterojunction Nanostructure Small 9 2005-11

[540] Gao C, Li X, Zhu X, Chen L, Wang Y, Teng F, Zhang Z, Duan H and Xie E 2014 High performance, self-powered UV-photodetector based on ultrathin, transparent, $\mathrm{SnO} 2-\mathrm{TiO} 2$ core-shell electrodes Journal of Alloys and Compounds $616510-5$

[541] Huang Y, Yu Q, Wang J, Li X, Yan Y, Gao S, Shi F, Wang D and Yu C 2015 A high-performance self-powered UV photodetector based on $\mathrm{SnO} 2$ mesoporous spheres@ TiO2 Electronic Materials Letters 11 1059-65

[542] Liu J, Li Y, Huang X and Zhu Z 2010 Tin Oxide Nanorod Array-Based Electrochemical Hydrogen Peroxide Biosensor Nanoscale Research Letters 5 1177 
[543] Haider A J, Jasim Mohammed A, Shaker S S, Yahya K Z and Haider M J 2017 Sensing Characteristics of Nanostructured SnO2 Thin Films as Glucose Sensor Energy Procedia 119 473-81

[544] Li L, Huang J, Wang T, Zhang H, Liu Y and Li J 2010 An excellent enzyme biosensor based on Sb-doped $\mathrm{SnO} 2$ nanowires Biosensors and Bioelectronics 25 $2436-41$

[545] Lavanya N, Radhakrishnan S and Sekar C 2012 Fabrication of hydrogen peroxide biosensor based on Ni doped $\mathrm{SnO} 2$ nanoparticles Biosensors and Bioelectronics $3641-7$

[546] Lavanya N, Radhakrishnan S, Sekar C, Navaneethan M and Hayakawa Y 2013 Fabrication of $\mathrm{Cr}$ doped $\mathrm{SnO} 2$ nanoparticles based biosensor for the selective determination of riboflavin in pharmaceuticals Analyst 138 2061-7

[547] Shen Q, Jiang J, Liu S, Han L, Fan X, Fan M, Fan Q, Wang L and Huang W 2014 Facile synthesis of Au-SnO2 hybrid nanospheres with enhanced photoelectrochemical biosensing performance vol 6

[548] $\mathrm{Wu} \mathrm{R}$, Chen X and $\mathrm{Hu} \mathrm{J} 2012$ Synthesis, characterization, and biosensing application of $\mathrm{ZnO} / \mathrm{SnO} 2$ heterostructured nanomaterials Journal of Solid State Electrochemistry 16 1975-82

[549] Zhu C, Fang Y, Wen D and Dong S 2011 One-pot synthesis of functional twodimensional graphene/SnO2 composite nanosheets as a building block for selfassembly and an enhancing nanomaterial for biosensing Journal of Materials Chemistry 21 16911-7

[550] Li F, Song J, Li F, Wang X, Zhang Q, Han D, Ivaska A and Niu L 2009 Direct electrochemistry of glucose oxidase and biosensing for glucose based on carbon nanotubes@SnO2-Au composite Biosensors and Bioelectronics 25 883-8 
[551] Yang L, Zhou Q, Wang G and Yang Y 2013 Acetylcholinesterase biosensor based on SnO2 nanoparticles-carboxylic graphene-nafion modified electrode for detection of pesticides vol 49C

[552] Chen D, Sun X, Guo Y, Qiao L and Wang X 2015 Acetylcholinesterase biosensor based on multi-walled carbon nanotubes-SnO2-chitosan nanocomposite Bioprocess and Biosystems Engineering 38 315-21

[553] Kaçar C, Erden P E and Kılıç E 2017 Amperometric 1-lysine biosensor based on carboxylated multiwalled carbon nanotubes-SnO2 nanoparticles-graphene composite Applied Surface Science 419 916-23

[554] Schoiswohl J, Surnev S, Netzer F P and Kresse G 2006 Vanadium oxide nanostructures: from zero- to three-dimensional Journal of Physics: Condensed Matter 18 R1

[555] Fu H, Jiang X, Yang X, Yu A, Su D and Wang G 2012 Glycothermal synthesis of assembled vanadium oxide nanostructures for gas sensing J Nanopart Res 14871

[556] Naoufal B and Damien L 2014 Vanadium Oxide Compounds: Structure, Properties, and Growth from the Gas Phase Chemical Vapor Deposition 20299 311

[557] Peys N, Ling Y, Dewulf D, Gielis S, De Dobbelaere C, Cuypers D, Adriaensens P, Van Doorslaer S, De Gendt S, Hardy A and Van Bael M K 2013 V6O13 films by control of the oxidation state from aqueous precursor to crystalline phase Dalton Transactions 42 959-68

[558] Haihong Y, Ke Y, Zhengli Z, Min Z, Lei L and Ziqiang Z 2011 Humidity Sensing Properties of Flower-Like VO2(B) and VO2(M) Nanostructures Electroanalysis $231752-8$ 
[559] Leroux C, Nihoul G and Van Tendeloo G 1998 From $\$\{\backslash \text { mathrm }\{\text { VO }\}\}_{-}\{2\}(B) \$$ to $\$\{\backslash \text { mathrm }\{\mathrm{VO}\}\}_{-}\{2\}(\mathrm{R}): \$$ Theoretical structures of $\$\{\backslash \text { mathrm }\{\mathrm{VO}\}\}_{-}\{2\} \$$ polymorphs and in situ electron microscopy Physical Review B 57 5111-21

[560] Lee S, Ivanov I N, Keum J K and Lee H N 2016 Epitaxial stabilization and phase instability of VO2 polymorphs Scientific Reports 619621

[561] Zhang S, Shang B, Yang J, Yan W, Wei S and Xie Y 2011 From VO2 (B) to VO2 (A) nanobelts: first hydrothermal transformation, spectroscopic study and first principles calculation Physical Chemistry Chemical Physics 13 15873-81

[562] Li H, He P, Wang Y, Hosono E and Zhou H 2011 High-surface vanadium oxides with large capacities for lithium-ion batteries: from hydrated aerogel to nanocrystalline VO2(B), V6O13 and V2O5 Journal of Materials Chemistry 21 10999-1009

[563] Hongbo Q, Memgmeng Y, Yongqi D, Han X, Bin H, Yueliang G, Yuanjun Y, Chongwen Z, Zhenlin L and Chen G 2015 The tetragonal-like to rutile structural phase transition in epitaxial VO 2 /TiO 2 (001) thick films New Journal of Physics 17113016

[564] Belbeoch B, Kleinberger R and Roulliay M 1978 Correlation between the high temperature anomalies in V2O3 and the lattice parameters Journal of Physics and Chemistry of Solids 39 1007-12

[565] Liu J, Xia H, Xue D and Lu L 2009 Double-Shelled Nanocapsules of V2O5-Based Composites as High-Performance Anode and Cathode Materials for Li Ion Batteries Journal of the American Chemical Society 131 12086-7

[566] Mettan Y, Caputo R and Chatterji T 2015 A theoretical and experimental study of the crystal structure of H2V3O8 RSC Advances 5 106543-50 
[567] Yamazaki S, Li C, Ohoyama K, Nishi M, Ichihara M, Ueda H and Ueda Y 2010 Synthesis, structure and magnetic properties of V4O9-A missing link in binary vanadium oxides Journal of Solid State Chemistry 183 1496-503

[568] Horiuchi S, Saeki M, Matsui Y and Nagata F 1975 Transition of V6O13 to VO2 observed with a high-resolution electron microscope vol 31

[569] Dai L, Gao Y, Cao C, Chen Z, Luo H, Kanehira M, Jin J and Liu Y 2012 VO2 (A) nanostructures with controllable feature sizes and giant aspect ratios: one-step hydrothermal synthesis and lithium-ion battery performance RSC Advances 2 $5265-70$

[570] Kysar J S, Wignes F L and Sekhar P K 2017 Growth Mechanism of Vanadium (II) Oxide Nanowires IEEE Transactions on Nanotechnology 16 3-10

[571] V. G A, M. B S, A. G E, N. R M, M. G A, Alexander B and D. T Y 2010 Synthesis, Structure, and Sensor Properties of Vanadium Pentoxide Nanorods European Journal of Inorganic Chemistry $20105247-53$

[572] Wu M, Zhang X, Gao S, Cheng X, Rong Z, Xu Y, Zhao H and Huo L 2013 Construction of monodisperse vanadium pentoxide hollow spheres via a facile route and triethylamine sensing property CrystEngComm 15 10123-31

[573] Nakano M, Shibuya K, Ogawa N, Hatano T, Kawasaki M, Iwasa Y and Tokura Y 2013 Infrared-sensitive electrochromic device based on VO2 Applied Physics Letters 103153503

[574] Gonçalves A, Resende J, Marques A C, Pinto J V, Nunes D, Marie A, Goncalves R, Pereira L, Martins R and Fortunato E 2016 Smart optically active VO2 nanostructured layers applied in roof-type ceramic tiles for energy efficiency Solar Energy Materials and Solar Cells 150 1-9 
[575] Lim H, Stavrias N, Johnson B, Marvel R, Haglund R and McCallum J 2014 Optical Switching and Photoluminescence in Erbium Implanted Vanadium Dioxide Thin Films vol 115

[576] McGahan C, Appavoo K, Jr. R F H and Shapera E P 2013 Switchable plasmoninduced transparency in gold nanoarrays on vanadium dioxide film Journal of Vacuum Science \& Technology B 31 06FE1

[577] Yang Y, Strong K, Pandey G P and Meda L 2018 Nanostructured V2O5/Nitrogendoped Graphene Hybrids for High Rate Lithium Storage MRS Advances 1-6

[578] Lee J, Badie S, Srimuk P, Ridder A, Shim H, Choudhury S, Nah Y-C and Presser V 2018 Electrodeposition of hydrated vanadium pentoxide on nanoporous carbon cloth for hybrid energy storage Sustainable Energy \& Fuels 2 577-88

[579] J. L, X. W, Q. P and Y. L 2005 Vanadium Pentoxide Nanobelts: Highly Selective and Stable Ethanol Sensor Materials Advanced Materials 17 764-7

[580] Liang J, Zhu K, Yang R and Hu M 2018 Room temperature NO2 sensing properties of Au-decorated vanadium oxide nanowires sensor Ceramics International 44 2261-8

[581] Vernardou D, Sapountzis A, Spanakis E, Kenanakis G, Koudoumas E and Katsarakis N 2013 Electrochemical Activity of Electrodeposited V2O5 Coatings Journal of The Electrochemical Society 160 D6-D9

[582] Rasoulis M and Vernardou D 2017 Electrodeposition of Vanadium Oxides at Room Temperature as Cathodes in Lithium-Ion Batteries Coatings 7100

[583] Araújo E S, Libardi J, Faia P M and de Oliveira H P 2018 Characterization and Electrical Response to Humidity of Sintered Polymeric Electrospun Fibers of Vanadium Oxide-( $\$ \$\{\operatorname{hbox}\{\mathrm{TiO}\}\}_{-}\{\{2\}\} /\{\operatorname{lhbox}\{\mathrm{WO}\}\}_{-}\{\{3\}\} \$ \$ \mathrm{TiO} 2 /$ WO 3 ) Journal of Electronic Materials 47 2710-7 
[584] Grigorieva A V, Goodilin E A, Anikina A V, Kolesnik I V and Tretyakov Y D 2008 Surfactants in the formation of vanadium oxide nanotubes Mendeleev Communications 18 71-2

[585] Niederberger M, Muhr H-J, Krumeich F, Bieri F, Günther D and Nesper R 2000 Low-Cost Synthesis of Vanadium Oxide Nanotubes via Two Novel NonAlkoxide Routes Chemistry of Materials 12 1995-2000

[586] Khan Z, Senthilkumar B, Park S O, Park S, Yang J, Lee J H, Song H-K, Kim Y, Kwak S K and Ko H 2017 Carambola-shaped VO2 nanostructures: a binder-free air electrode for an aqueous Na-air battery Journal of Materials Chemistry A $\mathbf{5}$ $2037-44$

[587] Schneider K, Lubecka M and Czapla A 2016 V2O5 thin films for gas sensor applications Sensors and Actuators B: Chemical 236 970-7

[588] Qu W and Meyer J-U 1997 A novel thick-film ceramic humidity sensor Sensors and Actuators B: Chemical 40 175-82

[589] Evans G P, Powell M J, Johnson I D, Howard D P, Bauer D, Darr J A and Parkin I P 2018 Room temperature vanadium dioxide-carbon nanotube gas sensors made via continuous hydrothermal flow synthesis Sensors and Actuators B: Chemical $2551119-29$

[590] Zhai T, Liu H, Li H, Fang X, Liao M, Li L, Zhou H, Koide Y, Bando Y and Golberg D 2010 Centimeter-Long V2O5 Nanowires: From Synthesis to FieldEmission, Electrochemical, Electrical Transport, and Photoconductive Properties Advanced Materials 22 2547-52

[591] Wu J M and Chang W E 2014 Ultrahigh Responsivity and External Quantum Efficiency of an Ultraviolet-Light Photodetector Based on a Single VO2 Microwire ACS Applied Materials \& Interfaces 6 14286-92 
[592] Miyazaki H, Matsuura T and Ota T 2017 Vanadium oxide-based photochromic composite film RSC Advances 7 2388-91

[593] Srivastava T, Bajpai G, Rathore G, Liu S W, Biring S and Sen S 2018 Vanadium substitution: A simple and economic way to improve UV sensing in $\mathrm{ZnO}$ Journal of Applied Physics 123161407

[594] Alagappan L P, Shanmugasundaram P, Ramachandra B L, Gumpu M B, Nesakumar N, Jayanth Babu K, Vedantham S and Balaguru Rayappan J B 2017 Fabrication of electrochemical biosensor with vanadium pentoxide nano-interface for the detection of methylglyoxal in rice Analytical Biochemistry 528 19-25

[595] Suresh R, Giribabu K, Manigandan R, Kumar S P, Munusamy S, Muthamizh S, Stephen A and Narayanan V 2014 New electrochemical sensor based on Ni-doped V2O5 nanoplates modified glassy carbon electrode for selective determination of dopamine at nanomolar level Sensors and Actuators B: Chemical 202 440-7

[596] Yang F, Jiang X, Zhong X, Wei S and Yuan R 2018 Highly sensitive electrochemiluminescence detection of mucin1 based on V2O5 nanospheres as peroxidase mimetics to catalyze $\mathrm{H} 2 \mathrm{O} 2$ for signal amplification Sensors and Actuators B: Chemical 265 126-33

[597] Hu X, Goud K Y, Kumar V S, Catanante G, Li Z, Zhu Z and Marty J L 2018 Disposable electrochemical aptasensor based on carbon nanotubes- V2O5chitosan nanocomposite for detection of ciprofloxacin Sensors and Actuators B: Chemical 268 278-86

[598] Sun W, Qin P, Gao H, Li G and Jiao K 2010 Electrochemical DNA biosensor based on chitosan/nano-V2O5/MWCNTs composite film modified carbon ionic liquid electrode and its application to the LAMP product of Yersinia enterocolitica gene sequence Biosensors and Bioelectronics 25 1264-70 
[599] Zhu L and Zeng W 2017 Room-temperature gas sensing of ZnO-based gas sensor: A review Sensors and Actuators A: Physical 267 242-61

[600] Long H, Zeng W and Zhang H 2015 Synthesis of WO3 and its gas sensing: a review Journal of Materials Science: Materials in Electronics 26 4698-707

[601] Kaisti M 2017 Detection principles of biological and chemical FET sensors Biosensors and Bioelectronics 98 437-48

[602] Feng P, Shao F, Shi Y and Wan Q 2014 Gas Sensors Based on Semiconducting Nanowire Field-Effect Transistors Sensors 1417406

[603] Nunes D, Santos L, Pimental A, Barquinha P, Pereira L, Fortunato E and Martins R 2018 Metal Oxide Nanostructures: Synthesis, Properties and Applications: Elsevier)

[604] Diao F and Wang Y 2018 Transition metal oxide nanostructures: premeditated fabrication and applications in electronic and photonic devices Journal of Materials Science $\mathbf{5 3} 4334-59$

[605] Xiang J K, Ji Hun; Lu, Wei 2014 Semiconductor Nanowires: From NextGeneration Electronics to Sustainable Energy, ed W X Lu, Jie (Cambridge: Royal Society of Chemistry)

[606] Mathews N, Varghese B, Sun C, Thavasi V, Andreasson B P, Sow C H, Ramakrishna S and Mhaisalkar S G 2010 Oxide nanowire networks and their electronic and optoelectronic characteristics Nanoscale 2 1984-98

[607] Chang P C and Lu J G 2008 ZnO Nanowire Field-Effect Transistors IEEE Transactions on Electron Devices 55 2977-87

[608] Ju S, Lee K, Yoon M-H, Facchetti A, Marks T, J. and Janes D 2007 High performance $\mathrm{ZnO}$ nanowire field effect transistors with organic gate 
nanodielectrics: effects of metal contacts and ozone treatment Nanotechnology 18 155201

[609] Tiong T-Y, Dee C-F, Hamzah A A, Goh B T, Wong Y-Y, Ooi L, Majlis B Y, Salleh M M and Ahmad I 2017 A rapid responding ultraviolet sensor based on multi-parallel aligned $\mathrm{ZnO}$ nanowires field effect transistor Sensors and Actuators A: Physical 260 139-45

[610] Liu X, Lin P, Yan X, Kang Z, Zhao Y, Lei Y, Li C, Du H and Zhang Y 2013 Enzyme-coated single $\mathrm{ZnO}$ nanowire FET biosensor for detection of uric acid Sensors and Actuators B: Chemical 176 22-7

[611] Lundström I, Shivaraman S, Svensson C and Lundkvist L 1975 A hydrogen-sensitive MOS field-effect transistor Applied Physics Letters 26 55-7

[612] Zhao X, Cai B, Tang Q, Tong Y and Liu Y 2014 One-Dimensional Nanostructure Field-Effect Sensors for Gas Detection Sensors 1413999

[613] Andringa A-M, Piliego C, Katsouras I, Blom P W M and Leeuw D M d 2014 NO2 Detection and Real-Time Sensing with Field-Effect Transistors Chemistry of Materials 26 773-85

[614] Choi K J and Jang H W 2010 One-Dimensional Oxide Nanostructures as GasSensing Materials: Review and Issues Sensors 104083

[615] Zhang Y, Kolmakov A, Chretien S, Metiu H and Moskovits M 2004 Control of Catalytic Reactions at the Surface of a Metal Oxide Nanowire by Manipulating Electron Density Inside It Nano Letters 4 403-7

[616] Vomiero A, Bianchi S, Comini E, Faglia G, Ferroni M and Sberveglieri G 2007 Controlled Growth and Sensing Properties of In2O3 Nanowires Crystal Growth \& Design 7 2500-4 
[617] Yoshizumi T and Miyahara Y 2017 Different Types of Field-Effect Transistors, ed M Pejović: Intech)

[618] Kuang Q, Lao C-S, Li Z, Liu Y-Z, Xie Z-X, Zheng L-S and Wang Z L 2008 Enhancing the Photon- and Gas-Sensing Properties of a Single SnO 2 Nanowire Based Nanodevice by Nanoparticle Surface Functionalization The Journal of Physical Chemistry C 112 11539-44

[619] Syed M and Martin M 2011 Gate-Tunable Surface Processes on a SingleNanowire Field-Effect Transistor Advanced Materials 23 2306-12

[620] Dattoli E N, Davydov A V and Benkstein K D 2012 Tin oxide nanowire sensor with integrated temperature and gate control for multi-gas recognition Nanoscale 4 1760-9

[621] Matt L, Hannes K, Benjamin M, Franklin K and Peidong Y 2002 Photochemical Sensing of NO2 with $\mathrm{SnO} 2$ Nanoribbon Nanosensors at Room Temperature Angewandte Chemie 114 2511-4

[622] Sharma B, Sharma A and Kim J-S 2018 Recent advances on H2 sensor technologies based on MOX and FET devices: A review Sensors and Actuators B: Chemical 262 758-70 